\section{C4A}

- Chido/Rodgers-Blutgruppensystem

$\mathrm{Ca}^{2+}$

> Gerinnungsfaktor IV

\section{CA 15-3}

- Carbohydrate antigen 15-3

\section{CA 19-9}

- Carbohydrate antigen 19-9

\section{CA 27-29}

- Carbohydrate antigen 27-29

\section{CA 50}

- Carbohydrate antigen 50

\section{CA 72-4}

- Carbohydrate antigen 72-4

\section{CA 125}

- Carbohydrate antigen 125

\section{CA 195}

- Carbohydrate antigen 195

\section{CA 242}

- Carbohydrate Antigen 242

\title{
CA 549
}

Carbohydrate antigen 549

\section{Cabot-Ringe}

H. Baum

Synonym(e) Cabot-Schleip-Ringe

Englischer Begriff Cabot's ring bodies

Definition Ringförmige oder schleifenförmige, basophile, fadenartige Gebilde in Erythrozyten. 
Beschreibung Cabot-Ringe (s. Abbildung, Pfeil) sind ringoder schleifenförmige intraerythrozytäre Einschlusskörper $(1000 \times$, May-Grünwald-Giemsa-Färbung):

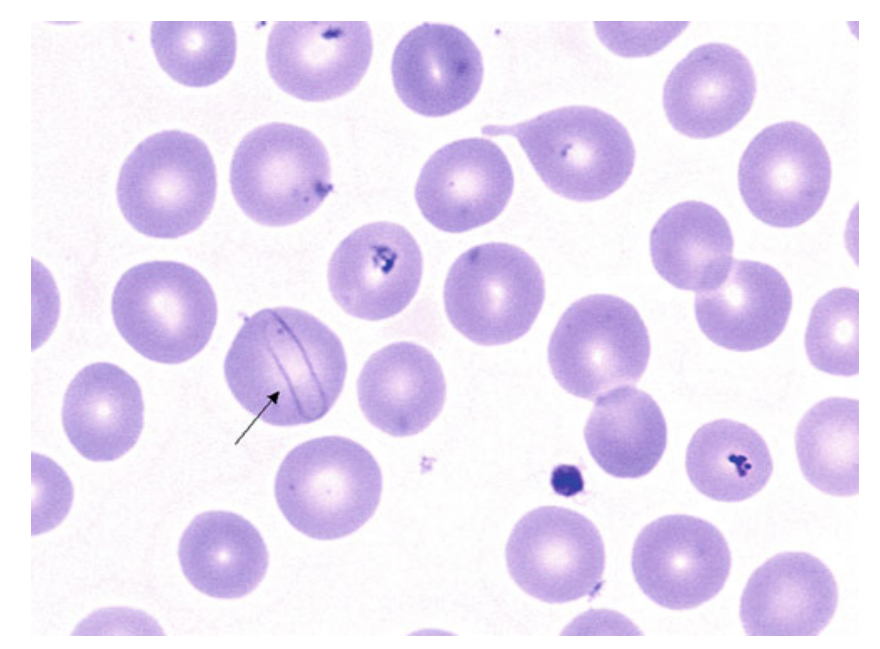

Die genaue Herkunft der Cabot-Ringe ist nicht sicher geklärt. Es wird diskutiert, ob es sich um Reste der Kernmembran, der Spindelfasern, toxische Produkte oder lediglich um ein Artefakt handelt. Cabot-Ringe sind häufig bei schweren Anämien nachweisbar und werden als Zeichen einer überstürzten und gestörten Blutregeneration interpretiert.

\section{Literatur}

Kaboth W (1993) Anämien. In: Begemann H, Rastetter J (Hrsg) Klinische Hämatologie, 4. Aufl. Georg Thieme Verlag, Stuttgart, S 243

\section{Cabot-Schleip-Ringe}

$>$ Cabot-Ringe

\section{Cadmium}

D. Meißner und T. Arndt

\section{Synonym(e) Kadmium}

\section{Englischer Begriff cadmium}

Definition Cadmium (chemisches Symbol: Cd) ist ein dem Zink chemisch verwandtes, giftiges Übergangsmetall ( $\triangleright$ Übergangsmetalle) mit der Ordnungszahl 48. Es gehört zu den für den Menschen nicht essenziellen $>$ Ultraspurenelemente.
Struktur Cadmium liegt als zweiwertiges Kation vor. Im Blutplasma ist $\mathrm{Cd}$ vorwiegend an Albumin und $>\alpha 2$-Makroglobulin, in Zellen zum großen Teil an $>$ Metallothionein (MT) gebunden. In seinem Ionenradius ist $\mathrm{Cd}$ dem $\checkmark$ Calcium ähnlich.

Molmasse Relative Atommasse: 112,411.

Synthese - Verteilung - Abbau - Elimination Cadmium wird hauptsächlich über die Nahrung, nur zu einem geringen Teil über Trinkwasser und die Atemluft aufgenommen. Die Resorptionsrate beträgt $5 \%$, sie erhöht sich bei Calcium-, Eisen- und Proteinmangel auf 15-20\%. Im Blut liegt $\mathrm{Cd}$ an Erythrozyten und Lymphozyten gebunden vor, der Anteil im Plasma ist gering. In der Leber, die etwa $15 \%$ des Körpercadmiums enthält, induziert $\mathrm{Cd}$ die Synthese des MT und wird von diesem gebunden. MT übt neben der Speichereine Schutzfunktion aus, indem es freies $\mathrm{Cd}$ bindet. Als MT-Komplex gelangt Cd zur Niere als dem Hauptspeicherorgan (50 \% der Körperlast). Dort wird Cd-MT glomerulär filtriert, tubulär rückresorbiert und in den Tubuluszellen gespeichert, was zu einer Akkumulation in der Nierenrinde führt. Resorbiertes Cd wird renal, der Rest über den Stuhl ausgeschieden. Tolerierbare Aufnahme pro Tag: $1 \mu \mathrm{g} / \mathrm{kg} \mathrm{KG}$.

Halbwertszeit Zweiphasige Ausscheidungskinetik: schnell 75-128 Tage, langsam 10-30 Jahre.

Funktion - Pathophysiologie Eine physiologische Funktion des Cadmiums ist für den Menschen nicht bekannt, dagegen hat es als Umweltgift Bedeutung. Cadmiumquellen sind Industrieemissionen, belastete Böden und Nahrungsmittel, Düngemittel, Farben, Glasuren, Akkumulatoren, Batterien, Zusätze zu Kunststoffen, Tabakrauch. In Abhängigkeit vom Aufnahmeweg, der aufgenommenen Menge und der Widerstandsfähigkeit des Organismus treten bei erhöhter Zufuhr akute und/oder chronische Intoxikationen mit verschieden schweren klinischen Symptomen auf, die bei akuter Belastung bis zum Tod führen können. Im Vordergrund stehen Nephrotoxizität (Proteinurie, Reduzierung der glomerulären Filtration), Wirkungen auf das Gefäßsystem (Bluthochdruck) und kanzerogene Wirkungen (Lungenkrebs nach Inhalation). In Japan wurden bei hoher Belastung Störungen des Knochenstoffwechsels (Itai-Itai-Krankheit) beobachtet.

Untersuchungsmaterial - Entnahmebedingungen Blut, Urin, Haare.

Probenstabilität Blut und Urin: $20{ }^{\circ} \mathrm{C}, 4-8{ }^{\circ} \mathrm{C} 28$ Tage, $-20{ }^{\circ} \mathrm{C} 1 \mathrm{Jahr}$.

Präanalytik Blutabnahme in mit Li-Heparin oder EDTA vorgefüllte Spurenelementröhrchen. Für Urin keine Glasge- 
fäße verwenden. Längere Aufbewahrung bei $-20{ }^{\circ} \mathrm{C}$ möglich. Urin kann mit Salpetersäure (suprapur, $1 \mathrm{~mL} / \mathrm{L}$ Urin) angesäuert werden. Gefäße abdecken (keine Gummistopfen). Kontamination vermeiden.

Analytik Elektrothermische Atomabsorptionsspektrometrie, potenziometrische Strippinganalyse.

Konventionelle Einheit $\mu \mathrm{g} / \mathrm{L}, \mu \mathrm{g} / \mathrm{d}, \mu \mathrm{g} / \mathrm{g}, \mu \mathrm{g} / \mathrm{g}$ Kreatinin.

Internationale Einheit $\mathrm{nmol} / \mathrm{L}, \mathrm{nmol} / \mathrm{d}, \mathrm{nmol} / \mathrm{g}$.

Umrechnungsfaktor zw. konv. u. int. Einheit $\mathrm{nmol} / \mathrm{L}$ (d, $\mathrm{g})=8,896 \times \mu \mathrm{g} / \mathrm{L}(\mathrm{d}, \mathrm{g}), \mu \mathrm{g} / \mathrm{L}(\mathrm{d}, \mathrm{g})=0,1124 \times \mathrm{nmol} / \mathrm{L}$ $(d, g)$.

Referenzbereich - Erwachsene (Nichtraucher). Blut: $<1,0 \mu \mathrm{g} / \mathrm{L}$. Urin: $<0,8 \mu \mathrm{g} / \mathrm{L}$ (Umweltbundesamt 2011). Haare: $<0,25 \mu \mathrm{g} / \mathrm{g}$ (Geipel 2003).

Referenzbereich - Kinder Blut: $<0,3 \mu \mathrm{g} / \mathrm{L}$. Urin: $<0,2 \mu \mathrm{g} /$ L. Haare: $<0,25 \mu \mathrm{g} / \mathrm{g}$ (Literatur s. Erwachsene).

Indikation Verdacht auf akute oder chronische Cadmiumbelastung oder -vergiftung.

\section{Interpretation}

- Die Cadmiumwerte sind stark von der geographischen Region und der Umweltbelastung abhängig. Im Alter nehmen die Werte leicht zu. Raucher haben bis zu 5-fach höhere Werte als Nichtraucher.

- Cadmium im Blut dient der Erfassung der aktuellen (akuten) Belastung, Cadmium im Urin der Beurteilung der Gesamtkörperlast (chronische Belastung). Bei Überschreiten einer Blutkonzentration von $2 \mu \mathrm{g} / \mathrm{L}$ oder der HBM-I-Werte ( $\triangleright$ Human-Biomonitoring-Wert) im Urin sind Kontrolluntersuchungen angezeigt, die zusätzlich den Eisenstoffwechsel und die Nierenfunktion mit erfassen sollen. Cadmium und Eisen werden über denselben Transporter resorbiert, weshalb bei Eisenmangelanämie eine verstärkte Cadmiumresorption eintreten kann. Eine eingeschränkte Nierenfunktion könnte eine verstärkte Cadmiumspeicherung erklären.

- Cadmium im Haar ist als Belastungsindikator nicht geeignet und nur als Zusatzuntersuchung bei gering erhöhten Blut- und Urinwerten zu empfehlen. Es wird die Cadmiumaufnahme während der Wachstumsphase des Haares angezeigt, und es bestehen keine Zusammenhänge mit der Konzentration im Blut und Urin.

- BAT-Wert: Cadmium und seine anorganischen Verbindungen: wegen deren karzinogener Wirkung ausgesetzt (Arndt 2012; BAT-Liste in DFG 2017).
- BLW-Wert (Urin): nicht festgelegt (BAT-Liste in DFG 2017).

- BAR-Wert (Blut): $1 \mu \mathrm{g} / \mathrm{L}$; BAR-Wert (Urin): 0,8 mg/L (BAT-Liste in DFG 2017).

- HBM-I-Werte (Urin): Kinder und Jugendliche 0,5 $\mu \mathrm{g} / \mathrm{L}$, Erwachsene $1 \mu \mathrm{g} / \mathrm{L}$; HBM-II-Werte (Urin): Kinder und Jugendliche $2 \mu \mathrm{g} / \mathrm{L}$, Erwachsene $4 \mu \mathrm{g} / \mathrm{L}$ (Umweltbundesamt 2011).

- PTWI-Wert: $7 \mu \mathrm{g} \mathrm{Cd} / \mathrm{kg} \mathrm{KG.}$

- Grenzwert im Trinkwasser: $3 \mu \mathrm{g} \mathrm{Cd} / \mathrm{L}$. (Trinkwasser-VO 2016).

Diagnostische Wertigkeit Diagnose einer übermäßigen Aufnahme, einer Belastung oder einer Vergiftung durch Cadmium.

\section{Literatur}

Arndt T (2012) Problematik, Klinik und ausgewählte Beispiele der Spurenelementanalytik - Cadmium. Toxichem Krimtech 36:127-132

DFG (2017) Ständige Senatskommission zur Prüfung gesundheitsschädlicher Arbeitsstoffe. Mitteilung 53. MAK- und BAT-Liste 2017. Wiley-VCH, Weinheim

Geipel D (2003) Urbane und rurale Schwermetallbelastung in Haaren und Knochen vergangener Jahrhunderte. Dissertation HHU Düsseldorf

Kommission Human-Biomonitoring des Umweltbundesamtes (2011) Aktualisierung der Stoffmonographie Cadmium - Referenz- und Human-Biomonitoring(HBM)-Werte. Bundesgesundheitsbl Gesundheitsforsch Gesundheitsschutz 54:981-996

Trinkwasser-VO (2016) Trinkwasserverordnung in der Fassung der Bekanntmachung vom 10.03.2016. https://www.gesetze-im-internet. de/bundesrecht/trinkwv_2001/gesamt.pdf. zugegriffen am 14.08.2017

\section{CAF-Elektrophorese}

$>$ Celluloseacetatfolien-Elektrophorese

\section{Caffein-Eliminationstest}

A. M. Gressner und O. A. Gressner

Synonym(e) Koffeinbelastungstest

Englischer Begriff caffeine elimination test, caffeine clearance test

Definition Quantitativer Leberfunktionstest, bei dem nach oraler Verabreichung von Caffein (engl. für Coffein) dessen Eliminationsrate aus der Zirkulation, die nahezu ausschließlich von der funktionellen Leberzellmasse bestimmt ist, gemessen wird. 
Durchführung Nach Applikation von 280 mg Caffein oral oder $125 \mathrm{mg}$ Caffein intravenös wird in seriell entnommenen Blutproben die Caffeinkonzentration im Serum zur Berechnung der Caffeinclearance gemessen. Eine Messung von Caffein im Speichel ist möglich (Saliva-Variante). Die Variante des ${ }^{13} \mathrm{C}$-Caffein-Atemtests misst nach oraler Aufnahme die Menge des exhalierten ${ }^{13} \mathrm{CO}_{2}$.

\section{Halbwertszeit 2-5 Stunden.}

Funktion - Pathophysiologie Oral aufgenommenes Caffein (1,3,7-Trimethylxanthin) wird vollständig intestinal resorbiert und zu 97 \% in der Leber metabolisiert. Die Proteinbindung ist relativ gering (ca. $40 \%$ ). Wie bei Aminopyrin erfolgt durch $>$ Cytochrom $\mathrm{P} 450$-abhängige mikrosomale Oxigenasen (im Wesentlichen durch CYP1A2) eine $\mathrm{N}$-Demethylierung zu renal eliminiertem Methylxanthin und zu exhaliertem $\mathrm{CO}_{2}$. Die Caffeinclearance ist verlängert bei Patienten mit ausgeprägter Leberzellinsuffizienz (bis $\mathrm{zu}$ 20 Stunden).

Untersuchungsmaterial- Entnahmebedingungen Serum, Speichel (Saliva).

Präanalytik Patient sollte 12 Stunden nüchtern sein und 30 Minuten vor Caffeinapplikation liegen.

Analytik Die Caffeinbestimmung kann mit $\triangleright$ Enzymimmunoassay, > Gaschromatographie oder $>$ HochleistungsFlüssigkeitschromatographie (HPLC) erfolgen.

Referenzbereich - Erwachsene Plasmaclearance: $>2 \mathrm{~mL} / \mathrm{kg}$ $\mathrm{KG} / \mathrm{min}$, altersabhängige Abnahme.

Referenzbereich - Kinder s. Erwachsene.

Indikation Diagnose, Verlaufskontrolle und Feststellung des Schweregrads einer Leberinsuffizienz im Rahmen fortschreitender chronischer Lebererkrankungen.

Interpretation Die Clearance ist reduziert bei ausgeprägter Leberzellinsuffizienz, jedoch bei milden und frühen Lebererkrankungen noch normal.

$\mathrm{Ob}$ der Funktionstest eine prognostische Zusatzinformation gegenüber klinischen Parametern (z. B. > ChildTurcotte-Pugh-Score) bietet, ist kontrovers. Gegenüber dem vergleichbaren $>$ Aminopyrinatemtest hat er den Vorteil der Nichtradioaktivität. Die Caffeinclearance ist vermindert bei fortgeschrittenem Alter und Patienten mit Cimetidinmedikation. Beschleunigungen der Clearance finden sich bei Rauchern und bei Komedikation mit Rifampin, Carbamazepin, Kontrazeptiva und hohen Dosen von Omeprazol.
Diagnostische Wertigkeit Der klinische Einsatz des Caffeineliminationstests ist begrenzt.

\section{Literatur}

Park GJH, Katelaris PH, Jones DB et al (2003) Validity of the $13 \mathrm{C}$-caffeine breath test as a noninvasive, quantitative test of liver function. Hepatology 38:1227-1236

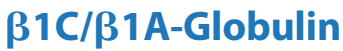

C3-Komplement

\section{CAH (Congenital Adrenal Hyperplasia)- Screening}

17-Hydroxyprogesteron, Bestimmung aus Trockenblut

\section{Calcidiol}

Vitamin D

\section{Calciol (Vitamin $\mathrm{D}_{3}$ )}

Vitamin D

\section{Calcitonin}

M. Bidlingmaier

Synonym(e) Kalzitonin; Thyreocalcitonin

Englischer Begriff calcitonin; thyrocalcitonin

Definition Peptidhormon aus den C-Zellen der Schilddrüse. Calcitonin senkt die $>$ Calcium-Konzentration im Blut und steigert die renale $\triangleright$ Phosphat-Ausscheidung.

Struktur Protein aus 32 Aminosäuren mit einer intramolekularen Disulfidbindung am Aminoterminus. Verschiedene 
zirkulierende Fragmente ohne die Disulfidbrücke binden zwar auch den Rezeptor, wirkend jedoch als Antagonisten.

Molmasse 3421 Da.

Synthese - Verteilung - Abbau - Elimination Die Synthese von Calcitonin erfolgt bei Säugern in den C-Zellen (parafollikulären Zellen) der Schilddrüse über ein 141 Aminosäuren langes Prohormon ( $\triangleright$ Procalcitonin). Stimuliert wird die Freisetzung physiologisch durch hohe Calciumkonzentrationen im Blut. Außerdem stimuliert $\gg$ Gastrin die Freisetzung von Calcitonin, was man sich diagnostisch im Pentagastrintest ( $\triangleright$ Calcitonin-Stimulationstest) zunutze macht. Die Senkung der Blutcalciumkonzentration erfolgt über 3 Mechanismen: Calcitonin hemmt die Osteoklastenaktivität und damit die Freisetzung von Calcium aus dem Knochen, es reduziert die Calciumresorption im Darm und stimuliert die Calciumausscheidung über die Niere. Damit ist es ein Antagonist vom $>$ Parathormon im Calciumstoffwechsel. Calcitonin hat eine kurze Halbwertszeit und wird überwiegend renal eliminiert.

\section{Halbwertszeit Wenige Minuten.}

Pathophysiologie Die klinische Bedeutung von Calcitonin im Calciumstoffwechsel ist geringer als die von $>$ Vitamin D und Parathormon. Therapeutisch wird (Lachs-)Calcitonin bei akuter und chronischer Hyperkalzämie sowie bei Erkrankungen mit erhöhtem Knochenumsatz eingesetzt.

Calcitonin ist ein sensitiver Marker der C-Zellhyperplasie und des C-Zell-Karzinoms (medulläres Schilddrüsenkarzinom). Zudem ist die Bildung bei anderen - insbesondere neuroendokrinen - Tumoren beschrieben.

Basal können sich erhöhte Calcitoninkonzentrationen auch bei Erkrankungen mit erhöhter Gastrinkonzentration (perniziöse Anämie), chronischer Niereninsuffizienz, Sepsis und Autoimmunerkrankungen der Schilddrüse finden. Auch im dritten Trimenon der Schwangerschaft und unter oraler Kontrazeption können die Werte erhöht sein.

Calciumzufuhr steigert die Calcitoninfreisetzung. Dies macht man sich diagnostisch beim Calciumstimulationstest zu nutze. Es muss aber auch bei der Beurteilung von Calcitoninwerten unter Infusionstherapie (Calciumgabe) beachtet werden.

Untersuchungsmaterial Serum, Plasma - Versand gefroren!

Probenstabilität Calcitonin ist extrem instabil, Peptidasen beschleunigen den Abbau. Der Zusatz von Proteaseinhibitoren kann die Stabilität erhöhen.

Präanalytik Blutproben müssen innerhalb von 30 Minuten verarbeitet und eingefroren werden.
Analytik Immunoassays. Verschiedene Assays unterscheiden sich stark hinsichtlich der Spezifität und somit im Grad der Miterkennung von Präkursoren und Fragmenten. Bei extremen Calcitoninkonzentrationen kann es bei manchen Assays durch einen - High-Dose-Hook-Effekt zu falsch niedrigen Messergebnissen kommen. Auch sind Probleme mit heterophilen Antikörpern ( $\triangleright$ Antikörper, heterophile) bei Calcitoninassays überproportional oft beschrieben.

Konventionelle Einheit $\mathrm{pg} / \mathrm{mL}$.

Internationale Einheit $\mathrm{pmol} / \mathrm{L}$.

Umrechnungsfaktor zw. konv. u. int. Einheit $1 \mathrm{pg} / \mathrm{mL}=$ $0,28 \mathrm{pmol} / \mathrm{L}$.

Referenzbereich Die Referenzbereiche sind vom verwendeten Assay abhängig. Typischerweise werden Angaben in folgender Größenordnung gemacht:

- $\quad<10 \mathrm{pg} / \mathrm{mL}$ : Normalbefund

- $10-100 \mathrm{pg} / \mathrm{mL}$ : Graubereich

- $>100$ pg/mL: Verdacht auf medulläres Schilddrüsenkarzinom

\section{Indikation}

- Verdacht auf medulläres Schilddrüsenkarzinom (basal und nach Stimulation).

- Verdacht auf ektope Calcitoninproduktion.

- Nachdem das medulläre Schilddrüsenkarzinom im Rahmen der multiplen endokrinen Neoplasie (MEN) vorkommt, 10-30 \% der MEN-Patienten zudem therapierefraktäre Durchfälle haben, ist die Bestimmung von Calcitonin auch in der Differenzialdiagnostik des therapierefraktären Durchfalls ggf. sinnvoll.

Interpretation S. Pathophysiologie und Referenzbereiche.

Diagnostische Wertigkeit Die Wertigkeit der Bestimmung der basalen Calcitoninkonzentration bei Patienten mit Schilddrüsenknoten im Sinne eines Screenings ist sehr umstritten. Bei niedrigem positiven prädiktiven Wert ergeben sich viele falsch positive Befunde, denen keine nachgewiesenen Reduktion der Mortalität entgegensteht. Insbesondere basale Werte im Graubereich zwischen 10 und 100 pg/mL sind praktisch bedeutungslos. Verbessert wird die Aussagekraft durch einen Stimulationstest (Pentagastrin oder Calcium).

Größte prognostische und therapeutische Relevanz hat die Messung von Calcitonin hingegen präoperativ und postoperativ sowie langfristig in der Nachsorge bei Tumorpatienten mit initial erhöhten Calcitoninkonzentrationen. 


\section{Literatur}

Costante G, Durante C, Francis Z, Schlumberger M, Filetti S (2009) Determination of calcitonin levels in C-cell disease: clinical interest and potential pitfalls. Nat Clin Pract Endocrinol Metab 5(1):35-44

\section{Calcitonin gene-related peptide}

T. Arndt

Synonym(e) CGRP

Definition Ein aus 37 Aminosäuren bestehendes, stark blutgefäßerweiterndes Neuropeptid.

Beschreibung Derzeit sind zwei Isoformen ( $\alpha$ - und $\beta$ CGRP) bekannt. Sie unterscheiden sich in 3 Aminosäuren voneinander. Ihre Genloci auf Chromosom 11 sind identisch mit denen für $\alpha$-bzw. $\beta$-Calcitonin. Beide Gene ( $\alpha$-Calcitonin/CGRP und $\beta$-Calcitonin/CGRP) bestehen aus 6 Exons, aus denen durch gewebespezifisches alternatives Splicing im Nervensystem die „calcitonin gene-related peptide“ und in der Schilddrüse die $>$ Calcitonine gebildet werden. Die blutgefäßerweiternde CGRP-Wirkung beruht auf einer Relaxation der glatten Muskulatur sowie auf Freisetzung von Stickstoffmonoxid aus dem Endothel.

Forschungsgebiete für CGRP-Analoga oder CGRP-Antagonisten sind Alterungsprozesse, Arthritis, Atherosklerose, erektile Dysfunktionen, Diabetes, Fettsucht, Herzversagen, Hypertonie, Migräne, Myokardinfarkt, pulmonale Hypertonie, Sepsis und Wundheilung. Testkits zur Bestimmung von CGRP in Serum oder Plasma auf der Basis von Immunoassays sind verfügbar, Norm- oder Referenzbereiche nicht.

\section{Literatur}

Russell FA, King R, Smillie S-J, Kodji X, Brain SD (2014) Calcitoninegene related peptide: physiology and pathophysiology. Physiol Rev 94:1099-1142

Wimalawansa SJ (1996) Calcitonin gene-related peptide and its receptors: molecular genetics, physiology, pathophysiology, and therapeutic potentials. Endocrinol Rev 17:533-585

\section{Calcitonin-Stimulationstest}

M. Bidlingmaier

Synonym(e) Pentagastrin-Test
Englischer Begriff pentagastrin stimulation test

Definition Stimulationstest unter Verwendung des synthetisch hergestellten Oligopeptids Pentagastrin. Überprüft wird die Stimulierbarkeit der $>$ Calcitonin-Sekretion, die bei Patienten mit C-Zell-Karzinom erhöht ist.

Durchführung Legen einer Verweilkanüle, Offenhalten durch langsame Infusion von Kochsalzlösung. Basale Blutentnahmen unmittelbar vor Testbeginn (0 Minuten). Injektion von $0,5 \mu \mathrm{g} / \mathrm{kg}$ Körpergewicht Pentagastrin. Weitere Blutentnahmen bei 2, 5 und 10 Minuten.

Eine vorrübergehende Flushsymptomatik ist häufig.

Struktur Calcitonin.

Molmasse Calcitonin.

Synthese-Verteilung-Abbau-Elimination $>$ Calcitonin.

Halbwertszeit Calcitonin.

Pathophysiologie $>$ Calcitonin. Gastrin gehört neben $>$ Calcium zu den Stimulatoren der Calcitoninausschüttung. Patienten mit medullärem Schilddrüsenkarzinom oder C-ZellHyperplasie können basal normale Calcitoninkonzentrationen aufweisen, reagieren aber auf Stimulation mit einem überschießenden Anstieg.

\section{Untersuchungsmaterial $>$ Calcitonin.}

Präanalytik $>$ Calcitonin.

Analytik $>$ Calcitonin.

Probenstabilität $>$ Calcitonin.

Konventionelle Einheit $>$ Calcitonin.

Internationale Einheit $>$ Calcitonin.

Umrechnungsfaktor zw. konv. u. int. Einheit $>$ Calcitonin.

Referenzbereich Die Referenzbereiche sind vom verwendeten Assay abhängig. In der Literatur finden sich folgende Angaben:

- $\quad<10 \mathrm{pg} / \mathrm{mL}$ : Normalbefund

- 10-100 pg/mL: Graubereich, falsch positive Ergebnisse möglich

- >100-<500 pg/mL: suspekt, häufig C-Zell-Hyperplasie 
- $\quad>500-<1000 \mathrm{pg} / \mathrm{mL}$ : hohe Wahrscheinlichkeit für medulläres Schilddrüsenkarzinom

- $>1000 \mathrm{pg} / \mathrm{mL}$ : beweisend für medulläres Schilddrüsenkarzinom

Indikation Verdacht auf medulläres Schilddrüsenkarzinom. Postoperativ bei medullärem Schilddrüsenkarzinom zur Verlaufsbeurteilung.

Die früher übliche jährliche Testung von Angehörigen im Rahmen des Familienscreenings bei der multiplen endokrinen Neoplasie (MEN) ist durch die molekularbiologische Diagnostik hinfällig geworden.

Interpretation S. Referenzbereich. Auch ein $>10$-facher Anstieg des Calcitonins nach Stimulation spricht für eine C-Zell-Erkrankung.

Diagnostische Wertigkeit Der Calcitoninstimulationstest ist unbestritten der am besten valdierte Test in der Diagnostik des medullären Schilddrüsenkarzinoms, seine Sensitivität ist gut dokumentiert. Problematisch ist, dass in vielen Ländern Pentagastrin nicht oder nicht mehr (Deutschland 2017) verfügbar ist. Alternative Tests zur Stimulation der Calcitoninsekretion sind der in den USA häufig eingesetzte Calciumstimulationstest oder eine Stimulation mit Protonenpumpeninhibitoren. Beide Test sind mit den derzeit verfügbaren Calcitoninassays jedoch nicht in gleicher Weise validiert wie der Pentagastrintest.

Beim Pentagastrintest wie beim Calciumstimulationstest kommt es häufig zu einer Flushsymptomatik, andere Nebenwirkungen sind Kopfschmerz, Übelkeit, Erbrechen und Harndrang. Dabei scheinen Frauen den Pentagastrintest, Männer den Calciumbelastungstest besser zu tolerieren. Kontraindikationen sind zu beachten bei Patienten mit kardiovaskulären Vorerkrankungen, Hypertonus und Verdacht auf Phäochromozytom (z. B. im Rahmen einer MEN).

\section{Literatur}

Costante G, Durante C, Francis Z, Schlumberger M, Filetti S (2009) Determination of calcitonin levels in C-cell disease: clinical interest and potential pitfalls. Nat Clin Pract Endocrinol Metab 5(1):35-44

Ubl P, Gincu T, Keilani M, Ponhold L, Crevenna R, Niederle B, Hacker M, Li S (2014) Comparison of side effects of pentagastrin test and calcium stimulation test in patients with increased basal calcitonin concentration: the gender-specific differences. Endocrine 46(3):549-553. https://doi.org/10.1007/s12020-013-0109-6. Epub 23 Nov 2013

\section{Calcitriol}

- Vitamin D

\section{Calcium}

O. Müller-Plathe

Synonym(e) Kalzium

Englischer Begriff calcium

Definition Calcium (chemisches Symbol: $\mathrm{Ca}$ ) ist als Kation $\left(\mathrm{Ca}^{2+}\right)$ wichtig für Knochenstoffwechsel und neuromuskuläre Erregungsvorgänge.

Molmasse Relative Atommasse: 40,08.

Synthese - Verteilung - Abbau - Elimination Tägliche Calciumaufnahme 10-25 mmol (0,4-1,0 g), vorwiegend aus Milch und Milchprodukten, Getreideprodukten und Leitungswasser. Ein Drittel davon wird im Jejunum absorbiert, der Rest wird mit den Fäzes ausgeschieden.

Bestand Bei $70 \mathrm{~kg}$ Körpergewicht etwa $25.000 \mathrm{mmol}(1 \mathrm{~kg})$, davon rasch austauschbar $100 \mathrm{mmol}$.

Verteilung Knochen (extrazellulär als kristalliner Hydroxylapatit) $99 \%$, EZR und IZR $1 \%$. Calciumkonzentration im IZR $0,1-1,0 \mu \mathrm{mol} / \mathrm{L}$

Elimination Mit den Fäzes 10-20 mmol/Tag, mit dem Urin etwa $5 \mathrm{mmol} / \mathrm{Tag}$.

Calciumfraktionen im Plasma Gesamtcalcium $\left(\mathrm{Ca}_{\mathrm{tot}}\right)$ mit einer Konzentration von 2,50 $\mathrm{mmol} / \mathrm{L}$ besteht aus folgenden Fraktionen:

- An Proteine (vorwiegend Albumin) gebunden $\left(\mathrm{Ca}_{\text {prot }}\right)$ : $40 \%$

- Komplex an Phosphat, Citrat, Laktat und $\mathrm{HCO}_{3}{ }^{-}$gebun$\operatorname{den}\left(\mathrm{Ca}_{\text {comp }}\right): 10 \%$

- Ionisiertes (freies) Calcium $\left(\mathrm{Ca}^{2+}\right): 50 \%$

Aktivitätskoeffizient 0,34 ( $\triangleright$ Elektrolyte)

Die Bindung des Calciums an Protein ist pH-abhängig. Alkalose begünstigt die Bindung und führt zur Abnahme von $\mathrm{Ca}^{2+}$, Azidose hemmt sie und führt zur Zunahme von $\mathrm{Ca}^{2+}$. Bei einer $\mathrm{pH}$-Verschiebung um 0,1 ändert sich $\mathrm{Ca}^{2+}$ invers um $0,07 \pm 0,03$ (s. a. Abbildung).

Die absolute Konzentration von $\mathrm{Ca}_{\text {prot }}$ und damit auch diejenige von $\mathrm{Ca}_{\text {tot }}$ wird stark von der Albumin- bzw. Gesamteiweißkonzentration im Plasma beeinflusst. Pro g/L Albuminänderung ändert sich $\mathrm{Ca}_{\text {tot }}$ gleichsinnig um etwa 
0,025 $\mathrm{mmol} / \mathrm{L}$ (Pseudohypokalziämie bei Hypalbuminämie!). Zur Orientierung kann bei stark abweichenden Albuminwerten mit der Formel nach Payne (1979) auf Albumin = $40 \mathrm{~g} / \mathrm{L}$ umgerechnet werden:

$$
\begin{aligned}
\mathrm{Ca}_{\text {korr }}[\mathrm{mmol} / \mathrm{L}]= & \text { Ca } a_{\text {gemessen }}[\mathrm{mmol} / \mathrm{L}]-0,025 \\
& \times \text { Albumin }[\mathrm{g} / \mathrm{L}]+1
\end{aligned}
$$

Im Gegensatz zum Gesamtcalcium wird das ionisierte Calcium $\left(\mathrm{Ca}^{2+}\right)$ nicht durch Proteineinflüsse verfälscht. $\mathrm{Ca}^{2+}$ ist die biologisch aktive Fraktion. Sie wird von den Calciumhormonen reguliert, und sie beeinflusst die neuromuskuläre Erregbarkeit.

Funktion - Pathophysiologie $\mathrm{Ca}^{2+}$ und $\mathrm{Ca}_{\text {comp }}$, zusammen auch als ultrafiltrierbares Calcium bezeichnet, werden aus dem Primärharn zu $90 \%$ im proximalen Tubulus und in der Henleschen Schleife reabsorbiert. Etwa $9 \%$ werden im distalen Tubulus reabsorbiert.

Die Calciumkonzentration im Plasma wird durch folgende Substanzen reguliert:

1. Calcitriol (1,25-[OH] $]_{2}$-VitD): Es entsteht aus der Vorstufe Calciol ( $\triangleright$ Vitamin D) über die Zwischenstufe Calcidiol durch Hydroxylierung in der Niere und fördert die Aufnahme von Calcium im Jejunum durch Bildung eines calciumbindenden Proteins. Die Calcitriolbildung in der Niere wird durch PTH stimuliert, bei Niereninsuffizienz ist sie beeinträchtigt.

2. Parathormon (Parathyrin, PTH) steigert das Plasmacalcium hauptsächlich durch 3 Wirkungen:

- Steigerung der Reabsorption von $\mathrm{Ca}^{2+}$ im distalen Tubulus

- Mobilisierung von Calcium aus den Knochen

- Stimulierung der renalen Calcitriolbildung

Die PTH-Sekretion wird vermittelt über einen calciumsensitiven Rezeptor an den Hauptzellen der Parathyreoidea, der auf die extrazelluläre Konzentration des ionisierten Calciums anspricht.

3. Calcitonin: Das in den C-Zellen der Schilddrüse gebildete Calcitonin senkt, therapeutisch verabreicht, das Plasmacalcium durch folgende Wirkungen:

- Hemmung der Osteoklastentätigkeit

- Hemmung der tubulären Reabsorption von Calcium

Die physiologische Relevanz der körpereigenen Calcitoninsekretion scheint, mindestens für Erwachsene, gering zu sein, da weder Überproduktion beim medullären Schilddrüsenkarzinom noch fehlende Sekretion nach Thyreoidektomie Auswirkungen auf den Calciumhaushalt erkennen lassen.

\section{Folgen von Hypo- und Hyperkalziämie}

\section{- Hypokalziämie}

- Neurologisch: tetanische Krämpfe mit Carpopedalspasmen und perioralen sowie distalen Parästhesien; kardial: EKG-Veränderungen (QT-Verlängerung); Herzglykosidwirkung vermindert

- Bei chronischer Einwirkung Störung der Knochenmineralisation, Nägelbrüchigkeit, Katarakt

- Verstärkung aller Symptome durch Alkalose, Abschwächung bei Acidose

- Hyperkalziämie

- Kardiovaskulär: Hypertonie, EKG-Veränderungen (QTVerkürzung), verstärkte Herzglykosidwirkung

- Gastrointestinal: Übelkeit, Erbrechen, Ulzera, Pankreatitis

- Renal: Polyurie, Konzentrationsschwäche, Exsikkose, Niereninsuffizienz, Nephrokalzinose, Urolithiasis

- Kalzifikationen: an den inneren Organen, Gefäßwänden und der Hornhaut

- Neurologisch: Psychosen, Somnolenz, Koma

Untersuchungsmateria-Entnahmebedingungen Gesamtcalcium: Heparinplasma oder Serum.

Ionisiertes Calcium: anaerob behandeltes Heparinblut, bevorzugt in „Blutgasspritze“ oder Kapillare, präpariert mit lyophilisiertem, elektrolytbalancierten Heparin.

24-Stunden-Urin: zur ersten Urinportion $25 \mathrm{~mL} \mathrm{HCl}$ $(6 \mathrm{~mol} / \mathrm{L})$ geben und die weiteren Urinportionen hinzumischen.

Probenstabilität Gesamtcalcium: Plasma bei $25^{\circ} \mathrm{C} 7$ Tage, bei $4-8{ }^{\circ} \mathrm{C} 21$ Tage, bei $-20^{\circ} \mathrm{C} 8$ Monate.

Ionisiertes Calcium: Heparinblut bei $25{ }^{\circ} \mathrm{C} 30$ Minuten, bei $4-8{ }^{\circ} \mathrm{C} 2$ Stunden.

24-Stunden-Urin: Bei $25{ }^{\circ} \mathrm{C} 2$ Tage, bei $4-8{ }^{\circ} \mathrm{C} 4$ Tage. Ggf. Präzipitate mit $\mathrm{HCl}$ lösen $(\mathrm{pH}<2)$.

Präanalytik Gesamtcalcium im Plasma: Blutabnahme möglichst im Liegen, Venenstauung $<2$ Minuten.

Ionisiertes Calcium im Vollblut: folgende Fehlerquellen sind zu beachten:

- pH-Einfluss: Alkalisierung $\left(\mathrm{Ca}^{2+} \downarrow\right)$ durch Luftzutritt zur Probe oder Azidifizierung $\left(\mathrm{Ca}^{2+} \uparrow\right)$ durch Laktatbildung infolge zu lang anhaltender venöser Stauung, Muskelkontraktionen (,Pumpen“) während der Stauung oder zu langer Lagerung bei Raumtemperatur (Glykolyse in Erythrozyten).

- Chelatbildung zwischen $\mathrm{Ca}^{2+}$ und Heparin: Diese tritt ein bei gewöhnlichem Na- oder Li-Heparinat und mindert $\mathrm{Ca}^{2+}$ in einer Größenordnung von etwa $0,07 \mathrm{mmol} / \mathrm{L}$ pro 50 IU Heparin pro $\mathrm{mL}$ Blut, annähernd die Hälfte des Referenzintervalls. Deshalb ist entweder calciumtitriertes 
Heparin zur Vorbereitung des Probengefäßes notwendig oder das gewöhnliche Heparin ist auf $<15 \mathrm{IU}$ pro $\mathrm{mL}$ Blut zu begrenzen.

- Dilution durch das Volumen der Heparinlösung: zu umgehen durch Verwendung von Spritzen mit lyophilisiertem Heparin.

Analytik Molare Konzentration des Gesamtcalciums:

- Atomabsorptionsspektrometrie (AAS): Grundlage der IFCC-Referenzmethode; in geübter Hand auch für Routineanalytik in kleinen Serien, z. B. für Urincalciumbestimmungen, geeignet; nicht integrierbar in Analysenautomaten.

- Photometrische Messung einer Calciumkomplexverbindung mit

- o-Kresolphthalein bei $578 \mathrm{~nm}$; weit verbreitetes, automationsfähiges Routineverfahren,

- Arsenazo III bei $650 \mathrm{~nm}$ in einem System mit trägergebundenen Reagenzien.

- $>$ Ionenselektive Elektrode (ISE, indirekt) nach Verdünnung der Probe mit einem maleathaltigen Metallionenpuffer; das im Gleichgewicht mit dem Pufferkomplex stehende freie Calcium wird durch die ISE gemessen.

- Flammenatomemissionsspektrometrie (FAES), „Flammenphotometrie“ ( $\triangleright$ Flammenatomabsorptionsspektrometrie/spektroskopie): Dieses nicht in Analysenautomaten zu integrierende Verfahren ist für die Calciumbestimmung weitgehend verlassen.

Ionisiertes (freies) Calcium:

- Ionenselektive Elektrode (ISE, direkt) im unverdünnten Heparinblut: Die sehr schnelle Messung der biologisch aktiven Calciumfraktion im Vollblut steht in mehreren Blutgas-/Elektrolytgeräten vollmechanisiert zur Verfügung. Für die $\mathrm{Ca}^{2+}$-spezifische Elektrodenmembran werden neutrale Ionencarrier (z. B. ETH 1001) oder Ionenaustauscher (Organophosphate) benutzt. Messtechnisch wird die molale Aktivität der freien Calciumionen erfasst. Durch entsprechende Kalibration wird das Messsignal auf ein Plasma mit normalem Lipid- und Proteingehalt bezogen. Es handelt sich also um eine auf Molarität justierte Aktivitätsmessung. Irrtümer durch Pseudohypo- und Pseudohyperkalziämie werden im Gegensatz zur Gesamtcalciumbestimmung vermieden. Wegen der pH-Abhängigkeit von $\mathrm{Ca}^{2+}$-Ergebnismitteilung mit 3 Angaben:

$-\mathrm{Ca}^{2+}$ aktuell

- $\mathrm{Ca}^{2+}$ bezogen auf $\mathrm{pH} 7,4$

- pH aktuell

- Die nomographische Bestimmung von $\mathrm{Ca}^{2+}$ aus Gesamtcalcium, Albuminkonzentration und $\mathrm{pH}$ (Siggaard-
Andersen et al. 1983) erlaubt eine Abschätzung von $\mathrm{Ca}^{2+}$, berücksichtigt aber nicht den wechselnden Anteil des komplexgebundenen Calciums.

Konventionelle Einheit $\mathrm{mg} / \mathrm{dL}$.

Internationale Einheit $\mathrm{mmol} / \mathrm{L}$.

Umrechnungsfaktor zw. konv. u. int. Einheit 0,25.

Referenzbereich - Erwachsene Plasma- oder SerumCalcium, gesamt: 2,15-2,55 mmol/L; Blut-Calcium, ionisiert: 1,15-1,30 mmol/L; Urin-Calcium: 2,50-7,50 mmol/Tag.

Referenzbereich - Kinder Plasma- oder Serum-Calcium, gesamt:

- 1 Tag-4 Wochen 1,75-2,70 mmol/L

- 2 Monate-14 Jahre 2,05-2,70 mmol/L

Blut-Calcium, ionisiert:

- 1. Tag $1,06-1,36 \mathrm{mmol} / \mathrm{L}$

- 2. Tag $1,10-1,40 \mathrm{mmol} / \mathrm{L}$

- 3. Tag $1,19-1,47 \mathrm{mmol} / \mathrm{L}$

- Säugling/Kleinkind $1,15-1,45 \mathrm{mmol} / \mathrm{L}$

Indikation Erkrankungen des Skelettsystems, Knochenschmerzen, Spontanfrakturen, Gewichtsverlust, Nierenkrankheiten, Urolithiasis, peptisches Ulkus, Pankreatitis, Tetanie, Anfallsleiden, Depression, Zustand nach Schilddrüsenoperationen, endokrine Erkrankungen der Schilddrüse, Epithelkörperchen, Nebennierenrinde, maligne Tumoren und Lymphome. Medikation mit Vitamin D, Kortikosteroiden und Thiaziddiuretika.

Diese Indikationen gelten für Gesamtcalcium und ionisiertes Calcium. Spezifität und Sensitivität sind bei $\mathrm{Ca}^{2+}$ höher.

Spezielle Gründe für die Bestimmung des ionisierten Calciums sind gegeben

- bei Gesamtprotein $<60 \mathrm{~g} / \mathrm{L}$ und $>85 \mathrm{~g} / \mathrm{L}$ bzw. Albumin $<35 \mathrm{~g} / \mathrm{L}$ und $>50 \mathrm{~g} / \mathrm{L}$,

- in der Perinatalmedizin,

- nach Massentransfusion,

- intra- und postoperativ in der Kardiochirurgie sowie

- bei Komplikationen der Hämodialyse.

Interpretation Ist von Bedeutung bei:

Vorkommen der Hypokalziämie

- Verminderte enterale Aufnahme:

- Malabsorption: Sprue, Coeliakie, chronische Pankreatitis 


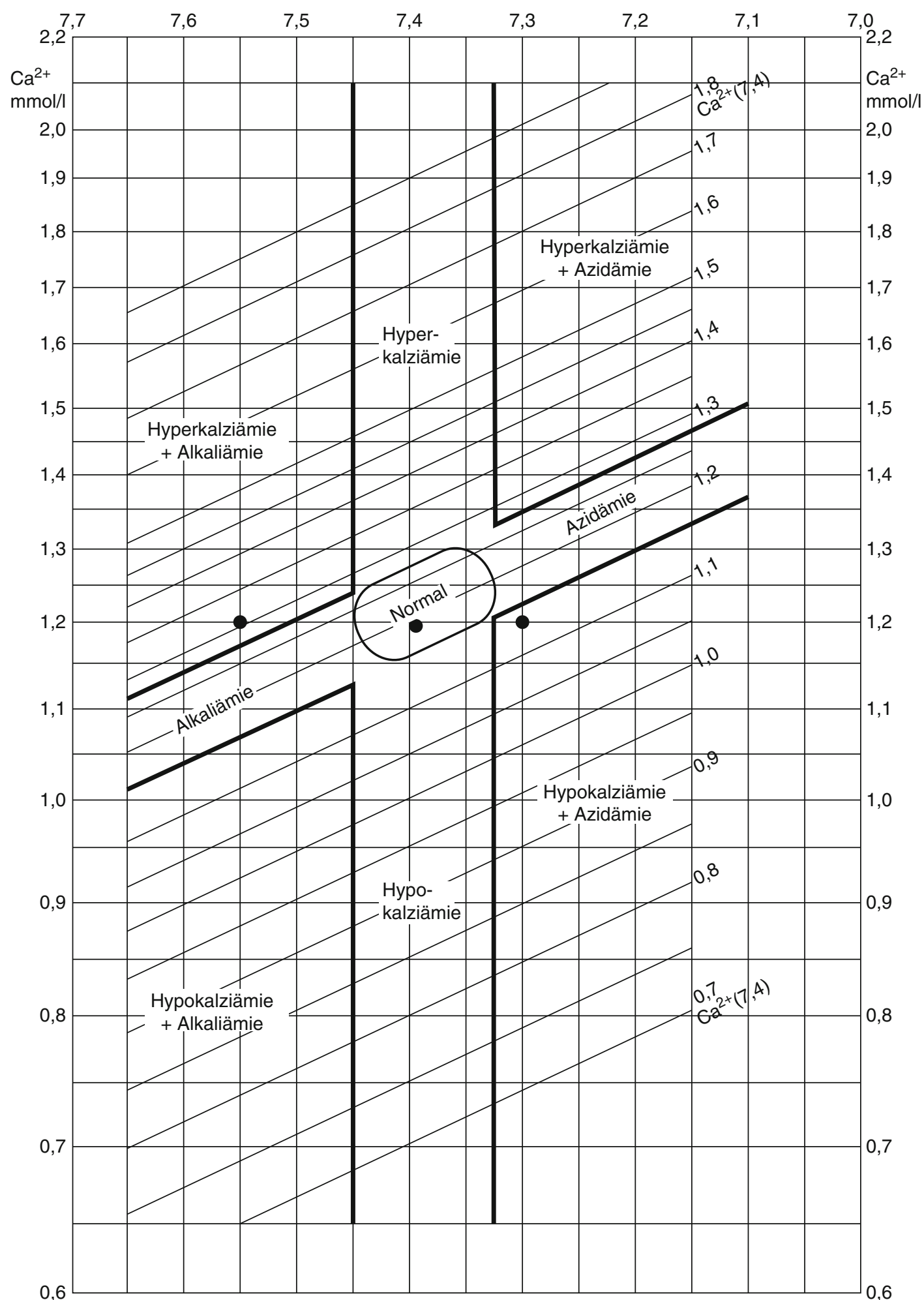

Calcium, Abb. 1 Nomogramm zur Interpretation des ionisierten Calciums

- Verminderte Vitamin-D-Wirkung: Vitamin-D-Mangel alimentär oder durch ungenügende Sonnenlichtexposition; unzureichende Bildung von Calcitriol bei Niereninsuffizienz sowie bei Leberzirrhose und Alkoholismus
- Verminderte Parathormonwirkung:

- Hypoparathyreoidismus (idiopathisch, postoperativ, destruktiv)

- Pseudohypoparathyreoidismus (Rezeptorstörung) 
- Hypomagnesiämie

- Osteoplastische Metastasen: Prostata- und Mammakarzinom, medulläres Schilddrüsen-Carcinom.

- Medikamentös: Schleifendiuretika (Furosemid, Etacrynsäure), Antiepileptika

- Weitere Zustände:

- Akute nekrotisierende Pankreatitis, Rhabdomyolyse, erhöhte Kortikoideinwirkung

- Erhöhte Phosphatfreisetzung (z. B. große Verbrennungen, Untergang großer Tumormassen, zytostatische Leukämietherapie)

- Pseudohypokalziämie bei Hypalbuminämie: Ausschluss durch ionisiertes Calcium

\section{Vorkommen der Hyperkalziämie}

- Erhöhte enterale Aufnahme: D-Hypervitaminose, MilchAlkali-Syndrom

- Vermehrte Parathormonwirkung:

- Primärer Hyperparathyreoidismus (Hyperplasie, Adenom oder Karzinom der Parathyreoidea)

- Tertiärer Hyperparathyreoidismus (aus dem sekundären, meist renal bedingten Hyperparathyreoidismus hervorgegangene Autonomie der PTH-Produktion)

- Vermehrte Calciummobilisation aus den Knochen:

- Neoplasien, besonders der Mamma, der Bronchien, der Niere und des Pankreas sowie beim multiplen Myelom; hierbei Hyperkalziämie sowohl durch metastatische Osteolyse als auch durch PTH-ähnlich wirkende Substanzen, sog. Parathormon-related Peptides (PTH-rP)

- Immobilisation

- Aufenthalt in der Schwerelosigkeit (Weltraumflug)

- Medikamentös: Thiazide, Tamoxifen, Lithium, VitaminA-Überdosierung

- Weitere Zustände:

- Hyperthyreose, M. Addison, Sarkoidose

- Familiäre hypokalzurische Hyperkalziämie (genetisch bedingter Defekt des calciumsensitiven Rezeptors der Parathyreoidea-Hauptzellen)

Unterscheidung von Stoffwechsel- und Aziditätseinflüssen auf das ionisierte Calcium Zur Entscheidung, ob ein gemessener $\mathrm{Ca}^{2+}$-Wert eine Störung der Calciumhomöostase anzeigt oder pH-bedingt ist oder ob beides der Fall ist, dient das Nomogramm in Abbildung 1. Das eingezeichnete Beispiel $\left(\mathrm{Ca}^{2+}=1,2 \mathrm{mmol} / \mathrm{L}\right)$ lässt erkennen, dass der gleiche Wert abhängig von $\mathrm{pH}$ im Hinblick auf die Calciumhomöostase als erniedrigt, normal oder erhöht einzustufen ist.

Diagnostische Wertigkeit Auswirkungen der Hypokalziämie zeigen sich ab $\mathrm{Ca}_{\text {tot }}<1,75 \mathrm{mmol} / \mathrm{L}$ bzw. $\mathrm{Ca}^{2+}<0,9 \mathrm{mmol} / \mathrm{L}$.
Auswirkungen der Hyperkalziämie zeigen sich ab $\mathrm{Ca}_{\text {tot }}$ $>3,3 \mathrm{mmol} / \mathrm{L}$ bzw. $\mathrm{Ca}^{2+}>1,7 \mathrm{mmol} / \mathrm{L}$.

$\mathrm{Ab} \mathrm{Ca}_{\text {tot }}>3,8 \mathrm{mmol} / \mathrm{L}$ bzw. $\mathrm{Ca}^{2+}>2,0 \mathrm{mmol} / \mathrm{L}$ Entwicklung einer hyperkalziämischen Krise mit Somnolenz, Koma, Nierenversagen und der Gefahr der Asystolie. Zur Erkennung drohender Gewebsverkalkungen ( $\triangleright$ Calcium-Phosphat-Produkt).

\section{Literatur}

Müller-Plathe O (1993) Improving the acceptance of ,,ionized calcium“ for routine clinical practice. Scand J Clin Lab Invest 53(Suppl 214):95-98

Siggaard-Andersen O, Thode J, Fogh-Andersen N (1983) Nomograms for calculating the concentration of ionized calcium of human blood from total calcium, total protein and/or albumin, and $\mathrm{pH}$. Scand J Clin Lab Invest 43(Suppl 165):57-63

\section{Calcium, ionisiertes}

Calcium

\section{Calcium im Urin}

$\triangleright$ Calciumausscheidung

\section{Calciumausscheidung}

H.-D. Haubeck

Synonym(e) Kalzium-Ausscheidung

Englischer Begriff calcium urinary excretion

Definition Die Messung der Calciumausscheidung im 24Stunden-Sammelurin ist ein Parameter zur Beurteilung des Calciumhaushalts.

Synthese - Verteilung - Abbau - Elimination Die Ausscheidung des Calciums erfolgt über die Niere und z. T. über den Darm. In der Niere wird Calcium glomerulär filtriert. Ca. $90 \%$ hiervon werden im proximalen Tubulus und in der Henleschen Schleife und ca. $10 \%$ im distalen Tubulus und z. T. in den Sammelrohren reabsorbiert. Nur der letztere Teil unterliegt der Regulation über Vitamin D3 ( $\vee$ Vitamin D) und > Parathormon (PTH). Während PTH die Calciumrückresorption und die Phosphatausscheidung fördert, stimuliert Vitamin D3 die Reabsorption von Calcium und Phosphat.

Funktion - Pathophysiologie Calcium ist nicht nur ein wichtiger Bestandteil der anorganischen Matrix des Kno- 
chens, sondern auch für die Steuerung zahlreicher Zellfunktionen, z. B. der Muskelkontraktion, von entscheidender Bedeutung. Die Regulation der konstanten Calciumkonzentration im Serum bzw. Plasma ( $\triangleright$ Calcium) erfolgt über Parathormon, $>$ Calcitonin und Vitamin D3 und deren Wirkung auf die Mobilisierung von Calcium aus dem Knochen, die Resorption im Darm und die Ausscheidung in der Niere.

Untersuchungsmaterial - Entnahmebedingungen 24Stunden-Sammelurin.

Probenstabilität Der Urin wird, um die Ausfällung von Calciumsalzen zu vermeiden, im Labor durch Zugabe von $10 \mathrm{~mL}$ konzentrierter Salzsäure $(6 \mathrm{~mol} / \mathrm{L})$ angesäuert. Zur Kontrolle der Urinsammlung ist die Kreatininbestimmung im Urin sinnvoll.

Analytik Die Bestimmung erfolgt durch Atomabsorptionsspektrometrie. Bei der alternativen Bestimmung durch Flammenphotometrie ist der Einsatz einer Kompensationslösung notwendig, die die gleiche Natriumkonzentration wie der Urin hat.

Konventionelle Einheit $\mathrm{mg} / 24 \mathrm{~h}$.

Internationale Einheit $\mathrm{mmol} / 24 \mathrm{~h}$.

Umrechnungsfaktor zw. konv. u. int. Einheit mg/ $24 \mathrm{~h} \times 0,025=\mathrm{mmol} / 24 \mathrm{~h}$.

Referenzbereich - Erwachsene 2,5-7,5 mmol/Tag.

Referenzbereich - Kinder $<0,1 \mathrm{mmol} / \mathrm{kg} \mathrm{KG/Tag}$.

Indikation Störungen des Calciumstoffwechsels.

Interpretation Die Interpretation der Calciumausscheidung in den Urin kann nur im Zusammenhang mit den Serumkonzentrationen von Calcium und Phosphat, Parathormon und Vitamin D3 erfolgen. Sie ist darüber hinaus von der oralen Calciumaufnahme abhängig. Eine vermehrte Calciumausscheidung findet sich vor allem beim primären Hyperparathyreoidismus, bei Tumoren, die $>$ Parathormon-related Peptide (PTHrP) bilden (u. a. Bronchial-, Nieren- und Ovarialkarzinome), bei Plasmozytomen und Tumoren, die Knochenmetastasen bilden, bei primär idiopathischer Hypercalciurie, beim Bartter-Syndrom, bei Hyperthyreose, Cushing-Syndrom, renal tubulärer Azidose, Milch-Alkali-Syndrom, aber auch verursacht durch Medikamente (z. B. Schleifendiuretika wie Furosemid). Die Hypercalciurie und insbesondere die idiopathische Hypercalciurie bilden die häufigste Ursache der Calciumnephrolithiasis. Eine verminderte Calciumausscheidung findet sich u. a. beim Hypoparathyreoidismus, beim Vitamin-D3-Mangel, bei chronischer Niereninsuffizienz, beim nephrotischen Syndrom sowie bei familiärer hypocalciurischer Hypercalciämie. Sie kann aber auch durch Medikamente (z. B. Thiazide, Amilorid) verursacht werden.

Diagnostische Wertigkeit Die Bestimmung der Calciumausscheidung in den Urin ist ein sinnvoller Zusatzparameter für die Beurteilung von Calciumstoffwechselstörungen.

\section{Literatur}

Frick KK, Bushinsky DA (2003) Molecular mechanisms of primary hypercalciuria. J Am Soc Nephrol 14:1082-1095

Hebert SC (2003) Bartter syndrome. Curr Opin Nephrol Hypertens 12:527-532

\section{Calciumhydrogenphosphat (Brushit)}

- Calciumphosphat-Stein

\section{Calcium-lonen}

- Gerinnungsfaktor IV

\section{Calciumkanalantikörper}

- Autoantikörper gegen Calciumkanäle

\section{Calciumoxalatkristalle}

- Oxalatkristalle

\section{Calciumoxalatmonohydrat}

Whewellit

\section{Calciumoxalatsteine}

- Oxalatsteine

\section{Calciumoxalatsteine als Weddellit oder Whewellit}

$>$ Oxalatsteine 


\section{Calcium-Phosphat-Produkt}

\section{O. Müller-Plathe}

\section{$\operatorname{Synonym}(e)[\mathrm{Ca} \times \mathrm{P}]$}

Englischer Begriff calcium-phosphorus product; calciumphosphate product

Definition Produkt aus den Konzentrationen von Gesamtcalcium (auf normale Albuminkonzentration umgerechnet; $>$ Calcium) und anorganischem Phosphat im Serum bzw. Plasma.

Beschreibung Ein Calcium-Phosphat-Produkt über 4,9 $\mathrm{mmol}^{2} / \mathrm{L}^{2}$ bzw. $60 \mathrm{mg}^{2} / \mathrm{dL}^{2}$ weist generell auf die Gefahr von Gewebsverkalkungen hin.

Bevorzugte Anwendung hat $[\mathrm{Ca} \times \mathrm{P}]$ in der Nephrologie bei fortgeschrittener Niereninsuffizienz mit sekundärem Hyperparathyreoidismus gefunden, um das Risiko der extraossären Kalzifikation mit ihren teilweise lebensverkürzenden Auswirkungen auf Arterien, Herzklappen, Nierenparenchym und Haut (Kalziphylaxie) zu begrenzen. Neuere Richtlinien setzen hierfür als therapeutischen Zielwert:

$$
<4,5 \mathrm{mmol}^{2} / \mathrm{L}^{2}\left(<55 \mathrm{mg}^{2} / \mathrm{dL}^{2}\right) \text {. }
$$

Bei Einsatz von ionisiertem Calcium ergibt sich als Zielwert $<2,25 \mathrm{mmol}^{2} / \mathrm{L}^{2}$.

\section{Literatur}

Bock A, Keusch G, Kress P, Martin PY (2005) Das Kalzium-PhosphatProblem bei chronischer Niereninsuffizienz. Schweiz Med Forum 5:976-982

\section{Calciumphosphat-Stein}

W. G. Guder

Synonym(e) Calciumhydrogenphosphat (Brushit); Karbonatapatit (Dahllit)

Englischer Begriff calcium phosphate stones; carbonateapatite; dahllite stones; brushite stones

Definition Calciumphosphatsteine treten in 2 Formen auf, als Brushit (Ca-Hydrogenphosphat) monomineralisch im sauren Harn und als Dahllit (Karbonatapatit) im alkalischen Urin, meist in Kombination mit Magnesium-Ammonium-Phosphat (Struvit).
Beschreibung Calciumphosphat tritt in Form von Kristallen im Harnsediment, pathogenetisch aber als Harnkonkrement oder Harnstein auf, wenn es infolge einer Infektion ableitender Harnwege auf der Basis der Alkalisierung des Harns im Nierenbecken ausfällt, meist gemeinsam mit Oxalat oder Magnesium-Ammonium-Phosphat (Struvit) als Mischstein. Dieser kann als Stein abgehen oder als Ausgussstein das gesamte Nierenbecken ausfüllen.

Im sauren Harn kann Calciumphosphat als basisches Calciumphosphat/-karbonat (Dahllit) kristallisieren, das im Sediment als eher pseudoamorphes Kristall in Erscheinung tritt.

\section{Literatur}

Hesse A, Jahnen A, Klocke K et al (1996) Nachsorge beim HarnsteinPatienten. Gustav-Fischer Verlag, Jena

Hesse A, Tiselius HG, Jahnen A (2002) Urinary stones. Diagnosis, treatment and prevention of recurrence. Karger, Basel

\section{Calciumpyrophosphatdihydrat- Kristalle}

H.-D. Haubeck

Synonym(e) Calciumpyrophosphat-Kristalle; CPPD-Kristalle; Pyrophosphat-Kristalle

Englischer Begriff calcium pyrophosphate dihydrate crystals

Definition Calciumpyrophosphatdihydrat-Kristalle werden bei Chondrocalcinose (Pseudogicht) in der Synovialflüssigkeit beobachtet.

Beschreibung Calciumpyrophosphatdihydrat-Kristalle lassen sich bei Chondrocalcinose in der Synovialflüssigkeit durch Polarisationsmikroskopie nachweisen. Im Gegensatz zu den nadelförmigen, stark doppelbrechenden HarnsäureKristallen bei der Gicht sind CalciumpyrophosphatdihydratKristalle meist plumper und nur schwach doppelbrechend. Die eindeutige Identifizierung erfolgt durch Infrarotspektroskopie.

\section{Literatur}

Swan A, Heywood B, Chapman B et al (1995) Evidence for a causal relationship between the structure, size, and load of calcium pyrophosphate dihydrate crystals, and attacks of pseudogout. Ann Rheum Dis $54: 825-830$ 


\section{Calciumpyrophosphat-Kristalle}

- Calciumpyrophosphatdihydrat-Kristalle

\section{Calciumreaktion nach Sulkowitch}

- Sulkowitch-Test

\section{Calgranulin (A und B)}

$\checkmark$ Calprotectin

\section{Calgranulin-C}

- S100A12-Protein

\section{Calprotectin}

T. Arndt

Synonym(e) Calgranulin (A und B); CFA; S-100a und b; Humanes Leukozyten-Protein; L1-Protein; Protein L1

Englischer Begriff L1 protein; protein L1; calprotectin; human leukocyte protein; calgranulin; MRP-8/14; cystic fibrosis antigen; CFA; S-100a and b (calcium-binding proteins)

Definition Calcium- und Zink-bindendes Protein mit einer Molmasse von ca. 36,5 kDa, mit 2 Schwerketten von ca. $14 \mathrm{kDa}$ und einer Leichtkette von ca. $8 \mathrm{kDa}$, das zur S-100-Proteingruppe gehört und vorwiegend von Monozyten und neutrophilen Granulozyten freigesetzt wird.

Beschreibung In Gegenwart von EDTA (Calciumentzug) ist Calprotectin anionisch und Bestandteil der $\alpha_{2}$-Globulinfraktion der Serumeiweißelektrophorese, unter Beladung mit Calcium ist das Molekül basisch und erscheint in der $\gamma$-Globulinfraktion. Calciumbindung macht das Protein hitze- und proteolysestabil.
Calprotectin hat eine Protein-S-100-ähnliche Struktur. Genlokus ist das Chromosom 1, q12-q21.

Calprotectin kommt in allen Zellen, Geweben und Flüssigkeiten des menschlichen Organismus vor. In Neutrophilen liegt es im extralysosomalen Zytosol in einer Konzentration von $5-15 \mathrm{mg} / \mathrm{L}$ vor und macht ca. $60 \%$ der löslichen Bestandteile bzw. $5 \%$ des Gesamtproteins von neutrophilen Granulozyten aus. Calprotectin und seine Untereinheiten haben intra- und extrazelluläre regulatorische Funktionen im Entzündungsgeschehen sowie antimikrobielle und antiproliferative Eigenschaften.

Die klinische Relevanz der Calprotectinbestimmung im Plasma wird für die Diagnose entzündlicher, einiger mikrobieller und neoplastischer Erkrankungen gesehen. Höchste Anstiege werden bei zystischer Fibrose, rheumatoider Arthritis, M.Crohn, Colitis ulcerosa und bakteriellen Infektionen berichtet. Die Plasmakonzentration von Calprotectin korreliert nicht mit jener von CRP ( $\triangleright$ C-reaktives Protein), Leukozytenzahl und Blutsenkungsgeschwindigkeit (๖ Blutkörperchensenkungsgeschwindigkeit nach Westergren; - Wintrobe-Methode der Blutkörperchensenkungsgeschwindigkeit). Da Calprotectin gespeichert in den Neutrophilen vorliegt, können bei akuter Infektion schnell große Mengen ausgeschüttet werden. Die Plasmakonzentration von Calprotectin zeigt deshalb schneller eine Infektion an, als z. B. CRP, das erst von der Leber synthetisiert werden muss. Dieser Anstieg ist bei bakteriellen Infektionen stärker ausgeprägt als bei viralen. Calprotectin könnte deshalb Bedeutung für die (notfall)medizinische Differenzialdiagnose dieser beiden Infektionsformen bekommen (s. z. B. Simm et al. 2016).

Die klinische Relevanz der Calprotectinbestimmung im Stuhl liegt insbesondere in der Differenzialdiagnose von chronisch entzündlichen Darmerkrankungen und dem Reizdarmsyndrom. Bei chemotaktischem Stimulus im Rahmen einer entzündlichen intestinalen Erkrankung, transmigrieren Granulozyten in das Darmlumen und entleeren dabei das antibakteriell wirkende Calprotectin. Dessen Konzentration im Stuhl ist ein Maß für die Anzahl der Granulozyten im Darmlumen und damit für das Ausmaß der entzündlichen Darmerkrankung. Calprotectin ist im Stuhl mehrere Tage bei Raumtemperatur stabil. Die Bestimmung erfolgt aus einer Spontanstuhlprobe (wenige $\mathrm{mg}$ ) mit einem $\triangleright$ Enzymimmunoassay (ELISA). Die obere Referenzbereichsgrenze liegt bei $50 \mu \mathrm{g} / \mathrm{g}$ Stuhl. Calprotectin soll eine außerordentliche Sensitivität ( $\triangleright$ Sensitivität, diagnostische) $(100 \%)$ und Spezifität ( $\triangleright$ Spezifität, diagnostische) $(97 \%)$ zur Differenzialdiagnose chronischer Darmentzündungen und des Reizdarmsyndroms haben (Abb. 1). Eine diagnostische Bedeutung wird auch der Prognose von Schüben chronischer Darmerkrankungen und als Vorsorgeparameter bei Risikopatienten für das kolorektale Karzinom gesehen. 


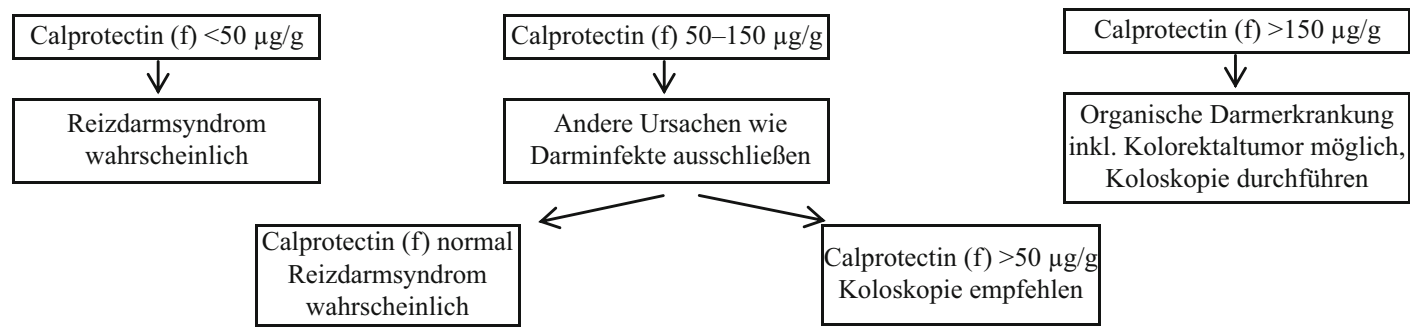

Calprotectin, Abb. 1 Differenzierung entzündlicher Darmerkrankungen vom Reizdarmsyndrom durch Calprotectin im Stuhl. (Nach: Walsham und Sherwood 2016)

\section{Literatur}

Carroccio et al (2003) Diagnostic accuracy of fecal calprotectin assay in distinguishing organic causes of chronic diarrhea from irritable bowel syndrome: a prospective study in adults and children. Clin Chem 49:861-867

Johne B et al (1997) Functional and clinical aspects of the myelomonocyte protein calprotectin. J Clin Pathol Mol Pathol 50:113-123

Simm M et al (2016) Performance of plasma calprotectin as a biomarker of early sepsis: a pilot study. Biomark Med 10(8):811-818

Walsham NE, Sherwood RA (2016) Fecal calprotectin in inflammatory bowel disease. Clin Exp Gastroenterol 9:21-29

\section{CAMP}

- Cyclisches Adenosinmonophosphat

\section{Campylobacter coli und jejuni}

W. Stöcker

\section{Englischer Begriff Campylobacter coli and jejuni}

Beschreibung des Erregers Familie: Campylobacteriaceae; Gattung: Campylobacter; mehr als 30 verschiedene Spezies, die wichtigsten sind C. jejuni, C. coli und C. lari.

Spiral- oder S-förmige gramnegative Stäbchen ( $\triangleright$ Bakterien), $0,2-0,5 \mu \mathrm{m}$ dick, $0,5-5 \mu \mathrm{m}$ lang, je 1 Geißel an beiden Polen. Mikroaerophil.

Erkrankungen Krankheitsbilder: Campylobacter ist der häufigste bakterielle Enterokolitiserreger (70.190 gemeldete Fälle im Jahr 2015). Prodromalstadium mit Kopfschmerzen, Myalgien, Arthralgien, danach Fieber, abdominelle Krämpfe, wässrig-schleimig-blutige Diarrhoe, Erbrechen. Abklingen nach 3-7 Tagen. Mögliche Folgeerkrankungen: GuillainBarré-Syndrom, reaktive Arthritis.
C. coli steht in enger Beziehung zu C. jejuni (von letzterem zu unterscheiden durch den Hippurattest) und gilt ebenfalls als bedeutender Nahrungsmittel-übertragener Erreger für eine Enterokolitis.

Übertragung: nicht durchgegarte Nahrungsmittel (Geflügel, Milch), kontaminiertes Trinkwasser, selten fäkal-oral, Infektionsdosis: $>500$.

Inkubationszeit: $2-10$ Tage.

Therapie: bei unkompliziertem Verlauf nur symptomatische Behandlung (Elektrolytsubstitution), sonst mit Antibiotika (Makrolide oder Fluorchinolone). Resistenzen werden beobachtet.

Analytik Direktnachweis und Kultur (Mikroskopie): kulturelle Anzüchtung auf Blutplatten oder Selektivmedien (48 Stunden, $37{ }^{\circ} \mathrm{C}$, Wachstumsoptimum $42{ }^{\circ} \mathrm{C}$, mikroaerobes, $\mathrm{CO}_{2}-$ angereichertes Milieu). Biochemische Differenzierung durch Nachweis von Oxidase und Katalase, $\mathrm{H}_{2} \mathrm{~S}$-Bildung, DNAse, Hippurathydrolyse, Indoxylazetathydrolyse, Nitratreduktion, Fehlen von Glukosespaltung. Ggf. gaschromatographische Bestimmung der Fettsäuren und PCR ( $\vee$ PCR (PolymeraseKettenreaktion)).

Molekularbiologische Typisierung mittels Pulsfeldgelelektrophorese.

Serologie: Die Bestimmung erregerspezifischer $\triangleright$ Antikörper insbesondere der Klasse IgA durch $\triangleright$ Enzyme-linked Immunosorbent Assay oder $>$ Western blot ist nur bei Folgeerkrankungen indiziert: Guillain-Barré-Syndrom, reaktive Arthritis.

Untersuchungsmaterial - Probenstabilität Direktnachweis und Kultur: Stuhl, Nahrungsmittelreste oder Proben verdächtiger Tierbestände. Untersucht werden auch Blutbestandteile, Liquor oder Biopsiematerial. Das Material sollte bis zur Weiterverarbeitung bei +4 bis $+8{ }^{\circ} \mathrm{C}$ aufbewahrt werden. Direktnachweise sind innerhalb von 24 Stunden durchzuführen, Kulturen innerhalb von 6 Stunden anzulegen. Bei längerer Transportzeit ist das Material einzufrieren.

Serologie: Serum oder Plasma für den Nachweis der Antikörper sind bei $+4{ }^{\circ} \mathrm{C}$ bis zu 2 Wochen lang beständig, bei 
$-20{ }^{\circ} \mathrm{C}$ über Monate und Jahre hinweg. Zur Tiefkühlkonservierung des IgM kann man den Proben 80 \% gepuffertes Glyzerin beifügen.

Diagnostische Wertigkeit Dem Erregernachweis mittels Kultur kommt eine wesentliche Bedeutung bei der Diagnose akuter Campylobacter-Infektionen zu. Durch biochemische Differenzierung und Serotypisierung erfolgt die weitere Erregercharakterisierung. Bei direktem Nachweis darmpathogener Campylobacter-Spezies besteht Meldepflicht.

Die Antikörperdiagnostik ist für die Diagnose der Darminfektion von untergeordneter Bedeutung, persistierende erregerspezifische IgA-Antikörper werden bei Folgeerkrankungen beobachtet.

\section{Literatur}

Kist M (1996) Campylobacter- und Archebacter-Infektionen. In: Hofmann F (Hrsg) Infektiologie. Ecomed Verlag, Landsberg

Nachamkin I, Blaser MJ (Hrsg) (2000) Campylobacter. ASM Press, Washington, DC

Robert-Koch-Institut, Berlin (2015) RKI-Ratgeber für Ärzte, 26.03.2015. Campylobacter-Enteritis. https://www.rki.de/DE/Content/Infekt/Epid Bull/Merkblaetter/Ratgeber_Campylobacter.html. Zugegriffen am 16.03.2017

Robert Koch Institut, Berlin (2016) Infektionsepidemiologisches Jahrbuch meldepflichtiger Krankheiten für 2015, S 56-59. https://www.rki.de/ DE/Content/Infekt/Jahrbuch/Jahrbuch_2015.pdf?__blob=publicationFile. Zugegriffen am 16.03.2017

\section{Campylobacter pylori}

$\checkmark$ Helicobacter pylori

\section{CANCA}

- Autoantikörper gegen Granulozytenzytoplasma

\section{Cancer Antigen 15-3}

- Carbohydrate antigen 15-3

\section{Cancer Antigen 27-29}

- Carbohydrate antigen 27-29

\section{Cancer Antigen 50}

> Carbohydrate antigen 50

\section{Cancer Antigen 72-4}

> Carbohydrate antigen 72-4

\section{Cancer Antigen 125}

$\checkmark$ Carbohydrate antigen 125

\section{Cancer Antigen 549}

- Carbohydrate antigen 549

\section{Cancer-associated serum antigen}

S. Holdenrieder und P. Stieber

\section{Synonym(e) CASA}

Englischer Begriff cancer-associated serum antigen

Definition CASA wurde durch einen monoklonalen $>$ Antikörper definiert, der ein Epitop eines polymorphen epithelialen Muzins erkannte.

Untersuchungsmaterial - Entnahmebedingungen Serum, Plasma.

Analytik > Enzymimmunoassay (EIA), > Radioimmunoassay (RIA), - Immunradiometrischer Assay (IRMA).

Referenzbereich - Erwachsene $<4$ U/mL (methodenabhängig).

Indikation Therapiekontrolle und Nachsorge beim Ovarialkarzinom fraglich.

Interpretation Zwar wurde CASA als sensitiver Marker beim Ovarialkarzinom beschrieben, doch konnte dies verglichen mit CA 125 ( $\triangleright$ Carbohydrate antigen 125) zu keiner 
nennenswerten Verbesserung der Diagnose führen. Als Anwendungsgebiet kommt eventuell die Verlaufskontrolle vor und nach Therapie beim Ovarialkarzinom infrage, jedoch konnte auch hier bisher keine wesentliche Verbesserung zu CA 125 gezeigt werden.

Diagnostische Wertigkeit Ovarialkarzinom: Therapiemonitoring, Rezidiverkennung fraglich. CASA ist erhöht in Personen höheren Alters, in Rauchern, während der Gravidität im letzten Trimenon sowie in Personen mit malignen Erkrankungen. Insbesondere wird CASA von allen histologischen Arten des Ovarialkarzinoms exprimiert.

\section{Literatur}

Diamandis E, Fritsche HA, Lilja H et al (2002) Tumor markers. Physiology, pathobiology, technology, and clinical applications, 1. Aufl. AACC Press, Washington, DC

Sturgeon CM, Duffy MJ, Stenman UH et al (2008) National Academy of Clinical Biochemistry laboratory medicine practice guidelines for use of tumor markers in testicular, prostate, colorectal, breast, and ovarian cancers. Clin Chem 54:e11-e79

\section{Candida}

\section{W. Stöcker}

\section{Englischer Begriff Candida}

Beschreibung des Erregers Polymorpher Hefepilz, der in Abhängigkeit von Kultur- und Umgebungsbedingungen Hyphen, Myzele, Pseudomyzele, Blastokonidien und z. T. Chlamydosporen ausbildet. Ubiquitäres Vorkommen in der Natur (feuchtigkeitsliebend), unter anderem auch im Verdauungstrakt von Warmblütern. Die Vermehrung erfolgt intraund extrazellulär.

Familie: Endomycetaceae; Gattung: Candida; klinisch relevante Spezies: Candida albicans, C. glabrata, C. parapsilosis, C. tropicalis, C. dubliniensis, C. krusei, C. guilliermondii, C. lusitaniae, C. kefyr, C. famata, C. inconspicua, C. rugosa, C. norvegensis.

Erkrankungen Krankheitsbilder: C. albicans (ca. $90 \%$ aller humanen Candida-Infektionen) und die übrigen Candida-Spezies verursachen opportunistische Infektionen der Haut (intertriginöse, perianale, perineale, genitale, interdigitale Dermatitis) und der Nägel sowie der Schleimhaut (Soor, Ösophagitis, Vulvitis, Kolpitis, Balanitis, Harnwegsinfektionen).
Neben superfizieller Besiedlung können bei geschwächter Immunkompetenz systemische Kandidosen auftreten (Endophthalmitis, basale Meningitis, Osteomyelitis, interstitielle Nephritis, Perikarditis, Peritonitis etc.). Risikogruppen sind Neugeborene und Kleinkinder (Windelbereich), Personen mit großflächigen Hautverletzungen, Organtransplantierte, Intensivtherapierte, Diabetiker.

Übertragung: endogene Infektion z. B. bei Störungen der Barrierefunktion von Haut und Schleimhaut (kommensales Reservoir); exogene Infektionen z. B. durch kontaminierte Beatmungssysteme oder Venenkatheter.

Therapie: begünstigende Umstände beseitigen, bei Kandidosen der Haut lokale Behandlung mit Nystatin, Clotrimazol und anderen Azolen, systemisch Fluconazol, Itraconazol, bei systemisch disseminierten Kandidosen parenterale Gabe von Amphotericin B/Flucytosin oder Caspofungin, Fluconazol oder Itraconazol. Bei Resistenzen Einsatz neuer Glukansynthesehemmer.

Analytik Direktnachweis und Kultur: Gewebeuntersuchung und Pilzanzucht. Biochemische, mikroskopische und Antigenmerkmale ermöglichen die Differenzierung.

Serologie: Nachweis spezifischer Antikörper durch Hämagglutinationstest, indirekte Immunfluoreszenz ( $\triangleright$ Immunfluoreszenz, indirekte) und ELISA ( $\triangleright$ Enzyme-linked Immunosorbent assay).

Untersuchungsmaterial - Probenstabilität Direktnachweis und Kultur: Entnahme von Material aus dem jeweiligen infizierten Bereich, nicht sterile Proben müssen antibakteriell behandelt werden (Antibiotikazugabe zum Kulturmedium). Das Material sollte bis zur Weiterverarbeitung bei +4 bis $+8{ }^{\circ} \mathrm{C}$ aufbewahrt werden. Direktnachweise sind innerhalb von 24 Stunden durchzuführen, Kulturen innerhalb von 6 Stunden anzulegen.

Serologie: Serum oder Plasma für den Nachweis der Antikörper sind bei $+4{ }^{\circ} \mathrm{C}$ bis zu 2 Wochen lang beständig, bei $-20{ }^{\circ} \mathrm{C}$ über Monate und Jahre hinweg. Zur Tiefkühlkonservierung des IgM kann man den Proben $80 \%$ gepuffertes Glyzerin beifügen.

Diagnostische Wertigkeit Dem Erregernachweis mittels Mikroskopie und Kultur kommt eine wesentliche Bedeutung bei der Diagnose superfizieller, systemisch disseminierter und invasiver Candida-Infektionen zu. Durch biochemische Differenzierung und morphologische Analyse ist eine weitere Erregercharakterisierung möglich.

Der Einsatz serologischer Verfahren zum Antigen- und zum Antikörpernachweis ist diagnostisch sinnvoll zum Screening von Risikopatienten und zum Monitoring lebensbedrohlicher Kandidosen bei immunkompromittierten Patienten. 


\section{Literatur}

Müllensiefen M et al (1991) Labordiagnostik invasiver Candidosen. Lab Med 15:410-413

Odds FC (1988) Candida and Candidosis, 2. Aufl. Balliere Tindall, London

Papon N et al (2013) Emerging and emerged pathogenic Candida species: beyond the Candida albicans paradigm. PLoS Pathog 9(9): e1003550

\section{Cannabinoide}

C. Vidal und W.-R. Külpmann

Synonym(e) Tetrahydrocannabinol

Englischer Begriff cannabinoids

Definition Psychomimetikum, Halluzinogen.

Molmasse THC: $314,47 \mathrm{~g}$

THC-OH: $330,47 \mathrm{~g}$

THC-COOH: $344,45 \mathrm{~g}$

Synthese - Verteilung - Abbau - Elimination Der Wirkstoff $\Delta 9$-Tetrahydrocannabinol (THC) (s. Abbildung) wird meist durch Inhalation beim Rauchen von Haschisch (Cannabis-Harz) bzw. Marihuana (Cannabis-Kraut) aufgenommen, seltener durch intestinale Resorption nach oraler Zufuhr von THC-haltigem Gebäck, Tee oder Haschischöl. Der Abbau zu verschiedenen Metaboliten, u. a. 11-Hydroxy- $\Delta$ 9-THC (s. Abbildung), 11-Nor- $\Delta$ 9-THC-9-Karbonsäure (THC-COOH; s. Abbildung) erfolgt in der Leber. THC und seine Metabolite lagern sich im Fettgewebe ein, weshalb noch Wochen nach dem letzten Konsum dessen Analyte im Urin nachweisbar sein können (s. Indikation).

Strukturformel $\Delta$ 9-Tetrahydrocannabinol:<smiles>CCCCCc1cc(O)c2c(c1)OC(C)(C)C1CCC(C)=CC21</smiles>

Strukturformel 11-Hydroxy- $\Delta 9$-Tetrahydrocannabinol:

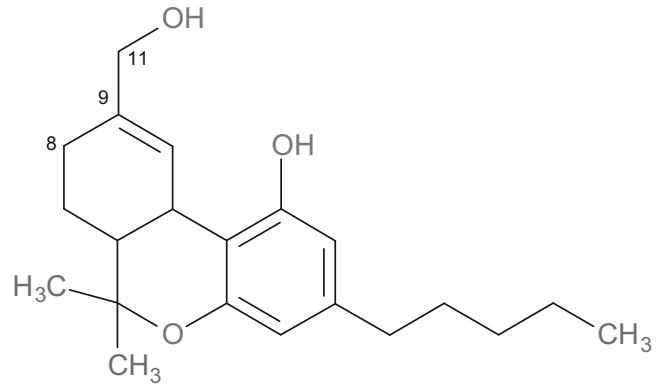

Strukturformel 11-Nor- $\Delta$ 9-Tetrahydrocannabinol-9-Karbonsäure:

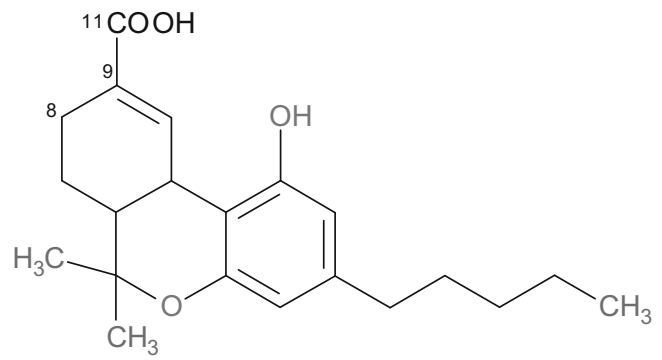

Halbwertszeit $\Delta 9$-Tetrahydrocannabinol: 50 Stunden (Plasma).

Untersuchungsmaterial - Entnahmebedingungen Urin, Plasma, Serum, Haare.

Analytik \Immunoassay (Urin), GC-MS, LC-MS/MS ( $\triangleright$ Chromatographie; $\triangleright$ Massenspektrometrie).

Indikation Verdacht auf THC-Konsum $>$ Drogenscreening.

Interpretation Der Nachweis von THC-Metaboliten im Urin kann in der Regel als Hinweis auf THC-Aufnahme gelten. Eine im Vergleich zu den Metaboliten hohe Konzentration von THC im Plasma ist verdächtig auf aktuelle THC-Zufuhr. THC-COOH ist im Urin bei Probierkonsum 2-3 Tage, bei wiederholtem Konsum je Woche 5-14 Tage und bei Dauerkonsum 2-6 Wochen, mitunter auch länger nachweisbar.

\section{Literatur}

Von Meyer L, Käferstein H (2009) Cannabinoids. In: Külpmann WR (Hrsg) Clinical toxicological analysis. Wiley-VCH, Weinheim, S $470-480$

\section{Cannabinoide, endogene}

- Endocannabinoide 


\section{Cannabinoide, synthetische}

$>$ Spice

\section{Cannabis sativa $\mathrm{L}$.}

$>$ Hanf

\section{Cannabis}

$\checkmark$ Cannabinoide

$\checkmark$ Hanf

$[\mathrm{Ca} \times \mathbf{P}]$

$>$ Calcium-Phosphat-Produkt

\section{CAP}

- College of American Pathologists

\section{CAPAP}

- Carboxypeptidase-B-Aktivierungs-Peptid

\section{Capping}

J. Arnemann

Synonym(e) RNA-Blockierung

\section{Englischer Begriff capping}

Definition Capping ist ein Teilschritt der posttranskriptionellen Modifikation, welches das mRNA-Molekül an seinem $5^{\prime}$-Ende blockiert.
Beschreibung Nach > Transkription der DNA-Matrize durch die RNA-Polymerase II wird unmittelbar folgend der prä-mRNA über eine $5^{\prime}-5^{\prime}$-Phosphodiesterbindung ein 7-Methyl-Guanosin $\left(\mathrm{m}^{7} \mathrm{G}\right)$ an das $5^{\prime}$-Ende angekoppelt (vorgeschaltet), was als Capping bezeichnet wird. Das Capping der mRNA dient 1 . vor allem als Schutz vor einem Abbau durch 5'-3'-Exonukleasen, 2. einem erleichterten Spleißen der prä-mRNA, 3. einem erleichterten Transport der mRNA vom Zellkern ins Zytoplasma und 4. erleichtert die Bindung der mRNA an die zytoplasmatischen Ribosomen für eine $>$ Translation.

\section{Literatur}

Strachan T, Read AP (2005) Molekulare Humangenetik. Elsevier $\mathrm{GmbH}$, München

\section{Caproylglyzin}

- Hexanoylglyzin

\section{Captopril-Suppressionstest}

$>$ Captopril-Test

\section{Captopril-Test}

W. Hubl

Synonym(e) Captopril-Suppressionstest

Englischer Begriff captopril challenge test (CCT)

Definition Der Captopril-Test dient zur Bestätigungsdiagnostik eines Hyperaldosteronismus nach klinischen Zeichen sowie einem pathologischen Aldosteron-Renin-Quotienten.

\section{Durchführung}

- Erste Blutentnahme (7 und 9 Uhr) nach mindestens 20 Minuten Ruhe im Liegen für die Bestimmung von Aldosteron und Renin, Kanüle liegen lassen

- Orale Gabe von 25 mg Captopril, Patient im Liegen oder Sitzen während des Testes 
- Blutdruckmessungen $1 \times /$ Stunde

- Zweite Blutentnahme nach 120 Minuten

Nebenwirkung: Möglichkeit einer Hypotonie.

Folgende Kontraindikationen für die Verabreichung von Captopril sind zu beachten: Unverträglichkeiten für Angiotensin-Converting-Enzym-Hemmer, wie bei beidseitiger Nierenarterienstenose bzw. einseitiger Stenose bei Einzelniere, Angioödem sowie nach Nierentransplantation.

Medikamenteneinflüsse durch vorheriges Absetzen vermeiden: Diuretika und Antihypertensiva (außer Kalziumantagonisten) möglichst eine Woche vor dem Test absetzen.

Struktur $\mathrm{C}_{9} \mathrm{H}_{15} \mathrm{NO}_{3} \mathrm{~S}$.<smiles>C[C@H](CS)C(=O)N1CCC[C@H]1C(=O)O</smiles>

Molmasse $217,29 \mathrm{~g} / \mathrm{mol}$.

Pathophysiologie Im Rahmen des Renin-Angiotensin-Aldosteron-Systems wird Angiotensin I mithilfe des Angiotensin-Converting-Enzyms (ACE) zu Angiotensin II abgebaut. Das Angiotensin II stimuliert die Nebennierenrinde zur Aldosteronproduktion.

Captopril ist ein ACE-Hemmer, wodurch die Umwandlung zu Angiotensin II supprimiert wird. In der Folge bleibt eine Aldosteronstimulation aus, die Aldosteronkonzentration fällt bei Gesunden ab. Im Gegensatz hierzu wird bei Patienten mit einem primären Hyperaldosteronismus (Conn-Syndrom) die autonome Aldosteronproduktion nicht gehemmt. Diese Reaktion wird zur Bestätigungsdiagnostik des Conn-Syndroms verwendet.

Untersuchungsmaterial $>$ Aldosteron und $\triangleright$ Renin.

Präanalytik $\triangleright$ Aldosteron und $\triangleright$ Renin.

Analytik $>$ Aldosteron und $\gg$ Renin.

Probenstabilität $>$ Aldosteron und $\gg$ Renin.

Konventionelle Einheit $>$ Aldosteron und $>$ Renin.

Internationale Einheit $>$ Aldosteron und $\triangleright$ Renin.

Umrechnungsfaktor zw. konv. u. int. Einheit $>$ Aldosteron und $\triangleright$ Renin.

\section{Referenzbereich - Erwachsene}

\begin{tabular}{l|l}
\hline Substanz & Referenzbereich \\
\hline Aldosteron & $\begin{array}{l}\text { Abfall auf }<80 \% \text { des Basalwertes bzw. } \\
<415 \text { pmol } / \mathrm{L}\end{array}$ \\
\hline $\begin{array}{l}\text { Renin } \\
\text { Aldosteron-Renin- } \\
\text { Quotient }\end{array}$ & \begin{tabular}{l} 
Abfieg auf $>150 \%$ des Basalwertes \\
\hline
\end{tabular}
\end{tabular}

\section{Indikation}

- Verdacht auf einen primären Hyperaldosteronismus (ConnSyndrom)

- Differenzialdiagnostik des primären Hyperaldosteronismus von der essenziellen Hypertonie

- Verdacht auf eine renovaskuläre Hypertonie

Interpretation Befundinterpretation:

\begin{tabular}{l|l}
$\begin{array}{l}\text { Aldosteron- und } \\
\text { Reninveränderungen nach } \\
\text { Captopril }\end{array}$ & Interpretation \\
\hline $\begin{array}{l}\text { Aldosteron basal erhöht: kein oder } \\
\text { geringer Abfall }(<30 \%)\end{array}$ & $\begin{array}{l}\text { Aldosteron-produzierendes } \\
\text { Adenom (Conn-Syndrom) }\end{array}$ \\
$\begin{array}{l}\text { Renin basal erniedrigt: keine oder } \\
\text { geringe Veränderung auf }\end{array}$ & \\
$100 \pm 50 \%$ des Basalwertes & \\
Aldosteron-Renin-Quotient & \\
$\geq 100 \%$ des Basalwertes & \\
\hline $\begin{array}{l}\text { Aldosteron: normaler Abfall des } \\
\text { basal erhöhten Aldosterons auf } \\
<80 \% \text { des Basalwertes bzw. }<415\end{array}$ & $\begin{array}{l}\text { Sekundärer } \\
\text { Hyperaldosteronismus } \\
\text { (renovaskuläre Hypertonie) }\end{array}$ \\
$\begin{array}{l}\text { Reninanstieg auf }>200 \% \text { des } \\
\text { Basalwertes } \\
\text { Aldosteron-Renin-Quotient } \\
<40 \% \text { des Basalwertes }\end{array}$ & \\
\hline
\end{tabular}

Diagnostische Wertigkeit Der Captopril-Test dient neben dem Kochsalz-Belastungstest sowie dem FludrokortisonSuppressionstest als Bestätigungstest des primären Hyperaldosteronismus. Für den Ausschluss bzw. einer Bestätigung einer Nierenarterienstenose besitzt der Test eine relativ niedrige Sensitivität, aber eine relativ hohe Spezifität.

\section{Literatur}

Funder J, Carey R, Fardella C, Gomez-Sanchez C, Matero F, Stowasser $\mathrm{M}$ et al (2008) Case detection, diagnosis, and treatment of patients with primary aldosteronism: an endocrine society clinical practice guideline. J Clin Endocrinol Metabol 93:3266-3281

Rossi GP, Belfiore A, Bernini G et al (2007) Comparison of the captopril and the saline infusion test for excluding aldosterone-producing adenoma. Hypertension 50(S):424-431 
Schäffler A (Hrsg) (2015) Funktionsdiagnostik in Endokrinologie, Diabetologie und Stoffwechsel, Indikation, Testvorbereitung, Testdurchführung, Interpretation. Springer-Verlag GmbH, 3. Aufl. Berlin, Heidelberg. S 275, Abb 43

\section{Capture Assay}

$>$ Sandwich-Assay

$\mu$-Capture-Assay

Antibody Capture Assay

\section{Capture Test}

- Festphasenimmunglobulintest

\section{Carbamate}

C. Vidal und W.-R. Külpmann

Englischer Begriff carbamates

Definition Im toxikologischen Sinn Insektizide ( $\triangleright$ Kohlenwasserstoffe, chlorierte insektizide), die sich in der Regel von Estern der Monomethylcarbaminsäure ableiten.

Carbamatgrundstruktur:<smiles>[R3]OC(=O)N([R2])[R2]</smiles>

Struktur Aldicarb:<smiles>CNC(=O)O/N=C/C(C)(C)SC</smiles>

Struktur Carbaryl:

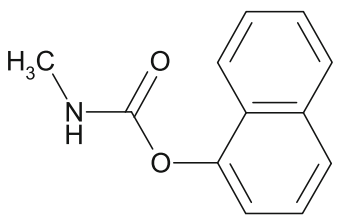

Struktur Propoxur:<smiles>CNC(=O)Oc1ccccc1OC(C)C</smiles>

Molmasse Aldicarb 190,3 g, Carbaryl 201,2 g, Propoxur $209,2 \mathrm{~g}$.

Synthese - Verteilung - Abbau - Elimination Die insektiziden Carbamate werden eingeatmet (Sprühnebel, Staub) oder über den Magen-Darm-Trakt oder die Haut aufgenommen und schnell hydrolysiert. Die Metabolite werden mit dem Urin eliminiert.

Halbwertszeit Carbaryl 1,3 Stunden (Plasma).

Funktion - Pathophysiologie Die Carbamate hemmen die Acetylcholinesterase rasch. Im Gegensatz zu den Organophosphaten wird das Enzym jedoch bald funktionell komplett reaktiviert.

Untersuchungsmaterial- Entnahmebedingungen Serum, Plasma, Urin.

Analytik DC, GC-MS, HPLC, LC-MS/MS ( $\triangleright$ Chromatographie; $>$ Massenspektrometrie).

Indikation Verdacht auf Carbamatintoxikation.

Interpretation Erhöhte Konzentrationen von Carbamaten im Blut sind Hinweis auf eine Intoxikation. Im Unterschied zur Vergiftung mit insektiziden Organophosphorverbindungen mit ähnlichen Symptomen ist jedoch die Gabe von z. B. Obidoxim kontraindiziert und die (Pseudo-)Cholinesteraseaktivität nur kurzzeitig erniedrigt. Ihre Aktivitätsbestimmung ist nur kurz nach der Carbamataufnahme diagnostisch hilfreich. 


\section{Literatur}

Geldmacher-von Mallinckrodt M (2009) Pesticides. In: Külpmann WR (Hrsg) Clinical toxicological analysis. Wiley-VCH, Weinheim, S 559-576

\section{Carbamazepin}

C. Vidal und W.-R. Külpmann

Englischer Begriff carbamazepine

Definition Antiepileptikum.

Molmasse 236,28 g.

Strukturformel Carbamazepin:

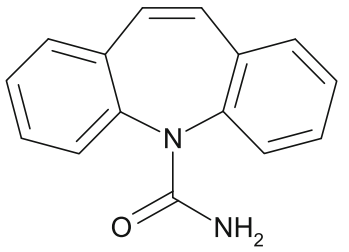

Synthese - Verteilung - Abbau - Elimination Carbamazepin wird oral appliziert und in der Leber u. a. zu dem ebenfalls wirksamen Carbamazepin-10,11-Epoxid metabolisiert.

Halbwertszeit 10-20 Stunden.

Funktion - Pathophysiologie Unter Carbamazepintherapie findet sich meist ein beschleunigter Abbau anderer Pharmaka, Phenytoin wird jedoch verlangsamt eliminiert.

Untersuchungsmaterial - Entnahmebedingungen Plasma, Serum.

Analytik Immunoassay; HPLC GC, GC-MS, LC-MS/MS erlauben die gleichzeitige Bestimmung des Epoxids ( $>$ Chromatographie; $>$ Massenspektrometrie).

Indikation Therapeutisches Drug Monitoring.

Interpretation Therapeutischer Bereich: 4-10 mg/L, toxisch ab $20 \mathrm{mg} / \mathrm{L}$ (Hiemke et al. 2012), komatös/letal ab $20 \mathrm{mg} / \mathrm{L}$ (Hannak et al. 2009).

\section{Literatur}

Hannak D, Külpmann WR, Hallbach J (2009) Anticonvulsants. In: Külpmann WR (Hrsg) Clinical toxicological analysis. Wiley-VCH, Weinheim, S 287-300

Hiemke C et al (2012) AGNP-Konsensus-Leitlinien für therapeutisches Drug-Monitoring in der Psychiatrie: Update 2011. Psychopharmakotherapie 19:91-122

\section{Carbohydrate antigen 15-3}

\section{S. Holdenrieder und P. Stieber}

Synonym(e) CA 15-3; Cancer antigen 15-3

Englischer Begriff carbohydrate antigen 15-3

Definition Carbohydrate antigen 15-3 ist ein $300 \mathrm{kDa}$ schweres muzinöses Glykoprotein ( $\$$ Glykoproteine).

Struktur CA 15-3 ist ein hochmolekulares Kohlenhydratantigen der Milchfettkügelchen-Muzin-Familie, das mittels des monoklonalen Antikörpers 115D8, der gegen das MAM-6aAntigen gerichtet ist, und dem monoklonalen DF3-Antikörper als Tracer detektiert wird.

Molmasse $300 \mathrm{kDa}$.

Synthese - Verteilung - Abbau - Elimination Immunhistologisch wurde MAM-6 auf epithelialen, normalen duktalen und alveolären Strukturen der Brustdrüse sowie in Mammakarzinomzellen nachgewiesen werden. Außerdem fand es sich in Adenomen und Karzinomen des Kolons sowie bei Adenokarzinomen anderer Genese.

Halbwertszeit 5-7 Tage.

Funktion - Pathophysiologie CA 15-3 gilt als sensitiver und spezifischer Marker beim Mammakarzinom und wird vorwiegend zur Therapiekontrolle und zur Nachsorge empfohlen. Daneben hat sich in neueren Untersuchungen auch CEA ( $\triangleright$ Carcinoembryonales Antigen) als sensitiver Marker für diese Indikation trotz seiner relativen Organunspezifität herauskristallisiert. In der Nachsorgesituation weisen beide Marker bei der Entdeckung von Fernmetastasen ein deutliches additives Potenzial auf und ermöglichen - ausgehend von den individuellen Basiswerten - in $66 \%$ der Fälle sichere Früherkennung einer Fernmetastase (>98\% Spezifität) ( $>$ Spezifität, diagnostische) mit einer Sensitivität ( $\triangleright$ Sensitivität, diagnostische) von $66 \%$ ausgehend von den individuellen Basiswerten. Bei der Primärtherapie ,negative“ Marker können später dennoch ansteigen und eine Metastasierung frühzeitig anzeigen. Deshalb empfiehlt 
sich in der Nachsorge des Mammakarzinoms eine kontinuierliche Bestimmung beider Marker. Durch die Hinzunahme von CA 125 konnte die Sensitivität bei gleichbleibend hoher Spezifität weiter gesteigert werden.

Bei der Primärtherapie des Mammakarzinoms ist der Abfall des prä- zum postoperativen CA-15-3-Werts darüber hinaus von prognostischer Bedeutung. Innerhalb aller Lymphknotenstadiengruppen war ein stärkerer Abfall (>33 \%) in der multivariaten Analyse ein unabhängiger Prognosemarker - auch wenn diese Dynamik sich im sehr niedrigen Wertebereich abspielte.

Untersuchungsmaterial - Entnahmebedingungen Plasma, Serum, Liquor, Aszites, Pleurapunktat.

Analytik $>$ Enzymimmunoassay (EIA), $>$ Radioimmunoassay (RIA), Immunradiometrischer Assay (IRMA), > Elektrochemilumineszenz-Immunoassay (ECLIA).

\section{Konventionelle Einheit U/mL (kU/L).}

Referenzbereich - Erwachsene Serum: Median 13,6 kU/L $95 \%$-Perzentile 23,1 kU/L (methodenabhängig).

Indikation Prognose, Therapiekontrolle und Nachsorge beim Mammakarzinom (mit CEA).

Interpretation Die meisten CA-15-3-Assays sind für die Anwendung im Serum und Plasma ausgetestet.

Obwohl CA 15-3 beim Mammakarzinom als sensitiver und spezifischer Marker gilt, kann er auch bei anderen Karzinomen, insbesondere bei Adenokarzinomen des Gastrointestinaltrakts, der Lunge, der Ovars, der Zervix, des Endometriums oder der Prostata, vermehrt freigesetzt werden.

Außerdem können mäßig erhöhte CA-15-3-Werte bei benignen Erkrankungen der Brust wie Mastopathien und Fibroadenomen, bei dialysepflichtiger Niereninsuffizienz, bei HIV-Infektion, bei benignen Leber-, Pankreas-, Lungenund Rheumaerkrankungen sowie im 3. Trimenon der Gravidität vorgefunden werden.

Diagnostische Wertigkeit Mammakarzinom: Therapiemonitoring, Rezidiverkennung (mit CEA), Prognose.

\section{Literatur}

Duffy MJ (2017) Clinical use of biomarkers in breast cancer: Updated guidelines from the European Group on Tumor Markers (EGTM. Eur J Cancer 75:284-298

Lamerz R (2012) CA 15-3. In: Thomas L (Hrsg) Labor und Diagnose, 8. Aufl. TH-Books, Frankfurt am Main, S 1644-1648
Stieber P et al (2015) Diagnostic efficacy of CA 15-3 and CEA in the early detection of metastatic breast cancer-A retrospective analysis of kinetics on 743 breast cancer patients. Clin Chim Acta 448:228-231 Sturgeon CM, Duffy MJ, Stenman UH et al (2008) National Academy of Clinical Biochemistry laboratory medicine practice guidelines for use of tumor markers in testicular, prostate, colorectal, breast, and ovarian cancers. Clin Chem 54:e11-e79

Trapé J et al (2011) Increased plasma concentrations of tumour markers in the absence of neoplasia. Clin Chem Lab Med 49:1605-1620

\section{Carbohydrate antigen 19-9}

\section{S. Holdenrieder und P. Stieber}

\section{Synonym(e) CA 19-9}

Englischer Begriff carbohydrate antigen 19-9

Definition Carbohydrate antigen 19-9 ist ein $36 \mathrm{kDa}$ schweres Glykolipid und entspricht einem Hapten der Lewis-aBlutgruppendeterminante ( $\triangleright$ Lewis-(Le-)Blutgruppensystem).

Struktur Carbohydrate antigen 19-9 ist ein Sialylderivat der Lakto- $N$-Fucopentaose II. Es entsteht aus der Vorstufe $>$ Carbohydrate antigen 50 nach Fucosylierung in a-1-4-Stellung am $N$-Acetylglukosamin, wobei die $N$-Acetylneuraminsäure an einen terminalen Galaktoserest in a-2-3-Stellung gebunden ist.

Molmasse $36 \mathrm{kDa}$.

Synthese - Verteilung - Abbau - Elimination Physiologisch kommt CA 19-9 im fetalen Epithel von Magen, Kolon, Dünndarm, Leber und Pankreas vor, in Spuren auch in normalen adulten Organen des Gastrointestinaltrakts und der Lunge. Daneben ist es Bestandteil vieler Schleimhautzellen und von deren Sekretionsprodukten wie Speichel oder Mekonium.

CA 19-9 wird rein biliär ausgeschieden. Eine Cholestase auch geringeren Ausmaßes kann z. T. deutlich erhöhte CA19-9-Konzentrationen verursachen.

Halbwertszeit 4-8 Tage.

Untersuchungsmaterial-Entnahmebedingungen Plasma, Serum, Aszites, Pleurapunktat.

Analytik $>$ Enzymimmunoassay (EIA), \ Radioimmunoassay (RIA), Immunradiometrischer Assay (IRMA), $\checkmark$ Elektrochemilumineszenz-Immunoassay (ECLIA) insbesondere unter Verwendung von monoklonalen Antikörpern. 
Konventionelle Einheit $\mathrm{U} / \mathrm{mL}(\mathrm{kU} / \mathrm{L})$.

Referenzbereich - Erwachsene Serum: Median 3,1 kU/L; $95 \%$-Perzentile 28,4 kU/L (methodenabhängig).

\section{Indikation}

- Verdacht auf Pankreaskarzinom, hepatobiliäres Karzinom, Magenkarzinom

- Therapiekontrolle und Nachsorge der genannten Karzinome

- Prognose beim kolorektalen Karzinom

Interpretation Die meisten CA-19-9-Assays sind für die Anwendung im Serum und Plasma ausgetestet.

Das CA 19-9 weist weder eine eindeutige Tumor- noch eine Organspezifität auf. Es kann von verschiedenen Karzinomen des Gastrointestinaltrakts und von Adenokarzinomen anderer Genese deutlich vermehrt freigesetzt werden. In sehr hohen Konzentrationen ( $>10000 \mathrm{U} / \mathrm{mL})$ ist CA 19-9 jedoch fast pathognomonisch für ein bereits metastasiertes Pankreasoder hepatobiliäres Karzinom. Zwar genügt für die Diagnostik eines Kolonkarzinoms in der Regel die CEA-Bestimmung ( $\triangleright$ Carcinoembryonales Antigen), doch ist der präoperative CA-19-9-Wert in der multivariaten Analyse neben dem Tumorstadium ein unabhängiger Prädiktor für das Überleben. Auch ist ein Therapiemonitoring durch CA 19-9 bei CEA-negativen Patienten sinnvoll.

Verschiedene benigne Erkrankungen insbesondere mit cholestatischer Komponente wie akute und chronisch aktive Erkrankungen von Leber und Galle sowie die Mukoviszidose führen in Abhängigkeit von Aktivität und Ausmaß der Erkrankung in 10-30 \% der Fälle zu einem transitorischen Anstieg der CA-19-9-Konzentrationen (maximal bis $500 \mathrm{U} / \mathrm{mL}$ ). Ansteigende CA-19-9-Werte bei fehlenden oder gleichbleibenden Entzündungs- oder Cholestasezeichen weisen jedoch auf eine maligne Pankreaserkrankung hin.

Patienten, welche die Blutgruppenkonstellation Lewis (a-/b-) haben (etwa 3-7 \% der Bevölkerung), können CA 19-9 nicht exprimieren.

Während der Menstruation und der Schwangerschaft sind transiente, leichte CA-19-9-Erhöhungen beschrieben.

\section{Diagnostische Wertigkeit}

- Pankreaskarzinom, hepatobiliäres Karzinom, Magenkarzinom: Differenzialdiagnose, Prognose, Therapiemonitoring, Rezidiverkennung

- Kolorektales Karzinom: Prognose und Therapiemonitoring bei CEA-negativen Patienten

\section{Literatur}

Duffy MJ et al (2010) Tumor markers in pancreatic cancer: a European Group on Tumor Markers (EGTM) status report. Ann Oncol 21:441-447

Lamerz R (2012) CA 19-9. In: Thomas L (Hrsg) Labor und Diagnose, 8. Aufl. TH-Books, Frankfurt am Main, S 1629-1634

Stieber P, Heinemann V (2008) Sinnvoller Einsatz von Tumormarkern. J Lab Med 32:339-360

Trapé $\mathrm{J}$ et al (2011) Increased plasma concentrations of tumour markers in the absence of neoplasia. Clin Chem Lab Med 49:1605-1620

\section{Carbohydrate antigen 27-29}

\author{
S. Holdenrieder und P. Stieber
}

Synonym(e) CA 27-29; Cancer antigen 27-29

Englischer Begriff carbohydrate antigen 27-29

Definition Carbohydrate antigen 27-29 ist ein $300 \mathrm{kDa}$ schweres muzinöses Glykoprotein namens MUC-1. Das gleiche Muzin wird auch von $>$ Carbohydrate antigen 15-3Assays erkannt.

Struktur Carbohydrate antigen 27-29 ist ein hochmolekulares Kohlenhydratantigen der Milchfettkügelchen-MuzinFamilie, das mittels des monoklonalen Antikörpers B27-29 detektiert wird.

\section{Molmasse $300 \mathrm{kDa}$.}

Synthese - Verteilung - Abbau - Elimination Immunhistologisch wird CA 27-29 von Mammakarzinomen exprimiert, ebenso von normalem Brustdrüsengewebe. Außerdem fand es sich in Adenomen und Karzinomen des Kolons sowie bei Adenokarzinomen anderer Genese.

Funktion - Pathophysiologie CA 27-29 kann wie alle Muzinmarker zur Therapiekontrolle und Nachsorge des Mammakarzinoms eingesetzt werden. Wegen nicht vorhandener Komplementarität zu CA 15-3 und MCA (> Mucinlike cancer associated antigen) ist eine Kombination nicht sinnvoll. Als Zweitmarker empfiehlt sich CEA ( $\triangleright$ Carcinoembryonales Antigen).

Untersuchungsmaterial - Entnahmebedingungen Plasma, Serum, Liquor, Aszites, Pleurapunktat. 
Analytik $>$ Enzymimmunoassay (EIA), \ Radioimmunoassay (RIA), Immunradiometrischer Assay (IRMA), - Elektrochemilumineszenz-Immunoassay (ECLIA).

Konventionelle Einheit U/mL (kU/L).

Referenzbereich - Erwachsene $<25 \mathrm{kU} / \mathrm{L}$ (methodenabhängig).

Indikation Therapiekontrolle und Nachsorge beim Mammakarzinom (mit CEA).

Interpretation Neben dem Mammakarzinom kann CA 27-29 auch bei anderen Karzinomen des Kolons, des Magens, der Leber, der Lunge, des Kopf-Hals-Bereichs, des Ovars, der Prostata sowie bei Non-Hodgkin-Lymphomen erhöht sein.

Hinsichtlich benigner Erkrankungen sind gutartige Lebererkrankungen herauszuheben. Auch bei Mastopathien, benignen pulmonalen, gastrointestinalen und gynäkologischen Erkrankungen können erhöhte Werte gefunden werden.

Diagnostische Wertigkeit Mammakarzinom: Therapiemonitoring, Rezidiverkennung (mit CEA).

\section{Literatur}

Stieber P, Heinemann V (2008) Sinnvoller Einsatz von Tumormarkern. J Lab Med 32:339-360

Sturgeon CM, Duffy MJ, Stenman UH et al (2008) National Academy of Clinical Biochemistry laboratory medicine practice guidelines for use of tumor markers in testicular, prostate, colorectal, breast, and ovarian cancers. Clin Chem 54:e11-e79

\section{Carbohydrate antigen $\mathbf{5 0}$}

S. Holdenrieder und P. Stieber

Synonym(e) CA 50; Cancer antigen 50

Englischer Begriff carbohydrate antigen 50

Definition Glykolipid mit klinischer Bedeutung als Tumormarker beim Pankreaskarzinom.

Struktur Carbohydrate antigen 50 ist ein Glykolipid oder Glykoprotein, das durch die C-50-Antikörper als sialysierte Lewis-a-Struktur (๖ Lewis-(Le-)Blutgruppensystem) und eine bisher unbekannte sialylierte Laktotetraosestruktur definiert ist, die in ihrem Vorkommen nicht an Lewis-positive Blutgruppen gebunden ist.
Synthese - Verteilung - Abbau - Elimination Physiologisch kommt CA 50 in geringen Mengen in Geweben des Gastrointestinaltrakts vor. Es wird insbesondere bei Pankreasund cholangiozellulären Karzinomen gefunden.

Halbwertszeit 2-5 Tage.

Funktion - Pathophysiologie CA 50 kann zur Therapiekontrolle und Nachsorge des Pankreaskarzinoms eingesetzt werden. Allerdings bietet CA 50 keine Vorteile gegenüber dem $>$ Carbohydrate antigen 19-9 und sollte wegen nicht vorhandener Komplementarität zu CA 19-9 mit diesem nicht kombiniert werden.

Untersuchungsmaterial-Entnahmebedingungen Serum, Aszites, Pleurapunktat.

Analytik $>$ Immunradiometrischer Assay (IRMA).

\section{Konventionelle Einheit kU/L.}

Referenzbereich - Erwachsene Empfohlener Referenzbereich im Serum: $23 \mathrm{kU} / \mathrm{L}$ (methodenabhängig).

Indikation Evtl. Therapiekontrolle und Nachsorge beim Pankreaskarzinom.

Interpretation Das CA 50 weist weder eindeutige Tumornoch Organspezifität auf. Es kann von verschiedenen Karzinomen des Gastrointestinaltrakts freigesetzt werden. Am häufigsten finden sich hohe Konzentrationen $(>100 \mathrm{kU} / \mathrm{L})$ bei Pankreas- und cholangiozellulären Karzinomen.

Differenzialdiagnostisch ist an benigne Pankreaserkrankungen oder Leberzirrhosen zu denken, die in $16-18 \%$ der Fälle Werte über $100 \mathrm{kU} / \mathrm{L}$ hervorrufen können.

In den aktuellen Richtlinien der European Group on Tumor Markers (EGTM) zum Gebrauch von Tumormarkern beim Pankreaskarzinom wird CA 19-9 im Vergleich zu CA 50 der Vorzug gegeben. Aufgrund der fehlenden Automatisierung von CA-50-Testen ist dieser Marker eher als historisch zu betrachten.

Diagnostische Wertigkeit Evtl. Pankreaskarzinom: Therapiemonitoring, Rezidiverkennung.

\section{Literatur}

Duffy MJ, Sturgeon C, Lamerz R et al (2010) Tumor markers in pancreatic cancer: a European Group on Tumor Markers (EGTM) status report. Ann Oncol 21:441-447

Lamerz R, Dati F, Feller AC et al (1998) Tumordiagnostik: Tumormarker bei malignen Erkrankungen. Behring Diagnostika, München 


\section{Carbohydrate antigen 72-4}

\section{S. Holdenrieder und P. Stieber}

Synonym(e) CA 72-4; Cancer Antigen 72-4

Englischer Begriff carbohydrate antigen 72-4

Definition Carbohydrate antigen 72-4 ist ein $400 \mathrm{kDa}$ schweres muzinähnliches Glykoprotein TAG 72.

Struktur Carbohydrate antigen 72-4 wurde als Sialyl-TnAntigen (NeuAca(2-6)GalNAca-0-Ser) identifiziert.

Molmasse $400 \mathrm{kDa}$.

Synthese - Verteilung - Abbau - Elimination Immunhistologisch wurde das TAG 72 auf Adenokarzinomen verschiedener Organe gefunden, z. B. beim Kolonkarzinom, beim Magenkarzinom und beim nichtkleinzelligen Lungenkarzinom; ferner auf verschiedenen fetalen Geweben.

Halbwertszeit 3-7 Tage.

Funktion - Pathophysiologie Das TAG-72-Epitop wird mit Hilfe von 2 monoklonalen Antikörpern detektiert: dem an eine feste Phase gebundenen cc-49-Antikörper und dem Detektor/Tracer-Antikörper B72-3.

Untersuchungsmaterial - Entnahmebedingungen Plasma, Serum, Liquor, Aszites, Pleurapunktat.

Analytik $>$ Enzymimmunoassay (EIA), > Radioimmunoassay (RIA), Immunradiometrischer Assay (IRMA), - Elektrochemilumineszenz-Immunoassay (ECLIA).

Konventionelle Einheit $\mathrm{kU} / \mathrm{L}$.

Referenzbereich - Erwachsene Serum: Median 1,5 kU/L; $95 \%$-Perzentile 5,9 kU/L (methodenabhängig).

\section{Indikation}

- Therapiekontrolle und Nachsorge beim Magenkarzinom als Erstmarker (Zweitmarker CEA oder CA 19-9) ( $\triangleright$ Carcinoembryonales Antigen)

- Zweitmarker beim muzinösen Ovarialkarzinom

Interpretation Die meisten CA-72-4-Assays sind für die Anwendung im Serum und Plasma ausgetestet.

Das CA 72-4 weist weder eine eindeutige Tumor- noch eine Organspezifität auf. Sehr hohe Konzentrationen
$(>100 \mathrm{kU} / \mathrm{L})$ sind meist mit einem Magenkarzinom oder einem muzinösen Ovarialkarzinomen assoziiert; daneben können CA-72-4-Erhöhungen auch von anderen Karzinomen des Gastrointestinaltrakts, der Lunge oder der Brust sowie anderen gynäkologischen Tumoren hervorgerufen werden.

Vereinzelt werden leicht bis moderat erhöhte CA-72-4-Werte bei Patienten mit benignen Erkrankungen insbesondere des Gastrointestinaltrakts und der gynäkologischen Organsysteme beobachtet. Auch klinisch unauffällige Personen können transiente oder persistierende CA-72-4-Erhöhungen aufweisen. Insgesamt ist jedoch im Vergleich zu anderen Markern eine auffallend hohe diagnostische Spezifität ( $\triangleright$ Spezifität, diagnostische) zur Abgrenzung von benignen Erkrankungen zu betonen.

\section{Diagnostische Wertigkeit}

- Magenkarzinom: Therapiemonitoring, Rezidiverkennung

- Muzinöses Ovarialkarzinom: Therapiemonitoring, Rezidiverkennung

\section{Literatur}

Lamerz R (2008) CA 72-4. In: Thomas L (Hrsg) Labor und Diagnose, 7. Aufl. TH-Books, Frankfurt am Main, S 1310-1313

Stieber P, Heinemann V (2008) Sinnvoller Einsatz von Tumormarkern. J Lab Med 32:339-360

\section{Carbohydrate antigen 125}

S. Holdenrieder und P. Stieber

Synonym(e) CA 125; Cancer Antigen 125

Englischer Begriff carbohydrate antigen 125

Definition Carbohydrate antigen 125 ist ein $200 \mathrm{kDa}$ schweres Glykoprotein und neben $>$ Carbohydrate antigen 19-9 der zweite Hybridom-definierte Tumormarker.

Struktur CA 125 ist vermutlich ein Glykoprotein, bei dem $\mathrm{N}$-Acetylneuraminsäure in a-2-6-Bindung an ein internes $\mathrm{N}$-Acetylglukosamin als Teil des CA-125-Epitops gebunden ist.

Molmasse $200 \mathrm{kDa}$.

Synthese - Verteilung - Abbau - Elimination Physiologisch kommt CA 125 im Fetalgewebe von Zölomepithelderivaten sowie in serösen und anderen nicht muzinösen Ovarialkarzinomen vor, ferner in Grenzzellen und Mesothelzellen von Peritoneum, Pleura und Perikard. 
Halbwertszeit 4-6 Tage.

Untersuchungsmaterial - Entnahmebedingungen Plasma, Serum, Liquor.

Analytik - Enzymimmunoassay (EIA), \ Radioimmunoassay (RIA), Immunradiometrischer Assay (IRMA), - Elektrochemilumineszenz-Immunoassay (ECLIA), insbesondere unter Verwendung monoklonaler Antikörper.

\section{Konventionelle Einheit kU/L.}

Referenzbereich - Erwachsene Serum: Median 13,9 kU/L; $95 \%$-Perzentile 31,5 kU/L (methodenabhängig).

\section{Indikation}

- Verdacht auf Ovarialkarzinom

- Therapiekontrolle und Nachsorge beim Ovarialkarzinom

Interpretation Die meisten CA-125-Assays sind für die Anwendung im Serum und Plasma ausgetestet.

CA 125 weist weder eine eindeutige Tumor- noch eine Organspezifität auf. Sehr hohe Konzentrationen $(>10.000 \mathrm{kU} / \mathrm{L})$ werden zwar meist bei Ovarialkarzinomen beobachtet, doch können Karzinome des Gastrointestinaltrakts, der Lunge oder der Brust z. T. ebenfalls deutlich erhöhte CA-125-Konzentrationen hervorrufen.

Differenzialdiagnostisch relevante benigne Erkrankungen wie gutartige gynäkologische Tumoren und entzündliche Prozesse im Bereich der Adnexe können ebenso Ursache (stark) erhöhter CA-125-Werte sein. Geringfügige CA-125-Erhöhungen finden sich außerdem im ersten Tertial der Gravidität, bei verschiedenen Autoimmunerkrankungen, Hepatitiden und chronischen Pankreatitiden, Leberzirrhosen, Herz- und Niereninsuffizienz sowie bei weiteren benignen Erkrankungen des Gastrointestinaltrakts und der Lunge, die mit einer Reizung des Peritoneums (z. B. durch Aszites) oder der Pleura (z. B. durch Pleuraerguss) einhergehen.

Neuere Studien zeigen eine additive Sensitivität von CA 125 mit dem Human Epidydimis 4-(HE4-)Marker für das Ovarialkarzinom. HE4 ist seltener bei differenzialdiagnostisch relevanten benignen gynäkologischen Erkrankungen erhöht, was zu einer höheren Spezifität insbesondere bei prämenopausalen Frauen beiträgt. Die Kombination von CA 125 und HE4 ist im $>$ Risk of ovarian malignancy algorithm (ROMA) als neuer Parameter zusammengefasst, der für prä- und postmenopausale Frauen mit getrennten Formeln berechnet wird.

Diagnostische Wertigkeit Ovarialkarzinom: Differenzialdiagnose, Prognose, Therapiemonitoring, Rezidiverkennung.

\section{Literatur}

Lamerz R (2012) CA 125. In: Thomas L (Hrsg) Labor und Diagnose, 8. Aufl. TH-Books, Frankfurt am Main, S 1634-1639

Moore RG et al (2014) Combining clinical assessment and the Risk of Ovarian Malignancy Algorithm for the prediction of ovarian cancer. Gynecol Oncol 135:547-551

Sölétormos G et al (2016) Clinical use of cancer biomarkers in epithelial ovarian cancer: updated guidelines from the European group on tumor markers. Int J Gynecol Cancer 26:43-51

Sturgeon CM, Duffy MJ, Stenman UH et al (2008) National Academy of Clinical Biochemistry laboratory medicine practice guidelines for use of tumor markers in testicular, prostate, colorectal, breast, and ovarian cancers. Clin Chem 54:e11-e79

Trapé J et al (2011) Increased plasma concentrations of tumour markers in the absence of neoplasia. Clin Chem Lab Med 49:1605-1620

\section{Carbohydrate antigen 195}

S. Holdenrieder und P. Stieber

Synonym(e) CA 195

Englischer Begriff carbohydrate antigen 195

Definition Carbohydrate antigen 195 wird diejenige Fraktion der Lewis-Blutgruppendeterminanten ( $\triangleright$ Lewis-(Le-) Blutgruppensystem) bezeichnet, an die der monoklonale IgM-Antikörper CC 3 C 195 spezifisch bindet.

Synthese - Verteilung - Abbau - Elimination Physiologisch kommt CA 195 in geringen Mengen in Geweben des Gastrointestinaltrakts vor.

Funktion - Pathophysiologie CA 195 kann zur Therapiekontrolle und Nachsorge des Pankreaskarzinoms eingesetzt werden. Allerdings bietet CA 195 keine Vorteile gegenüber dem CA 19-9 ( $\triangleright$ Carbohydrate antigen 19-9) und sollte wegen nicht vorhandener Komplementarität zu CA 19-9 mit diesem nicht kombiniert werden.

Untersuchungsmaterial- Entnahmebedingungen Serum, Aszites, Pleurapunktat.

Analytik $>$ Immunradiometrischer Assay (IRMA).

\section{Konventionelle Einheit kU/L.}

Referenzbereich - Erwachsene $<10 \mathrm{kU} / \mathrm{L}$ (methodenabhängig).

Indikation Evtl. Therapiekontrolle und Nachsorge beim Pankreaskarzinom. 
Interpretation CA 195 kann zur Therapiekontrolle und Nachsorge des Pankreaskarzinoms eingesetzt werden.

In den aktuellen Richtlinien der European Group on Tumor Markers (EGTM) zum Gebrauch von Tumormarkern beim Pankreaskarzinom wird CA 19-9 im Vergleich zu CA 195 der Vorzug gegeben. Aufgrund der fehlenden Automatisierung von CA-195-Testen ist dieser Marker eher als historisch zu betrachten.

Diagnostische Wertigkeit Evtl. Pankreaskarzinom: Therapiemonitoring, Rezidiverkennung.

\section{Literatur}

Duffy MJ, Sturgeon C, Lamerz R et al (2010) Tumor markers in pancreatic cancer: a European Group on Tumor Markers (EGTM) status report. Ann Oncol 21:44144-44147

Lamerz R, Dati F, Feller AC et al (1998) Tumordiagnostik: Tumormarker bei malignen Erkrankungen. Behring Diagnostika, München

\section{Carbohydrate Antigen 242}

S. Holdenrieder und P. Stieber

\section{Synonym(e) CA 242}

Englischer Begriff carbohydrate antigen 242

Definition Carbohydrate antigen 242 wurde durch den monoklonalen Antikörper C 242 ( $\$$ Antikörper) definiert, der ein Epitop eines polymorphen epithelialen Muzins erkennt.

Synthese - Verteilung - Abbau - Elimination Physiologisch kommt CA 242 in geringen Mengen in Geweben des Gastrointestinaltrakts vor.

Untersuchungsmaterial-Entnahmebedingungen Serum, Aszites, Pleurapunktat.

Analytik Immunradiometrischer Assay (IRMA).

\section{Konventionelle Einheit $\mathrm{kU} / \mathrm{L}$.}

Referenzbereich - Erwachsene $<20 \mathrm{kU} / \mathrm{L}$ (methodenabhängig).

Indikation Evtl. Therapiekontrolle und Nachsorge beim Pankreaskarzinom.

Interpretation CA 242 kann zur Therapiekontrolle und Nachsorge des Pankreaskarzinoms eingesetzt werden. Allerdings bietet CA 242 keine Vorteile gegenüber dem CA 19-9 und sollte wegen nicht vorhandener Komplementarität zu CA 19-9 mit diesem nicht kombiniert werden.

In den aktuellen Richtlinien der European Group on Tumor Markers (EGTM) zum Gebrauch von Tumormarkern beim Pankreaskarzinom wird CA 19-9 im Vergleich zu CA 242 der Vorzug gegeben. Aufgrund der fehlenden Automatisierung von CA-242-Testen ist dieser Marker eher als historisch zu betrachten.

Diagnostische Wertigkeit Evtl. Pankreaskarzinom: Therapiemonitoring, Rezidiverkennung.

\section{Literatur}

Duffy MJ, Sturgeon C, Lamerz R et al (2010) Tumor markers in pancreatic cancer: a European Group on Tumor Markers (EGTM) status report. Ann Oncol 21:441-447

Lamerz R, Dati F, Feller AC et al (1998) Tumordiagnostik: Tumormarker bei malignen Erkrankungen. Behring Diagnostika, München

\section{Carbohydrate antigen 549}

S. Holdenrieder und P. Stieber

Synonym(e) CA 549; Cancer Antigen 549

Englischer Begriff carbohydrate antigen 549

Definition Carbohydrate antigen 549 ist ein 400-500 kDa schweres muzinöses Glykoprotein.

Struktur CA 549 ist ein hoch molekulares Kohlenhydratantigen der Milchfettkügelchen-Muzin-Familie, das mittels der monoklonalen Antikörper BC4E 549 und BC4N 154 detektiert wird.

Molmasse $400-500 \mathrm{kDa}$.

Synthese - Verteilung - Abbau - Elimination Immunhistologisch wird CA 549 von Mammakarzinomen exprimiert, ebenso von normalem Brustdrüsengewebe sowie von normalen Geweben in Kolon, Niere, Blase, Leber, Gallengang, Lunge, Pankreas, Ovar, Endometrium, Prostata, KopfNacken-Gewebe und Speicheldrüsen.

Halbwertszeit 2-5 Tage.

Untersuchungsmaterial - Entnahmebedingungen Plasma, Serum, Liquor, Aszites, Pleurapunktat.

Analytik $>$ Enzymimmunoassay (EIA), > Radioimmunoassay (RIA), > Immunradiometrischer Assay (IRMA). 


\section{Konventionelle Einheit $\mathrm{U} / \mathrm{mL}$.}

Referenzbereich - Erwachsene Empfohlener Referenzbereich im Serum: $12 \mathrm{U} / \mathrm{mL}$ (methodenabhängig).

Indikation Evtl. Therapiekontrolle und Nachsorge beim Mammakarzinom (mit CEA) ( $\triangleright$ Carcinoembryonales Antigen).

Interpretation CA 549 kann wie alle Muzinmarker zur Therapiekontrolle und Nachsorge des Mammakarzinoms eingesetzt werden. Wegen nicht vorhandener Komplementarität $\mathrm{zu} \triangleright$ Carbohydrate antigen 15-3 und MCA ( $\triangleright$ Mucin-like cancer associated antigen) ist eine Kombination nicht sinnvoll. Als Zweitmarker empfiehlt sich CEA.

Neben dem Mammakarzinom kann CA 549 auch bei anderen Karzinomen des Kolons, des Magens, der Leber, der Lunge, des Kopf-Hals-Bereichs, des Ovars, der Prostata sowie bei Non-Hodgkin-Lymphomen erhöht sein.

Hinsichtlich benigner Erkrankungen sind gutartige Lebererkrankungen herauszuheben. Auch bei Mastopathien, benignen pulmonalen, gastrointestinalen und gynäkologischen Erkrankungen können erhöhte Werte gefunden werden.

In den aktuellen Richtlinien der National Academy of Clinical Biochemistry (NACB) zum Gebrauch von Tumormarkern beim Mammakarzinom werden lediglich die Muzinmarker CA 15-3 und CA 27-29 aufgeführt und empfohlen. Aufgrund der fehlenden Automatisierung von CA-549-Testen ist dieser Marker eher als historisch zu betrachten.

Diagnostische Wertigkeit Evtl. Mammakarzinom: Therapiemonitoring, Rezidiverkennung (mit CEA).

\section{Literatur}

Stieber P, Heinemann V (2008) Sinnvoller Einsatz von Tumormarkern. J Lab Med 32:339-360

Sturgeon CM, Duffy MJ, Stenman UH et al (2008) National Academy of Clinical Biochemistry laboratory medicine practice guidelines for use of tumor markers in testicular, prostate, colorectal, breast, and ovarian cancers. Clin Chem 54:e11-e79

\section{Carbohydrate-deficient glycoprotein(s)}

$>\mathrm{CDG}$

\section{Carbohydrate-deficient transferrin}

\section{T. Arndt}

Synonym(e) CDT; Kohlenhydrat-defizientes Transferrin; Sialinsäure-defizientes Transferrin
Englischer Begriff carbohydrate-deficient transferrin; sialic acid-deficient transferrin; CDT

Definition CDT ist die Summe der unter chronischem Alkoholmissbrauch in erhöhter Serumkonzentration vorliegenden Kohlenhydrat-defizienten Transferrinisoformen:

$\mathrm{CDT}=$ Asialotransferrin + Monosialotransferrin + Disialotransferrin.

Struktur Transferrin ist ein Glykoprotein mit 1 Polypeptidund 2 Kohlenhydratketten. Die Polypeptidkette setzt sich aus 2 homologen Einheiten mit 336 (N-terminale Domäne) und 333 (C-terminale Domäne) Aminosäuren zusammen. In diese ist je eine Eisenbindungsstelle integriert. Die Kohlenhydratketten sind über je eine Asparaginsäure-Aminogruppe in der C-terminalen Domäne der Polypeptidkette des Transferrinmoleküls verankert.

Das Transferrinmolekül zeigt schon unter physiologischen Bedingungen eine ausgeprägte Mikroheterogenität. Diese beruht auf unterschiedlicher Eisenbeladung $\left(\mathrm{Fe}_{0^{-}}, \mathrm{Fe}_{1 \mathrm{~N}^{-}}\right.$, $\mathrm{Fe}_{1 \mathrm{C}^{-}}$und $\mathrm{Fe}_{2}$-Transferrine), unterschiedlicher Kohlenhydratstruktur (Asialo- bis Octasialotransferrine) und Modifikationen in der Aminosäuresequenz (genetische Transferrinvarianten) (Abb. 1).

Molmasse Ca. $80 \mathrm{kDa}$, in Abhängigkeit von der Kohlenhydratstruktur des Transferrinmoleküls um ca. $10 \%$ differierend.

Synthese - Verteilung - Abbau - Elimination Der Anstieg der CDT-Serumkonzentration beruht offenbar auf Ethanolund/oder Acetaldehyd-induzierten Synthesestörungen der Transferrin-N-Glykane. So wurden verminderte Aktivitäten der an der Kohlenhydratkettensynthese beteiligten Enzyme auf der Basis erniedrigter mRNA-Konzentrationen und erhöhte Aktivitäten von N-Glykan abbauenden Enzymen gefunden. Ethanol-induzierte Veränderungen der CDTClearance von Leber und Niere sind als Ursachen für den CDT-Anstieg weitestgehend ausgeschlossen. Als kritischer Alkoholkonsum für einen CDT-Anstieg gilt eine minimale Aufnahme von 50-80 g Ethanol/Tag an wenigstens 7 aufeinanderfolgenden Tagen.

Halbwertszeit Ca. 14 Tage.

Untersuchungsmaterial-Entnahmebedingungen Serum. Venöse Blutentnahme.

Probenstabilität Raumtemperatur 30 Stunden, $4{ }^{\circ} \mathrm{C} 7$ Tage, $-22{ }^{\circ} \mathrm{C}$ Jahre. Ein Anstieg des Serum-CDT um $25 \%$ nach 3 Tagen bei Raumtemperatur (u. U. durch die Wirkung bakterieller Sialidasen) wurde beobachtet. Andere Autoren 


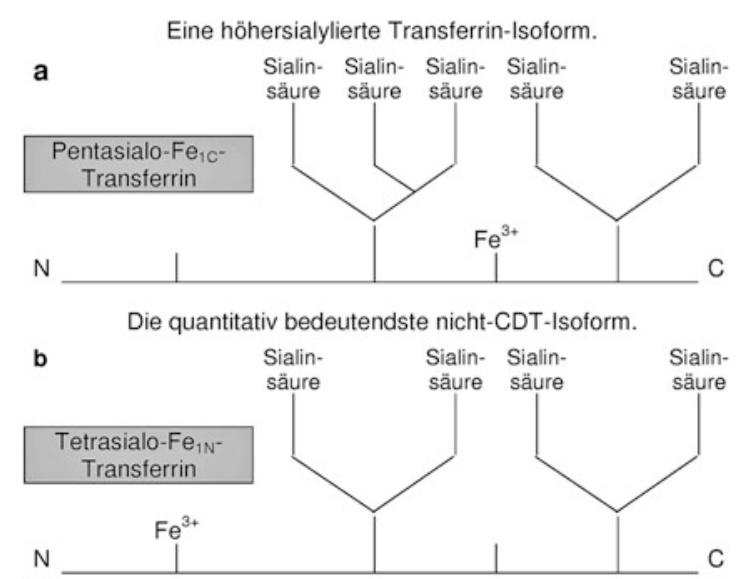

Lange Zeit unter konträrer Debatte, ob CDT- oder nicht-CDTIsoform.

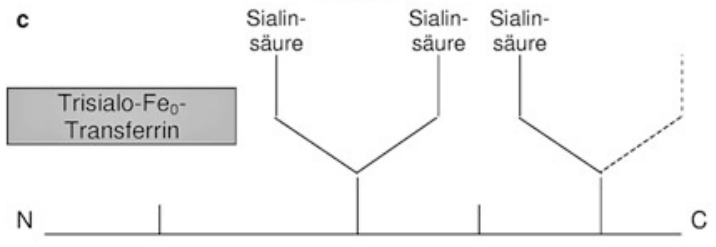

N

Die quantitativ bedeutendste CDT-Isoform.

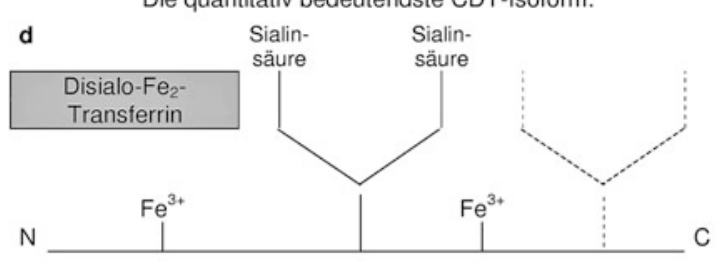

Die quantitativ zweitwichtigste CDT-Isoform.

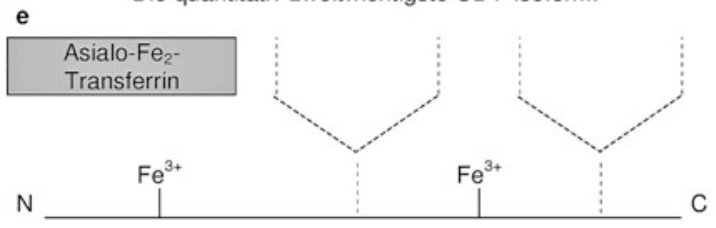

Carbohydrate-deficient transferrin, Abb. 1 Wichtige Transferrinisoformen aufgrund unterschiedlicher $\mathrm{Fe}^{3+}$-Beladung und Kohlenhydratstrukturen

fanden einen signifikanten Anstieg des CDT in der bei Raumtemperatur gelagerten Vollblutprobe erst nach ca. 6 Tagen. Wiederholtes Einfrieren und Auftauen war ohne signifikanten Einfluss auf das Serum-CDT.

Präanalytik Serum $(0,1-1,0 \mathrm{~mL}$ in Abhängigkeit von der Analysenmethode), keine spezielle Patientenvorbereitung, Plasma ist für einige Testsysteme nicht oder eingeschränkt geeignet (Störung der CDT- und Nicht-CDT-Fraktionierung)

Analytik Die HPLC gilt derzeit als Referenz- und am weitesten verbreitete Methode der CDT-Analytik (Abb. 2). Eine noch bessere Auflösung (Trennleistung) hat die Isoelektrische Fokussierung (IEF), die allerdings eher im Forschungslabor zum Einsatz kommt (Abb. 3). Kommerziell verfügbar sind außerdem Applikationen für $>$ Kapillarelektrophorese, Säulenchromatographie zur Trennung von CDT- und Nicht-CDTIsoformen mit anschließendem Immunoassay und ein direkter Immunoassay mit Antikörpern gegen CDT.

Eine Trennung von CDT-Isoformen und Nicht-CDTIsoformen mit identischem isoelektrischen Punkt bzw. sehr ähnlichem chromatographischen Elutionsverhalten wird erreicht, indem in einem ersten Analyseschritt durch Zugabe einer $\mathrm{Fe}^{3+}$-Lösung eine einheitliche (gesättigte) TransferrinEisenbeladung eingestellt wird, sodass alle Transferrin als $\mathrm{Fe}_{2}$-Isoformen vorliegen.

Konventionelle Einheit $\mathrm{mg} / \mathrm{L}, \mathrm{U} / \mathrm{L}$ (historisch), CDT/ Transferrin-Quotient in \%.

Internationale Einheit $\mathrm{mg} / \mathrm{L}, \%$ des Gesamttransferrins.

Umrechnungsfaktor zw. konv. u. int. Einheit Per Definition entspricht $1 \mathrm{U} / \mathrm{L}=1 \mathrm{mg} / \mathrm{L}$ (historisch).

Referenzbereich - Erwachsene CDT-Referenzbereiche und Entscheidungsgrenzen sind abhängig von den Analysenmethoden. Als Entscheidungsgrenzen werden oft Graubereiche angewandt. Der Graubereich des CDT/TransferrinQuotienten ist geschlechtsunabhängig. Er beträgt für die derzeit am häufigsten eingesetzten Tests 2,5-3,0 \% ( $\triangleright$ Immunoassay) bzw. 1,75-2,50\% (HPLC), für eine > KapillarelektrophoreseApplikation nur 1,3\%. Mit einer Standardisierung der CDTAnalytik auf Disialotransferrin $\left(\mathrm{CDT}_{\mathrm{IFCC}}\right)$ wurde eine Vergleichbarkeit der Messergebnisse verschiedener CDT-Tests realisiert. Die Cut-offs liegen hier bei 1,7\% (klinische Anwendung) bzw. 2,0\% (Forensik).

Referenzbereich - Kinder keine Unterschiede zu Erwachsenen.

\section{Indikation}

- Compliance- und Therapiekontrolle bei Alkohol-und/oder Drogenabhängigen

- Nachweis eines chronischen Alkoholmissbrauchs (in Arbeits-, Rechts- und Verkehrsmedizin, bei internistischen und chirurgischen Fragestellungen)

- Objektivierung eines Verdachts auf chronischen Alkoholmissbrauch bei negativem Befragungsbefund und/oder normaler $\triangleright \gamma$-Glutamyltransferase aktivität (GGT)

- Differenzierung Alkohol- und Medikamenten-induzierter Erhöhungen der GGT-Serumaktivität

- Pränataldiagnostik einer potenziellen Alkoholexposition

- Präoperative Erkennung von Risikopatienten

- Post-mortem-Diagnostik eines chronischen Alkoholmissbrauchs 


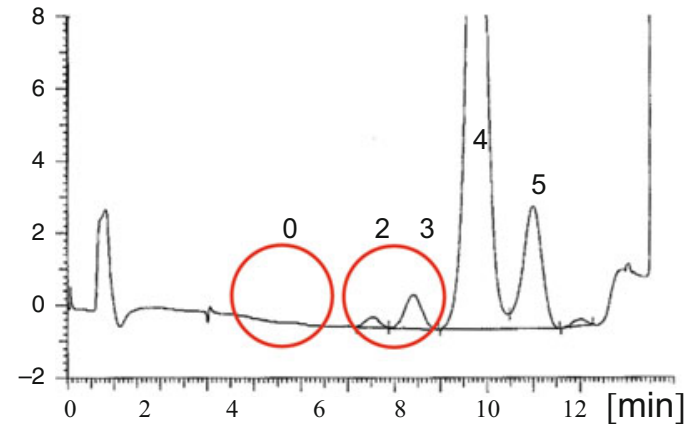

Normalbefund

Tetrasialotransferrin (4) dominiert

Disialotransferrin (2) < Trisialotransferrin (3)

Asialotransferrin (0) nicht nachweisbar

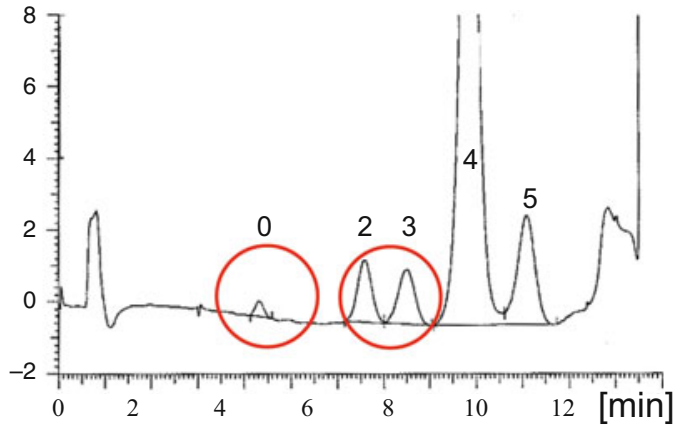

Pathologischer Befund

Tetrasialotransferrin (4) dominiert

Disialotransferrin (2) $\geq$ Trisialotransferrin (3)

Asialotransferrin (0) an-oder abwesend

Carbohydrate-deficient transferrin, Abb. 2 HPLC-Trennung der Transferrinisoformen im Serum, links „,normaler“ Alkoholkonsum, rechts chronischer Alkoholmissbrauch

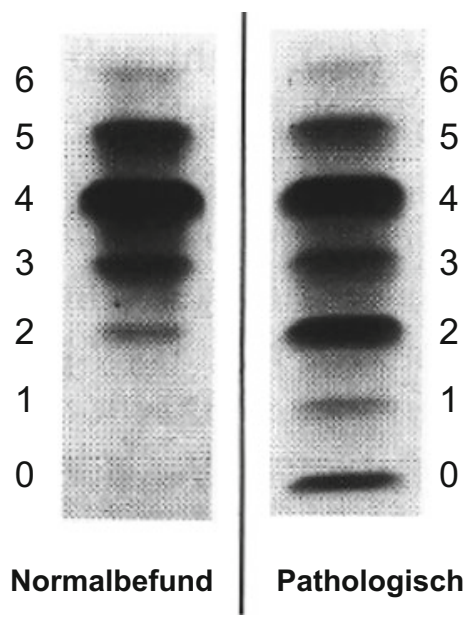

Carbohydrate-deficient transferrin, Abb. 3 Isoelektrische Fokussierung der Transferrinisoformen im Serum bei „normalem“ Alkoholkonsum (Normalbefund) und chronisch erhöhtem Alkoholkonsum (Pathologisch)

- Screening auf „,congenital disorders of glycosylation“ (frühere Nomenklatur CDG-Syndrom) mit HPLC

\section{Interpretation}

- Auch unter lebenslanger Ethanolabstinenz werden keine Null-CDT-Werte erreicht. Der individuelle (normale) CDT-Wert sagt nichts über die Ethanoltrinkgewohnheiten und -menge aus. Eine Person mit z. B. 1,2\% CDT (HPLC-Methode) trinkt nicht zwingend mehr oder gar doppelt so viel Ethanol wie eine Person mit 0,6 \% CDT (HPLC).

- Eine Korrelation zwischen der CDT- und der TransferrinSerumkonzentration konnte im Allgemeinen nicht nachgewiesen werden. Es wird deshalb zumeist der CDT/ Transferrin-Quotient ermittelt.
- Es besteht keine Korrelation zwischen absoluten oder relativen CDT-Konzentrationen und der (häufig zur Detektion eines Alkoholmissbrauchs bestimmten) GGT-Aktivität im Serum. Die Parallelbestimmung von CDT und GGT zum Nachweis eines chronischen Alkoholmissbrauchs ist deshalb sinnvoll. Dabei ist CDT die signifikant spezifischere und die GGT-Aktivität die empfindlichere Kenngröße.

- Die rechnerische Verknüpfung von CDT und GGT als $\gamma$-CDT hat sich nicht durchgesetzt.

- Mit immunologischen Methoden erhobene positive CDTBefunde sind, in Analogie zur Vorgehensweise bei Drogenuntersuchungen ( $\triangleright$ Drogenscreening), durch ein physikochemisches Verfahren, z. B. HPLC, zu bestätigen. Diese verfügen über eine höhere Spezifität und visualisieren/dokumentieren zudem das Transferrinisoformenmuster.

- Genetische Transferrin-D-Varianten können falsch positive, genetische Transferrin-B-Varianten falsch negative CDTBefunde verursachen. Bei Einsatz einer HPLC-Analytik werden solche Varianten jedoch regelmäßig erkannt.

- CDT ist unbeeinflusst von Pharmaka.

- Berichte über erhöhte CDT-Befunde während Schwangerschaft bedürfen einer statistisch validen Überprüfung.

- Erblich bedingte Glykosylierungsstörungen (,congenital disorders of glycosylation“, frühere Bezeichnung CDGSyndrom) können hinsichtlich Alkoholmissbrauch zu falsch positiven CDT-Befunden führen. Es handelt sich hierbei um eine genetisch bedingte, generalisierte Störung der Synthese der Kohlenhydratstruktur der Glykoproteine. CDG-Patienten (Erstdiagnose zumeist nach Geburt oder im Frühkindalter) zeigen im Serum u. a. TransferrrinisoformenMuster die jenen von Patienten mit chronischem Alkoholmissbrauch gleichen, d. h. mit ausgeprägten Disialo- und Asialotransferrin-Fraktionen. Eine HPLC-CDT-Analyse wird deshalb nicht selten zum Screening auf CDG veranlasst. 
- Falsch positive CDT-Befunde können bei fortgeschrittenen Lebererkrankungen (Zirrhose, Hepatitiden) auftreten.

\section{Diagnostische Wertigkeit}

- CDT ist Kenngröße eines chronischen Alkoholmissbrauchs, jedoch kein Screeningparameter.

- Die Angaben zur diagnostischen Sensitivität ( $\triangleright$ Sensitivität, diagnostische) streuen sehr stark. Sie beträgt für Frauen im Mittel 30-50 \%, für Männer 50-70\%.

- Die diagnostische Spezifität liegt im Mittel deutlich über $90 \%$. CDT ist derzeit der spezifischste Marker eines chronischen Alkoholmissbrauchs. (Wie immer müssen diagnostische Sensitivität und Spezifität sowie die zur ihrer Ermittlung herangezogenen Entscheidungsgrenzen (Cut-offs) gemeinsam betrachtet werden.)

- Ein positiver CDT-Befund weist chronischen Alkoholmissbrauch mit hoher Spezifität ( $\triangleright$ Spezifität, diagnostische) nach, ein normaler CDT-Wert schließt diesen nicht aus.

\section{Literatur}

Arndt T (2001) Carbohydrate-deficient transferrin as a marker of chronic alcohol abuse: a critical review of preanalysis, analysis, and interpretation. ClinChem 47:13-27

Helander A, Wielders J, Anton R, Arndt T, International Federation of Clinical Chemistry and Laboratory Medicine Working Group on Standardisation of Carbohydrate-Deficient Transferrin (IFCC WG-CDT) et al (2016) Standardisation and use of the alcohol biomarker carbohydrate-deficient transferrin (CDT). Clin Chim Acta 459:19-24

\section{Carbonatapatit (Dahllit)}

Calciumphosphat-Stein

\section{Carbonylproteine}

- Modifikation, posttranslationale

\section{(4-[2-Carboxyethyl]-3-[carboxymethyl]} pyrrol-2-yl)methyl-transferase, PräUroporphyrinogen-I-Synthase

> Porphobilinogendesaminase

\section{$\gamma$-Carboxyglutamat-Protein}

Osteocalcin

\section{$\gamma$-Carboxyglutaminsäure}

$>$ Vitamin $\mathrm{K}$

\section{Carboxyhämoglobin}

\Kohlenmonoxidhämoglobin

\section{Carboxyhydrate Antigen}

S. Holdenrieder und P. Stieber

Definition Carboxyhydrate antigene sind in der Regel membranständige Glykoproteine oder -lipide. Von Tumorzellen werden einige dieser Antigene vermehrt exprimiert und zum Teil auch sezerniert. Die Menge und die Art der Antigene im Blut oder anderen Körperflüssigkeiten können einen Hinweis auf den histologischen Gewebstyp, die Größe oder Aktivität des Tumors geben. Allerdings kann die Konzentration verschiedener Antigene auch bei benignen Erkrankungen variieren und je nach Metabolismus z. T. deutlich erhöht sein.

\section{Carboxylesterhydrolase}

- Cholesterinesterase

\section{Carboxypeptidase-B-Aktivierungs-} Peptid

A. M. Gressner und O. A. Gressner

Synonym(e) CAPAP

Englischer Begriff carboxypeptidase activation peptide 
Definition Polypeptid, das nach Sekretion von Procarboxypeptidase B durch das exokrine Pankreas im Intestinallumen bei der tryptischen Aktivierung abgespalten wird und dessen Serum- und/oder Urinkonzentration als Kenngröße des Schweregrades der akuten Pankreatitis dient.

Molmasse 9,4 kDa.

Synthese - Verteilung - Abbau - Elimination Carboxypeptidase B (EC 3.4.17.2) ist ein lineares Polypeptid aus 81 Aminosäuren der Molmasse 9,4 kDa. Es wird als Proform ( $\triangleright$ Zymogene, Molmasse $47 \mathrm{kDa}$ ) von den Azinuszellen des Pankreas sezerniert und intestinal durch limitierte $>$ Trypsinkatalysierte Proteolyse in aktive Carboxypeptidase (Molmasse $35 \mathrm{kDa}$ ) überführt. Das dabei abgespaltene CAPAP wird intestinal nicht resorbiert und mit den Fäzes ausgeschieden.

Funktion - Pathophysiologie Während der initialen Phase der akuten Pankreatitis erfolgt eine prämature Aktivierung von Procarboxypeptidase mit Abspaltung von CAPAP bereits im Pankreas. Danach Freisetzung in den interstitiellen Raum und Eintritt in die Zirkulation mit renaler Elimination. $90 \%$ werden tubulär resorbiert und degradiert, $10 \%$ finden sich im Endurin. Konzentrationserhöhungen im Serum und Urin weisen auf Pankreasnekrosen hin, das Ausmaß korreliert mit dem Schweregrad der akuten (hämorrhagischen versus ödematösen) Pankreatitis.

Untersuchungsmaterial - Entnahmebedingungen Serum, Urin.

Probenstabilität Sehr stabil in Serum und Urin.

Präanalytik Keine Besonderheiten.

Analytik Kompetitiver $\triangleright$ Radioimmunoassay mit Antikörpern gegen humanes CAPAP.

Referenzbereich - Erwachsene Serum $\leq 0,8 \mathrm{nmol} / \mathrm{L}$, Urin $\leq 2,3 \mathrm{nmol} / \mathrm{L}$.

Indikation Diagnostik des Schweregrads einer akuten Pankreatitis.

Interpretation CAPAP-Konzentrationen im Serum und Urin korrelieren mit dem Schweregrad der akuten Pankreatitis:

- Milde Verläufe: Serum und Urin: keine oder gering erhöhte Konzentrationen

- Moderate Verläufe: Serum: 3-10 nmol/L, Urin: $10-50 \mathrm{nmol} / \mathrm{L}$

- Schwere Verläufe: Serum: $>10 \mathrm{nmol} / \mathrm{L}$, Urin: $>100 \mathrm{nmol} / \mathrm{L}$
Diagnostische Wertigkeit In Bezug auf die Schweregradbeurteilung der akuten Pankreatitis: $85 \%$ Sensitivität ( $\triangleright$ Sensitivität, diagnostische), 59 \% Spezifität ( $\triangleright$ Spezifität, diagnostische).

\section{Literatur}

Muller CA, Appelros S, Uhl W et al (2002) Serum levels of procarboxypeptidase $\mathrm{B}$ and its activation peptide in patients with acute pancreatitis and non-pancreatic diseases. Gut 51:229-235

\section{Carboxy-terminales-pro Arginin Vasopressin (C-terminales proAVP)}

Copeptin

\section{Carboxyterminales Typ-I-Kollagen- Telopeptid}

H.-D. Haubeck

Synonym(e) CTX; ICTP

Englischer Begriff carboxyterminal telopeptide of type I collagen (CTX); cross-linked carboxyterminal telopeptide of type I collagen (ICTP)

Definition Carboxyterminale Typ-I-Kollagen-Telopeptide entstehen durch die Wirkung proteolytischer Enzyme bei der Knochenresorption und eignen sich als Marker des Knochenum- bzw. Knochenabbaus.

Beschreibung Kollagen Typ I ist mit einem Anteil von ca. $90 \%$ der organischen Knochenmatrix das wichtigste Protein des Knochens. Dementsprechend lassen sich die durch proteolytischen Abbau von Kollagen Typ I entstehenden Degradationsprodukte als Marker von Knochenumbau bzw. Knochenresorption nutzen. Neben $>$ Desoxypyridinolin (DPD) wurden vor allem Fragmente der carboxyterminalen und aminoterminalen Typ-I-Kollagen-Telopeptide (NTX) im Serum und/oder Urin gemessen. Von den carboxyterminalen Telopeptiden wurden bisher 2 Fragmente isoliert, charakterisiert und für den Aufbau von Immunoassays ( Immunoassay) verwendet: ICTP (,,cross-linked carboxyterminal telopeptide of collagen type $\mathrm{I}^{\circ}$ ) und CTX (,C-terminal cross-linked telopeptide of 
collagen type I"). Während ICTP ein größeres konformationsabhängiges Epitop bildet, besteht das Spaltprodukt CTX aus 8 Aminosäureresten, die in den $\alpha 1$-Ketten des Kollagens zweimal quervernetzt vorkommen, d. h., das Fragment enthält das CTX-Motiv aus 8 Aminosäuren zweimal ( $\triangleright$ Carboxyterminales Typ-I-Kollagen-Telopeptid, quervernetztes). Die beiden Fragmente CTX (bzw. CrossLaps) und ICTP entstehen durch die proteolytische Aktivität unterschiedlicher Enzyme. Das Fragment CTX wird im Rahmen des normalen Turnover aus Kollagen Typ I durch Kathepsin $\mathrm{K}$ (aus den Osteoklasten) freigesetzt.

Im Gegensatz hierzu wird das Fragment bzw. ICTP-Epitop durch Kathepsin K zerstört. ICTP entsteht durch die Wirkung verschiedener Matrix-Metalloproteinasen (u. a. MMP-1, -2-, $-9,-13$, und -14), die nicht bzw. nicht nur von Osteoklasten freigesetzt werden. Dementsprechend eignet sich CTX, im Gegensatz zu ICTP, gut für die Verlaufs- und Therapiekontrolle des Knochenabbaus bei der Osteoporose, während ICTP vor allem Bedeutung für die Verlaufs- und Therapiekontrolle bei Patienten mit osteolytischen Knochenmetastasen, z. B. bei Mamma-, Prostata- und Bronchialkarzinom sowie beim multiplen Myelom, aber auch bei Patienten mit rheumatoider Arthritis und reaktiven Arthritiden mit einer Knochenbeteiligung besitzt.

\section{Literatur}

Garnero P, Ferreras M, Karsdal MA et al (2003) The type I collagen fragments ICTP and CTX reveal distinct enzymatic pathways of bone collagen degradation. JBMR 18:859-867

Ju H-SJ, Leung S, Brown B et al (1997) Comparison of analytical performance and biological variability of three bone resorption assays. Clin Chem 43:1570-1576

\section{Carboxyterminales Typ-I-Kollagen- Telopeptid, quervernetztes}

H.-D. Haubeck

Synonym(e) $\beta$-Crosslaps; $\beta$-CTx; CTX

\section{Englischer Begriff CrossLaps}

Definition CrossLaps sind spezifische Abbauprodukte carboxyterminaler Telopeptide des Typ-I-Kollagens.

Beschreibung Während für die Diagnose der Osteoporose die Messung der Knochendichte von entscheidender Bedeu- tung ist, erlauben Parameter zur Erfassung der Knochenresorption die Messung des aktuellen Knochenverlusts und eine Therapiekontrolle. Die Knochenresorption kann über den Nachweis von verschiedenen Abbauprodukten des Typ-IKollagens gemessen werden. Hierfür wurde bisher vor allem der Nachweis von $>$ Desoxypyridinolin (DPD) im Urin eingesetzt, während die $>$ Calciumausscheidung und der Nachweis von $>$ Hydroxyprolin von geringerer Bedeutung waren. Neben der Messung von DPD kann auch der Nachweis von $\checkmark$ carboxyterminales Typ-I-Kollagen-Telopeptid und $>$ aminoterminales Typ-I-Kollagen-Telopeptid, die im Rahmen der Knochenresorption durch Osteoklasten u. a. durch die Wirkung von Kathepsin K aus Kollagen freigesetzt werden, für diese Zwecke genutzt werden. Mit dem CrossLaps-Immunoassay werden Fragmente des carboxyterminalen Typ-I-Kollagentelopeptids erfasst, die das Oktapeptid EKAHD- $\beta$-GGR, in dem der Aspartatsäurerest (D) $\beta$-isomerisiert ist, zweifach (,,cross-linked“) enthalten. Ein wesentlicher Vorteil dieses Assays ist, dass er aufgrund der höheren Empfindlichkeit den Nachweis carboxyterminaler Telopeptide im Serum erlaubt und damit die Probleme der Messungen im Urin vermeidet.

\section{Literatur}

Ju H-SJ, Leung S, Brown B et al (1997) Comparison of analytical performance and biological variability of three bone resorption assays. Clin Chem 43:1570-1576

Rosenquist C, Fledelius C, Christgau S et al (1998) Serum crossLaps one step ELISA. First application of monoclonal antibodies for measurement in serum of bone-related degradation products from C-terminal telopeptides of Type I collagen. Clin Chem 44:2281-2289

\section{6-Carboxyuracil}

> Orotsäure

\section{Carcinoembryonales Antigen}

S. Holdenrieder und P. Stieber

\section{$\operatorname{Synonym(e)~CEA~}$}

\section{Englischer Begriff carcino-embryonic antigen}

Definition Das carcinoembryonale Antigen ist ein $180 \mathrm{kDa}$ schweres Glykoprotein mit 50-70 \% Kohlenhydratanteil und einer Sedimentationskonstanten von 7-8 S. 
Struktur Das carcinoembryonale Antigen besteht vermutlich aus einer einzelnen Polypeptidkette mit 668 Aminosäuren, an die eine größere Anzahl von komplexen, verzweigten Oligosaccharidketten über $N$-Acetylglukosamin-AsparaginBindungen verknüpft ist.

\section{Molmasse $180 \mathrm{kDa}$.}

Synthese - Verteilung - Abbau - Elimination Physiologisch kommt das CEA im fetalen Gastrointestinaltrakt sowie im fetalen Serum ab der 8. Schwangerschaftswoche (mit einem Maximum um die 22. Schwangerschaftswoche) vor. Beim erwachsenen Menschen werden geringe Mengen von Zellen des Gastrointestinaltrakts, des Pankreas und der Leber produziert.

\section{Halbwertszeit 2-8 Tage.}

Funktion - Pathophysiologie Die wesentliche klinische Bedeutung der CEA-Bestimmung liegt in der Entdeckung und Verlaufsbeobachtung des Kolonkarzinoms, in der Differenzialdiagnose von Leberrundherden sowie Therapiemonitoring und frühzeitiger Rezidiverkennung beim Mammakarzinom.

Die gesteigerte CEA-Synthese und die Freisetzung werden durch die Derepression von für die CEA-Bildung verantwortlichen Genen erklärt, die bei der Geburt reprimiert wurden. Das CEA-kodierende Gen ist Mitglied einer Familie von mindestens 17 transkriptionell aktiven Genen mit hoher struktureller Homologie. Aufgrund der Ähnlichkeit von Produkten der CEA-Genfamilie können mono- und polyklonale $>$ Antikörper mit CEA-ähnlichen Antigenen kreuzreagieren (z. B. $>$ Non cross reacting antigen [NCA] 1 und 2, biliäres Glykoprotein $[\triangleright$ Glykoprotein, biliäres, BGP] u. a.).

Untersuchungsmaterial- Entnahmebedingungen Serum, Plasma, Pleurapunktat, Aszites, Liquor.

Analytik $>$ Enzymimmunoassay (EIA), > Radioimmunoassay (RIA), Immunradiometrischer Assay (IRMA), $>$ Elektrochemilumineszenz-Immunoassay (ECLIA), insbesondere unter Verwendung von monoklonalen Antikörpern.

\section{Konventionelle Einheit $\mu \mathrm{g} / \mathrm{L}$.}

Referenzbereich - Erwachsene Serum: Median 1,0 $\mu \mathrm{g} / \mathrm{L}$; $95 \%$-Perzentile 2,3 $\mu \mathrm{g} / \mathrm{L}$ (methodenabhängig).

\section{Indikation}

- Verdacht auf primäres kolorektales Karzinom
- Differenzialdiagnose von Leberrundherden (mit $>\alpha_{1}$ Fetoprotein [AFP])

- Therapiekontrolle und Nachsorge von kolorektalem Karzinom und Mammakarzinom (mit $>$ Carbohydrate antigen 15-3)

Interpretation Die meisten CEA-Assays sind für die Anwendung im Serum und Plasma ausgetestet und können auch für die CEA-Bestimmung in anderen Körperflüssigkeiten eingesetzt werden.

Das carcinoembryonale Antigen wird in sehr hohen Konzentrationen $(>1000 \mu \mathrm{g} / \mathrm{L})$ insbesondere vom (hepatisch metastasierten) kolorektalen Karzinom, aber auch vom Bronchial-, Magen- und Ovarialkarzinom freigesetzt. Werte bis $1000 \mu \mathrm{g} / \mathrm{L}$ wurden außerdem beim Pankreas-, Mammaund Leberzellkarzinom beobachtet.

Niedrig pathologische CEA-Werte (bis $10 \mu \mathrm{g} / \mathrm{L}$ ) werden auch bei benignen Erkrankungen, vor allem des Darms, des Pankreas, der Leber und der Lunge, so bei Leberzirrhose, chronischer Hepatitis, Pankreatitis, Colitis ulcerosa, Morbus Crohn, Pneumonie, Bronchitis, Tuberkulose, Emphysem, Mukoviszidose sowie bei Autoimmunerkrankungen beobachtet. Bei einigen Assays können Raucher eine permanent erhöhte CEA-Konzentration (bis $10 \mu \mathrm{g} / \mathrm{L}$ ) aufweisen.

Bei Vorliegen von Leberrundherden kann die gemeinsame Bestimmung von carcinoembryonalem Antigen und AFP differenzialdiagnostisch wegweisend sein:

- Stark erhöhtes AFP bei niedrigem carcinoembryonalen Antigen spricht für ein primäres hepatozelluläres Karzinom - Stark erhöhtes carcinoembryonales Antigen bei niedrigem AFP spricht für eine Lebermetastase eines kolorektalen Karzinoms oder eines anderen Adenokarzinoms, z. B. der Lunge oder der Brust

Für die Therapiekontrolle und die Rezidiverkennung in der Nachsorge des Mammakarzinoms hat sich CEA neben CA 15-3 als sensitiver und additiver Marker etabliert. Mit beiden Markern gelingt eine sichere Früherkennung einer Fernmetastase ( $>98 \%$ Spezifität) ( $>$ Spezifität, diagnostische) mit einer Sensitivität ( $\triangleright$ Sensitivität, diagnostische) von $66 \%$ ausgehend von den individuellen Basiswerten. Bei der Primärtherapie ,negative“ Marker können im weiteren Verlauf ansteigen und hilfreich für die Erkennung einer Metastasierung sein. Deshalb empfiehlt sich in der Nachsorge des Mammakarzinoms eine kontinuierliche Bestimmung von carcinoembryonalem Antigen und CA 15-3.

\section{Diagnostische Wertigkeit}

- Primäres kolorektales Karzinom: Therapiemonitoring, Rezidiverkennung 
- Leberrundherde: Differenzialdiagnose (mit AFP)

- Mammakarzinom: Therapiemonitoring, Rezidiverkennung (mit CA 15-3)

\section{Literatur}

Duffy MJ et al (2014) Tumor markers in colorectal cancer, gastric cancer and gastrointestinal stromal cancers: European group on tumor markers 2014 guidelines update. Int J Cancer 134:2513-2522

Nollau P, Wagener C, Lamerz R (2012) CEA. In: Thomas L (Hrsg) Labor und diagnose, 8. Aufl. TH-Books, Frankfurt am Main, S 1652-1657

Stieber P, Heinemann V (2008) Sinnvoller Einsatz von Tumormarkern. J Lab Med 32:339-360

Stieber P et al (2015) Diagnostic efficacy of CA 15-3 and CEA in the early detection of metastatic breast cancer-a retrospective analysis of kinetics on 743 breast cancer patients. Clin Chim Acta 448:228-231

Sturgeon CM et al (2008) National Academy of Clinical Biochemistry laboratory medicine practice guidelines for use of tumor markers in testicular, prostate, colorectal, breast, and ovarian cancers. Clin Chem 54:e11-e79

Trapé J et al (2011) Increased plasma concentrations of tumour markers in the absence of neoplasia. Clin Chem Lab Med 49:1605-1620

\section{Carcinoembryonic antigen cell} adhesion molecule

\section{S. Holdenrieder und P. Stieber}

Synonym(e) CEACAM-1

Englischer Begriff carcinoembryonic antigen cell adhesion molecule 1

Definition Das „carcinoembryonic antigen cell adhesion molecule 1" ist ein Typ-1-transmembranöses Glykoprotein, Mitglied der CEA-Genfamilie $(\triangleright$ Carcinoembryonales Antigen) und gleichzeitig ein Adhäsionsmolekül ( $\triangleright$ Adhäsionsmoleküle) der Immunglobulinsuperfamilie.

Struktur CEACAM-1 wurde ursprünglich in Leber und Galle als CEA-kreuzreagierendes Antigen entdeckt. Es besteht aus 4 Immunglobulin-ähnlichen Ektodomänen und einer kurzen zytoplasmatischen Domäne. CEACAM-1 assoziiert direkt mit Annexin II, einem mit „Lipid-Raft“ assoziierten Molekül.

Synthese-Verteilung-Abbau-Elimination CEACAM-1 wird auf der Oberfläche der Epithelien des Gastrointestinaltrakts, von Brust, Niere, Prostata, Leber sowie in aktivierten
Endothelzellen, T- und B-Zellen, in dendritischen Zellen und Granulozyten exprimiert.

Funktion - Pathophysiologie Sowohl CEACAM-1 als auch Annexin II sind in vielen soliden Karzinomen, wie z. B. von Kolon und Rektum, Prostata, Brust und Leber herabreguliert. Somit scheinen sie tumorsupprimierende Wirkung zu haben. Daneben spielt CEACAM-1 bei der Signaltransduktion ins Zellinnere, der Reorganisation des Zytoskeletts und der Apoptose eine Rolle. Dazu kontrastierende Ergebnisse lieferte eine Studie über Patienten mit Bronchialkarzinom, bei der eine erhöhte CEACAM-1-Konzentration im Tumorgewebe gefunden wurde, die zusätzlich mit einer ungünstigen Prognose assoziiert war.

Untersuchungsmaterial - Entnahmebedingungen Serum, Plasma.

Indikation Prognosemarker bei verschiedenen soliden Tumoren.

Interpretation CEACAM-1 könnte sich als ein neuer Marker für die Prognoseeinschätzung und möglicherweise als Hilfe zur Differenzialdiagnose bei verschiedenen soliden Tumoren etablieren. Bislang liegen noch keine aussagekräftigen Studien vor, die eine eindeutige Empfehlung rechtfertigen würden.

Diagnostische Wertigkeit Potenzieller Prognosemarker.

\section{Literatur}

Kirshner J, Schumann D, Shively JE (2003) CEACAM-1, a cell-cell adhesion molecule, directly associates with annexin II in a threedimensional model of mammary morphogenesis. J Biol Chem 50:50.338-50.345

Sienel W, Dango S, Woelfle U et al (2003) Elevated expression of carcinoembryonic antigen-related cell adhesion molecule 1 promotes progression of non-small cell lung cancer. Clin Cancer Res 9:2260-2266

\section{Cardenolide}

K. J. Lackner und D. Peetz

Englischer Begriff cardenolides

Definition Substanzklasse bestehend aus einem Sterolgrundgerüst und einem ungesättigten fünfgliedrigen Lactonring. 
Struktur der Cardenolide:

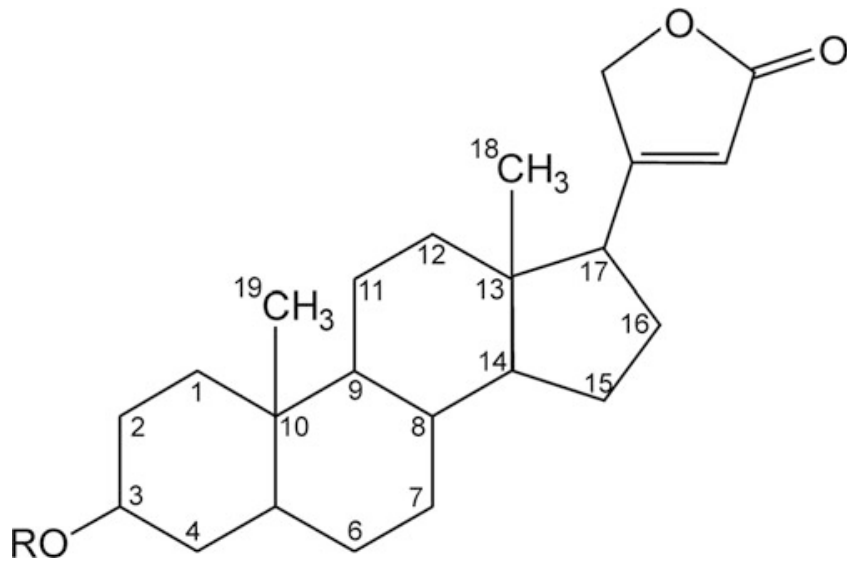

Beschreibung $\mathrm{Zu}$ den Cardenoliden gehören u. a. die positiv inotropen Glykoside $\triangleright$ Digoxin, $\triangleright$ Digitoxin und Strophantin sowie deren Derivate.

\section{Cardiokine}

$>$ Kardiokine

\section{Cardiolipin}

K. J. Lackner und D. Peetz

Synonym(e) Diphosphatidylglycerol

Englischer Begriff cardiolipin

Definition Anionisches Phospholipid mit dimerer Struktur, die über ein Glyzerinmolekül verknüpft ist. Cardiolipin enthält 2 Phosphatgruppen und 4 Azylketten.

Beschreibung Cardiolipin kommt in Bakterienmembranen ( $\vee$ Bakterien) und der mitochondrialen Membran von Eukaryonten und Wirbeltieren vor. Der Name bezieht sich auf die ursprüngliche Isolation aus Herzmuskelgewebe, in dem Cardiolipin etwa $10 \%$ der Gesamtphospholipide ausmacht. Bei Säugern sind etwa $80 \%$ der Azylreste Linolsäure, der Rest vorwiegend Ölsäure und Linolensäure. In Mitochondrien interagiert Cardiolipin mit nahezu allen Proteinkomplexen der Atmungskette und ist essenziell für die Funktion dieser Komplexe. Diagnostisch ist Cardiolipin als Antigen der Antiphospholipidantikörper von Bedeutung.

\section{Literatur}

Schlame M, Rua D, Greenberg ML (2000) The biosynthesis and functional role of cardiolipin. Prog Lipid Res 39:257-288

\section{Cardiolipin-Antikörper}

- Autoantikörper gegen Cardiolipin

\section{Caretaker-Gen}

- Hausmeister-Gen

\section{Carnitin}

\section{A. C. Sewell}

Englischer Begriff carnitine

Definition Ein essenzieller und integrierter Bestandteil im Transport langkettiger Fettsäuren durch die Membran der Mitochondrien in die innere Matrix. Dort erfolgt die weitere $\beta$-Oxidation. Carnitin hält das Verhältnis Acetyl-CoA/CoA im Gleichgewicht.

Struktur $\left(\mathrm{CH}_{3}\right)_{3} \mathrm{~N}^{+}-\mathrm{CH}_{2}-\mathrm{HCOH}-\mathrm{CH}_{2} \mathrm{COO}^{-}$, Summenformel: $\mathrm{C}_{7} \mathrm{H}_{15} \mathrm{NO}_{3}$

Molmasse 161,2 g.

Beschreibung Im Jahr 1905 wurde Carnitin fast gleichzeitig von Gulewitsch und Krimberg in Moskau und von Kutscher in Marburg entdeckt. Carnitin blieb lange Zeit einer der Naturstoffe, deren Funktion nicht bekannt war. Bei Untersuchungen über den Vitaminbedarf des Mehlkäfers Tenebrio molitor stießen Fraenkel und Friedman auf einen für die Metamorphose des Käfers essenziellen Wachstumsfaktor. Im Jahr 1952 wurde die Identität dieses Faktors als L-Carnitin nachgewiesen.

1955 beobachten Friedman und Fraenkel die reversible Übertragung von aktivierten Acetylgruppen zwischen Carnitin und CoA. Im gleichen Jahr beschrieb Fritz die Erhöhung der Oxidationsrate von Palmitat in Rattenleberhomogenat, wenn Muskelextrakt zugefügt wurde. Es zeigte sich, dass 
das im Muskelextrakt vorliegende Carnitin die Oxidation der langkettigen Fettsäuren stimuliert. Im Jahr 1963 entdeckten Bremer und Fritz das Enzym Carnitin-PalmitoylTransferase, das folgende Reaktion katalysiert:

Palmitoyl-CoA + L-Carnitin $\rightleftarrows$ Palmitoyl-L-Carnitin + CoA

Sie postulierten dessen Bedeutung bei der Oxidation von Fettsäuren. Die Hauptrolle zeigt L-Carnitin bei der $\beta$-Oxidation von mittel- und langkettigen Fettsäuren in den Mitochondrien. Mithilfe von Carnitin gelangen aktivierte Fettsäuren als Carnitinester aus dem Zytosol durch die innere Mitochondrienmembran in die Mitochondrienmatrix.

Die Bestimmung von Carnitin in Körperflüssigkeiten und Gewebextrakten wird traditionell mit der radioenzymatischen Methode von McGarry und Foster durchgeführt. Hier werden Gesamtcarnitin, das freie Carnitin und das Acylcarnitin ermittelt. Heute ist es möglich, durch Tandem- $\triangleright$ Massenspektrometrie das freie Carnitin und gleichzeitig die einzelnen Acylcarnitin-Spezies zu bestimmen. Dies ist für die Diagnostik angeborener Stoffwechselerkrankungen im Neugeborenenalter unentbehrlich.

Der größte Anteil an Gesamtcarnitin befindet sich beim Menschen in der Skelettmuskulatur. Die Konzentrationen in den verschiedenen Geweben sind bis zu 100-fach höher als die im Plasma. Carnitin wird hauptsächlich über den Urin ausgeschieden. Die renale Clearance beträgt bei gesunden Probanden $1-2 \mathrm{~mL} / \mathrm{min}$, die tubuläre Rückresorption liegt dementsprechend weit über $90 \%$. Folglich wird L-Carnitin von der Niere wie eine essenzielle Aminosäure angesehen.

Aus der zentralen Stellung im Intermediärstoffwechsel besitzt L-Carnitin Wirkungen auf verschiedene Organsysteme.

Normale gesunde Erwachsene haben eine adäquate Carnitinspeicherung und benötigen kein zusätzliches Carnitin. Bedeutung gewinnt die exogene Zufuhr jedoch bei verschiedenen Erkrankungen und bei Carnitinmangelzuständen. Carnitinmangel kann als intrazellulärer Mangel an Carnitin definiert werden. Ein solcher Mangel führt zu einer Akkumulation von AcylCoA-Estern und zu einer Hemmung des Acyltransports durch die innere Mitochondrienmembran. Dieser Mangel kann in einen primären (mit einem Basisdefekt, Ursache im Carnitinstoffwechsel) und in einen sekundären (als Folge anderer Erkrankungen und Zustände) eingeteilt werden.

\section{Literatur}

Gürtler A-K, Löster H (1996) Carnitin und seine Bedeutung bei der Pathogenese und Therapie der Herz- und Kreislauferkrankungen. Ponte Press, Bochum

McGarry JD, Foster DW (1976) An improved and simplified radioisotopic assay for the determination of free and esterified carnitine. J Lipid Res 17:277-281

\section{Carnitin-Palmitoyl-Transferase}

A. C. Sewell

Synonym(e) CPT

Englischer Begriff carnitine palmitoyl transferase

Definition CPT (EC 2.3.1.21) ist ein mitochondriales Enzym, das den Transport langkettiger Fettsäuren durch die Membran der Mitochondrien mittels Bindung an Carnitin ermöglicht.

Beschreibung Zwei Formen von CPT (CPT I und CPT II) sowie 3 Subformen für CPT I sind bekannt. CPT I katalysiert die Reaktion zwischen Carnitin und Palmitoyl-CoA, aus der Palmitoylcarnitin entsteht. CPT-I-Mangel führt zur hypoketonischen Hypoglykämie, Hepatomegalie und Erhöhung der Carnitinkonzentration im Plasma.

CPT II ist Bestandteil der inneren mitochondrialen Membran und katalysiert die Transesterifikation von Palmitoylcarnitin zu Palmitoyl-CoA, das als Substrat der mitochondrialen $\beta$-Oxidation zur Verfügung steht; Carnitin wird freigesetzt. CPT-II-Mangel führt ebenfalls zur hypoketonischen Hypoglykämie mit Leber-, Muskel- und Herzbeteiligung.

\section{Literatur}

Foster DW (2004) The role of the carnitine system in human metabolism. Ann N Y Acad Sci 1033:1-16

\section{Carnosin}

A. C. Sewell

Synonym(e) Anti-aging-Dipeptide

Englischer Begriff carnosine

Definition Ein aus $\triangleright \beta$-Alanin und $\gg$ Histidin zusammengesetztes Dipeptid. Beim Menschen kommt es hauptsächlich in der Skelettmuskulatur und im Gehirn vor. Spielt evtl. eine Rolle als Neurotransmitter. Rolle in Alterungsprozessen vermutet. 
Beschreibung Carnosin wurde im Jahr 1900 von Gulewitsch im Muskelextrakt entdeckt. Die Struktur wurde als Dipeptid beschrieben, und bis 1953 wurde Carnosin als ,uninteressant“ eingestuft. Die genaue Rolle des Carnosins bleibt bis heute unbekannt. Im Muskel dient Carnosin als Puffer (pK 6,9), insbesondere bei den Schnellfasern (fast twitch).

Carnosin kann mithilfe der quantitativen Aminosäurenanalytik in Körperflüssigkeiten nachgewiesen werden, allerdings ist Carnosin weder im Plasma noch im Urin eines gesunden Menschen zu finden. Beim Verzehr hoher Mengen von Geflügelfleisch kann der Carnosinspiegel im Plasma deutlich ansteigen mit einer entsprechenden renalen Ausscheidung. Dies stellt häufig ein Problem bei der Beurteilung von Ergebnissen der Aminosäurenanalyse dar.

Ca. 25 Fälle von Carnosinämie wurden weltweit bisher beschrieben. Es handelt sich um eine vermutlich autosomal rezessiv vererbte Stoffwechselerkrankung. Ein Mangel der Serumcarnosinase liegt zugrunde. Das klinische Bild ist sehr variabel, sodass die Carnosinämie als ,benigne Erkrankung“ anzusehen ist.

Heute werden dem Carnosin neue Funktionen zugeschrieben, so z. B. antioxidative Eigenschaften, ,,anti-aging dipeptide“ und zusammen mit Antibiotika und Protonenpumpenhemmer als Unterstützung bei der Behandlung von Helicobacter-pyloriInfektionen.

\section{Literatur}

Hipkiss AR et al (2002) Reaction of carnosine with aged proteins: another protective process? Ann N Y Acad Sci 959:285-294

Scriver CR, Beudet AL, Sly WS et al (1995) The metabolic and molecular bases of inherited disease, 8. Aufl. McGraw-Hill, New York, S $1362-1363$

Skulachev VP (2000) Biological role of carnosine in the functioning of excitable tissues. Centenary of Gulewitsch's discovery. Biochemistry (Mosc) 75:749-750

\section{$\boldsymbol{\beta}$-Carotin}

\section{H. Jomaa}

Synonym(e) Provitamin A

Englischer Begriff $\beta$-carotene; provitamin A

Definition $\beta$-Carotin ist der Hauptvertreter der Carotinoide, die in Retinol (Vitamin A) umgewandelt werden.

Molmasse $536,87 \mathrm{~g} / \mathrm{mol}$.
Synthese - Verteilung - Abbau - Elimination $\beta$-Carotin ist ein Tetraterpen mit symmetrischer Struktur und besteht aus einer Isoprenkette mit 11 konjugierten Doppelbindungen und je einem endständigen $\beta$-Iononring (Abb. 1).

$\beta$-Carotin kommt in allen pflanzlichen Lebensmitteln vor, insbesondere in Karotten, Grünkohl, roten Paprika und Spinat. Es wird in der Lebensmittelindustrie häufig als Farbstoff eingesetzt.

Das mit der Nahrung eingenommene $\beta$-Carotin wird im Dünndarm über den „scavenger receptor class B type I“ (SCARB1) und CD36 in die Enterozyten aufgenommen. Noch in den Enterozyten erfolgt die Spaltung eines großen Teils $\beta$-Carotin durch die $\beta$-Carotin-15,15'-Oxygenase (BCO1) in 2 Moleküle Retinal, die zu Retinol reduziert und weiter in Retinylester umgewandelt werden (Abb. 1). Die Expression der Gene SCARB1 und BCO1 ist durch Retinsäure reguliert. Damit werden Aufnahme und Metabolisierung von $\beta$-Carotin dem Vitamin-A-Bedarf angepasst.

Sowohl das Retinylester als auch das nicht gespaltene $\beta$-Carotin werden in Chylomikronen gepackt, in die Lymphe abgegeben und gelangen so in die Blutbahn. Mit den Chylomikronenremnants gelangen Retinylester und $\beta$-Carotin in die Leber. Der weitere Transport von $\beta$-Carotin im Blut erfolgt, an LDL- und VLDL-Lipoproteine gebunden, u. a. in das subkutane Fettgewebe. Daher verursacht die Aufnahme großer Mengen an $\beta$-Carotin eine Gelbfärbung der Haut.

Funktion - Pathophysiologie Neben seiner Bedeutung als Vitamin-A-Quelle (Siehe $\triangleright$ Vitamin A) besitzt $\beta$-Carotin antioxidative Eigenschaften in lipophiler Umgebung, wie z. B. in Zellmembranen und Lipoproteinen. Epidemiologische Studien belegen, dass Probanden mit hoher $\beta$-CarotinAufnahme ein reduziertes Risiko für Lungenkrebs und kardiovaskuläre Erkrankungen haben. Jedoch zeigen Supplementierungsstudien eine Zunahme der Lungenkrebshäufigkeit bei starken Rauchern nach Behandlung mit mehr als dem 10-fachen der Empfehlung über 4-12 Jahre. Daher wird Rauchern von der Supplementierung mit $\beta$-Carotin abgeraten.

Die $\beta$-Carotin-Aufnahme im Dünndarm ist abhängig vom Vitamin-A-Bedarf. Daher verursachen auch hohe $\beta$-CarotinGaben keine Hypervitaminose A (1 Retinoläquivalent [RE]entspricht $2 \mu \mathrm{g} \beta$-Carotin in Supplementen oder $12 \mu \mathrm{g}$ $\beta$-Carotin in Lebensmitteln). $\beta$-Carotin wird aufgrund der photoprotektiven Eigenschaften auch zur symptomatischen Behandlung der Lichtüberempfindlichkeit bei erythropoetischer Protoporphyrie eingesetzt.

Charakteristische $\beta$-Carotin-Mangelsymptome sind bislang nicht bekannt.

Untersuchungsmaterial Serum. Proben lichtgeschützt transportieren und aufbewahren. 
$\beta$-Carotin, Abb. 1 Provitamin A ( $\beta$-Carotin), Vitamin

A (all-trans-Retinol) und aktive

Derivate (ARAT, Acyl-CoA:

Retinol-Acyltransferase; LRAT,

Lecithin:Retinol-Acyltransferase)

(aus: Heinrich et al. 2014)

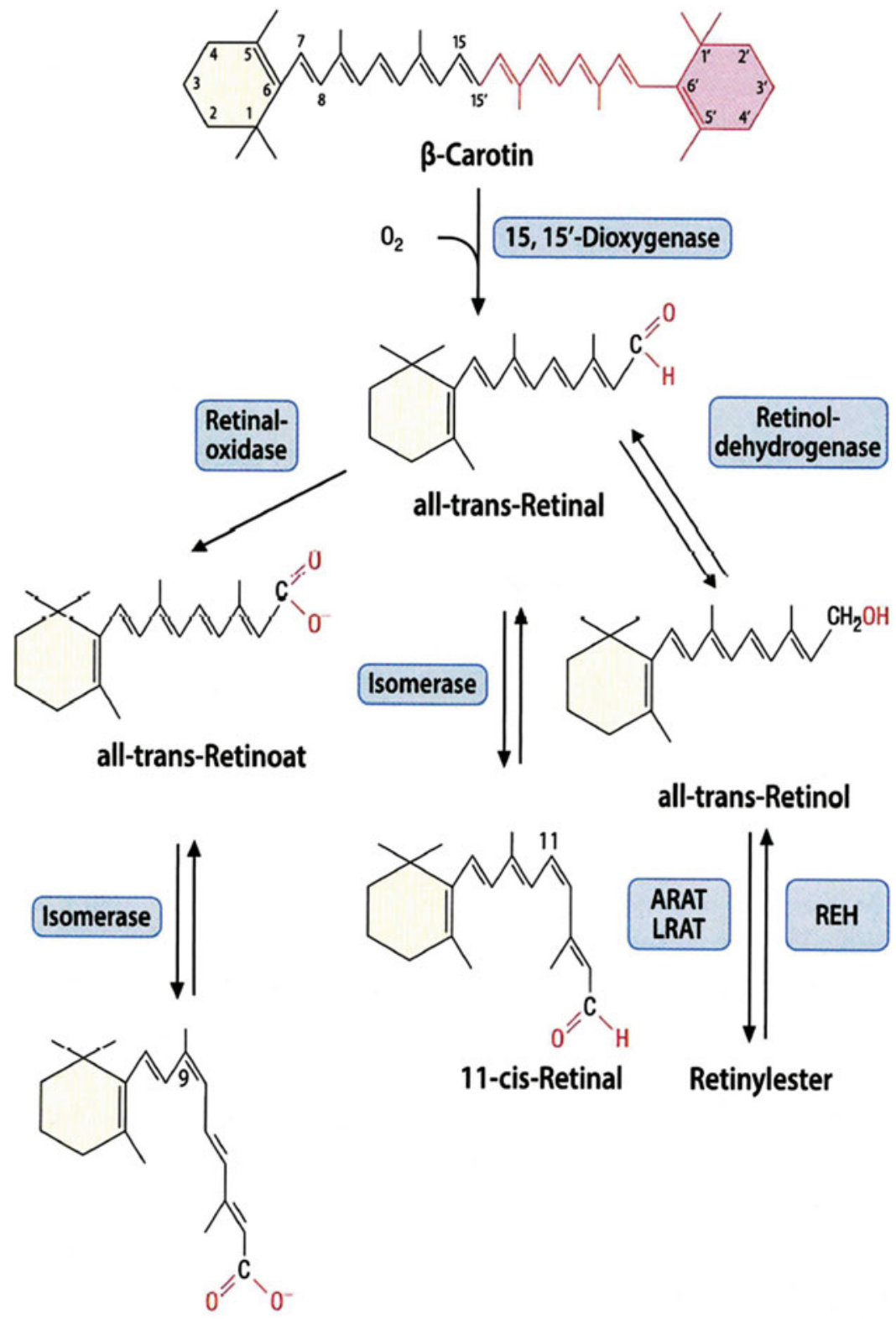

9-cis-Retinoat
Analytik Hochleistungs-Flüssigkeitschromatographie (HPLC) mit UV/VIS- oder MS-Detektion.

Referenzbereich - Erwachsene $600-2000 \mu \mathrm{g} / \mathrm{L}(1,12-3,72$ $\mu \mathrm{mol} / \mathrm{L})$. In der Literatur angegebene Referenzbereiche reichen von Angaben von $100 \mu \mathrm{g} / \mathrm{L}$ als untere Grenze bis $\mathrm{zu}$ $3000 \mu \mathrm{g} / \mathrm{L}$ als obere Referenzgrenze.

\section{Referenzbereich - Kinder Nicht verfügbar.}

Indikation Maldigestion/Malabsorption, $\beta$-Carotin-Therapie von Lichtdermatosen.
Interpretation Deutlich erhöhte $\beta$-Carotin-Werte sind auf Supplementierung oder auf einen BCO1-Polymorphismus zurückzuführen.

Diagnostische Wertigkeit Die $\beta$-Carotin-Konzentration im Blut ist ein Indikator für die Ernährung der letzten 8-14 Tage.

Bei dem Enzym $\beta$-Carotin-Oxygenase (BCO1) sind Varianten mit einer herabgesetzten Aktivität beschrieben. Dieser Polymorphismus ist zwar mit einer erhöhten $\beta$-Carotin-Kon zentration im Blut assoziiert, jedoch kann bei vorwiegend pflanzlicher Kost ein Vitamin-A-Defizit auftreten. 


\section{Literatur}

Bässler KH, Golly I, Loew D et al (2007) Vitaminlexikon, 4. Aufl. Urban und Fischer, München

Biesalski HK (2016) Vitamine und Minerale. Thieme, Stuttgart

Harrison EH (2012) Mechanisms involved in the intestinal absorption of dietary vitamin A and provitamin A carotenoids. Biochim Biophys Acta 1821:70-77

Heinrich PC, Müller H, Graeve L, Löffler G, Petrides PE (Hrsg) (2014) Biochemie und Pathobiochemie, 9. Aufl. Springer, Heidelberg

\section{CarP}

Autoantikörper gegen carbamyliertes Protein

\section{CARP-VIII-Autoantikörper}

- Autoantikörper gegen CARP VIII

\section{Carrier-Testung}

J. Arnemann

Synonym(e) Überträger-Testung

Englischer Begriff transmitter analysis

Definition Bei einer Carrier- oder Überträger-Testung wird eine ratsuchende Person auf das Vorhandensein einer familiär segregierenden Genmutation getestet.

Beschreibung Bei einer Überträger- oder Carrier-Testung wird mittels molekulargenetischer Nachweismethoden getestet, ob Ratsuchende oder Patienten in ihrem Genom die bekannte und in ihrer Familie segregierende, d. h. vererbte, Mutation tragen (s. a. - Mutationsanalyse). Diese Analyse kann beispielsweise eingesetzt werden zu einer Risikovorhersage oder Abschätzung eines Wiederholungsrisikos für eine Erkrankung in der nächsten Generation, aber auch im Sinne der prädiktiven Diagnostik (s. a. \ Prädiktive Diagnostik) einer einen selbst betreffenden Late-onset-Erkrankung, wie z. B. Chorea Huntington, erblichen Darmkrebs oder erblichen Brust- und Eierstockkrebs.

Das Ergebnis einer Carrier-Testung dient zum einen der genetischen Beratung und der Familienplanung, ermöglicht aber im Sinne einer prädiktiven Testung oftmals eine gezielte Erkrankungsprävention.

\section{Literatur}

Kingsmore S (2012) Comprehensive carrier screening and molecular diagnostic testing for recessive childhood diseases. PLoS Curr 4: e4f9877ab8ffa9

\section{Carter-Robbins-Test}

- Kochsalz-Belastungstest

\section{Cartwright}

- Yt-Blutgruppensystem

\section{Cartwright-Gruppe}

- Yt-Blutgruppensystem

\section{CASA}

Cancer-associated serum antigen

\section{CAS-Nummer}

C. Vidal und W.-R. Külpmann

Englischer Begriff chemical abstracts service registry number

Definition System zur Codierung von einzelnen Substanzen.

Beschreibung Die CAS-Nummer wird vom Chemical Abstracts Service der American Chemical Society entsprechend der Reihenfolge, in der die Substanzen in den Chemical Abstracts besprochen werden, vergeben. Für jeden bekannten chemischen Stoff (auch Biosequenzen, Legierungen, Polymere) existiert eine eigene CAS-Nummer. Selbst verschiedene Isomere eines Moleküls erhalten verschiedene CAS-Nummern, die so eine eindeutige Identifikation einer Substanz erlauben. 


\section{CAST}

- Leukotrien-Freisetzung

\section{Catecholamine}

- Katecholamine

\section{Catha edulis Forsk.}

> Kath

\section{Cathepsine}

- Kathepsine

\section{Cathin}

- Kath

\section{Cathinon}

× Kath

\section{Cathinone}

\section{T. Arndt}

Synonym(e) Kathinone

\section{Englischer Begriff cathinones}

Definition Cathinone sind eine Gruppe organischer Verbindungen mit der Grundstruktur des im $>$ Kath natürlich vorkommenden psychoaktiven Alkaloids Cathinon (Abb. 1).

Beschreibung Cathinone sind $\beta$-Keto-Analoga der entsprechenden Phenylethylamine, z. B. Cathinon von Amphetamin oder Cathin, Methcathinon von Methamphetamin etc.
Synthetische Cathinone kamen in den letzten 10 Jahren in Form vielfältiger ring- und/oder N-substituierter, ggf. zusätzlich im Alkylteil verzweigter Verbindungen wegen ihrer sympathomimetischen, vor allem stimulierenden, Wirkung als Ersatz oder Ergänzung für die dem Betäubungsmittelgesetz unterstellten $>$ Amphetamine und $>$ Kokain als sog. Legal Highs auf den Drogenmarkt. Dabei werden diese zumeist als „Badesalz“, „Pflanzennahrung“ oder „Forschungschemikalie" deklariert gehandelt.

Das erste bekannt gewordene synthetische Cathinon war Methcathinon (syn. $\beta$-Keto-Methamphetamin oder Ephedron, ein $\beta$-Keto-Analogon des natürlich in Pflanzen der Gattung Ephedra L. vorkommenden Alkaloids Ephedrin). Synthetische Cathinone wurden in Europa erstmals im Jahr 2004 nachgewiesen, seitdem wurden 103 neue Cathinone entdeckt, davon allein $26 \mathrm{im}$ Jahr 2015. Ergänzt man diese Zahlen um die zwischen 2009-2015 zusätzlich neu registrierten 58 Phenylethylamine, wird die Bedeutung stimulierender Verbindungen und die Dynamik der aktuellen Drogenszene deutlich. Zurzeit bilden allein die Cathinone nach den natürlichen und synthetischen Cannabinoiden die zweitgrößte Gruppe der von der EMCDDA (s. Literatur) in Europa beobachteten Substanzen.

Identifizierung, Nachweis und Bestimmung von Cathinonen werden erschwert durch das Vorkommen von Stellungsisomeren, z. B. 2-Methylmethcathinon, 3-Methylmethcathinon und 4-Methylmethcathinon (syn. Mephedron) und durch die Existenz von Stereoisomeren, z. B. (S)-(-)-Cathinon und $R$-(+)-Cathinon mit z. T. sehr ähnlichen, die Analytik erschwerenden, chemischen Eigenschaften, aber auch sehr unterschiedlichen pharmakologischen Potenzialen.

Die verschiedenen Cathinone ähneln in ihren Wirkungen jenen des Amphetamins als indirekt wirkende zentralnervale Stimulanzien. Da das pharmakologische Potenzial und die Gesundheitsrisiken für die meisten Cathinone nicht oder kaum bekannt sind, kommt es immer wieder zu ,unerwünschten Zwischenfällen". So wurden z. B. von der EMCDDA bis November 2015 in Europa 200 akute Vergiftungen und 100 Todesfälle in Verbindung mit dem Cathinon alpha-PVP (alpha-Pyrrolidinopentiophenon) gebracht.

Dem pharmakologischen Potenzial entsprechen die Konsummengen der Cathinone. Sie variieren zwischen 100-250 mg je eingenommener (mitunter geschnupfter) Dosis für 4-Methylmethcathinon und 5-10 mg für die lipophileren und deshalb die Blut-Hirn-Schranke noch besser überwindenden Pyrrolidinderivate, wie z. B. 3,4-Methylendioxypyrovaleron (MDPV).

Der Nachweis in biologischen Matrices erfolgt mit GC-MS oder LC-MS/MS ggf. mit hochauflösender Massenspektrometrie, aber derzeit zumeist noch ohne Trennung von Stereoisomeren.

Der Markt für Cathinone zeigt sich weiterhin variabel und dynamisch. Aktuelle Informationen zu Sicherstellungen 
<smiles>CNC(C)C(=O)c1ccccc1</smiles>

Cathinon<smiles>[R4]CC([R5])(C(=O)c1ccc([R3])cc1)N([R])[R]</smiles>

Allgemeine Strukturformel für Cathinone

R1: H, Alkyl, Pyrrolidino

R2: H, Alkyl, Pyrrolidino

R3: H, Alkyl, Methoxy, Methylendioxy Halogen

R4: H, Alkyl

R5: H, Alkyl<smiles>CNC(C)C(=O)c1ccccc1</smiles>

Methcathinon<smiles>CNC(C)C(=O)c1ccc(C)cc1</smiles><smiles>CCCC(C(=O)c1ccc2c(c1)OCO2)N1CCCC1</smiles>

3,4-Methylendioxypyrovaleron (MDPV) neuer Substanzen finden sich unter der Webseite der EMCDDA (www.emcdda.europa.eu).

In den letzten Jahren wurden verschiedene Cathinone über Betäubungsmittelrechts-Änderungsverordnungen

(BtMÄndV) dem Betäubungsmittelgesetz (BtmG) unterstellt. Einzelheiten hierzu finden sich unter BfArM 2017.

Am 21. November 2016 wurde ein „Gesetz zur Bekämpfung der Verbreitung neuer psychoaktiver Stoffe (Neuepsychoaktive-Stoffe-Gesetz, NpSG)“ erlassen, das im Unterschied zum einzelstofflichen Ansatz des BtmG eine Stoffgruppenregelung beinhaltet und dadurch z. B. den Umgang mit vom Phenylethylamin abgeleiteten Verbindungen einschließlich der Cathinone unter Strafe stellen kann.

\section{Literatur}

BfArM (2017) Betäubungsmittel. http://www.bfarm.de/DE/Bundesopi umstelle/Betaeubungsmittel/_node.html. Zugegriffen am 04.07.2017

Europäische Beobachtungsstelle für Drogen und Drogensucht (2016) Europäischer Drogenbericht 2016: Trends und Entwicklungen. Amt für Veröffentlichungen der Europäischen Union, Luxemburg unter http://www.emcdda.europa.eu. Zugegriffen am 03.01.2017

http://www.emcdda.europa.eu/publications/drug-profiles/synthetic-cath inones/de. Zugegriffen am 03.07.2017

\section{CBG}

- Transkortin

\section{CBP-35}

- Galectin-3

\section{C3/C4b-Rezeptor}

- Knops-Blutgruppensystem

\section{CCK}

Cholecystokinin 


\section{CCP-Antikörper}

Autoantikörper gegen citrullinierte Peptide

\section{Cd}

$>$ Cadmium

\section{CD3}

H. Renz und B. Gierten

Synonym(e) Komplex aus: CD $3 \delta, C D 3 \gamma, C D 3 \varepsilon ;$ T3-Lymphozyt

Englischer Begriff T3 lymphocyte; T3 cell

Definition $\mathrm{CD}^{+}$-Zellen sind durch den exprimierten Oberflächenmarker $\mathrm{CD} 3$ charakterisiert.

Synthese - Verteilung - Abbau - Elimination CD3 ist auf der Oberfläche von T-Lymphozyten in enger Nähe zum TZell-Rezeptor (TCR) nachweisbar. Die Nomenklatur des CD3-TCR-Komplexes baut aufeinander auf: Die Proteinketten werden fortlaufend mit $\alpha-\varepsilon$ bezeichnet. $\alpha$ - und $\beta$-Kette bilden einen extrazellulären Teil des TCR. $\gamma-, \delta$ - und $\varepsilon$-Kette gehören als akzessorische Ketten zu CD3. Die $\zeta$-Kette stellt eine intrazelluläre Komponente des Komplexes dar.

Funktion - Pathophysiologie CD3-kodierende Gene werden auch für Expression und Signaltransduktion des TCR benötigt.

Untersuchungsmaterial-Entnahmebedingungen $>\mathrm{CD} 4$

Analytik $>$ Durchflusszytometrie

Konventionelle Einheit $\mathrm{CD}^{+}$-Zellen in \% und Anzahl der Lymphozyten $/ \mu \mathrm{L}$.

\section{Referenzbereich - Erwachsene}

$\mathrm{CD}^{+}(\%)$

$55-83$
$\mathrm{CD}^{+}($Zellen $/ \mu \mathrm{L})$ $700-1200$

\section{Referenzbereich - Kinder}

\begin{tabular}{|l|l|l|}
\hline Alter & $\mathrm{CD}^{+}(\%)$ & $\mathrm{CD}^{+}($Zellen$/ \mu \mathrm{L})$ \\
\hline Neugeborene & $28-76$ & $600-5000$ \\
\hline 1 Woche -2 Monate & $60-85$ & $2300-7000$ \\
\hline 2-5 Monate & $48-75$ & $2300-6500$ \\
\hline 5-9 Monate & $50-77$ & $2400-6900$ \\
\hline 9-15 Monate & $54-76$ & $1600-6700$ \\
\hline 15-24 Monate & $39-73$ & $1400-8000$ \\
\hline 2-5 Jahre & $43-76$ & $900-4500$ \\
\hline 5-10 Jahre & $55-78$ & $700-4200$ \\
\hline 10-16 Jahre & $52-78$ & $800-3500$ \\
\hline
\end{tabular}

Indikation $>\mathrm{CD} 4$

\section{Literatur}

Janeway CA et al (2001) Immunobiology: the immune system in health and disease, 5. Aufl. Churchill Livingstone, London, S 196

Klein J, Horejsi V (1997) Immunology, 2. Aufl. Blackwell Sciences, Oxford, S 193-195

\section{$\mathrm{CD}^{+}$-Zellen im Liquor cerebrospinalis} (CSF)

- Liquor-CD3-T-Lymphozyten

\section{$\mathrm{CD}^{+} 4^{+}$-Zellen im Liquor cerebrospinalis (CSF)}

- Liquor-CD4-T-(Helfer)-Lymphozyten

\section{$\mathrm{CD}^{+} 8^{+}$Zellen im Liquor \\ cerebrospinalis (CSF)}

- Liquor-CD8-T-(Suppressor)-Lymphozyten

\section{CD4}

H. Renz und B. Gierten

Synonym(e) T4-Helfer-Zelle; T4-Lymphozyt

Englischer Begriff T4 lymphocyte; T4 helper cell 
Definition $\mathrm{CD}^{+}$-Zellen sind durch den exprimierten Oberflächenmarker CD4 charakterisiert.

Synthese - Verteilung - Abbau - Elimination CD4 wird hauptsächlich von Lymphozyten exprimiert, ist jedoch auch in geringerer Dichte beispielsweise auf Monozyten nachweisbar.

$\mathrm{CD}^{+}$-Lymphozyten werden wie alle Lymphozyten im Knochenmark produziert. Sie reifen im Thymus heran (T-Lymphozyten) und produzieren neben verschiedenen Rezeptoren, die für ihre physiologischen Aufgaben verantwortlich sind, auch zahlreiche Zytokine. Mit den genetischen Informationen für Immunglobuline werden T-Zell-Rezeptoren produziert, die zur Erkennung von Peptidantigenen auf der Zelloberfläche exprimiert werden.

Funktion - Pathophysiologie Naive $\mathrm{CD}^{+}$-Lymphozyten reifen nach Antigenkontakt unter dem Einfluss der von antigenpräsentierenden Zellen (APC) freigesetzten Zytokine $\mathrm{zu}$ Effektor-T-Helfer-Zellen heran, die sowohl die humorale wie auch die zelluläre Immunreaktion beeinflussen. Diese Reifung findet in Lymphknoten und Milz statt. CD4 ${ }^{+}$-Lymphozyten erkennen vorwiegend auf MHC-II-Molekülen präsentierte Peptidantigene. Durch verschiedene kostimulatorische Moleküle und Transkriptionsfaktoren der APC differenzieren sie zu Effektor-T-Zellen, die unterschiedliche Zytokinprofile haben: Th1 und Th2-Zellen.

Th1-Zellen erkennen vorwiegend von $>$ Makrophagen präsentierte Antigene. Ihre Hauptfunktion besteht in der Aktivierung der Makrophagen und damit der Verstärkung der zellvermittelten Immunität durch Produktion von IL-2, Interferon- $\gamma$ und TNF- $\alpha$. Die freigesetzten Zytokine fördern Proliferation und Differenzierung von CD8-Lymphozyten zu zytotoxischen T-Zellen und NK-Zellen, erhöhen die Zellteilungsrate von $\mathrm{CD}^{+}$-Zellen, stimulieren die Produktion opsonisierender und komplementaktivierender Immunglobuline durch Plasmazellen und funktionieren als chemotaktische Agenzien ( $\triangleright$ Chemotaktische Aktivität) für phagozytierende Zellen. Pathophysiologische Beispiele für Th1-vermittelte Abwehrreaktionen sind Lepra tuberculosa, lokale Leishmaniose, Sarkoidose, Kontaktdermatitis, Typ-I-Diabetes oder Hashimoto-Thyreoiditis.

Th2-Lymphozyten erkennen $>$ Antigene, die von B-Zellen präsentiert werden. Sie produzieren Zytokine wie IL-2, IL-4, IL-5, IL-10 und IL-13. Diese Zytokine beeinflussen über Aktivierung und Proliferation von B-Zellen zu immunglobulinproduzierenden Plasmazellen und den Klassenswitch ( $\operatorname{IgE} / \operatorname{IgA})$ der produzierten Immunglobuline den humoralen Arm des Immunsystems. Andere Effektorzellen sind Eosinophile und Mastzellen. Als Beispiel für überwiegend Th2vermittelte Abwehrreaktionen kann neben den klinischen Formen der Typ-I-Allergie vor allem die Abwehr von Parasiten angesehen werden.
Untersuchungsmaterial - Entnahmebedingungen Heparinblut, EDTA-Blut.

Probenstabilität 1,24 Stunden bei Raumtemperatur.

Analytik $>$ Durchflusszytometrie

Konventionelle Einheit $\mathrm{CD}^{+}-/ \mathrm{CD}^{+}$-Zellen in \% der Gesamtzahl an $\mathrm{CD}^{+}-$Zellen, Anzahl $\mathrm{CD}^{+}{ }^{+} / \mathrm{CD}^{+}{ }^{+}$-Zellen $/ \mu \mathrm{L}$.

\section{Referenzbereich - Erwachsene}

\begin{tabular}{|l|l|}
\hline $\mathrm{CD}^{+} / \mathrm{CD}^{+}(\%)$ & $\mathrm{CD}^{+} / \mathrm{CD}^{+}($Zellen$/ \mu \mathrm{L})$ \\
\hline $28-57$ & $300-1400$
\end{tabular}

\section{Referenzbereich - Kinder}

\begin{tabular}{|l|l|r|}
\hline Alter & $\mathrm{CD}^{+} / \mathrm{CD}^{+}(\%)$ & $\mathrm{CD}^{+} / \mathrm{CD}^{+}($Zellen$/ \mu \mathrm{L})$ \\
\hline Neugeborene & $17-52$ & $400-3500$ \\
\hline 1 Woche -2 Monate & $41-68$ & $1700-5300$ \\
\hline 2-5 Monate & $33-58$ & $1500-5000$ \\
\hline 5-9 Monate & $33-58$ & $1400-5100$ \\
\hline 9-15 Monate & $31-54$ & $1000-4600$ \\
\hline 15-24 Monate & $25-50$ & $900-5500$ \\
\hline 2-5 Jahre & $23-48$ & $500-2400$ \\
\hline 5-10 Jahre & $27-53$ & $300-2000$ \\
\hline 10-16 Jahre & $25-48$ & $300-1400$
\end{tabular}

\section{Indikation}

- Verdacht auf primäre Immundefekte

- Diagnose und Verlaufsbeobachtung von sekundären Immundefekten (HIV-Infektion, z. T. Malignom)

- Lymphozytopenie

- Lymphozytose (Diagnostik lymphoproliferativer Erkrankungen)

- Diagnostik und Therapiemonitoring von persistierenden Virusinfektionen (v. a. CMV, EBV, HBV, HCV, HHV-6)

- Monitoring von Patienten unter immunsuppressiver oder immunstimulierender Behandlung (Transplantatempfänger, Tumorpatienten)

Interpretation Bei der Interpretation der Durchflusszytometrieergebnisse von Lymphozytensubpopulationen müssen sowohl die Prozent- als auch die Absolutzahlen berücksichtigt werden. Wichtig bei einer Diagnosestellung sind auch anamnestische Angaben. $\mathrm{Zu}$ bedenken ist außerdem, dass die durchflusszytometrische Analyse keine Auskunft über die Funktionsfähigkeit der verschiedenen Zellpopulationen gibt, da numerisch unauffällige Lymphozytenpopulationen einen funktionellen Immundefekt nicht ausschließen. In bestimmten Fällen sollten zelluläre Funktionsteste durchgeführt werden. 
Ein Anstieg der $\mathrm{CD}^{+}$-T-Lymphozyten kann als Frühzeichen einer immunologischen Aktivierung (auch bei Koaktivierung im Rahmen bakterieller Infekte) gewertet werden. Weiterhin wurden erhöhte Werte von $\mathrm{CD} 4^{+}$-Zellen bei SezarySyndrom und anderen T-Zell-Leukämien sowie (nicht obligat) bei Sarkoidose, multipler Sklerose, Leberzirrhose, rheumatoiden Erkrankungen und Typ-I-Diabetes beobachtet. Erniedrigte Werte findet man in der Spätphase systemischer Virusinfektionen, chronisch persistierenden Virusinfekten (CMV, EBV u. a.) sowie bei HIV-Infektion, Leukämien, Tumorerkrankungen und nach längerer therapeutischer Immunsuppression.

Diagnostische Wertigkeit Die durchflusszytometrische Analyse von Lymphozytensubpopulationen ist ein inzwischen gut standardisierter Test, der insbesondere gut für Verlaufsbeobachtungen bestimmter Erkrankungen und zur Therapiekontrolle einer Immunsuppression geeignet ist.

\section{Literatur}

Comans-Bitter WM, de Groot R, von den Beemd R et al (1997) Immunophenotyping of blood lymphocytes in childhood. J Pediatrics 130:388-393

Peter HH, Pichler WJ (1996) Klinische Immunologie, 2. Aufl. Urban \& Schwarzenberg, München, S $242 \mathrm{f}$

www.immune-monitoring.de

\section{CD8}

H. Renz und B. Gierten

Synonym(e) $C D 8^{+}$-Lymphozyt; T8-Lymphozyt

Englischer Begriff T8 lymphocyte; cytotoxic T lymphocyte; $\mathrm{CD} 8^{+}$lymphocyte

Definition $\mathrm{CD}^{+}$-Zellen sind durch den exprimierten Oberflächenmarker CD8 charakterisiert.

Synthese - Verteilung - Abbau - Elimination $>$ CD4

Funktion - Pathophysiologie Ebenso wie $\mathrm{CD}^{+}$-Lymphozyten reifen $\mathrm{CD} 8^{+}$-Zellen zu $\mathrm{CD} 8^{+}$-Effektorzellen unter Einfluss der Zytokine von APC ( $\triangleright$ Antigenpräsentierende Zelle) und T-Helfer-Zellen. Die CD8 ${ }^{+}$-Effektorzellen werden bezugnehmend auf ihre physiologischen Effekte als zytotoxische und Suppressor-T-Zellen bezeichnet. Sie sind die
Effektorzellen bei der Abwehr von Viren, intrazellulären Bakterien und Tumorzellen. $\mathrm{CD} 8^{+}$-Zellen erkennen $>$Antigene, die an MHC-I-Molekülen auf APC gebunden sind und zerstören sie, indem sie deren Apoptose einleiten. Sie exprimieren analog den $\mathrm{CD}^{+}{ }^{+}$-T-Zellen die entsprechenden Zytokinmuster von Th1- und Th2-Zellen.

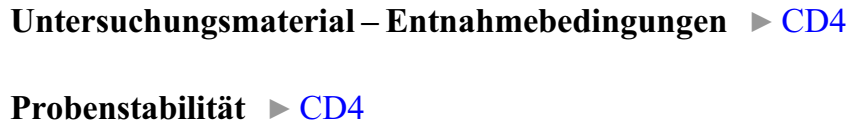

Konventionelle Einheit $\mathrm{CD}^{+}-/ \mathrm{CD} 8^{+}$-Zellen in \% der Gesamtzahl an CD3-Zellen, Anzahl CD3 ${ }^{+}-/ \mathrm{CD}^{+}$-Zellen/ $\mu \mathrm{L}$.

\section{Referenzbereich - Erwachsene}

\begin{tabular}{|l|l}
\hline $\mathrm{CD}^{+} / \mathrm{CD}^{+}(\%)$ & $\mathrm{CD}^{+} / \mathrm{CD}^{+}($Zellen$/ \mu \mathrm{L})$ \\
\hline $10-39$ & $200-900$
\end{tabular}

\section{Referenzbereich - Kinder}

\begin{tabular}{|l|l|l|}
\hline Alter & $\mathrm{CD}^{+} / \mathrm{CD}^{+}(\%)$ & $\mathrm{CD}^{+} / \mathrm{CD}^{+}($Zellen$/ \mu \mathrm{L})$ \\
\hline Neugeborene & $10-41$ & $200-1900$ \\
\hline 1 Woche -2 Monate & $9-23$ & $400-1700$ \\
\hline 2-5 Monate & $11-25$ & $500-1600$ \\
\hline 5-9 Monate & $13-26$ & $600-2200$ \\
\hline 9-15 Monate & $12-28$ & $400-2100$ \\
\hline 15-24 Monate & $11-32$ & $400-2300$ \\
\hline 2-5 Jahre & $14-33$ & $300-1600$ \\
\hline 5-10 Jahre & $19-34$ & $300-1800$ \\
\hline 10-16 Jahre & $9-35$ & $200-1200$ \\
\hline
\end{tabular}

Indikation $>\mathrm{CD} 4$

\section{Interpretation $>\mathrm{CD} 4$}

Erhöhte Zahlen von $\mathrm{CD} 8^{+}$-T-Zellen findet man bei akuten systemischen Virusinfektionen, chronisch aktiven Virusinfektionen (HBV, HCV, CMV, EBV), in der Frühphase einer HIV-Infektion, bei multiplem Myelom, aber auch bei Stress (Blutentnahme, besonders bei Kindern!).

Eine verminderte Anzahl von Suppressor- und Helferzellen wird in der Spätphase der HIV-Infektion (CD4/CD8-Ratio!), in Zusammenhang mit verschiedenen Leukämien und Tumoren sowie nach länger andauernder therapeutischer Immunsuppression und Chemo-/Strahlentherapie nachgewiesen.

\section{Diagnostische Wertigkeit $>$ CD4}




\section{Literatur}

Comans-Bitter WM, de Groot R, von den Beemd R et al (1997) Immunophenotying of blood lymphocytes in childhood. J Pediatr 130:388-393

Peter H-H, Pichler WJ (1996) Klinische Immunologie, 2. Aufl. Urban \& Schwarzenberg, München, S $242 \mathrm{f}$

www.immune-monitoring.de

CD8 ${ }^{+}$-Lymphozyt

$\checkmark \mathrm{CD} 8$

CD14

H. Renz und B. Gierten

Definition Rezeptor für Lipopolysaccharide (LPS).

Struktur Membranprotein aus 356 Aminosäuren.

Molmasse $53-55 \mathrm{kDa}$ (Monozyten).

Synthese - Verteilung - Abbau - Elimination Zellständiges CD14 wird vorwiegend auf $\triangleright$ Monozyten und in geringerem Maße auf neutrophilen Granulozyten und den meisten Gewebsmakrophagen exprimiert.

Funktion - Pathophysiologie CD14 bindet LPS. Der Vorgang wird durch vorherige Bindung von LPS an LBP erleichtert. Die Bindung aktiviert die Monozyten und Neutrophilen zur verstärkten Expression von Oberflächenmolekülen (z. B. Adhäsionsmoleküle) und Freisetzung von Zytokinen (z. B. TNF- $\alpha$ ).

Untersuchungsmaterial - Entnahmebedingungen Heparinblut, EDTA-Blut.

Probenstabilität Nach Entnahme bei $4{ }^{\circ} \mathrm{C}$ (in Eiswasser) lagern, um die In-vitro-Aktivierung der Monozyten zu vermeiden.

Analytik $>$ Durchflusszytometrie
Referenzbereich - Erwachsene $>$ Monozyten

Referenzbereich - Kinder $\vee$ Monozyten

Literatur

www.ncbi.nlm.nih.gov

CD14, lösliches

H. Renz und B. Gierten

Synonym(e) LPS-Rezeptor

Englischer Begriff LPS receptor; LPS-R

Definition Lipopolysaccharid(LPS)-Rezeptor.

Molmasse ca. $48 \mathrm{kDa}$.

Funktion - Pathophysiologie Der Komplex aus löslichem CD14 und LPS kann Zellen stimulieren, die anders als - Monozyten/ $\triangleright$ Makrophagen kein membrangebundenes CD14 exprimieren (z. B. Endothelzellen und einige Arten epithelialer Zellen). Die Stimulation führt zu vermehrter Freisetzung von Zytokinen und Adhäsionsmolekülen.

\section{Literatur}

www.ncbi.nlm.nih.gov

CD14 ${ }^{+} 3^{-} 19^{-}$-Zellen in

Cerebrospinalflüssigkeit (CSF)

> Liquor-Monozyten

\section{CD16/56}

H. Renz und B. Gierten

Synonym(e) CTL; Natürliche Killerzellen $\left(\mathrm{CD}^{-} / \mathrm{CD} 16 / 56^{+}\right)$ 
Englischer Begriff cytotoxic $\mathrm{T}$ cells $\left(\mathrm{CD}^{+} / \mathrm{CD} 16 / 56^{+}\right)$; CTL; natural killer cells $\left(\mathrm{CD}^{-} / \mathrm{CD} 16 / 56^{+}\right)$; NK cells

Definition Zytotoxische T-Zellen sind eine Subpopulation der T-Zellen, sie tragen den T-Zell-Marker CD3 auf ihrer Zelloberfläche. Natürliche Killerzellen bilden eine Gruppe von - Lymphozyten, die anhand ihrer Oberflächenmarker nicht in die Gruppe der B- und T-Lymphozyten eingeordnet werden können. Zytotoxische T-Zellen oder natürliche Killerzellen sind CD16- und/oder CD56-positiv. Funktionell gehören sie zum angeborenen sowie zum erworbenen Immunsystem.

Funktion - Pathophysiologie. Zytotoxische T-Zellen: $\triangleright$ CD8. Natürliche Killerzellen gehören zur Gruppe zytolytischer Lymphozyten. Sie sind Teil des angeborenen sowie des erworbenen Immunsystems. Ihnen fehlen jedoch die für Boder T-Lymphozyten typischen Oberflächenrezeptoren CD19 und CD3. Für die Lyse virusinfizierter oder maligne transformierter körpereigener Zellen stehen ihnen 2 Mechanismen zur Verfügung:

- Sie können die Lyse einer Zielzelle über die antikörpervermittelte zelluläre Zytotoxizität (,,antibody-dependant cellular cytotoxicity“, ADCC) auslösen. Voraussetzung hierfür ist die Bindung von Immunglobulinen (Fab-Fragment) an die Zielzelle. NK-Zellen besitzen Fc-Rezeptoren, die die freiliegenden Fc-Teile der gebundenen $\triangleright$ Antikörper binden. Die NK-Zelle kann so in engen Kontakt mit der Zielzelle treten; die von der NK-Zelle ausgeschütteten Mediatoren (Perforine, proteolytische $>$ Enzyme und - Chemokine) lösen die Apoptose der Zielzelle aus.

- Der zweite mögliche Mechanismus wird durch stressinduzierte Expression bestimmter Kombinationen von Oberflächenmolekülen (MICA, MICB) auf der Zielzelle ausgelöst. Einer der NK-Zell-Rezeptoren (,killer activation receptor") erkennt diese Moleküle und versucht, Apoptose auszulösen. Exprimiert diese Zelle gleichzeitig einen zweiten, MHC-I-Moleküle erkennenden Rezeptor (,killer inhibitory receptor"), wird auf der NK-Zelle ein anderer Rezeptor (,killer inhibitor receptor“) aktiviert, dessen Signal das des „killer activation receptor“ überwiegt. Dieser Mechanismus trägt auch zur Erkennung von körperfremd und -eigen bei. Viren und maligne Transformation somatischer Zellen unterdrücken in einigen Fällen die Expression von MHC-I-Molekülen, weshalb diese Zellen von NK-Zellen lysiert werden können.

Untersuchungsmaterial- Entnahmebedingungen $>\mathrm{CD} 4$
Analytik > Durchflusszytometrie

\section{Konventionelle Einheit}

- $\left(\mathrm{CD}^{+} / \mathrm{CD} 16 / 56^{+}\right)$in $\%$ der Gesamtlymphozyten

- $\left(\mathrm{CD} 3^{-} / \mathrm{CD} 16 / 56^{+}\right)$in \% der Gesamtlymphozyten

\section{Referenzbereich - Erwachsene}

\begin{tabular}{l|ll|l|}
\hline NK-Zellen & & \multicolumn{2}{l|}{ Zytotoxische T-Zellen } \\
\hline$\left(\mathrm{CD} 3^{-} /\right.$ & & $\left(\mathrm{CD}^{+} /\right.$ & \\
$\left.\mathrm{CD} 16 / 56^{+}\right)$ & $\left(\mathrm{CD} 3^{-} / \mathrm{CD} 16 /\right.$ & $\left.\mathrm{CD} 16 / 56^{+}\right)$ & $\left(\mathrm{CD}^{+} / \mathrm{CD} 16 /\right.$ \\
$(\%)$ & $\left.56^{+}\right)($Zellen$/ \mu \mathrm{L})$ & $(\%)$ & $\left.56^{+}\right)($Zellen$/ \mu \mathrm{L})$ \\
\hline $7-31$ & $90-600$ & $2-10$ & $32-360$
\end{tabular}

\section{Referenzbereich - Kinder}

\begin{tabular}{|l|l|l|}
\hline Alter & $\begin{array}{l}\mathrm{CD}^{-} / \mathrm{CD}^{\circ} / 56^{+} \\
(\%)\end{array}$ & $\begin{array}{l}\mathrm{CD}^{-} / \mathrm{CD} 16 / 56^{+} \\
(\text {Zellen/ } \mu \mathrm{L})\end{array}$ \\
\hline Neugeborene & $6-58$ & $100-1900$ \\
\hline 1 Woche -2 Monate & $3-23$ & $200-1400$ \\
\hline 2-5 Monate & $2-14$ & $100-1300$ \\
\hline 5-9 Monate & $2-13$ & $100-1000$ \\
\hline 9-15 Monate & $3-17$ & $200-1200$ \\
\hline 15-24 Monate & $3-16$ & $100-1400$ \\
\hline 2-5 Jahre & $4-23$ & $100-1000$ \\
\hline 5-10 Jahre & $4-26$ & $90-900$ \\
\hline 10-16 Jahre & $6-27$ & $70-1200$ \\
\hline
\end{tabular}

\section{Indikation $>\mathrm{CD} 4$}

\section{Interpretation $>\mathrm{CD} 4$}

Bei der Interpretation der Durchflusszytometrieergebnisse ist zu bedenken, dass es sich nicht um funktionelle Untersuchungen handelt. Funktionelle Aspekte der NK-Zellen werden in $>$ Killing-Tests oder Zytotoxizitätsassays berücksichtigt.

Zytotoxische T-Zellen $\mathrm{CD}^{+} / \mathrm{CD} 16 / 56^{+}$werden bei akuten systemischen Virusinfektionen und HIV-Infektion in erhöhter Anzahl nachgewiesen. Sie können im Rahmen von Malignomen, sekundären Immundefekten, nach Chemo-/Strahlentherapie von Tumoren und bei chronisch persistierenden Virusinfektionen unter den Referenzwert absinken. NK-Zellen $\left(\mathrm{CD}^{-} / \mathrm{CD} 16 / 56^{+}\right)$ können außer aus den vorgenannten Ursachen auch einer ausgeprägten zirkadianen Rhythmik mit Absenkung in Abend- und Nachtstunden unterliegen.

\section{Diagnostische Wertigkeit $>$ CD4}




\section{Literatur}

Comans-Bitter WM, de Groot R, von den Beemd R et al (1997) Immunophenotying of blood lymphocytes in childhood. J Pediatr 130:388-393

Peter H-H, Pichler WJ (1996) Klinische Immunologie, 2. Aufl. Urban \& Schwarzenberg, München, S 242 f

www.immune-monitoring.de

\section{CD $16^{+} 56^{+} 3^{-}$-Zellen in CSF}

Liquor-natürliche Killerzellen

\section{CD19}

H. Renz und B. Gierten

\section{Englischer Begriff CD19}

Definition CD 19 ist ein Transmembranglykoprotein, das der Immunglobulinsuperfamilie zuzuordnen ist.

Funktion - Pathophysiologie $\triangleright$ B-Lymphozyt, APC ( $\triangleright$ Antigenpräsentierende Zelle) (follikuläre dendritische Zellen).

CD19 wird in der B-Zell-Entwicklung von den frühesten Vorstufen, die der B-Zell-Entwicklung zugeordnet werden können, bis zu B-Zell-Blasten exprimiert. Bei Reifung zu Plasmazellen geht die Expression verloren.

Untersuchungsmaterial - Entnahmebedingungen Нераrinblut.

Analytik $>$ Durchflusszytometrie

Konventionelle Einheit CD19 in \% der Gesamtlymphozyten, Anzahl CD19 ${ }^{+}$-Zellen $/ \mu \mathrm{L}$.

\section{Referenzbereich - Erwachsene}

\begin{tabular}{l|l}
\hline $\mathrm{CD} 19^{+}(\%)$ & $\mathrm{CD} 19^{+}($Zellen$/ \mu \mathrm{L})$ \\
\hline $6-19$ & $100-500$
\end{tabular}

\section{Referenzbereich - Kinder}

\begin{tabular}{|l|l|l|}
\hline Alter & $\mathrm{CD}^{+} 9^{+}(\%)$ & $\mathrm{CD} 19^{+}($Zellen$/ \mu \mathrm{l})$ \\
\hline Neugeborene & $5-22$ & $40-1100$ \\
\hline 1 Woche -2 Monate & $4-26$ & $600-1900$ \\
\hline $2-5$ Monate & $14-39$ & $600-3000$ \\
& & (Fortsetzung)
\end{tabular}

\begin{tabular}{|l|l|l|}
\hline Alter & $\mathrm{CD}^{+}(\%)$ & $\mathrm{CD}^{+} 9^{+}($Zellen$/ \mu \mathrm{l})$ \\
\hline 5-9 Monate & $13-35$ & $700-2500$ \\
\hline 9-15 Monate & $15-39$ & $600-2700$ \\
\hline 15-24 Monate & $17-41$ & $600-3100$ \\
\hline 2-5 Jahre & $14-44$ & $200-2100$ \\
\hline 5-10 Jahre & $10-31$ & $200-1600$ \\
\hline 10-16 Jahre & $8-24$ & $100-600$
\end{tabular}

\section{Literatur}

Klein J, Horejsi V (1997) Immunology, 2. Aufl. Blackwell Sciences, Oxford, S 484-485

www.immune-monitoring.de

$\mathrm{CD}^{+}{ }^{+} 3^{-}$Zellen im Liquor cerebrospinalis (CSF)

- Liquor-B-Lymphozyten (CD19-B-Zellen)

\section{CD25}

H. Renz und B. Gierten

Synonym(e) IL-2-Rezeptor; Tac-Antigen

Englischer Begriff CD25; IL-2 receptor ( $\alpha$ chain); IL-2R; tac antigen

Definition Oberflächenmarker, der vorwiegend von aktivierten T- und B-Lymphozyten sowie $\triangleright$ Monozyten/ $\triangleright$ Makrophagen exprimiert wird.

Struktur Transmembranrezeptor.

Molmasse $55 \mathrm{kDa}$.

Synthese - Verteilung - Abbau - Elimination $>$ Interleukin-2-Rezeptor, löslicher

Funktion - Pathophysiologie - Interleukin-2-Rezeptor, löslicher

Analytik > Durchflusszytometrie

Literatur

www.ncbi.nlm.nih.gov 


\section{CD25, lösliches}

- Interleukin-2-Rezeptor, löslicher

\section{CD35}

- Knops-Blutgruppensystem

\section{CD44}

$\checkmark$ Hyaluronan-Rezeptor

- Indian-(IN-)Blutgruppensystem

\section{CD44, ISBT Collection 203}

- Indian-(IN-)Blutgruppensystem

\section{CD45}

H. Renz und B. Gierten

Englischer Begriff leukocyte common antigen; LCA; EC 3.1.3.4; CD45R; CD45RA; CD45RB; CD45RC; CD45RO; $\mathrm{T} 200$

Definition CD45 ist eine Tyrosinphosphatase, die als Transmembranmolekül auf der Zelloberfläche von $>$ Leukozyten lokalisiert ist.

Synthese - Verteilung - Abbau - Elimination CD45 wird von allen hämatopoetischen Zellen und Leukozyten in großen Mengen exprimiert („,common leukocyte antigen“). Hervorstechend sind hämatopoetische Zellen und $>$ Lymphozyten. Als Molekül stellt es eine der Hauptkomponenten der Glykokalyx dar. Durch alternatives Splicing von Exon 4, 5 und 6 entstehen verschiedene Isoformen von CD45. CD45RA ist vorwiegend auf naiven T-Zellen und medullären Thymozyten nachweisbar, während die Splice-Variante CD45RB vom
Gedächtnis-T-Zellen und kortikalen Thymozyten produziert wird. Ein Zellklon exprimiert mehrere Isoformen gleichzeitig und verändert deren Anteil unter Zytokineinfluss.

Funktion - Pathophysiologie Die CD45-Moleküle stellen einen wichtigen Anteil bei der rezeptorvermittelten Aktivierung von B- und T-Zellen, aber auch anderer Leukozyten dar.

Untersuchungsmaterial-Entnahmebedingungen $>\mathrm{CD} 4$

Analytik $>$ Durchflusszytometrie

Referenzbereich Ein gültiger Referenzbereich sollte im individuellen Ergebnisbericht enthalten sein.

\section{Literatur}

www.ncbi.nlm.nih.gov

\section{CD55}

- Cromer-Blutgruppensystem

\section{CD66a}

- Glykoprotein, biliäres

\section{CD69}

H. Renz und B. Gierten

Englischer Begriff activation inducer molecule (AIM); EA 1; MLR3; gp34/28; very early activation (VEA)

Definition Homodimeres, durch Disulfidbrücken verbundenes Membranprotein.

Molmasse ca. $22 \mathrm{kDa}$.

Synthese - Verteilung - Abbau - Elimination CD69 wird von aktivierten T-Zellen, Thymozyten, B-Zellen, NK-Zellen, 
Neutrophilen ( $\triangleright$ Granulozytopoese, neutrophile) und Eosinophilen ( $\triangleright$ Granulozyten, eosinophile) exprimiert. Konstitutiv ist CD69 auf der Oberfläche bestimmter Subtypen von Thymozyten und B-Zellen sowie von > CD4-Zellen in Lymphknoten, Thrombozyten und epidermalen LangerhansZellen nachweisbar.

Funktion - Pathophysiologie CD69 dient als Rezeptor zur Signaltransmission in vielen Zelltypen (aktivierte Leukozyten wie T-Zellen, Thymozyten, B-Zellen, NK-Zellen, Neutrophile und Eosinophile). Konstitutiv wird CD69 auf bestimmten Subtypen von Thymozyten und B-Zellen sowie von $\mathrm{CD}^{+}$-Zellen in Lymphknoten, Thrombozyten und epidermalen Langerhans-Zellen exprimiert. Besonders wichtig ist CD69 im Rahmen der frühen Aktivierungsphase vom Lymphozyten, Monozyten und Thrombozyten. In Lymphozyten führt die Expression von CD69 zu erhöhtem Calciumeinstrom, Synthese verschiedener Zytokine und deren Rezeptoren und zur Induktion der Expression von Protoonkogenen.

Analytik $>$ Durchflusszytometrie

Referenzbereich Ein gültiger Referenzbereich sollte im individuellen Ergebnisbericht enthalten sein.

\section{Literatur}

www.ncbi.nlm.nih.gov

\section{CD71}

H. Renz und B. Gierten

Synonym(e) T9; Transferrinrezeptor

Englischer Begriff Transferrin receptor protein

Definition Oberflächenbindungsmolekül für Transferrin, das die Aufnahme von Transferrin in die Zelle vermittelt.

Struktur Homodimeres Transmembranmolekül (ca. 760 AS).

Synthese - Verteilung - Abbau - Elimination Expression auf allen proliferierenden Zellen.

Funktion - Pathophysiologie CD71 wird neben erythropoetischen Zellen und $>$ Retikulozyt auch in hoher Dichte von allen anderen proliferierenden Zellen exprimiert.
Eisenbeladene Transferrinmoleküle binden bei neutralem pH-Wert $(7,4)$ an CD71, sie werden zusammen in die Zelle transferiert (internalisiert). Bei einem intrazellulären $\mathrm{pH}$ von ca. 5 verliert Transferrin die Affinität zum gebundenen Eisen. Das $>$ Eisen wird freigesetzt und über noch nicht vollständig verstandene Vorgänge in das Zytoplasma transportiert. Das nun freie Transferrinmolekül wird danach zur Zelloberfläche transportiert und wieder vom CD71 gelöst, sodass es zu erneuter Aufnahme von Eisen zur Verfügung steht.

Analytik > Durchflusszytometrie

Referenzbereich Ein gültiger Referenzbereich sollte im individuellen Ergebnisbericht enthalten sein.

\section{Literatur}

Derek K. Marsee, Geraldine S. Pinkus, Hongbo Yu (2010) CD71 (Transferrin Receptor). American Journal of Clinical Pathology 134(3):429-435

Klein J, Horejsi V (1997) Immunology, 2. Aufl. Blackwell Sciences, Oxford, S 466-468

\section{CD95}

Fas-Rezeptor

\section{CD95-Ligand}

- Fas-Ligand

CD95-Rezeptor

- Fas-Rezeptor

\section{CD142}

Tissue Factor 


\section{CD169}

$>$ Siglec-1

\section{CD238}

- Kell-Blutgruppensystem

\section{CD297}

> Dombrock-(DO-)Blutgruppensystem

\section{C3D-Beladung}

K. Kleesiek, C. Götting, J. Diekmann, J. Dreier und M. Schmidt

Synonym(e) Komplementbeladung

Englischer Begriff C3D on erythrocytes

Definition Nachweis des Komplementprodukts C3D auf - Erythrozyten im direkten Antihumanglobulintest (CoombsTest).

Beschreibung Das Komplementsystem ist ein komplexes System unterschiedlicher Proteasen, Rezeptoren und Regulatorproteine, das nach kaskadischer Aktivierung zur Ausbildung des lytischen Komplexes und zur Membranlyse von Zellen führen kann. Auslöser des klassischen Wegs der Komplementaktivierung ist die Bindung des Proteins $\mathrm{C} 1 \mathrm{q}$ an Antikörper, die z. B. an Erythrozyten gebunden vorliegen. Dieses führt über eine Reihe von Zwischenstufen zur Ausbildung des lytischen Komplexes, der eine Zerstörung der Zellmembran und folglich eine Hämolyse bewirkt. Stoppt die Komplementaktivierung in einem frühen Stadium (C3, C4 oder höchstens C5), dann spricht man von Komplementbindung, da die Erythrozyten mit Antikörpern und den Komplementprodukten C3, C4 oder C5 bzw. deren Zerfallsprodukten beladen sind. Die Komplementbindung wird nicht nur durch Alloantikörper, sondern auch durch Autoantikörper vermittelt, wobei C3D am häufigsten nachgewiesen wird. Der Nachweis erfolgt mit dem direkten Antihumanglobulintest (direkter Coombs-Test), mit dem Antikörper und Komplementproteine auf den Zellen des Patienten nachgewiesen werden. Mit monospezifischen Antiglobulinseren, die isoliert gegen IgG, IgM, IgA oder Komplement gerichtet sind, kann die Beladung der Patientenerythrozyten charakterisiert werden. Eine isolierte C3D-Beladung der Erythrozyten wird sowohl bei normalen Personen wie auch passager bei Infekten nachgewiesen. So zeigt etwa die Hälfte aller Malaria-infizierten Kinder eine isolierte C3D-Beladung im direkten Antihumanglobulintest. Bei 40-45 \% der Blutspender mit einem positiven direkten Coombs-Test werden isoliert eine Komplementbeladung der Erythrozyten nachgewiesen, was als eine kontinuierliche geringgradige Komplementaktivierung angesehen wird, ohne dass dieser eine klinische Relevanz oder die Präsenz von Autoantikörpern zugesprochen wird.

\section{Literatur}

Metaxas-Bühler M (1993) Blutgruppen und Transfusionsmedizin. Verlag Hans Huber, Bern/Göttingen/Toronto/Seattle

Mollison PL, Engelfriet CP (1993) Blood transfusion in clinical medicine. Blackwell Scientific Publications, London

\section{CDC-Referenzmethode}

K. J. Lackner und D. Peetz

Definition Die Centers for Disease Control and Prevention der USA beschreiben für zahlreiche Analyte Referenzmethoden und stellen teilweise auch Referenzmaterialien zur Verfügung.

\section{CDE-Nomenklatur}

K. Kleesiek, C. Götting, J. Diekmann, J. Dreier und M. Schmidt

Synonym(e) Fisher-Race-System 
Englischer Begriff CDE nomenclature; Fisher's scheme

Definition Nomenklatur zur Bezeichnung der Allele des Rhesussystems

Beschreibung Die CDE-Nomenklatur ist die am weitesten verbreitete Nomenklatur zur Beschreibung der Allele vom - Rhesus-Blutgruppensystem und wurde von Ronald Aylmer Fisher und Robert Russell Race in den Jahren 1943/44 entwickelt. Sie basierte auf der - heute korrigierten - Theorie, dass das Rhesus-System aus 3 benachbart lokalisierten Genen besteht, die jeweils die beiden Allele $\mathrm{C}$ und c, D und d sowie E und e beinhalten. Nach dieser Theorie erbt jede Person jeweils ein Set von Allelen der 3 Rhesus-Loci von jedem Elternteil (z. B. cde oder Cde). Heute ist jedoch bekannt, dass das Rhesus-System aus 2 auf dem Chromosom 1 benachbart lokalisierten Genen besteht, wobei auf dem ersten Locus das D-Allel vorhanden ist und auf dem zweiten Locus sich die Allele C und c sowie die Allele E und e wechselseitig vertreten können. Das d-Allel beschreibt hierbei einen Verlust des D-Antigens, der durch Deletionen oder Mutationen im RHDGen verursacht wird. Aufgrund der direkten Nachbarschaft der beiden Gene wird die jeweilige Allelkombination als ein Haplotyp untrennbar miteinander vererbt. Alternativ existiert noch die Nomenklatur nach Wiener, die sich an einer aus dem ursprünglichen Rhesus-Symbol abgeleiteten Schreibweise orientiert. Obwohl sich die CDE-Nomenklatur aufgrund ihrer klareren Darstellungsweise weltweit durchgesetzt hat, wird die Nomenklatur nach Wiener ebenfalls noch vereinzelt verwendet.

Entsprechungen der Allele des Rhesus_Systems in CDEund Wiener-Nomenklatur:

\begin{tabular}{l|l} 
CDE-Nomenklatur & Wiener-Nomenklatur \\
\hline cde & $\mathrm{r}$ \\
cdE & $\mathrm{r}^{\prime \prime}$ \\
cDe & $\mathrm{R}_{0}$ \\
cDE & $\mathrm{R}_{2}$ \\
Cde & $\mathrm{r}^{\prime}$ \\
CdE & $\mathrm{r}_{\mathrm{y}}$ \\
$\mathrm{CDe}$ & $\mathrm{R}_{1}$ \\
$\mathrm{CDE}$ & $\mathrm{R}_{\mathrm{z}}$ \\
\hline
\end{tabular}

\section{Literatur}

Eckstein R (2005) Immunhämatologie und Transfusionsmedizin. Urban \& Fischer, München

Mollison PL, Engelfriet CP (1993) Blood transfusion in clinical medicine. Blackwell Scientific, London

Race RR (1944) An incomplete antibody in human serum. Nature $153: 771$

\section{CDG}

G. F. Hoffmann, C.-D. Langhans und A. Schulze

Synonym(e) Angeborene Glykosylierungsstörungen

Englischer Begriff carbohydrate-deficient glycoprotein syndrome; congenital disorders of glycosylation

Definition CDG umfassen eine Gruppe von Stoffwechselerkrankungen, die durch genetische Defekte in der Synthese von Glykoproteinen oder Glykolipiden verursacht werden. Die biochemische Einteilung des CDG erfolgt in 2 Typen. Während Typ I alle Defekte bei der Bildung der Dolicholgebundenen Oligosaccharideinheiten und ihres Transfers auf die verschiedenen Proteine oder Lipide umfasst, beinhaltet Typ II Prozessierungsdefekte der Glykanseitenketten. Bisher konnten über 100 verschiedene Defekte innerhalb der N- und O-Glykosylierungswege identifiziert, lokalisiert und beschrieben werden. Tab. 1 zeigt die am häufigsten detektierten CDG-Defekte mit Schwerpunkt auf der N-Glykosylierung.

\section{Untersuchungsmaterial Serum}

Präanalytik Die Primärdiagnose erfolgt durch Auftrennung der Transferrinisoformen mittels isoelektrischer Fokussierung (IEF; s. > Isoelektrische Fokussierung) oder HPLC ( $\triangleright$ Hochleistungs-Flüssigkeitschromatographie). Mit diesen Methoden lässt sich eine unvollständige Glykosylierung des Glykoproteins > Transferrin gut darstellen. Weist das Glykosylierungsmuster des Transferrins erhöhte Di- und Asialotransferrinbanden bei gleichzeitiger Erniedrigung der Tetrasialotransferrinbande auf, liegt ein CDG Typ I (zumeist Defekt im Zytosol oder ER) vor. CDG Typ II (zumeist Defekte im Golgi) ist hingegen durch zusätzlich erhöhte Triund Monosialotransferrinbanden charakterisiert. Weiterführende Analysen zu O-Glykosylierungsstörungen (Mucintyp) können mit dem Serummarkerprotein Apolipoprotein CIII (ApoCIII) analog zum Transferrin durchgeführt werden.

Bewertung IEF und HPLC sind sensitive Methoden zur Diagnostik von Glykosylierungsdefekten. Jedoch können auch sekundäre Glykosylierungsstörungen wie Galaktosämie, Fruktoseintoleranz oder Alkoholabusus ( $>$ Alkoholmissbrauchskenngrößen) zu auffälligen Ergebnissen führen. Einige Defekte (z. B. GCS1-CDG, SLC35C1-CDG) lassen sich hingegen nicht mit diesen Methoden nachweisen 
CDG, Tab. 1 Übersicht über die am häufigsten detektierten CDGDefekte. O-Mucintypglykosylierungsdefekte lassen sich im Serum mit Hilfe des Apolipoproteins CIII nachweisen. Für O-Mannosylierungsstö-

rungen gibt es bislang keinen Serummarker, so dass Analysen anhand von Patientenzellen erfolgen müssen

\begin{tabular}{|c|c|c|c|c|}
\hline Defekt & $\begin{array}{l}\text { Alter } \\
\text { Name }\end{array}$ & Betroffenes Protein & CDG Typ I/Typ II & Häufigkeit \\
\hline PMM2-CDG & CDG-Ia & Phosphomannomutase 2 & Typ I & Ca. $60 \%$ \\
\hline MPI-CDG & CDG-Ib & Phosphomannose-Isomerase & Typ I & $<5 \%$ \\
\hline $\begin{array}{l}\text { GMPPA- } \\
\text { CDG }\end{array}$ & - & GDP-mannose pyrophosphorylase subunit A & Nicht detektierbar & $\begin{array}{l}\text { Sehr } \\
\text { selten }\end{array}$ \\
\hline $\begin{array}{l}\text { GMPPB- } \\
\text { CDG }\end{array}$ & - & GDP-mannose pyrophosphorylase subunit B & $\begin{array}{l}\text { Nicht detektierbar (nur } \\
\text { O-Mannosylierung) }\end{array}$ & $\begin{array}{l}\text { Sehr } \\
\text { selten }\end{array}$ \\
\hline PGM1-CDG & - & Phosphoglukomutase 1 & Typ I bis Typ II & \\
\hline PGM3-CDG & - & Phosphoglukomutase 3 & Nicht detektierbar & $\begin{array}{l}\text { Sehr } \\
\text { selten }\end{array}$ \\
\hline $\begin{array}{l}\text { DHDDS- } \\
\text { CDG }\end{array}$ & - & Dehydrodolichyl diphosphate synthase & Typ I & $\begin{array}{l}\text { Sehr } \\
\text { selten }\end{array}$ \\
\hline NgBR-CDG & - & Nogo-B receptor & Nicht detektierbar & $\begin{array}{l}\text { Sehr } \\
\text { selten }\end{array}$ \\
\hline $\begin{array}{l}\text { SRD5A3- } \\
\text { CDG }\end{array}$ & CDG-Iq & Steroid 5 - $\alpha$-reductase type 3 & Typ I & $<5 \%$ \\
\hline $\begin{array}{l}\text { DOLK1- } \\
\text { CDG }\end{array}$ & CDG-Im & Dolicholkinase 1 & Typ I & $<5 \%$ \\
\hline $\begin{array}{l}\text { MPDU1- } \\
\text { CDG }\end{array}$ & CDG-If & $\begin{array}{l}\text { Lec35/MPDU1 (utilization of dolichol-P-mannose and } \\
\text { dolichol-P-glucose) }\end{array}$ & Typ I & $\begin{array}{l}\text { Sehr } \\
\text { selten }\end{array}$ \\
\hline DPM1-CDG & CDG-Ie & Dolichol-P-mannose synthase-1 & $\begin{array}{l}\text { Typ I } \\
\text { (und O-Mannosylierung) }\end{array}$ & $\begin{array}{l}\text { Sehr } \\
\text { selten }\end{array}$ \\
\hline DPM2-CDG & & Dolichol-P-mannose synthase-2 & $\begin{array}{l}\text { Typ I } \\
\text { (und O-Mannosylierung) }\end{array}$ & $\begin{array}{l}\text { Sehr } \\
\text { selten }\end{array}$ \\
\hline DPM3-CDG & CDG-Io & Dolichol-P-mannose synthase-3 & $\begin{array}{l}\text { Typ I } \\
\text { (und O-Mannosylierung) }\end{array}$ & $\begin{array}{l}\text { Sehr } \\
\text { selten }\end{array}$ \\
\hline $\begin{array}{l}\text { DPAGT1- } \\
\text { CDG }\end{array}$ & CDG-Ij & $\begin{array}{l}\text { UDP-GlcNAc:dolichol-phosphate-N-acetylglucosamine-1- } \\
\text { phosphotransferase }\end{array}$ & Typ I & $\begin{array}{l}\text { Sehr } \\
\text { selten }\end{array}$ \\
\hline ALG13-CDG & - & $\begin{array}{l}\text { UDP-GlcNAc:dolichol pyrophosphate } \mathrm{N} \text {-acetylglucosamine } \\
\text { transferase }\end{array}$ & Typ I & $\begin{array}{l}\text { Sehr } \\
\text { selten }\end{array}$ \\
\hline ALG14-CDG & - & $\begin{array}{l}\text { UDP-GlcNAc:dolichol pyrophosphate } \mathrm{N} \text {-acetylglucosamine } \\
\text { transferase }\end{array}$ & Nicht detektierbar & $\begin{array}{l}\text { Sehr } \\
\text { selten }\end{array}$ \\
\hline ALG1-CDG & CDG-Ik & GDP-Man:GlcNAc ${ }_{2}$-PP-dolichol mannosyltransferase & $\begin{array}{l}\text { Typ I } \\
\text { (und O-Mannosylierung) }\end{array}$ & $\begin{array}{l}\mathrm{Ca} . \\
5-10 \%\end{array}$ \\
\hline ALG2-CDG & CDG-Ii & $\begin{array}{l}\text { GDP-mannose: } \mathrm{Man}_{1} \mathrm{GlcNAc}_{2}-\mathrm{PP} \text {-dolichol } \\
\text { mannosyltransferase }\end{array}$ & Typ I & $\begin{array}{l}\text { Sehr } \\
\text { selten }\end{array}$ \\
\hline ALG11-CDG & CDG-Ip & GDP-Man: $\mathrm{Man}_{3-4} \mathrm{GlcNAc}_{2}$-PP-dolichol mannosyltransferase & Typ I & $\begin{array}{l}\text { Sehr } \\
\text { selten }\end{array}$ \\
\hline RFT1-CDG & CDG-In & RFT1 protein & Typ I & $\begin{array}{l}\text { Sehr } \\
\text { selten }\end{array}$ \\
\hline ALG3-CDG & CDG-Id & $\begin{array}{l}\text { Dolichol-P-mannose: } \mathrm{Man}_{5} \mathrm{GlcNAc}_{2} \text {-PP-dolichol } \\
\text { mannosyltransferase }\end{array}$ & Typ I & $\begin{array}{l}\text { Sehr } \\
\text { selten }\end{array}$ \\
\hline ALG9-CDG & CDG-IL & Dolichol-P-mannose: $\alpha 1,2$-mannosyltransferase & Typ I & $\begin{array}{l}\text { Sehr } \\
\text { selten }\end{array}$ \\
\hline ALG12-CDG & CDG-Ig & $\begin{array}{l}\text { Dolichol-P-mannose: } \mathrm{Man}_{7} \mathrm{GlcNAc}_{2} \text {-PP-dolichol } \\
\text { mannosyltransferase }\end{array}$ & Typ I & $\begin{array}{l}\text { Sehr } \\
\text { selten }\end{array}$ \\
\hline ALG6-CDG & CDG-Ic & $\begin{array}{l}\text { Dolichol-P-glucose:Man }{ }_{9} \mathrm{GlcNAc}_{2} \text {-PP-dolichol } \\
\text { glucosyltransferase }\end{array}$ & Typ I & Ca. $10 \%$ \\
\hline ALG8-CDG & CDG-Ih & $\begin{array}{l}\text { Dolichol-P-glucose:Glc }{ }_{1} \mathrm{Man}_{9} \mathrm{GlcNAc}_{2} \text {-PP-dolichol- } \alpha 1,3- \\
\text { glucosyltransferase }\end{array}$ & Typ I & $\begin{array}{l}\text { Sehr } \\
\text { selten }\end{array}$ \\
\hline N33/TUSC3 & - & Subunit N33/TUSC3 of the OST complex & Nicht detektierbar & $\begin{array}{l}\text { Sehr } \\
\text { selten }\end{array}$ \\
\hline MAGT1 & - & Magnesiumtransporter 1 & Nicht detektierbar & $\begin{array}{l}\text { Sehr } \\
\text { selten }\end{array}$ \\
\hline STT3A-CDG & - & Subunit STT3A of the OST complex & Typ I & $\begin{array}{l}\text { Sehr } \\
\text { selten }\end{array}$ \\
\hline
\end{tabular}


CDG, Tab. 1 (Fortsetzung)

\begin{tabular}{|c|c|c|c|c|}
\hline Defekt & $\begin{array}{l}\text { Alter } \\
\text { Name }\end{array}$ & Betroffenes Protein & CDG Typ I/Typ II & Häufigkeit \\
\hline STT3B-CDG & - & Subunit STT3B of the OST complex & Typ I & $\begin{array}{l}\text { Sehr } \\
\text { selten }\end{array}$ \\
\hline SSR4-CDG & - & Signal sequence receptor 4 protein of the TRAP complex & Typ I & $\begin{array}{l}\text { Sehr } \\
\text { selten }\end{array}$ \\
\hline $\begin{array}{l}\text { DDOST- } \\
\text { CDG }\end{array}$ & - & Subunit DDOST of the OST complex & Typ II & $\begin{array}{l}\text { Sehr } \\
\text { selten }\end{array}$ \\
\hline MOGS-CDG & CDG-IIb & Endoplasmic reticulum glucosidase I & Nicht detektierbar & $\begin{array}{l}\text { Sehr } \\
\text { selten }\end{array}$ \\
\hline $\begin{array}{l}\text { SLC35A2- } \\
\text { CDG }\end{array}$ & - & Golgi UDP-galactose transporter & Typ II & $\begin{array}{l}\text { Sehr } \\
\text { selten }\end{array}$ \\
\hline $\begin{array}{l}\text { SLC35C1- } \\
\text { CDG }\end{array}$ & CDG-IIc & Golgi GDP-fucose transporter & Nicht detektierbar & $\begin{array}{l}\text { Sehr } \\
\text { selten }\end{array}$ \\
\hline $\begin{array}{l}\text { MGAT2- } \\
\text { CDG }\end{array}$ & CDG-IIa & Golgi N-acetyl-glucosaminyltransferase II & Typ II & $\begin{array}{l}\text { Sehr } \\
\text { selten }\end{array}$ \\
\hline $\begin{array}{l}\text { B4GALT1- } \\
\text { CDG }\end{array}$ & CDG-IId & $\begin{array}{l}\text { Golgi UDP-galactose: } \mathrm{N} \text {-acetylglucosamine } \\
\beta-1,4 \text {-galactosyltransferase }\end{array}$ & Typ II & $\begin{array}{l}\text { Sehr } \\
\text { selten }\end{array}$ \\
\hline $\begin{array}{l}\text { MAN1B1- } \\
\text { CDG }\end{array}$ & - & endoplasmic reticulum $1,2-\alpha$-mannosidase & $\begin{array}{l}\text { Typ II } \\
\text { (und O-Mucintyp) }\end{array}$ & $<5 \%$ \\
\hline $\begin{array}{l}\text { SLC35A1- } \\
\text { CDG }\end{array}$ & CDG-IIf & Golgi CMP-sialic acid transporter & $\begin{array}{l}\text { Typ II } \\
\text { (und O-Mucintyp) }\end{array}$ & $\begin{array}{l}\text { Sehr } \\
\text { selten }\end{array}$ \\
\hline $\begin{array}{l}\text { ATP6V0A2- } \\
\text { CDG }\end{array}$ & CDG-IIi & $\alpha-2$ subunit of the V-type $\mathrm{H}^{+}$ATPase & $\begin{array}{l}\text { Typ II } \\
\text { (und O-Mucintyp) }\end{array}$ & $\begin{array}{l}\text { Sehr } \\
\text { selten }\end{array}$ \\
\hline $\begin{array}{l}\text { TMEM165- } \\
\text { CDG }\end{array}$ & - & TMEM165 (TPARL) protein & $\begin{array}{l}\text { Typ II } \\
\text { (und O-Mucintyp) }\end{array}$ & $\begin{array}{l}\text { Sehr } \\
\text { selten }\end{array}$ \\
\hline COG1-CDG & CDG-IIg & Subunit 1 of the COG complex in Golgi trafficking & $\begin{array}{l}\text { Typ II } \\
\text { (und O-Mucintyp) }\end{array}$ & $\begin{array}{l}\text { Sehr } \\
\text { selten }\end{array}$ \\
\hline COG2-CDG & - & Subunit 2 of the COG complex in Golgi trafficking & $\begin{array}{l}\text { Typ II } \\
\text { (und O-Mucintyp) }\end{array}$ & $\begin{array}{l}\text { Sehr } \\
\text { selten }\end{array}$ \\
\hline COG4-CDG & CDG-IIj & Subunit 4 of the COG complex in Golgi trafficking & $\begin{array}{l}\text { Typ II } \\
\text { (und O-Mucintyp) }\end{array}$ & $\begin{array}{l}\text { Sehr } \\
\text { selten }\end{array}$ \\
\hline COG5-CDG & CDG-IIi & Subunit 5 of the COG complex in Golgi trafficking & $\begin{array}{l}\text { Typ II } \\
\text { (und O-Mucintyp) }\end{array}$ & $\begin{array}{l}\text { Sehr } \\
\text { selten }\end{array}$ \\
\hline COG6-CDG & $\begin{array}{l}\text { CDG- } \\
\text { IIL }\end{array}$ & Subunit 6 of the COG complex in Golgi trafficking & $\begin{array}{l}\text { Typ II } \\
\text { (und O-Mucintyp) }\end{array}$ & $\begin{array}{l}\text { Sehr } \\
\text { selten }\end{array}$ \\
\hline COG7-CDG & CDG-IIe & Subunit 7 of the COG complex in Golgi trafficking & $\begin{array}{l}\text { Typ II } \\
\text { (und O-Mucintyp) }\end{array}$ & $\begin{array}{l}\text { Sehr } \\
\text { selten }\end{array}$ \\
\hline COG8-CDG & CDG-IIh & Subunit 8 of the COG complex in Golgi trafficking & $\begin{array}{l}\text { Typ II } \\
\text { (und O-Mucintyp) }\end{array}$ & $\begin{array}{l}\text { Sehr } \\
\text { selten }\end{array}$ \\
\hline TMEM199 & - & TMEM199 (TPARL) protein & $\begin{array}{l}\text { Typ II } \\
\text { (und O-Mucintyp) }\end{array}$ & $\begin{array}{l}\text { Sehr } \\
\text { selten }\end{array}$ \\
\hline ATP6AP1 & - & AP1-Protein an der V0-Untereinheit der vacuolar $\mathrm{H}^{+}$ATPase & $\begin{array}{l}\text { Typ II } \\
\text { (und O-Mucintyp) }\end{array}$ & $\begin{array}{l}\text { Sehr } \\
\text { selten }\end{array}$ \\
\hline ATP6V1E1 & - & E1-Untereinheit der V1-Domäne des V-ATPase-Komplexes & $\begin{array}{l}\text { Typ II } \\
\text { (und O-Mucintyp) }\end{array}$ & $\begin{array}{l}\text { Sehr } \\
\text { selten }\end{array}$ \\
\hline ATP6V1A & - & A-Untereinheit der V1-Domäne des V-ATPase-Komplexes & $\begin{array}{l}\text { Typ II } \\
\text { (und O-Mucintyp) }\end{array}$ & $\begin{array}{l}\text { Sehr } \\
\text { selten }\end{array}$ \\
\hline
\end{tabular}

\section{Literatur}

Freeze HH, Eklund EA, Ng BG, Patterson MC (2015) Neurological aspects of human glycosylation disorders. Annu Rev Neurosci 38:105-125

Sparks SE, Krasnewich DM (2017) Congenital disorders of N-linked glycosylation and multiple pathway overview. In: Pagon RA, Adam MP, Ardinger HH, Wallace SE, Amemiya A, Bean LJH, Bird TD, Ledbetter N, Mefford HC, Smith RJH, Stephens K (Hrsg) GeneReviews ${ }^{\circledR}$ [Internet]. University of Washington, Seattle

\section{CD-Nomenklatur}

Cluster-of-differentiation-Nomenklatur

CDT

- Carbohydrate-deficient transferrin 


\section{$\gamma$-CDT}

- Carbohydrate-deficient transferrin

\section{CE}

- Kapillarelektrophorese

\section{CEA}

- Carcinoembryonales Antigen

\section{CEACAM-1}

- Carcinoembryonic antigen cell adhesion molecule

\section{CEDIA}

$\triangleright$ Cloned Enzyme Donor Immunoassay

\section{Ceiling-Effekt}

C. Vidal und W.-R. Külpmann

Englischer Begriff ceiling effect

Definition Beschreibt die sich selbst begrenzende Wirkungsstärke eines Pharmakons.

Beschreibung Die Konzentrations-Wirkung-Kurve eines Pharmakons kann ein Wirkungsplateau erreichen. Eine weitere Erhöhung der Konzentration, z. B. durch Steigerung der Dosis, verstärkt die gewünschte Wirkung nicht weiter. Es können allerdings vermehrt unerwünschte Nebenwirkungen auftreten. Ursache für den Ceiling-Effekt kann sein, dass ab einer bestimmten Konzentration alle für die Wirkung relevanten Rezeptoren von dem Pharmakon besetzt sind (z. B. Buprenorphin).

\section{CE-Kennzeichnung}

$>$ CE-Label

\section{CE-Label}

B. Güssregen

Synonym(e) CE-Kennzeichnung

\section{Englischer Begriff $\mathrm{CE}$ label}

Definition Kennzeichnung nach EU-Recht.

Beschreibung Die CE-Kennzeichnung (von franz. Communauté Européenne $=$ „Europäische Gemeinschaft" oder Conformité Européenne) ist eine Kennzeichnung nach EU-Recht für bestimmte Produkte wie z. B. elektrische Geräte und Medizinprodukte. Mit der CE-Kennzeichnung bestätigt der Hersteller die Konformität des Produkts mit den zutreffenden EG-Richtlinien und die Einhaltung der darin festgelegten ,wesentlichen Anforderungen". Verantwortlich für diese Kennzeichnung ist in der Regel der Hersteller des Produkts. Die CE-Kennzeichnung bestätigt die vollständige Einhaltung der ,grundlegenden (Sicherheits-)Anforderungen“, die in EG-Richtlinien konkret festgelegt sind.

\section{Literatur}

http://www.ce-zeichen.de/

\section{Cellano-Antigen}

- Kell-Blutgruppensystem

\section{$\boldsymbol{\beta}$-Cell E-box transactivator 2}

- Neurogenic differentiation 1

\section{Celluloseacetatfolien-Elektrophorese}

R. Westermeier

Synonym(e) CAF-Elektrophorese

Englischer Begriff cellulose acetate membrane electrophoresis

Definition Analytisches Verfahren zur Auftrennung von Proteinen im elektrischen Feld. Hierbei verwendet man Cel- 
luloseacetatfolien als stabilisierendes Medium. Celluloseacetatfolien haben für Proteine praktisch keine Molekularsiebwirkung. Wegen der unterschiedlichen Ladungen der Proteine beim gewählten Puffer-pH-Wert ergeben sich unterschiedliche Wanderungsgeschwindigkeiten; es bilden sich einzelne Proteinzonen aus.

Physikalisch-chemisches Prinzip Celluloseacetatfolien-Elektrophorese hat die > Papierelektrophorese weitgehend abgelöst, weil die Membranfolien keine Absorption auf die zu trennenden Substanzen (meist Proteine) ausüben. Die Poren sind mit ca. $45 \mu \mathrm{m}$ Durchmesser relativ groß. Deshalb tritt gegenüber den meist analysierten Proben kein Molekularsiebeffekt auf. Bei der elektrophoretischen Wanderung ist die Mobilität daher abhängig vom Ladungszustand. Die milchig-weißen Celluloseacetatfolien sind ca. $120 \mu \mathrm{m}$ dünn. Sie werden im - meist basischen - Puffer getränkt und mit ihrer Perforierung in die Haltestifte der Elektrophoresekammer eingespannt, sodass die jenseits der Perforierung überstehenden Folienenden in die Pufferkammern eintauchen (s. Abbildung). Normalerweise wird ein basischer Puffer um $\mathrm{pH} 8$ verwendet, die meisten Moleküle sind negativ geladen und wandern zur (positiv geladenen) Anode. Proteine, deren isoelektrischen Punkte höher sind als der pH-Wert des Puffers, wandern in Richtung Kathode. Zur Beobachtung der Elektrophorese werden geladene Farbmarker zur Probe hinzugemischt: Bromphenolblau für Proteine. Die Proteinproben werden mit Auftragestempeln appliziert.

Schematische Darstellung einer Trennkammer:

\section{Celluloseacetatfolien-Elektrophorese von Proteinen}

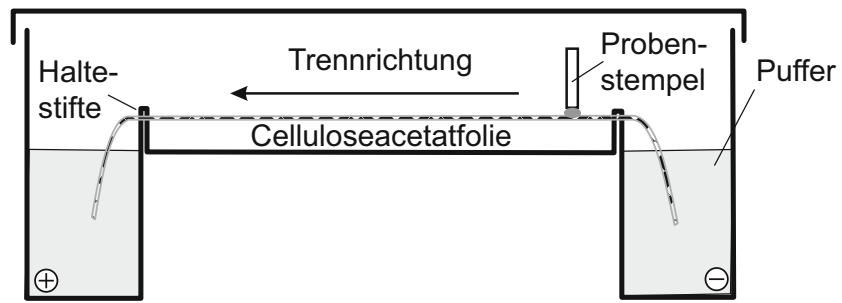

Der qualitative und quantitative Nachweis von Proteinzonen erfolgt mit Ponceaurot. Für Lipoproteine gibt es spezielle Farbstoffe wie z. B. Ölrot O. Daraufhin werden die Folien mit Ethanol gewaschen und in einem Transparenzbad durchsichtig gemacht.

Die transparenten Folien werden mit einem $>$ Densitometer optisch vermessen. Damit kann man die gefärbten Proteinzonen quantifizieren und Rückschlüsse auf bestimmte Erkrankungen ziehen.

Einsatzgebiet Celluloseacetatfolien-Elektrophorese wird hauptsächlich zur $>$ Serumprotein-Elektrophorese oder Plasmalipoprotein-Elektrophorese eingesetzt.
Untersuchungsmaterial Serum, Plasma.

Referenzbereich - Erwachsene und Kinder. $>$ Serumprotein-Elektrophorese.

\section{Instrumentierung}

- Elektrophoresekammer

- Stromversorger

- Färbeschalen

- Densitometer

Spezifität Die mit allgemeinen Proteinfärbetechniken detektierten Banden werden durch ihre Position im typischen Elektrophoresemuster im Elektropherogramm und $>$ Densitogramm identifiziert. Dies basiert auf Erfahrungswerten. Höhere Spezifität ( $\triangleright$ Spezifität, diagnostische) erreicht man durch immunologische Nachweise oder Enzymnachweise mit Substratlösungen.

Sensitivität Mit der meist verwendeten Ponceaurotfärbung kann man bis ca. $1 \mu \mathrm{g}$ Protein pro Bande nachweisen. Amidoschwarz ist etwas empfindlicher.

Fehlermöglichkeit Die Handhabung der Folien ist relativ einfach. Es ist jedoch darauf zu achten, dass sie gleichmäßig durch Auflegen („Floaten“) der Folien auf die Pufferoberfläche mit Puffer getränkt werden und die Folien nur mit Pinzetten und Gummihandschuhen berührt werden. Kommerzielle Kits mit Folien, Puffern, und Färbelösungen schränken die Fehlermöglichkeiten deutlich ein.

Praktikabilität - Automatisierung - Kosten Es werden von mehreren Firmen Fertiggele, Färbekits und automatisierte Elektrophoresesysteme für die klinischen Anwendungen angeboten. Auch die Densitometersteuerungs- und -Auswertungsprogramme sind bedienerfreundlich entwickelt.

\section{Literatur}

Kohn J (1957) A cellulose acetate supporting medium for zone electrophoresis. Clin Chim Acta 2:297

Westermeier R (2016) Elektrophorese leicht gemacht. Wiley-VCH, Weinheim

\section{CENP-Antikörper}

- Autoantikörper gegen Zentromere 


\section{Centriol/Centrosom-Antikörper}

Autoantikörper gegen Zentriolen/Zentrosomen

\section{Ceramid}

\section{K. J. Lackner und D. Peetz}

$\operatorname{Synonym(e)~} N$-Acylsphingosin

Englischer Begriff ceramide

Definition Ceramide sind eine Familie der Sphingolipide, die als Grundstruktur aus $N$-acyliertem Sphingosin bestehen. Ceramide sind Bausteine anderer Lipide wie der Glykosphingolipide.

Beschreibung Ceramide kommen in allen Geweben von Wirbeltieren vor. Sie haben unterschiedlichste Funktionen in der Zelle. Als Bestandteile von Zellmembranen sind sie einerseits wichtige Strukturmoleküle. Andererseits ist klar geworden, dass Ceramide und ihre Derivate wichtige Funktionen in der zellulären Signaltransduktion ausüben.

\section{Literatur}

Reynolds CP, Maurer BJ, Kolesnick RN (2004) Ceramide synthesis and metabolism as a target for cancer therapy. Cancer Lett 206:169-180

\section{c-erbB-2 oncoprotein}

- Human Epidermal Growth Factor Receptor

\section{Cerebrocuprein}

D. Meißner und T. Arndt

\section{Englischer Begriff cerebrocuprein}

Definition Ein kupferbindendes Protein aus Gehirnpräparationen, das schließlich als identisch mit zeitlich zuvor beschriebenen kupferbindenden Proteinen aus der Leber (Hepatocuprein) und den Erythrozyten (Erythrocuprein) erkannt wurde.
Beschreibung Diese Bezeichnungen und die von Carrico und Deutsch vorgeschlagene (Sammel)Bezeichnung Cytocuprein sind heute eher von historischem Interesse.

\section{Literatur}

Carrico RJ, Deutsch HF (1969) Isolation of human hepatocuprein and cerebrocuprein: their identity with erythrocuprein. J Biol Chem 244:6087-6093

\section{Cerebroglycan}

$\checkmark$ Glypicane

\section{Cerebrose}

$>$ Galaktose

\section{Cerebrospinalflüssigkeit}

- Liquor cerebrospinalis

\section{Cerotinsäure}

A. C. Sewell

Englischer Begriff cerotic acid; hexacosanoic acid

Definition Gesättigte, ultralangkettige Fettsäure (C26:0). Bestandteil des Carnauba- und Bienenwachses.

Beschreibung Cerotinsäure ist eine ultralangkettige Fettsäure, die für die Diagnose einer angeborenen peroxisomalen Fettsäurenoxidationsstörung unentbehrlich ist. Die Bestimmung erfolgt in Serum mittels GCMS mit Stabilisotopenverdünnung.

\section{Literatur}

Wanders RJA, Duran M (2008) Very-long-chain fatty acids and phytanic acid. In: Blau N, Duran M, Gibson KM (Hrsg) Laboratory guide to the methods in biochemical genetics. Springer, Heidelberg, S 221-231 


\section{Cerucal-Test}

- Metoclopramid-Test

ces

- V-Antigen

\section{C1-Esterase}

H. Renz und B. Gierten

Englischer Begriff complement component C1

Definition Katalytischer Anteil der Komplementkomponente $\mathrm{C} 1$.

Struktur $\mathrm{C} 1 \mathrm{q}, \mathrm{r}_{2} \mathrm{~s}_{2}$.

Molmasse $\triangleright$ Komplementsystem, klassische Aktivierung

Synthese - Verteilung - Abbau - Elimination Das komplexe C1-Molekül setzt sich aus den Komponenten C1q und jeweils 2 Anteilen $\mathrm{C} 1 \mathrm{r}$ und $\mathrm{C} 1 \mathrm{~s}$ zusammen. $\mathrm{C} 1 \mathrm{q}$ besteht aus 6 Untereinheiten, die je eine A-, B- und C-Kette enthalten. Disulfidbrückenbindungen verbinden jede $\alpha$-Kette $(22 \mathrm{kDa})$ mit einer $\beta$-Kette $(23 \mathrm{kDa})$ und jede C-Kette $(24 \mathrm{kDa})$ mit einer anderen C-Kette. Strukturell betrachtet bilden die C-terminalen Enden der Proteinketten globuläre Köpfe, an die sich die N-terminalen Molekülteile wie Stiele anschlieBen. Die globulären Anteile tragen Bindungsstellen für - Immunglobuline und andere Aktivatoren des Komplementsystems. An den linearen N-terminalen Enden des C1q-Moleküls sind die C1r- und C1s-Moleküle gebunden. Kugelförmige Anteile der C1r-Untereinheiten lagern sich innerhalb des Moleküls zu einer katalytischen Einheit zusammen. Unter C1-Esterase versteht man den katalytischen Anteil des C1-Moleküls.

Funktion - Pathophysiologie C1-Esterase initiiert den klassischen Komplementweg, indem sie die Komplementkomponente $\mathrm{C} 4$ spaltet. Zunächst wird $\mathrm{C} 1 \mathrm{q}$ durch Bindung von Immunglobulinen in Immunkomplexen ( 2 aneinander gebundene IgG oder 1 Molekül IgM) oder anderen biologischen Aktivatoren wie CRP, bestimmten Viren und Bakterien, Endotoxin, Natriumuratkristallen u. a. aktiviert. Dadurch entstehende Konformationsänderungen werden auf die $\mathrm{Clr}$ -
Anteile im Molekül übertragen, wo dadurch eine proteolytische Autoaktivierung stattfindet. Nachfolgend wird im C1s-Molekülanteil eine Peptidbindung gespalten, die die Aktivierung der Komplementkomponenten C2 und C4 ermöglicht.

Untersuchungsmaterial - Entnahmebedingungen Serum, Plasma (EDTA-, Heparin-).

Präanalytik $\triangleright$ Komplementsystem, alternative Aktivierung

Analytik Immunologische Bestimmung der Einzelkomponenten $\mathrm{C} 1 \mathrm{q}, \mathrm{C} 1 \mathrm{r}, \mathrm{C} 1 \mathrm{~s}$.

\section{Konventionelle Einheit $\mathrm{mg} / \mathrm{L}$.}

Referenzbereich - Erwachsene $\mathrm{Clq}>70 \mathrm{mg} / \mathrm{L}, \mathrm{Clr}$ $>35 \mathrm{mg} / \mathrm{L}, \mathrm{C} 1 \mathrm{~s}>30 \mathrm{mg} / \mathrm{L}$.

Referenzbereich - Kinder s. Erwachsene.

Indikation Komplementaktivierung, klassischer Weg im Rahmen von chronischen Entzündungen, Autoimmunerkrankungen, V. a. Mangelzustände von C1.

Diagnostische Wertigkeit Pathophysiologische Bedeutung haben nur Mangelzustände und Proteindysfunktion der Komponente $\mathrm{Clq}$.

\section{Literatur}

Klein J, Horejsi V (1997) Immunology, 2. Aufl. Blackwell Sciences, Oxford, S 353-356

\section{C1-Esterase-Inhibitor}

H. Renz und B. Gierten

Synonym(e) C1-INH; C1-Inaktivator

Englischer Begriff C1-inactivator; C1-inhibitor; esterase inhibitor

Definition Inhibitor von $\mathrm{C} 1 \mathrm{r}$ und damit der klassischen Aktivierung des Komplementsystems.

Molmasse $105 \mathrm{kDa}$.

Synthese - Verteilung - Abbau - Elimination Der C1-Esterase-Inhibitor ist eine Serinproteinase, die in Hepatozyten synthetisiert wird. 
Funktion - Pathophysiologie Sie bildet einen Komplex mit C1r und C1s. Zusätzlich werden die beiden Komponenten von C1q getrennt und die Aktivierung des klassischen Komplementwegs verhindert.

Bei verminderter Konzentration von C1-INH spaltet C1s unkontrolliert die Komplementkomponenten $\mathrm{C} 4$ und $\mathrm{C} 2$. Dies führt zur Produktion großer Mengen an $\mathrm{C} 2 \mathrm{~b}$ mit kininähnlicher Aktivität und dem Anaphylatoxin C4a.

Außerhalb des Komplementsystems kann der C1-INH auch Gerinnungsfaktoren (FXIIa) und Enzyme der Fibrinolyse (TPA) sowie Bradykinin inaktivieren.

Untersuchungsmaterial - Entnahmebedingungen Für Proteinbestimmung: Serum. Für funktionelle Bestimmung: EDTA- oder Citrat-Plasma.

Probenstabilität Gering; $>$ Komplementsystem, alternative Aktivierung.

Präanalytik $>$ Komplementsystem, alternative Aktivierung

Analytik Immunnephelometrie, Immunturbidimetrie, ELISA ( $\triangleright$ Enzyme-linked Immunosorbent Assay)

Konventionelle Einheit g/L.

Referenzbereich - Erwachsene $0,15-0,35 \mathrm{~g} / \mathrm{L}$.

Referenzbereich - Kinder s. Erwachsene.

Indikation Mangel an C1-Esterase-Inaktivator bei hereditärem Angioödem.

Interpretation Hereditäres Angioödem ist eine autosomal dominant vererbte Erkrankung mit inkompletter Penetranz. Bisher wurden 2 Typen des hereditären Angioödems beschrieben: Typ 1 (ca. $85 \%$ der Fälle) zeigt einen C1-INHMangel von 15-30\% der Norm sowohl in funktionellen wie auch in immunchemischen Tests; es liegt also eine verminderte Proteinkonzentration vor. Bei Typ 2 werden unauffällige Konzentrationen an C1-INH bei verminderter funktioneller Aktivität nachgewiesen.

Die Symptome eines hereditären Angioödems, also Schwellungen im Bereich von Schleimhäuten und Subkutangewebe des Respirations- und Gastrointestinaltrakts, treten bei angeborenem oder erworbenem C1-INH-Mangel bei einer funktionellen Aktivität von $<25 \%$ und C1-INH-Konzentration $<35 \%$ der Norm auf. Während einer Attacke kann C1-INH-Aktivität und -Funktion bis unter die Nachweisgrenze sinken.

Ein erworbener C1-INH-Mangel kann auf Autoantikörperbildung gegen $\mathrm{C} 1$-INH oder auf verstärkte $\mathrm{C} 1$-Aktivierung als Folge eines erhöhten Verbrauchs nachweisbar sein.

\section{Literatur}

Klein J, Horejsi V (1997) Immunology, 2. Aufl. Blackwell Sciences, Oxford, S 353-356

\section{CETP}

Cholesterylester-Transferprotein

\section{CFA}

Calprotectin

\section{CFABP}

Fettsäurebindungsprotein, cardiales

\section{CFU-C}

H. Baum

Synonym(e) CFU-GM; Kolonien-bildende Einheiten Granulozyt/Makrophage

Englischer Begriff colony forming unit in culture

Definition Granulopoetisch determinierte Vorläuferzelle mit der Fähigkeit, sich in der Kultur zu Zellen der Granulopoese ( $\triangleright$ Granulozytopoese) oder $\triangleright$ Makrophagen weiter zu differenzieren.

Beschreibung Die CFU-C (CFU-GM) ist eine granulopoetisch determinierte Vorläuferzelle der Hämatopoese. Sie entsteht in der Kultur aus der $>$ CFU-GEMM und besitzt die Fähigkeit, nach Stimulation mit Wachstumsfaktoren (IL-3, GM-CSF) zu Granulozyten oder Makrophagen auszudifferenzieren.

\section{Literatur}

Ferrero D et al (1983) ProcNatlAcadSci USA 80:4114-4118 


\section{CFU-GEMM}

H. Baum

Englischer Begriff colony-forming unit GEMM

Definition Unreife, multipotente Vorläuferzelle, die nach Stimulation mit Wachstumsfaktoren zu Zellen der Granulopoese ( $\triangleright$ Granulozytopoese) (G), Erythropoese (E), \ Makrophagen(M) und $\triangleright$ Megakaryozyten(M) ausreifen kann.

Beschreibung CFU-GEMM sind unreife, multipotente hämatologische Vorläuferzellen, die in Kultur nach Stimulation mit spezifischen Wachstumsfaktoren Kolonien bilden können, die Zellen der Granulopoese, Erythropoese, Makrophagen und Megakaryozyten enthalten. Sie geht aus der milzkolonienbildenden Stammzelle (CFU-S) nach Stimulation mit IL-3 hervor. Die Selbsterneuerung der CFU-GEMM ist jedoch limitiert. Sie stellt somit eine Zwischenform zwischen der pluripotenten Stammzelle und den unipotenten Progenitorzellen dar.

\section{Literatur}

Ash RC, Detrick RA, Zanjani ED (1981) Studies of human pluripotential hematopoietic stem cells (CFU-GEMM) in vitro. Blood 58:309-316

\section{CFU-GM}

$\triangleright$ CFU-C

\section{CFU-LM}

H. Baum

Synonym(e) Colony forming unit lymphoid-myeloid

\section{Englischer Begriff CFU-LM}

Definition Hämatopoetische Vorläuferzelle, die die Fähigkeit zur Differenzierung in lymphatische oder myeloische Zellen besitzt.

Beschreibung Die CFU-LM ist eine sehr frühe determinierte hämatopoetische Vorläuferzelle. Sie besitzt nach Sti- mulation durch spezifische Wachstums- und Differenzierungsfaktoren die Fähigkeit zur Differenzierung sowohl zu lymphatischen als auch zu myeloischen Vorläuferzellen.

\section{Literatur}

Quesenberry PJ (1991) The concept of the hemopoietic cells, and growth factors. In: Williams WJ, Beutler E, Ersler AJ et al (Hrsg) Hematology, 4. Aufl. International Edition. McGraw-Hill, New York, S 131

\section{$\operatorname{CgA}$}

- Chromogranin A

\section{CGRP}

$\checkmark$ Calcitonin gene-related peptide

\section{CH 50}

- Komplementsystem, Globalteste

\section{CH 100}

- Komplementsystem, Globalteste

\section{Chance}

$>$ Odds

> Odds Ratio

\section{Chancenverhältnis}

$>$ Odds Ratio

\section{Channel forming integral protein (CHIP-1)}

- Colton-Blutgruppensystem 


\section{Chaperone}

H. Fiedler

Synonym(e) Molekulare Chaperone

\section{Englischer Begriff chaperones}

Definition Molekulare Chaperone (franz. für „Anstandsdame") verhindern die Aggregation von Proteinen durch Abschirmung von hydrophoben Oberflächenbereichen. Sie unterstützen und beschleunigen die korrekte Faltung von neu synthetisierten oder falsch gefalteten Proteinen. Viele Chaperone gehören zu den Hitzeschockproteinen (HSPs; s. D Hitzeschockproteine). Die Faltungsvorgänge benötigen Energie, die durch Cochaperone geliefert werden, einige Chaperone erfüllen die Aufgaben ohne Energiezufuhr. Chaperone helfen auch bei der Bildung von Proteinkomplexen, Transportvorgängen und beim Abbau von fehlgefalteten Proteinen.

Beschreibung Das endoplasmatische Retikulum (ER) ist mit zahlreichen Chaperonen bestückt, die durch Überladung des ER (exzessive Biosynthesen), Glukose- und Kalziummangel sowie oxidativen und endoplasmatischen Stress ( $\triangleright$ Stress, oxidativer) hochreguliert werden. Das „binding immunoglobulin protein“ (BiP, ,glucose-regulated protein $78^{\prime \prime)}$ ist gemeinsam mit HSP40 ein wichtiger Regulator, verhindert Aggregationen und faltet kotranslational mit hoher Geschwindigkeit unter Mitwirkung der ProteindisulfidIsomerase die neu synthetisierten Proteine. Außerdem ist BiP am Import von Polypeptiden in das ER-Lumen/Membran sowie den retrograden Transport aus dem ER von falsch gefalteten Proteinen zum Abbau im Zytosol beteiligt. GRP94 ist ein stark vertretenes Glykoprotein im ER und ist spezialisiert auf die Faltung und Reifung von komplizierten Proteinen, wie $\mu$-Ketten, Integrin und Toll-like-Rezeptoren, und spielt eine wichtige Rolle im Immungeschehen. Die Kalzium-abhängigen Lektin-Chaperone Calreticulin und Calnexin sind Komponenten der Proteinqualitätskontrolle. Wenn Glykoproteine im ER falsch gefaltet sind, binden sie an ein verbliebenes Glukosemolekül der Oligosaccharidkette, verhindern den Weitertransport zum Golgi-Komplex und unternehmen weitere Faltungsversuche. Das Golgi-Chaperon Clusterin (Apolipoprotein J) erleichtert unabhängig von ATP die Faltung von sezernierten Proteinen und ist an Lipidtransport, Recycling von Membranen und der Apoptose beteiligt. HSP100-Chaperone gehören zur Gruppe der AAA+-ATPasen (Triple-A-ATPasen) und bilden Ringe mit zentralem Kanal, in dem die Proteine oder Aggregate entfaltet und für den Proteasomabbau vorbereitet werden.

Die Familie der Chaperonine (HSP60/10, sog. ,holdases“) bilden im Zytosol und Mitochondrien fassähnliche Strukturen aus 2 Halbkreisen mit 8 Untereinheiten. Damit werden große ungefaltete Proteine, wie Actin und Tubulin, von der Umgebung abgeschirmt und unter Mitwirkung von Prefoldin gefaltet. Nach Spaltung von ATP ändert der Komplex die Konformation und gibt das Protein frei.

Cochaperone interagieren mit Chaperonen bei der Faltung von Proteinketten oder übergeben sie der Proteolyse, wenn die Refaltung nicht möglich ist. Erwähnt sei das „,cysteine string protein" als Mitglied der J-Proteinfamilie, die die Energiegewinnung aus ATP regulieren. Es unterstützt die Refaltung von fehlgefalteten Synapseproteinen und spielt eine Rolle bei der zystischen Fibrose und der HuntingtonKrankheit.

Die Geschwindigkeit der Proteinfaltung wird durch den Wechsel der cis-trans-Konfiguration der Säureamidbindung des Prolins bestimmt. Als Faltungshelfer sind deshalb Peptidyl-Prolyl-cis-trans-Isomerasen notwendig, von denen beim Menschen 33 Isoformen bekannt sind. Die Stabilisierung der dreidimensionalen Struktur erfolgt mit der ProteinDisulfid-Isomerase, die freie SH-Gruppen zu Disulfidbrücken oxidiert und falsche Brücken korrigiert. Beide Enzyme sind in Chaperon-Netzwerke eingebunden.

Von den Molekularen Chaperonen sind Pharmakologische Chaperone (helfen direkt bei Faltung und Stabilisierung durch Bindung an die Proteine) und Chemische Chaperone (verhindern unspezifisch z. B. die Aggregation durch Erhöhung der Löslichkeit) zu unterscheiden. So wurde 2009 Sapropterin zur Behandlung der Phenylketonurie zugelassen (Erfolgsquote 30-50 \%).

Defekte oder Funktionsstörungen der Chaperone wurden bei mehreren Krankheiten und im Alter gefunden. Mit den neuen sensitiven Methoden (ELISA, Blotting, LC-MS) können Chaperone auch im Plasma und Liquor (nach Zelltod oder Sekretion) gemessen werden. Weitere Studien sind nötig, um die Eignung für Diagnostik und Monitoring zu klären. Außerdem wird jetzt erforscht, ob die Bildung von Autoantikörpern gegen Chaperone zu klinischen Veränderungen führt.

\section{Literatur}

Macario AJL, de Macario EC (2005) Sick chaperones, cellular stress, and disease. N Engl J Med 353:1489-1501

Mattoo RU, Goloubinoff P (2014) Molecular chaperones are nanomachines that catalytically unfold misfolded and alternatively folded proteins. Cell Mol Life Sci 71:3311-3325

Smith HL, Li W, Cheetham ME (2015) Molecular chaperones and neuronal proteostasis. Semin Cell Dev Biol 40:142-152 


\section{Chaperonine}

$>$ Chaperone

\section{Charcot-Leyden-Kristalle}

\section{H. Baum}

\section{Englischer Begriff Charcot-Leyden crystals}

Definition Spindelförmige, leicht gelbliche, oktaedrische bis bipyramidale Kristalle als Sekretions- oder Auskristallisationsprodukte eosinophiler Granulozyten.

Beschreibung Charcot-Leyden-Kristalle sind extra- oder intrazytoplasmatisch lokalisierte kristalline Strukturen. Ihre genaue Herkunft ist nicht geklärt, allerdings haben sie Eigenschaften der membranständigen Lysophospholipase der eosinophilen Granulozyten ( $\triangleright$ Granulozyten, eosinophile). Nachweisbar sind die Charcot-Leyden-Kristalle in Organen bei Erkrankungen mit starker eosinophiler Komponente wie allergisches Asthma bronchiale, pulmonalen eosinophilen Infiltraten oder im Stuhl von Patienten mit parasitären Erkrankungen.

Die Abbildung zeigt extrazellulär liegende CharcotLeyden-Kristalle bei einer Eosinophilenleukämie (Knochenmark, 1000× May-Grünwald-Giemsa-Färbung):

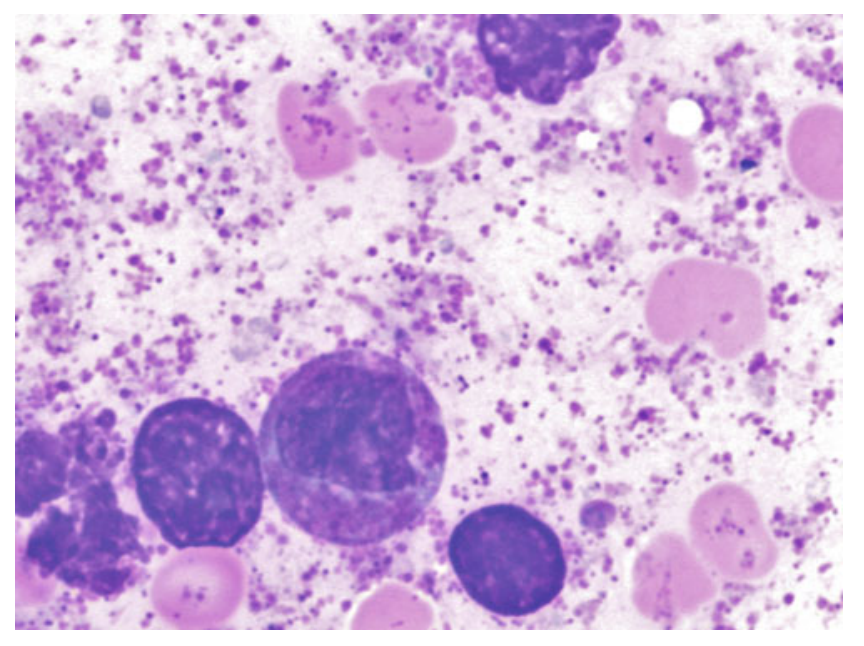

\section{Literatur}

Zucker-Franklin D (1991) Eosinopenia and eosinophilia. In: Williams WJ, Beutler E, Ersler AJ et al (Hrsg) Hematology, 4. Aufl. International Edition. McGraw-Hill, New York, S 845-849

\section{Chargenarchivierung}

O. Colhoun

$\operatorname{Synonym(e)~Chargenverwaltung~}$

Definition Zuordnung archivierter Chargendaten von Reagenzien zu den damit ermittelten Messwerten und Speicherung der Daten im Laborinformationssystem (LIS, > LaborEDV).

Beschreibung Das LIS soll Suchoptionen nach Chargennummer, Hersteller und Gültigkeitsdatum der gespeicherten Reagenzchargen anbieten. Die Funktion ist unabdingbar z. B. im Zusammenhang mit der Dokumentationspflicht nach Arzneimittelgesetz für medizinische Laboratorien sowie für Zwecke der Laborakkreditierung.

\section{Chargenverwaltung}

Chargenarchivierung

\section{${ }^{13} \mathrm{C}$-Harnstoff-Atemtest}

R. Tauber und F. H. Perschel

Englischer Begriff ${ }^{13} \mathrm{C}$-urea breath test

Definition Der ${ }^{13} \mathrm{C}$-Harnstoff-Atemtest ist ein nicht invasives Verfahren zum Nachweis von $>$ Helicobacter pylori im oberen Gastrointestinaltrakt, bei dem in einer Tracerdosis oral zugeführter ${ }^{13} \mathrm{C}$-Harnstoff durch die Urease von Helicobacter pylori abgebaut und das entstehende ${ }^{13} \mathrm{CO}_{2}$ als ${ }^{13} \mathrm{CO}_{2} /{ }^{12} \mathrm{CO}_{2}$ Verhältnis in der Atemluft bestimmt wird.

Durchführung Nach Gewinnung einer ersten Atemluftprobe ( $\mathrm{t}_{0}$-Probe) trinkt der nüchterne Patient $75 \mathrm{mg}{ }^{13} \mathrm{C}$-Harnstoff in $200 \mathrm{~mL}$ einer $0,1 \mathrm{mmol}$ Zitronensäurelösung. Nach 30 Minuten wird eine zweite Atemluftprobe ( $\mathrm{t}_{30}$-Probe) gewonnen In den Atemluftproben wird das ${ }^{13} \mathrm{CO}_{2} /{ }^{12} \mathrm{CO}_{2}$-Verhältnis mittels Isotopenverhältnis-Massenspektrometrie (IR-MS; s. > Massenspektrometrie) oder nicht dispersiver isotopenselektiver $\checkmark$ Infrarot-Spektrometrie (NDIRS) gemessen. 
Synthese - Verteilung - Abbau - Elimination Urease von Helicobacter pylori baut den oral zugeführten ${ }^{13} \mathrm{C}$-Harnstoff zu NH $\mathrm{N}_{3}$ und ${ }^{13} \mathrm{CO}_{2} \mathrm{ab}$. Entstehendes ${ }^{13} \mathrm{CO}_{2}$ wird abgeatmet. Hierdurch steigt der Anteil von ${ }^{13} \mathrm{CO}_{2}$ in Relation $\mathrm{zu}^{12} \mathrm{CO}_{2}$ in der ausgeatmeten alveolären Luft an.

Untersuchungsmaterial-Entnahmebedingungen Ausgeatmete alveoläre Atemluft.

Analytik Isotopenverhältnis-Massenspektrometrie (IR-MS) oder nicht dispersive isotopenselektive Infrarotspektroskopie (NDIRS)

Referenzbereich - Erwachsene Bei Besiedelung des oberen Gastrointestinaltrakts durch Helicobacter pylori steigt beim Patienten das ${ }^{13} \mathrm{CO}_{2} /{ }^{12} \mathrm{CO}_{2}$-Verhältnis in der alveolären Atemluft in der $\mathrm{t}_{30}$-Probe gegenüber der $\mathrm{t}_{0}$-Probe um mehr als $0,5 \delta \%$ an.

Indikation Verdacht auf Helicobacter-pylori-Infektion des oberen Gastrointestinaltrakts (bei Gastritis, Ulcus ventriculi, Ulcus duodeni, MALT-Lymphom, Magenkarzinom). Therapiekontrolle der Eradikation einer Helicobacter-pyloriInfektion.

Interpretation Ein Anstieg des ${ }^{13} \mathrm{CO}_{2} /{ }^{12} \mathrm{CO}_{2}$-Verhältnisses in der alveolären Atemluft zeigt eine Helicobacter-pyloriInfektion zuverlässig an, wobei der Anstieg mit dem Ausmaß der Infektion korreliert. Falsch negative Ergebnisse können trotz Erregerpersistenz nach Abschluss einer Antibiotikaoder Wismuttherapie infolge einer vorübergehenden Schädigung des Erregers beobachtet werden.

Diagnostische Wertigkeit Nicht invasives Nachweisverfahren einer Helicobacter-pylori-Infektion im oberen Gastrointestinaltrakt.

\section{Literatur}

Braden B, Lembcke B (2012) Heliobacter pylori-Infektion. In: Thomas L (Hrsg) Labor und Diagnose. Indikation und Bewertung von Laborbefunden für die medizinische Diagnostik, 8. Aufl. TH-Books, Frankfurt/Main, S 750-752

Fischbach W et al (2016) S2k-Leitlinie Helicobacter pylori und gastroduodenale Ulkuskrankheit. Z Gastroenterol 54:327-363

\section{Chelate}

H. Fiedler

Synonym(e) Chelatkomplexe; Komplexone
Englischer Begriff chelates; chelating agents

Definition Chelate sind Durchdringungskomplexe, bei denen ein zentrales Atom (Metallion) unter Ausbildung mehrerer Bindungen von einem oder mehreren mehrzähnigen Molekülen ringartig, wie von einer Krebsschere (chele), umgeben ist.

Beschreibung Die an der Komplexbildung beteiligten Gruppen sind funktionell verschieden, wie beispielsweise die Amino- und Carboxylgruppen von Aminosäuren oder Ethylendiamintetraessigsäure. Wichtige mehrzähnige Liganden sind Proteine, Polysaccharide, Nukleinsäuren, Porphyrine, Glutaminsäure und Histidin. Nach Bildung des Durchdringungskomplexes ist der Unterschied zwischen der Bindungsstärke der verschiedenen Gruppen aufgehoben, wodurch die Stabilität des Komplexes durch geringere Entropieabnahme deutlich erhöht wird.

Beispiele und Anwendungen von Chelaten:

- Hämoglobin, Zytochrome, Vitamin $\mathrm{B}_{12}$ und Calmodulin

- Matrix-Metalloproteinasen

- Biuretmethode

- Photometrische Bestimmung ( $\triangleright$ Komplexometrie) von Schwermetallen als Chelatkomplexe, während titrimetrische Analysen kaum noch angewendet werden

- EDTA (Antikoagulantien) und ähnliche Komplexbildner für die Plasmagewinnung

- Natriumcitrat für Gerinnungsanalysen

- Chelationstherapie wird nur für wenige toxische Metalle empfohlen, wie Ca-EDTA für Blei und Dimercaprol für Quecksilber. Die in der Alternativmedizin empfohlene „Ausleitung“ zur Prävention der Atherosklerose wird wegen zahlreicher Nebenwirkungen (Herzrhythmusstörungen, Krämpfe, Nierenversagen) strikt abgelehnt.

\section{Chelatkomplexe}

- Chelate

\section{Chelatometrie}

- Komplexometrie

\section{ChemG}

$>$ Chemikaliengesetz 


\section{Chemical lonization}

- Ionisationsmethoden (Massenspektrometrie)

\section{Chemikaliengesetz}

T. Arndt

Synonym(e) ChemG; Gesetz zum Schutz vor gefährlichen Stoffen

Definition Zweck des Chemikaliengesetzes (ChemG) ist es, den Menschen und die Umwelt vor schädlichen Einwirkungen gefährlicher Stoffe und Zubereitungen zu schützen, insbesondere sie erkennbar zu machen, sie abzuwenden und ihrem Entstehen vorzubeugen.

\section{Literatur}

http://www.gesetze-im-internet.de/bundesrecht/chemg/gesamt.pdf. Zugegriffen am 29.08.2017

\section{Chemilumineszenz}

>Chemolumineszenz

\section{Chemische Triebkraft}

- Affinität

\section{Chemokine}

\section{A. M. Gressner und O. A. Gressner}

\section{Englischer Begriff chemokines}

Definition Chemokine stellen eine Gruppe niedermolekularer (Molmasse ca. 8-14 kDa, 70-90 Aminosäuren), überwiegend basischer, strukturell verwandter Glykoproteine dar, die die Chemotaxis, Rekrutierung und Aktivierung verschiedener Subtypen von Leukozyten durch Interaktion mit einem Spektrum G-Protein-gekoppelter Rezeptoren bewirken.

Beschreibung Gegenwärtig sind etwa 40 Chemokine im Humansystem identifiziert, die hauptsächlich auf neutrophile
( $\triangleright$ Granulozyten, segmentkernige) und eosinophile Granulozyten ( $\triangleright$ Granulozyten, eosinophile), \Monozyten und - Lymphozyten wirken und entscheidende Funktionen bei der Immunabwehr, Entwicklung, Homöostase und Funktion des Immunsystems, Angiogenese und Angiostase sowie bei der Reaktion auf Virusinfektionen ausüben. Sie stimulieren subtypenspezifisch die zielgerichtete Leukozytenbewegung (Chemotaxis), -rekrutierung und -aktivierung $\left(\mathrm{Ca}^{2+}\right.$-Mobilisierung, oxidativer Burst) und sind daher für die Entzündungsregulation von entscheidender Bedeutung. Strukturell sind die niedermolekularen, basischen $>$ Glykoproteine durch die charakteristische Anordnung von bis zu vier konservierten Cysteinresten ähnlich und werden in vier Subklassen (Beispiele in Klammern) eingeteilt: CXC (IL-8, IP-10, Gro $\alpha, \beta, \gamma)$, CC (MIP-1 $\alpha$, RANTES), C (Lymphotactin) und CX3C (Fractalkine). Die Mitglieder der Chemokinfamilie üben die zellulären Effekte über mehr als 20 Rezeptoren großer Komplexität aus, die G-Protein-gekoppelt sind und 7 Membran-durchspannende Domänen besitzen (heptahelikale Rezeptoren). Trotz ihrer großen (patho)physiologischen Bedeutung haben Chemokinbestimmungen in der Diagnostik gegenwärtig noch keine Relevanz erlangt.

\section{Literatur}

Rollins BJ (1997) Chemokines. Blood 90(3):909-928

Zlotnik A, Yoshie O (2000) Chemokines: a new classification system and their role in immunity. Immunity 12:121-127

\section{Chemolumineszenz}

T. Arndt

Synonym(e) Chemilumineszenz

Englischer Begriff chemiluminescence

Definition Emission von Strahlung, die aus einer chemischen Reaktion resultiert. Die emittierende Substanz kann ein Reaktionsprodukt sein oder eine Verbindung, die durch Energieübertragung von einem angeregten Reaktionsprodukt angeregt wird (IUPAC 2014).

Beschreibung Der Anregungszustand kann Elektronensowie Schwingungs- und Rotationszustände betreffen. Liegt die Wellenlänge der Strahlung im Bereich des infraroten Lichts, spricht man von Infrarot-Chemolumineszenz.

Analysenverfahren auf der Basis von Chemolumineszenzmessungen haben eine wachsende Bedeutung im klinisch-chemischen Laboratorium, z. B. in der Hepatitisserologie und für die Bestimmung von Hormonen und $>$ Tumormarker. Hierzu steht eine 
relativ breite Auswahl an Analysen auf vollständig mechanisierten Analysensystemen zur Verfügung. Ein weiteres Anwendungsgebiet sind Techniken zur sensitiven Detektion bzw. Quantifizierung von Nukleinsäuren und Proteinen.

Chemolumineszenz durch Reaktionen innerhalb lebender Zellen wird als Biolumineszenz ( $\triangleright$ Biolumineszenz, allgemein) bezeichnet.

\section{Literatur}

IUPAC (2014) www.iupac.org/goldbook/L03641.pdf Zugegriffen am 14.08.2017

Latscha HP, Linti GW, Klein HA (2004) Analytische Chemie. Chemie-Basiswissen III. Springer, Berlin/Heidelberg/New York

\section{Chemotaktische Aktivität}

H. Renz und B. Gierten

Physikalisch-chemisches Prinzip Patienten-Granulozyten werden mittels eines Chemoattractants zur Chemotaxis angeregt. Als Testergebnis werden die Absolut- oder Prozentzahlen der zum Chemoattractant gewanderten Granulozyten ermittelt.

Untersuchungsmaterial Heparin-Blut.

Instrumentierung Keine.

\section{Fehlermöglichkeit}

- Blutprobe mit Gerinnseln

- Ungeeignete Komplementquelle oder bakterielles Peptid als Chemoattractant

- Fehler bei Färbung und Zählung der eingewanderten Granulozyten

Praktikabilität - Automatisierung - Kosten Keine Automatisierung möglich.

\section{Bewertung - Methodenhierarchie (allg.)}

- Schwer zu standardisierender manueller Test

- Bedarf großer Erfahrung des Untersuchenden

\section{Literatur}

Rich R (1996) Clinical immunology. Principles and practice. Mosby, St. Louis, S 2135

\section{Chenodesoxycholsäure}

$>$ Gallensäuren

\section{CH-50-Gesamtkomplement}

- Komplementsystem, Globalteste

\section{Chido: Ch, Cha, Chido, C4A}

- Chido/Rodgers-Blutgruppensystem

\section{Chido(Cha)-Antigen}

- Chido/Rodgers-Blutgruppensystem

\section{Chido/Rodgers-Blutgruppensystem}

K. Kleesiek, C. Götting, J. Diekmann, J. Dreier und M. Schmidt

Synonym(e) Chido: Ch, Cha, Chido, C4A; Rodgers: Rg, Rga, C4B

Englischer Begriff Chido/rodgers blood group system $(\mathrm{Ch} / \mathrm{Rg})$

Definition Die Antigene (s. - Antigen) des Chido/Rogers(Ch/Rg-)Blutgruppensystems stellen 2 Isoforme, C4A (sauer) und $\mathrm{C} 4 \mathrm{~B}$ (basisch), der vierten Komponente des Komplementsystems des klassischen Aktivierungswegs ( $\triangleright$ Komplementsystem, klassische Aktivierung) dar. Sie vermitteln die Interaktion zwischen Antigen-Antikörper-Komplexen und anderen Komplementkomponenten.

Beschreibung C4A und C4B werden als Vorläufer aus 1744 Aminosäuren (MW 200.000) exprimiert, glykosyliert und post-translational proteolytisch in 3 Polypeptidketten gespalten, die über Disulfidbrücken miteinander verbunden sind. Während der Komplementaktivierung wird das Protein in verschiedene Fragmente gespalten, wobei das C4d-Fragment die $\mathrm{Ch} / \mathrm{Rg}$-Epitope enthält (Tab. 1). Die proteolytischen Spaltungen sind inkomplette Reaktionen, wodurch viele strukturelle Formen des C4 im Plasma vorkommen. Diese 
Chido/Rodgers-Blutgruppensystem, Tab. 1 Eigenschaften der Hauptantigene des Chido/Rodgers-Blutgruppensystems

\begin{tabular}{|c|c|c|c|c|c|c|c|}
\hline \multirow[b]{2}{*}{$\begin{array}{l}\mathrm{Ch} / \mathrm{Rg}- \\
\text { Antigen }\end{array}$} & \multirow{2}{*}{$\begin{array}{l}\text { ISBT- } \\
\text { Symbol } \\
\text { (Zahl) }\end{array}$} & \multirow[b]{2}{*}{$\begin{array}{l}\text { Antigenfrequenz } \\
(\%)^{*}\end{array}$} & \multicolumn{3}{|c|}{ In-vitro-Charakteristika von Alloantikörpern } & \multicolumn{2}{|c|}{$\begin{array}{l}\text { Klinische Signifikanz von } \\
\text { Alloantikörpern }\end{array}$} \\
\hline & & & Immunglobulinklasse & $\begin{array}{l}\text { Optimale } \\
\text { Nachweistechnik }\end{array}$ & Komplementbindung & Transfusionsreaktion & MHN \\
\hline $\begin{array}{l}\mathrm{Ch}^{\mathrm{a}} \\
\text { Chido, } \\
\text { Ch1 }\end{array}$ & $\begin{array}{l}\mathrm{CH} / \mathrm{RG} 1 \\
(017.001)\end{array}$ & 96 & IgG & IAT & Nein & Keine & Keine \\
\hline $\begin{array}{l}\mathrm{Rg}^{\mathrm{a}}, \\
\text { Rodgers, } \\
\text { Rg1 }\end{array}$ & $\begin{array}{l}\text { CH/RG11 } \\
(017.001)\end{array}$ & 98 & $\operatorname{IgG}$ & IAT & Nein & Keine & Keine \\
\hline
\end{tabular}

Antigene werden aus dem Plasma an die Erythrozytenmembran gebunden. $\mathrm{Ch} / \mathrm{Rg}$-Antigene kommen im Plasma vor und werden an Blutzellen ( $>$ Erythrozyten, $>$ Makrophagen) adsorbiert. Sie werden primär in verschiedenen Organen synthetisiert.

Ein Fehlen der C4-Gene kann ein prädisponierender Faktor für Erkrankungen wie insulinabhängiger Diabetes und Autoimmunhepatitis sein. Spezifische C4-Allotypen oder Fehlen von Genen wurde mit Autoimmunerkrankungen wie Grave's Disease und rheumatoide Arthritis assoziiert. Fehlen von C4A führt zu einer höheren Suszeptibilität für den systemischen Lupus erythromatodes (SLE) und im Allgemeinen zu einer höheren Infektionsanfälligkeit.

Die $\mathrm{Ch} / \mathrm{Rg}$-Antigene können zur Bildung von erythrozytären Antikörpern führen, die zur Gruppe der > HTLA-Antikörper zählen. Besonderes Charakteristikum ist die Neutralisierbarkeit dieser Antikörper durch Plasma, das diese Antigene enthält ( $\triangleright$ Agglutinationstest)

Die Eigenschaften der Hauptantigene des Chido/RodgersBlutgruppensystems sind in Tab. 1 zusammengefasst.

\section{Literatur}

Blood Group Antigen Gene Mutation Database, NCBI, Bethesda, Maryland

Reid ME, Lomas-Francis C (2004) The blood group antigen facts book, 2. Aufl. Elsevier, NewYork

\section{Chikungunya-Viren}

W. Stöcker

\section{Englischer Begriff Chikungunya virus}

Beschreibung des Erregers Familie: Togaviridae; Gattung: Alphavirus; Art: Chikungunya-Virus. Plusstrang-RNAGenom, behüllt, 50-70 nm Durchmesser.

Erkrankungen Chikungunya-Fieber.
Verbreitung: Afrika, indischer Subkontinent, Südostasien, Südeuropa, Südamerika, Karibik.

Vektor: Stechmücken (Aedes aegypti, Ae. albopictus und Culex sp.).

Wirt: Primaten, Nagetiere, Mensch.

Übertragung: Durch Insekten, auch transplazentar und durch Bluttransfusion oder Organtransplantation möglich.

Klinik: plötzlich auftretendes hohes Fieber und grippales Syndrom, bei $80 \%$ Polyarthritis, die monate- bis jahrelang persistieren kann, Exantheme, Petechien; sehr selten Hämorrhagien, Meningoenzephalitis, Hepatitis.

Therapie und Prophylaxe: Es gibt keine spezifische Therapie, Behandlung nur symptomatisch. Bislang gibt es keinen zugelassenen Impfstoff, die Prävention besteht in der Vermeidung von Mückenstichen und in der Bekämpfung der Vektoren.

Analytik Das Arbeiten mit dem Erreger erfordert Sicherheitslaboratorien der Klasse 3.

Direktnachweis: RT-PCR $(\triangleright$ PCR (Polymerase-Kettenreaktion)), direkte Immunfluoreszenz oder Virusanzucht in Kulturzellen.

Serologie: Nachweis spezifischer Antikörper (IgG, IgM) im Serum durch indirekte Immunfluoreszenz ( Immunfluoreszenz, indirekte), ELISA ( $\triangleright$ Enzyme-linked Immunosorbent Assay), - Neutralisationstest oder Hämagglutinationshemmtest.

Untersuchungsmaterial - Probenstabilität Direktnachweis: Untersucht werden Blut und Blutbestandteile. Die Patientenproben sollten bis zur Weiterverarbeitung bei $+4{ }^{\circ} \mathrm{C}$ bis $+8{ }^{\circ} \mathrm{C}$ aufbewahrt werden. Direktnachweise sind innerhalb von 24 Stunden durchzuführen, Kulturen innerhalb von 6 Stunden anzulegen. Bei längerer Transportzeit ist das Material einzufrieren.

Serologie: Serum oder Plasma für den Nachweis der Antikörper sind bei $+4{ }^{\circ} \mathrm{C}$ bis zu 2 Wochen lang beständig, bei $-20{ }^{\circ} \mathrm{C}$ über Monate und Jahre hinweg. Zur Tiefkühlkonservierung des IgM kann man den Proben $80 \%$ gepuffertes Glyzerin beifügen.

Diagnostische Wertigkeit Screening von Blutkonserven auf virale RNA oder auf spezifische Antikörper. Der Direktnachweis ist nur während der ersten 3-5 Krankheitstage möglich, 
da die Erreger aus dem Blutkreislauf eliminiert werden, teilweise durch sich etablierende virusneutralisierende Antikörper.

Serologie: Spezifische Antikörper (IgG, IgM) findet man etwa vom 8. Krankheitstag an im Serum. Antikörper der Klasse IgM weisen auf eine akute Infektion hin, ebenso ein Titeranstieg des IgG innerhalb von 2 Wochen.

Differenzialdiagnosen: Unter anderem Dengue-Fieber ( $\triangleright$ Dengue-Viren), Zika-Fieber ( $>$ Zika-Viren), MayaroFieber, O'nyong-nyong-Fieber in Afrika, Ross-River-Fieber $(\triangleright$ Ross-River-Viren (RRV)) in Australien.

Durch die Verordnung zur Anpassung der Meldepflichten nach dem Infektionsschutzgesetz an die epidemische Lage (IfSG-Meldepflicht-Anpassungsverordnung), die am 01.05.2016 in Kraft getreten ist, wurde die Meldepflicht für Labore nach $\S 7$ Abs. 1 Satz 1 IfSG auf den direkten oder indirekten Nachweis von Chikungunya-Viren, D DengueViren, - West-Nil-Fieberviren, $>$ Zika-Viren und sonstige Arboviren ausgedehnt, soweit der Nachweis eine akute Infektion anzeigt. Darüber hinaus können allgemeine nicht erreger- oder krankheitsspezifische Meldepflichten bestehen.

\section{Literatur}

Her Z, Kam YW, Lin RT, Ng LF (2009) Chikungunya: A bending reality. Microbes Infect 11(14-15):1165-1176

Solignat M, Gay B, Higgs S, Briant L, Devaux C (2009) Replication cycle of chikungunya: a re-emerging arbovirus. Virology 393(2):183-197

Staples JE, Breiman RF, Powers AM (2009) Chikungunya fever: an epidemiological review of a re-emerging infectious disease. Clin Infect Dis 49(6):942-948

World Health Organization (2016) Media centre. Chikungunya fact sheet, April. http://www.who.int/mediacentre/factsheets/fs327/en/. Zugegriffen am 09.03.2017

\section{Child-Turcotte-Pugh-Klassifikation}

Child-Turcotte-Pugh-Score

\section{Child-Turcotte-Pugh-Score}

\section{A. M. Gressner und O. A. Gressner}

Synonym(e) Child-Turcotte-Pugh-Klassifikation;

Prognose-Score

Englischer Begriff Child-Turcotte-Pugh-classification; ChildTurcotte-Pugh-scoring system
Definition Aus klinischen und labormedizinischen Parametern zusammengesetzter Prognose-Score chronischer Lebererkrankungen, der u. a. für die Indikationsstellung zur Lebertransplantation herangezogen wird.

Beschreibung Der aus 5 bzw. 6 klinischen und labormedizinischen Kriterien bzw. Kenngrößen zusammengesetzte Score klassifiziert chronische Lebererkrankungen (z. B. Zirrhosen) in 3 Stadien der Ausprägung (mild $=\mathrm{A}$, mäßig $=\mathrm{B}$, schwer $=\mathrm{C}$ ):

\begin{tabular}{|l|l|l|l|}
\hline & $\begin{array}{l}\text { Stadium A } \\
\text { (1 Punkt) }\end{array}$ & $\begin{array}{l}\text { Stadium B } \\
\text { (2 Punkte) }\end{array}$ & $\begin{array}{l}\text { Stadium C } \\
\text { (3 Punkte) }\end{array}$ \\
\hline $\begin{array}{l}\text { Bilirubin } \\
\text { (mg/dL) }\end{array}$ & $<2,0$ & $2,0-3,0$ & $>30$ \\
\hline Albumin $(\mathrm{g} / \mathrm{L})$ & $>35$ & $28-35$ & $<28$ \\
\hline TPZ $(\%) ;$ INR & $>70 ;<1,7$ & $40-70 ; 1,7-2,3$ & $<40 ;>2,3$ \\
\hline Aszites & $\varnothing$ & $\begin{array}{l}\text { Leicht zu } \\
\text { behandeln }\end{array}$ & $\begin{array}{l}\text { Schwer zu } \\
\text { behandeln }\end{array}$ \\
\hline Enzephalopathie & $\varnothing$ & Stufen I, II & $\begin{array}{l}\text { Stufen III, IV } \\
\text { Stark reduziert }\end{array}$ \\
\hline Ernährungsstatus & Gut & Mäßig & $\mathbf{1 1 - 1 5}$ \\
\hline Score-Punkte & $\mathbf{5 - 7}$ & $\mathbf{8 - 1 0}$ & $\mathbf{1 0}$ \\
\hline
\end{tabular}

$I N R$, international normalized ratio; $T P Z$, Thromboplastinzeit

Einige Kenngrößen zeigen die Schwere der portalen Hypertension an (z. B. Aszites, Enzephalopathie), andere kennzeichnen die metabolische Leberfunktion (z. B. $>$ Bilirubin-, Albuminkonzentration, Thromboplastinzeit). Eine Alternative bietet der $>$ MELD-Score.

\section{Literatur}

Child CG III, Turcotte JG (1964) Surgery and portal hypertension. In: Child CG III (Hrsg) The liver and portal hypertension. WB Saunders, Philadelphia, S 50-64

Pugh RNH, Murray-Lyon IM, Dawson JJ et al (1973) Transection of the oesophagus for bleeding oesophageal varices. Br J Surg 60:646-649

\section{Chinablau}

Berlinerblau-Reaktion

\section{Chinidin}

C. Vidal und W.-R. Külpmann

Englischer Begriff quinidine

Definition Antiarrhythmikum (Klasse Ia). 
Strukturformel Chinidin:<smiles>C=CC1CN2CCC1C2C(O)c1ccnc2ccc(OC)cc12</smiles>

Molmasse $324,43 \mathrm{~g}$.

Synthese - Verteilung - Abbau - Elimination Chinidin wird oral appliziert und teilweise hepatisch metabolisiert. Muttersubstanz und Abbauprodukte werden renal eliminiert, bei saurem Urin-pH mehr, bei alkalischem weniger.

Halbwertszeit 4-12 Stunden (Plasma).

Funktion - Pathophysiologie Chinidin vermindert die Membranpermeabilität für $\triangleright$ Natrium-, $\triangleright$ Kalium- und - Calcium-Ionen, was zu einer verzögerten Erregungsfortleitung im Herzmuskel führt. Bei Überdosierung treten Blutdruckabfall, sowie Brady-, aber auch Tachykardie auf.

Untersuchungsmaterial - Entnahmebedingungen Plasma, Serum, Urin.

Analytik $\triangleright$ Immunoassay, HPLC, GC-MS; ( $\triangleright$ Chromatographie), LC-MS/MS ( $\triangleright$ Massenspektrometrie).

Interpretation Therapeutischer Bereich: $2-5 \mathrm{mg} / \mathrm{L}$; toxisch: $>5 \mathrm{mg} / \mathrm{L}$; komatös/letal: $>10 \mathrm{mg} / \mathrm{L}$.

Indikation Therapeutisches Drug Monitoring, Verdacht auf Vergiftung.

\section{Literatur}

König H, Schmoldt A (2009) Antidysrhythmic agents. In: Külpmann WR (Hrsg) Clinical toxicological analysis. Wiley-VCH, Weinheim, S $27-285$

\section{Chinolin}

$>$ Alkaloide

\section{Chip}

$>$ Mikroarray

\section{CHIP-1}

- Colton-Blutgruppensystem

\section{Chitinase 1}

$\checkmark$ Chitotriosidase

Chitotriosidase

\section{F. Bürger}

Synonym(e) Chitinase 1

Englischer Begriff chitotriosidase

Definition Chitotriosidase ist ein Enzym und gehört zu den Glykosyl-Hydrolasen. Sie ist für den Abbau von Chitin zuständig.

Struktur Die Chitotriosidase besteht aus einer N-terminalen katalytischen Domäne und einer C-terminalen Chitinbindenen Domäne, die mit einer flexiblen Region miteinander verbunden sind. Die Chitin-bindende Domäne liegt als eine 3 -dimensionale Faltung eines verdrillten $\beta$-Sandwiches vor. Die katalytische Domäne ist aus dem Sekundärstrukturmotiv „TIM barrel“ aufgebaut, das erstmals beim Enzym der Triosephosphat-Isomerase beobachtet worden ist. Hierbei sind $8 \alpha$-Helices und $8 \beta$-Faltblätter alternierend gefaltet, sodass sie die Form eines Fasses ausbilden.

Molmasse Es gibt 2 Isoformen: $50 \mathrm{kDa}$ (466 Aminosäuren) großes Protein und $39 \mathrm{kDa}$ (387 Aminosäuren) großes Protein.

Synthese - Verteilung - Abbau - Elimination Chitotriosidase ist sowohl als $50 \mathrm{kDa}$ - als auch als $39 \mathrm{kDa}$-Enzym katalytisch aktiv. In Geweben und speziell dort in Lysosomen kommt überwiegend das $39 \mathrm{kDa}$-Enzym vor; wohingegen im Blutkreislauf (Serum) vorwiegend das $50 \mathrm{kDa}$-Protein vorkommt.

Die Synthese des $50 \mathrm{kDa}$-Proteins erfolgt überwiegend in Makrophagen und Monozyten. Ein Teil davon wird zu den Lysosomen weitergeleitet. Die Verteilung der Chitotriosidase zu den Lysosomen erfolgt nicht - wie sonst üblich für lysosomale Enzyme - über die Wechselwirkung zwischen den N-Glykanen mit den Mannose-6-Phosphat-Rezeptoren. 
Pathophysiologie Chitotriosidase war und ist evolutionär von Vorteil bei der Abwehr von Parasiten sowie Hefe- und anderen Pilzinfektionen. Die Aktivität der Chitotriosidase ist bei Patienten mit Infektionen, chronischen Entzündungen und degenerativen Erkrankungen erhöht. Welche Rolle sie dabei spielt, ist bislang noch nicht geklärt.

Untersuchungsmaterial Serum, Plasma, Trockenblut.

Probenstabilität Serum/Plasma: bei Raumtemperatur 3-4 Wochen und bei $\leq 4{ }^{\circ} \mathrm{C} 3-4$ Monate. Trockenblut: bei Raumtemperatur 1 Monat, bei $4{ }^{\circ} \mathrm{C} 1$ Monat und bei $-80{ }^{\circ} \mathrm{C} 3-4$ Monate.

Präanalytik Plasma/Serum: Vollblut sollte innerhalb von 24 Stunden (optimal innerhalb von 2 Stunden) zentrifugiert werden. Der Überstand (Plasma/Serum) sollte anschließend in ein frisches Probengefäß überführt werden. Versand bei Raumtemperatur; im Sommer optimalerweise gekühlt oder gefroren.

Trockenblut: Blut auf Trockenblutkarte austropfen, sodass das Filterpapier auf der Vorder- und Rückseite vollständig durchtränkt ist. Die Trockenblutkarte lichtgeschützt mind. 2-4 Stunden bei Raumtemperatur trocknen lassen. Versand bei Raumtemperatur.

Analytik Fluorimetrische Ein-Schritt-Enzymatik mit dem künstlichen Substrat 4-Methylumbelliferyl- $\beta-\mathrm{D}-\mathrm{N}, \mathrm{N}^{\prime}, \mathrm{N}^{\prime \prime}$-triacetyl-chitotriose.

Konventionelle Einheit Plasma/Serum: $\mathrm{nmol} / \mathrm{ml} / \mathrm{h}$ (= $\mathrm{nmol} / \mathrm{ml} / 60 \mathrm{~min}$ ).

Trockenblut: pmol/Stanze/h (= pmol/3 $\mu \mathrm{l} / 60 \mathrm{~min})$.

(3 mm Stanzling ca. $3 \mu$ Blut.)

Internationale Einheit Plasma/Serum: $\mathrm{mU} / \mathrm{ml}(=\mathrm{nmol} /$ $\min / \mathrm{ml})$.

Trockenblut: $\mu \mathrm{U} / \mathrm{ml}(=\mathrm{pmol} / \mathrm{min} / \mathrm{ml})$.

Umrechnungsfaktor zw. konv. u. int. Einheit Plasma/ Serum: 1:60 ca. 0,0167.

Trockenblut: 5,55.

Referenzbereich - Erwachsene Laborabhängig! In der Regel ist die Aktivität der Chitotriosidase bei Erwachsenen aufgrund inflammatorischer Prozesse im Mittel höher als bei Kindern.

Indikation Erhöhte Aktivitäten finden sich z. B. bei M. Gaucher, M. Niemann-Pick Typ A/B oder Typ C, Sarkoidose, nephropatischer Cystinose, Atherosklerose, neurodegenerativen Erkrankungen, $\beta$-Thalassämie, Malaria.

Geeignet als Therapiekontrolle z. B. bei M. Gaucher, Sarkoidose, nephropatischer Cystinose.
Interpretation Cave: Ca. 6 \% der europäischen Bevölkerung haben eine sehr niedrige bis nicht nachweisbar niedrige Aktivität der Chitotriosidase. Dies ist durch eine Homozygotie für ein Null-Allel des CHIT1-Gens bedingt und kann zu falsch negativen Befunden führen.

Erhöhte Aktivität ( $>10$-fach im Plasma/Serum) deuten im allgemeinen auf M. Gaucher oder M. Niemann-Pick Typ A/B hin.

Diagnostische Wertigkeit Plasma/Serum ist gegenüber Trockenblut zu bevorzugen, da Trockenblut ein Mischwert aus Plasma/Serum und Blutzellen ist.

\section{Literatur}

Fadel $\mathrm{F}$ et al (2016) X-ray crystal structure of the full length human chitotriosidase (CHIT1) reveals features of its chitin binding domain. PLoS One 11(4):e0154190

Hollak C et al (1994) Marked elevation of plasma chitotriosidase activity. J Clin Invest 93:1288-1292

Stern R (2017) Go fly a chitin: the mystery of chitin and chitinases in vertebrate tissues. Front Biosci (Landmark) 22:580-595

\section{Chlamydia pneumoniae}

\section{W. Stöcker}

Englischer Begriff Chlamydia pneumoniae

Beschreibung des Erregers Der Erreger Chlamydia pneumoniae gehört neben Chlamydia trachomatis und Chlamydia psittaci zu den humanpathogenen Chlamydienarten. Sie sind gramnegativ und zählen zu den kleinsten obligat intrazellulär lebenden Bakterien. Ihr Stoffwechsel nutzt vor allem das Adenosintriphosphat der Wirtszelle. Ihr einzigartiger Entwicklungszyklus spielt in Diagnostik, Therapie und Pathogenese eine wichtige Rolle. Für Chlamydia pneumoniae gilt seit einigen Jahren der Gattungsname Chlamydophila, der sich allerdings noch nicht überall durchgesetzt hat.

Erkrankungen Chlamydia pneumoniae ruft Infektionen des oberen Respirationstrakts und Pneumonien hervor. Es wird über eine Rolle in der Pathogenese der koronaren Herzerkrankung diskutiert. Der Erreger wurde im Jahr 1986 entdeckt. Er kommt weltweit vor, ist ausschließlich humanpathogen und wird durch Aerosole übertragen. Die Serokonversion wird meistens im Alter zwischen 5-15 Jahren beobachtet. Über $50 \%$ aller Erwachsenen haben eine Infektion durchgemacht und sind gegenüber dem Erreger seropositiv. Bis heute gibt es keine Impfung gegen Chlamydien. Nachgewiesene Infektionen werden wirksam mit bestimmten Antibiotika, verabreicht über 7-14 Tage, behandelt. 
Analytik Direktnachweise durch Nukleinsäureamplifikationsverfahren (z. B. > PCR (Polymerase-Kettenreaktion)) sind für Chlamydia pneumoniae bisher nicht standardisiert. Die Kultur erfordert hohe technische Expertise.

Serologie: Nachweis von Antikörpern gegen Chlamydia pneumoniae durch Enzymimmuntechniken ( $\triangleright$ Enzymimmunoassay) oder indirekte Immunfluoreszenz ( $\triangleright$ Immunfluoreszenz, indirekte) (speziesspezifischer Mikroimmunfluoreszenztest: gereinigte Elementarkörperchen als Substrat, Inaktivierung des Lipopolysaccharid-(LPS-)Antigens, um Kreuzreaktivitäten zu minimieren, serologischer Goldstandard).

Untersuchungsmaterial - Probenstabilität Direktnachweis und Kultur: Das Abstrichmaterial (zellhaltiges Sekret aus den tieferen Atemwegen) wird in spezielle Transportmedien eingeimpft. Es sollte gekühlt transportiert und innerhalb von 4 Stunden analysiert werden.

Serologie: Serum oder Plasma für den Nachweis der Antikörper sind bei $+4{ }^{\circ} \mathrm{C}$ bis zu 2 Wochen lang beständig, bei $-20{ }^{\circ} \mathrm{C}$ über Monate und Jahre hinweg. Zur Tiefkühlkonservierung des IgM kann man den Proben $80 \%$ gepuffertes Glyzerin beifügen.

Diagnostische Wertigkeit Da sich Chlamydia-pneumoniaeInfektionen weder klinisch noch röntgenologisch eindeutig nachweisen lassen, fällt der Labordiagnostik eine besondere Rolle zu. Besonders wenn die Ansteckung länger zurückliegt, misslingt der Erregernachweis häufig, dann kommt der Diagnostik spezifischer Chlamydienantikörper eine besondere Bedeutung zu.

Kreuzreaktionen mit den übrigen Chlamydienspezies sind dabei auszuschließen, z. B. durch die parallele Untersuchung der Antikörper gegen Chlamydia psittaci und Chlamydia trachomatis, ggf. mit Biochip-Mosaiken.

\section{Literatur}

Burkhardt O, Staube E, Welte T (2003) Klinisches Bild, Diagnostik und Therapie. Pneumologie 57:449-458

Schütt S, Essig A (2004) Diagnostik von Chlamydien-Infektionen. J Lab Med 28(2):144-153

\section{Chlamydia psittaci}

W. Stöcker

Englischer Begriff Chlamydia psittaci
Beschreibung des Erregers Chlamydia psittaci gehört neben Chlamydia trachomatis und Chlamydia pneumoniae zu den humanpathogenen Chlamydienarten. Sie zählen zu den kleinsten intrazellulär lebenden, gramnegativen Bakterien und nutzen für den eigenen Stoffwechsel vor allem das Adenosintriphosphat der Wirtszelle. Für Chlamydia psittaci gilt seit einigen Jahren der Gattungsname Chlamydophila, der sich allerdings noch nicht überall durchgesetzt hat.

Erkrankungen Chlamydia psittaci ist der Erreger der Psittakose (Papageienkrankheit, auch Ornithose) - eine Zooanthroponose, die in der Regel von infizierten Zier- oder Zuchtvögeln, insbesondere Papageien, über erregerhaltiges Sekret und Exkremente aerogen auf den Menschen übertragen wird, selten auch durch Bisse. In wenigen Fällen erfolgt die Ansteckung von Mensch zu Mensch. Infektionsgefährdet sind neben Haltern von Zier- und Zuchtvögeln daher vor allem Tierhändler und Beschäftigte in der geflügelverarbeitenden Industrie. Als klinisches Bild resultiert eine subakute oder chronische Pneumonie, beobachtet werden milde Verläufe ebenso wie akute, fulminante Infektionen. In Deutschland ist die Erkrankung selten, im Jahre 2002 wurden nur 40 Fälle gemeldet. Bis heute gibt es keine Impfung gegen Chlamydien. Nachgewiesene Infektionen werden mit Antibiotika über 7-14 Tage behandelt.

Analytik Für den Direktnachweis stehen $>$ PCR (Polymerase-Kettenreaktion), die Anzucht in Zellkulturen oder die direkte Immunfluoreszenz unter Verwendung fluoreszeinmarkierter monoklonaler Antikörper gegen äußere Membranproteine von Chlamydia psittaci zur Verfügung. Der direkte Erregernachweis in der Zellkultur kann aufgrund der Kontagiosität des Erregers und der damit verbundenen Risiken nur in Einrichtungen durchgeführt werden, die über ein Sicherheitslabor der Klassifizierung L3 verfügen.

Serologie: Nachweis von Antikörpern gegen Chlamydia psittaci durch Enzymimmuntechniken ( $\triangleright$ Enzymimmunoassay) oder indirekte Immunfluoreszenz ( $\triangleright$ Immunfluoreszenz, indirekte) (speziesspezifischer Mikroimmunfluoreszenztest: gereinigte Elementarkörperchen als Antigen, Inaktivierung des Lipopolysaccharid-(LPS-)Antigens, um Kreuzreaktivitäten zu minimieren, serologischer Goldstandard).

Untersuchungsmaterial - Probenstabilität Direktnachweis und Kultur: Für die Anzucht und den Gennachweis werden Sputum, Trachealsekret und bronchoalveoläre Lavageflüssigkeit verwendet (Infektionsgefahr!). Das Material sollte gekühlt transportiert und innerhalb von 4 Stunden analysiert werden.

Serologie: Serum oder Plasma für den Nachweis der Antikörper sind bei $+4{ }^{\circ} \mathrm{C}$ bis zu 2 Wochen lang beständig, bei $-20^{\circ} \mathrm{C}$ über Monate und Jahre hinweg. Zur Tiefkühlkonservierung des IgM kann man den Proben 80 \% gepuffertes Glyzerin beifügen. 
Diagnostische Wertigkeit Bei der Diagnostik von Chlamydia-psittaci-Infektionen spielen das klinische Bild und die Anamnese (Vogelkontakte) eine große Rolle. Die labordiagnostischen Möglichkeiten zum Nachweis einer Chlamydia-psittaci-Infektion sind limitiert. PCR-Verfahren haben sich zum Nachweis akuter Infektionen als nützlich erwiesen, wurden bisher jedoch nicht anhand größerer Fallzahlen evaluiert. Infektionen mit Chlamydia psittaci werden daher im Allgemeinen serologisch diagnostiziert. Kreuzreaktionen mit den übrigen Chlamydienspezies sind dabei auszuschließen, z. B. durch die parallele Untersuchung der Antikörper gegen Chlamydia pneumoniae und Chlamydia trachomatis, ggf. mit Biochip-Mosaiken.

\section{Literatur}

RKI (2001) Infektionen durch Chlamydien (Teil 2): Erkrankungen durch Chlamydia psittaci und Chlamydia pneumoniae. Epid Bull 14:95-100 Schütt S, Essig A (2004) Diagnostik von Chlamydien-Infektionen. J Lab Med 28(2):144-153

\section{Chlamydia trachomatis}

\section{W. Stöcker}

Englischer Begriff Chlamydia trachomatis

Beschreibung des Erregers Chlamydia trachomatis gehört neben Chlamydia pneumoniae und Chlamydia psittaci zu den humanpathogenen Chlamydienarten. Sie zählen zu den kleinsten intrazellulär lebenden, gramnegativen $>$ Bakterien und nutzen für den eigenen Stoffwechsel vor allem das Adenosintriphosphat der Wirtszelle.

Erkrankungen Der Erreger verursacht folgende Erkrankungen:

- Das Trachom, eine chronische, follikuläre Keratokonjunktivitis (Serotypen A-B1, B2-C)

- Infektionen des Urogenitaltrakts bei Mann und Frau (Urethritis, Zervizitis, Salpingitis), teilweise mit reaktiver Arthritis (Serotypen D-K)

- Das Lymphogranuloma venereum, eine vor allem in warmen Ländern vorkommende Geschlechtskrankheit (Serotypen L1-L3)

Die Serotypen A-C werden durch infektiöses Augensekret übertragen, die Serotypen D-K sowie L1-L3 durch sexuellen Kontakt oder perinatal. Der Mensch ist das einzige Erregerreservoir.
Bis heute gibt es keine Impfung gegen Chlamydien. Chlamydieninfektionen sind mit Antibiotika über 7-14 Tage gut behandelbar. Bei einer reaktiven Arthritis ist eine längere, differenzierte Behandlung erforderlich, und zwar lokal und systemisch.

Analytik Direktnachweise durch Nukleinsäureamplifikationsverfahren (z. B. > PCR (Polymerase-Kettenreaktion)) oder mittels direkter Immunfluoreszenz. Die Kultur erfordert große technische Expertise.

Serologie: Nachweis von Antikörpern gegen Chlamydia trachomatis durch Enzymimmuntechniken ( $\triangleright$ Enzymimmunoassay) (die reaktiven Oberflächen werden vorwiegend mit Membranproteinen beschichtet) oder indirekte Immunfluoreszenz ( $\triangleright$ Immunfluoreszenz, indirekte) (speziesspezifischer Mikroimmunfluoreszenztest: gereinigte Elementarkörperchen als Substrat, Inaktivierung des Lipopolysaccharid-(LPS-)Antigens, um Kreuzreaktivitäten zu minimieren, serologischer Goldstandard).

Untersuchungsmaterial - Probenstabilität Direktnachweis und Kultur: Bei Genitalinfektionen werden Erststrahlurin oder Zervix-, Vaginal- und Urethralabstriche gewonnen (Dacron- oder Rayon-Abstrichtupfer verwenden!). Ideal zum Nachweis einer spezifischen Zervizitis sind laparoskopisch erhaltene Tubenabstriche oder Punktate des Douglas-Raums. Für die Zellkultur wird das Patientenmaterial in Spezialtransportmedien eingeimpft, es ist gekühlt zu transportieren und innerhalb von 4 Stunden anzusetzen.

Serologie: Serum oder Plasma für den Nachweis der Antikörper sind bei $+4{ }^{\circ} \mathrm{C}$ bis zu 2 Wochen lang beständig, bei $-20^{\circ} \mathrm{C}$ über Monate und Jahre hinweg. Zur Tiefkühlkonservierung des IgM kann man den Proben $80 \%$ gepuffertes Glyzerin beifügen.

Diagnostische Wertigkeit Bei akuten urogenitalen Infektionen wird angestrebt, die Erreger durch direkte Nachweisverfahren zu identifizieren. Aufgrund einer Spezifität von nahezu $100 \%$ galt der kulturelle Nachweis von Chlamydia trachomatis bis vor einiger Zeit als der Goldstandard in der Diagnostik urogenitaler Chlamydieninfektionen, wurde aber wegen des zu großen Aufwands und der zu geringen Sensitivität durch die PCR verdrängt.

Bei Chlamydia-trachomatis-assoziierten Folgeerkrankungen wie Tubarsterilität und reaktiver Arthritis ist der direkte Erregernachweis häufig nicht mehr möglich. Zur Sicherung der Diagnose kann der Nachweis spezifischer Antikörper in diesen Fällen hilfreich sein. Kreuzreaktionen mit den übrigen Chlamydienspezies sind auszuschließen, z. B. durch die parallele Untersuchung der Antikörper gegen Chlamydia psittaci und Chlamydia pneumoniae, gegebenenfalls mit BiochipMosaiken. 
Ein Chlamydia-trachomatis-Screening beider Elternteile vor einer geplanten Schwangerschaft wird empfohlen. Der Direktnachweis von Chlamydia trachomatis an der Portio uteri zu Beginn einer Schwangerschaft gehört heute zum Standardprogramm der Vorsorgeuntersuchungen, da diese Infektion mit dem Risiko von Früh- und Totgeburten assoziiert ist ( $\triangleright$ Mutterschaftsvorsorge).

\section{Literatur}

RKI (2009) Infektionen durch Chlamydien (Teil 1): Erkrankungen durch Chlamydia trachomatis. Epid Bull 37:369-373

Schütt S, Essig A (2004) Diagnostik von Chlamydien-Infektionen. J Lab Med 28(2):144-153

\section{Chlorid}

O. Müller-Plathe

\section{Englischer Begriff chloride}

Definition Chlorid (chemisches Symbol für Chlor: $\mathrm{Cl}$ ) ist mengenmäßig das wichtigste Anion des extrazellulären Raumes.

Molmasse $35,453 \mathrm{~g}$.

Synthese - Verteilung - Abbau - Elimination Aufnahme und Bedarf: Chlorid wird überwiegend als Kochsalz mit der Nahrung aufgenommen und im Dünndarm resorbiert (s. Tagesbedarf $>$ Natrium).

Bestand: Bei $70 \mathrm{~kg}$ Körpergewicht etwa $2300 \mathrm{mmol}$, davon rasch austauschbar $1600 \mathrm{mmol}$.

Verteilung: extrazellulärer Raum (EZR), ohne Knochen $56 \%$; Knochensubstanz $32 \%$; intrazellulärer Raum (IZR) $12 \%$.

Elimination: mit dem Urin $>90 \%$, mit dem Stuhl $<10 \%$. Starke Schweißbildung kann $\mathrm{zu}$ erheblichen $\mathrm{Cl}^{-}$-Verlusten führen.

Funktion - Pathophysiologie Nach glomerulärer Filtration folgt $\mathrm{Cl}^{-}$in den proximalen Tubuli dem aktiv reabsorbierten $\mathrm{Na}^{+}$. Im dicken aufsteigenden Teil der Henleschen Schleife wird $\mathrm{Cl}^{-}$duch eine $\mathrm{Cl}^{-}$-Pumpe reabsorbiert. Dieser Vorgang wird durch Schleifendiuretika wie Furosemid und Ethacrynsäure inhibiert.

Untersuchungsmaterial - Entnahmebedingungen Für herkömmliche Messung als Gesamtchlorid: Heparinplasma oder Serum nach venöser Abnahme. Für Messung in Vollblutproben (als ,ionisiertes Chlorid“) wird am besten eine mit lyophilisiertem, elektrolytadaptiertem Heparin ( $>$ Heparin und Heparinoide) präparierte Plastikspritze verwendet. Urin: Einzelproben oder 24-Stunden-Sammelurin. Schweiß: zur Diagnostik der zystischen Fibrose. Weitere Materialien: Magensaft, Stuhl, Drainageflüssigkeiten zur Erfassung von Elektrolytverlusten.

Probenstabilität Plasma, Serum: Bei $25{ }^{\circ} \mathrm{C} 4$ Tage, bei $4-8{ }^{\circ} \mathrm{C} 7$ Tage, bei $-20{ }^{\circ} \mathrm{C} 1 \mathrm{Jahr}$. Bei Aufbewahrung über mehr als 4 Tage Abtrennung von Erythrozyten erforderlich. Schutz vor Verdunstung! Heparinblut: Messung innerhalb von 8 Stunden. Da Chlorid meistens gemeinsam mit Natrium und Kalium gemessen wird, sind ggf. die strengeren Entnahme- und Stabilitätsregularien für Kalium zu beachten ( $\triangleright$ Kalium). Urin: wie Serum. Schutz vor Verdunstung.

Präanalytik Keine Patientenvorbereitung für $\mathrm{Cl}^{-}$-Messung in Vollblut, Plasma, Serum und Urin. Für die Schweißuntersuchung wird auf das NCCLS-Dokument C34-A2 (National Committee for Clinical Laboratory Standards 2000) verwiesen.

\section{Analytik}

1. Coulometrische Titration ( $\triangleright$ Coulometrie): Von der Silberelektrode des Chloridtitrators werden mit konstanter Geschwindigkeit $\mathrm{Ag}^{+}$freigesetzt. Solange $\mathrm{Cl}^{-}$in der Messlösung vorhanden ist, wird unlösliches $\mathrm{AgCl}$ gebildet. Sobald durch freies $\mathrm{Ag}^{+}$ein Stromfluss entsteht, wird sowohl die $\mathrm{Ag}^{+}$-Abgabe als auch ein mit Beginn der Titration gestartetes Zeitmesswerk gestoppt. Einstellung des Zeitmessers mit einer Kalibratorlösung. Bis auf Interferenzen durch $\mathrm{Br}^{-}, \mathrm{F}^{-}, \mathrm{CN}^{-}, \mathrm{SCN}^{-}$und SH-Gruppen, die normalerweise nur in geringsten Mengen vorliegen, ist die Methode spezifisch. Wegen des Messbereichs von 0 bis zu mehreren Hundert mmol/L ist das Verfahren für Plasma, Serum, Urin und für die Schweißuntersuchung geeignet. Impräzision bei bester Elektrodenpflege um $1 \% \mathrm{VK}$.

2. Ionenselektive Elektrode (ISE), indirekt nach Verdünnung der Probe: trotz gelegentlicher Instabilität verbreitetes Routineverfahren, mechanisierbar und gut in Analysenautomaten zu integrieren. Begrenzter Linearitätsbereich. Impräzision unter Routinebedingungen um $2 \%$.

3. Komplexometrisch-photometrische Methoden: Umsetzung von $\mathrm{Cl}^{-}$mit einem Quecksilbersalz, z. B. $\mathrm{Hg}$ $(\mathrm{SCN})_{2}$, zu HgCl. Das freigesetzte Thiozyanat wird zur Bildung eines photometrierbaren Farbkomplexes mit $\mathrm{Fe}^{3+}$ genutzt. Diese und ähnliche Methoden sind erfolgreich in Analysenautomaten integriert worden, sind jedoch durch spezielle Entsorgungsregularien wegen des $\mathrm{Hg}$-Anteils belastet. 
4. Enzymatisch-photometrische Methode: Sie beruht auf der Aktivierung der $\alpha$-Amylase durch Chlorid (Ono et al. 1988) und ist ohne weitere Messeinrichtungen in Analysenautomaten zu integrieren.

5. Ionenselektive Elektrode (ISE), direkt im unverdünnten Heparinblut oder Heparinplasma: sehr schnelle Messung im Vollblut ( $<1 \mathrm{~min}$ ), ohne den Aufwand der Zentrifugation und der Probendilution. Als $\mathrm{Cl}^{-}$-selektive Elektroden werden Membranelektroden mit neutralen Carriern oder mit Ionenaustauschern (z. B. quaternären Ammoniumsalzen) sowie Silberchlorid-Festkörperelektroden verwendet.

Die Methoden 1-4 erfassen die molare Chloridkonzentration im Plasma, Methode 5 die Aktivität des ionisierten Chlorids im Plasmawasser, also die molale Aktivität ( $\triangleright$ Elektrolyte). Durch ein entsprechendes Kalibrationsverfahren wird das Messsignal jedoch auf ein Plasma mit normalem Protein- und Lipidgehalt, also auf ein etwa 7,2 \% größeres Verteilungsvolumen bezogen, um die Ergebnisse kompatibel mit denen der konventionellen Chloridbestimmung zu machen. Es handelt sich also um eine ,justierte Molalitätmessung". Eine klinische Relevanz des ionisierten Chlorids gegenüber dem Gesamtchlorid hat sich - anders als beim Natrium - bisher nicht ergeben.

Konventionelle Einheit mval/L oder mEq/L.

Internationale Einheit $\mathrm{mmol} / \mathrm{L}$.

Umrechnungsfaktor zw. konv. u. int. Einheit 1 .

Referenzbereich - Erwachsene Plasma/Serum 98-107 $\mathrm{mmol} / \mathrm{L} ; 24-S t u n d e n-U r i n$ 100-250 mmol/Tag; Schweiß 5-35 $\mathrm{mmol} / \mathrm{L}$.

Referenzbereich - Kinder Plasma/Serum 98-107 mmol/L; Schweiß 5-35 mmol/L.

Indikation Plasma, Serum: intensivmedizinische Überwachung, anhaltende Magensaftverluste durch Erbrechen, Säure-Basen-Störungen (Berechnung der Anionenlücke, - Anionenlücke im Plasma), Störungen des Elektrolyt- und Wasserhaushalts bei Erkrankungen der Nieren und der Nebennieren, intensive diuretische Therapie.

Urin: Verdacht auf Bulimie; Kontrolle bei NaCl-armer Diät.

Schweiß: Diagnostik der zystischen Fibrose.

Interpretation Plasma: Fast immer folgt das Plasmachlorid bei Störungen im Wasser- und Salzhaushalt den Veränderungen der Natriumkonzentration. Chloridabweichungen ohne adäquate Natriumveränderungen weisen auf Säure-BasenStörungen hin.
Urin: Die Chloridausscheidung im Urin entspricht der $\mathrm{NaCl}$-Aufnahme. Bei chronischem Erbrechen und Bulimie findet man Werte $>15 \mathrm{mmol} / \mathrm{L}$.

Schweiß: $\mathrm{Cl}^{-}$bei zystischer Fibrose $>60 \mathrm{mmol} / \mathrm{L}$.

Vorkommen der Hypochlorämie

- Hyponatriämie: als begleitendes Symptom

- Hypochlorämische Alkalose: durch gastrointestinale Verluste (Erbrechen, Magensaftdrainage, konnatale Chloridorrhoe) oder renale Verluste (Hyperaldosteronismus, M. Cushing, Saluretika)

- Metabolische Azidose: Verdrängung durch andere Anionen (Azetazetat, Hydroxybutyrat, Laktat, Formiat)

- Respiratorischen Azidose: Verdrängung durch kompensatorischen Bikarbonatanstieg

\section{Vorkommen der Hyperchlorämie}

- Hypernatriämie: als begleitendes Symptom

- Hyperchlorämische Azidose: durch vermehrte Chloridaufnahme (Lysin- oder Argininhydrochlorid, Ureterosigmoideostomie) oder verminderte Chloridausscheidung (renaltubuläre Azidose, Karboanhydratasehemmer)

- Ersatz für vermindertes Plasmabikarbonat: Verluste von Pankreas- oder Dünndarmsekret

Diagnostische Wertigkeit Die Chloridbestimmung im Plasma hat eine geringere klinische Bedeutung als die der anderen Elektrolyte, da abweichende $\mathrm{Cl}^{-}$-Konzentrationen keine eigenständige Gefährdung anzeigen. $\mathrm{Cl}^{-}$im Plasma dient der ergänzenden Diagnostik und kann in Einzelfällen wertvolle Hinweise liefern. Sein Wert als Routinebestandteil eines jeden Elektrolytstatus ist umstritten.

\section{Literatur}

National Committee for Clinical Laboratory Standards (2000) Sweat testing: sample collection and quantitative analysis. Approved guideline. NCCLS document C34-A2. National Committee for Clinical Laboratory Standards, Wayne

Ono T, Taniguchi J, Mitsumaki H et al (1988) A new enzymatic assay of chloride in serum. Clin Chem 34:552-553

\section{Chlorid, ionisiertes}

$>$ Chlorid

\section{Chlorid im Schweiß}

Schweißanalytik 


\section{Chloroquin}

C. Vidal und W.-R. Külpmann

Englischer Begriff chloroquine

Definition Chloroquin wird zur Behandlung von Malaria, Polyarthritis und systemischem Lupus erythematodes eingesetzt. Strukturformel:<smiles>CCN(CC)CCCC(C)Nc1ccnc2cc(Cl)ccc12</smiles>

Molmasse $319,88 \mathrm{~g}$.

Synthese - Verteilung - Abbau - Elimination Chloroquin wird vollständig resorbiert und z. T. unverändert, z. T. in Form verschiedener Metabolite ausgeschieden.

Halbwertszeit 20 Stunden, zunehmend bis zu 50 Tage (Plasma).

Funktion - Pathophysiologie Bei akuter Vergiftung treten vor allem kardiotoxische Effekte auf, begleitet von einer Hypokaliämie. Insbesondere bei Patienten mit Glukose-6Phosphatdehydrogenasemangel kann sich eine Methämoglobinämie entwickeln.

Untersuchungsmaterial - Entnahmebedingungen Serum, Plasma, Urin.

Analytik HPLC ( $\triangleright$ Hochleistungs-Flüssigkeitschromatographie), $>$ GC-MS, Dünnschichtchromatographie ( $>$ Chromatographie)

Indikation Therapeutisches Drug Monitoring.

Interpretation Therapeutischer Bereich: 0,02-0,5 mg/L; toxisch: $>0,5 \mathrm{mg} / \mathrm{L}$; komatös-letal: $>3 \mathrm{mg} / \mathrm{L}$.

\section{Literatur}

Käferstein H (2009) Chloroquine. In: Külpmann WR (Hrsg) Clinical toxicological analysis. Wiley-VCH, Weinheim, S 635-639

\section{Chloroquinelution}

- Elution erythrozytärer Antikörper

\section{Cholecalciferol (Vitamin $\mathrm{D}_{3}$ )}

> Vitamin D

\section{Cholecystokinin}

A. M. Gressner und O. A. Gressner

Synonym(e) CCK; Pankreozymin; PZ

Englischer Begriff cholecystokinin; pancreozymin; CCK-PZ

Definition Ein in Dünndarm (Duodenum), Gehirn und Pankreas gebildetes, mit Pankreozymin identisches intestinales Polypeptidhormon mit stimulierender Wirkung auf die Gallenblasenkontraktion und Enzymsekretion des exokrinen Pankreas.

Beschreibung Das als Präpro-CCK gebildete, 33 - Aminosäuren große, lineare Polypeptid wird in den I-Zellen der Mukosa des oberen Dünndarms (vorwiegend Duodenum), in Hirn und Pankreas synthetisiert. Identisch mit Pankreozymin, große Ähnlichkeit mit $\gg$ Gastrin. Sekretionsstimuli sind intestinale Polypeptide und Aminosäuren (vorwiegend Tryptophan, Phenylalanin) von partiell verdauten Proteinen, Magensäure und längerkettige Fettsäuren (>9 Kohlenstoffatome, in Form von Mizellen). Kurzfristige postprandiale CCK-Erhöhung in der Zirkulation mit rascher Normalisierung, Halbwertszeit zwischen 2,5 und 5 Minuten.

Proteolytische Prozessierung führt zu strukturell heterogenen Formen (CCK-8, -33, -38, -59 Aminosäuren) mit jeweils gleichem C-terminalen Pentapeptid, das mit Gastrin identisch ist. Volle biologische Wirkung ist mit CCK-8 gegeben und abhängig von Tyrosinsulfatierung in Position 7. Über die beiden G-Protein-gekoppelten Rezeptoren CCK-A (Molmasse $120 \mathrm{kDa}$ und $80 \mathrm{kDa}$, vorwiegend Azinuszellen) und CCK-B (Molmasse 55 kDa, Magen-, Hirn- und ZNSLokalisation) werden folgende Wirkungen vermittelt:

- Stimulationen von Gallenblasenkontraktion und Gallesekretion

- Pankreatische Enzymsekretion und $>$ Sekretin-induzierte Wasser- und Bicarbonatsekretion

- Relaxation von Sphincter Oddi

- Stimulation der intestinalen Peristaltik

- Inhibition der Magenentleerung 
Im Nüchternplasma sehr niedrige Konzentration von $<80$ ng/L (genauer Wert stark methodenabhängig). Analyt sehr instabil (eisgekühltes, Aprotinin-enthaltendes Heparin-Plasma).

Konzentrationserhöhungen bei exokriner Pankreasinsuffizienz, Zoeliakie und Leberzirrhose, keine klinisch-diagnostische Relevanz. Pharmakologischer Einsatz von CCK-PZ im $>$ Sekretin-Pankreozymin-Test zur Diagnostik der exokrinen Pankreasinsuffizienz.

\section{Literatur}

Szelenyi Z, Szekely M, Hummel Z et al (2004) Cholecystokinin: possible mediator of fever and hypothermia. Front Biosci 9:301-308

\section{Cholestanol}

K. J. Lackner und D. Peetz

Synonym(e) Dihydrocholesterol

Englischer Begriff cholestanol

Definition Cholestanol ist ein Sterol, das durch Reduktion von Cholesterin entsteht.

Struktur $\mathrm{C}_{27} \mathrm{H}_{48} \mathrm{O}$.

Strukturformel:<smiles>CC(C)CCCC(C)C1=CCC2C3CC[C@H]4CC(O)CCC4(C)C3CCC12C</smiles>

Beschreibung Cholestanol ist ein Reduktionsprodukt von Cholesterin. Es findet sich im Stuhl und in der Galle. Cholestanol ist klinisch im Rahmen der zerebrotendinösen Xanthomatose bedeutsam, bei der es im Serum erhöht ist und diagnostisch genutzt wird. Die Bestimmung erfolgt üblicherweise mittels GC-MS.

\section{Literatur}

Moghadasian MH, Salen G, Frohlich JJ et al (2002) Cerebrotendinous xanthomatosis. A rare disease with diverse manifestations. Arch Neurol 59:527-529

\section{Cholestase-anzeigende Enzyme}

A. M. Gressner und O. A. Gressner

Synonym(e) Enzymmarker der Cholestase

Englischer Begriff enzymatic markers of cholestasis; cholestasis-indicating enzymes

Definition Es handelt sich um 4 Enzymaktivitäten im Blut, die bei Cholestase (Reduktion des Galleflusses der Leber) unterschiedlicher Ätiologie erhöht sind:

- Alkalische Phosphatase ( $>$ Phosphatase, alkalische; Leberisoenzym)

- $>\gamma$-Glutamyltransferase

- Leucinarylamidase(n) (eher historischer Parameter)

- $\quad 5$ '-Nukleotidase (eher historischer Parameter)

Synthese - Verteilung - Abbau - Elimination Bildung und Exkretion von täglich 500-600 mL Gallenflüssigkeit (Cholerese) stellen fundamentale Funktionen der Leber (Hepatozyten und Gallengangsepithelzellen) dar, die im Rahmen akuter und chronischer Lebererkrankung im unterschiedlichen Ausmaß beeinträchtigt sind (Cholestase). Intra- und extrahepatische, mechanische (Obstruktion) oder funktionelle (medikamentös toxische, infektiöse) Ursachen erzeugen charakteristische Enzymprofilveränderungen, die in einer Aktivitätserhöhung der oben genannten Enzyme bestehen.

Halbwertszeit s. Einzelenzyme.

Pathophysiologie Die Aktivitätsanstiege sind für die einzelnen Enzyme unterschiedlich und generell auf folgende Mechanismen zurückzuführen:

- Enzyminduktion in der Leber durch retenierte Gallensäuren

- Partielle Solubilisierung und Freisetzung membrangebundener Enzyme aus der kanalikulären oder sinusoidalen Hepatozytenplasmamembran durch Detergenzwirkung konzentrierter Gallensäuren

- Regurgitation von Galle durch Lockerung der ,tight junctions“" der Gallekapillaren 
- Verminderte Clearance der Enzyme aus der Zirkulation durch Veränderungen ihres Glykosylierungsmusters

Untersuchungsmaterial Serum.

Analytik s. Einzelenzyme.

Referenzbereich s. Einzelenzyme.

Bewertung s. Einzelenzyme.

\section{Literatur}

Trauner M, Meier PJ, Boyer JL (1998) Molecular pathogenesis of cholestasis. N Engl J Med 339:1217-1227

\section{Cholesterin}

\section{K. J. Lackner und D. Peetz}

Synonym(e) Cholesterol

\section{Englischer Begriff cholesterol}

Definition Wichtigstes Sterol bei Wirbeltieren.

Struktur $\mathrm{C}_{27} \mathrm{H}_{46} \mathrm{O}$.

Strukturformel:

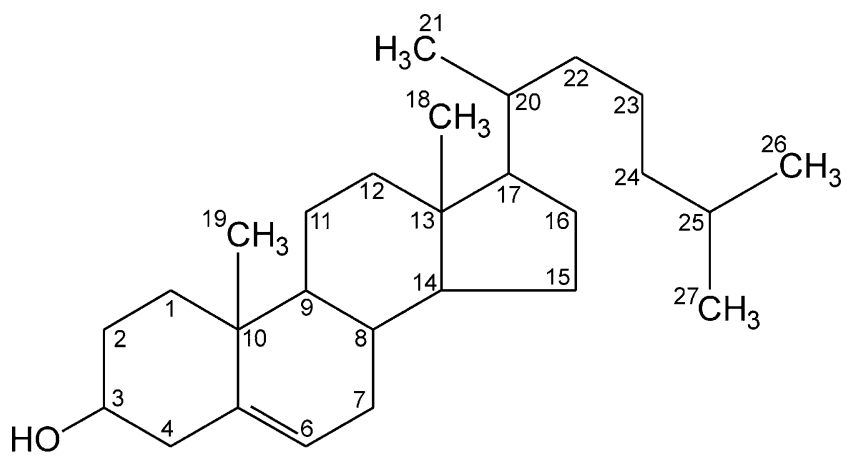

Molmasse $386,64 \mathrm{~g}$.

Synthese - Verteilung - Abbau - Elimination Prinzipiell können alle Körperzellen Cholesterin in einem komplexen Prozess synthetisieren. Geschwindigkeitsbestimmendes Enzym der Biosynthese, dessen Synthese und Aktivität u. a. über eine Produktrückkopplung reguliert werden, ist die HMG-CoA-Reduktase. Daneben können alle Körperzellen
Cholesterin rezeptorvermittelt aus der Zirkulation aufnehmen. Mit der Nahrung werden pro Tag ca. 0,2-1 g Cholesterin aufgenommen. Ausscheidung erfolgt über die Galle in Form von Cholesterin oder als Gallensäuren. Nicht hepatische Zellen können keine quantitativ bedeutsamen Mengen von Cholesterin abbauen. Eine Ausnahme bilden die Steroidhormon-produzierenden Gewebe, die Cholesterin in die jeweiligen Hormone (Glukokortikoide, Mineralokortikoide und Sexualhormone) umwandeln. Im Blut wird Cholesterin an Lipoproteine gebunden transportiert. Hier ist es zum gröBeren Teil an der $\mathrm{OH}-$ Gruppe des $\mathrm{C} 3$ mit einer Fettsäure verestert.

Halbwertszeit Die Halbwertszeit von Cholesterin im Blut korreliert mit der Halbwertszeit der jeweiligen Lipoproteinpartikel. Das bedeutet, dass mit LDL transportiertes Cholesterin eine andere Halbwertszeit hat als mit HDL transportiertes.

Funktion - Pathophysiologie Cholesterin ist das wichtigste Sterol aller Vertebraten. Es ist Bestandteil aller zellulären Membranen, deren Fluidität es beeinflusst. Daneben ist es Ausgangssubstanz für die Synthese von Steroidhormonen, > Gallensäuren, > Vitamin D u. a. Medizinisch ist Cholesterin als einer der wichtigsten Risikofaktoren der Atherosklerose in den Industrieländern von überragender Bedeutung.

Untersuchungsmaterial - Entnahmebedingungen Cholesterin wird üblicherweise aus Serum oder Plasma bestimmt. Es existieren aber auch Methoden zur Bestimmung aus Vollblut. Bei der Blutentnahme sollte der Patient 12 Stunden nüchtern sein, wobei inzwischen auch eine Blutentnahme in nicht nüchternem Zustand als akzeptabel für die Bewertung des kardiovaskulären Risikos angesehen wird. Es ist zu berücksichtigen, dass die Cholesterinspiegel aufgrund von Volumeneffekten im Sitzen um bis zu $5 \%$ höher sind als im Liegen. Cholesterin ist außerordentlich stabil. Nach Abtrennung zellulärer Bestandteile, die durch Lyse den Cholesterinspiegel im Serum verändern können, ist die Cholesterinkonzentration bei Raumtemperatur für mindestens 4 Tage stabil. Bei $-20^{\circ} \mathrm{C}$ kann Serum mindestens 5 Jahre gelagert werden, ohne dass sich die Cholesterinkonzentration wesentlich verändert.

Analytik Als definitive Methode gilt ein auf $\triangleright$ Isotopenverdünnung basierendes massenspektrometrisches Protokoll. Die Referenzmethode ist eine minimal modifizierte Methode nach Abell und Kendall. In der klinischen Routine wird Cholesterin enzymatisch bestimmt. Am weitesten verbreitet ist die Bestimmung mittels $>$ Cholesterinoxidase nach vorheriger Spaltung der Cholesterinester mit einer entsprechenden Cholesterinesterase nach dem Reaktionsschema in Abb. 1. 
Cholesterin, Abb. 1 Prinzip der enzymatischen

Cholesterinbestimmung

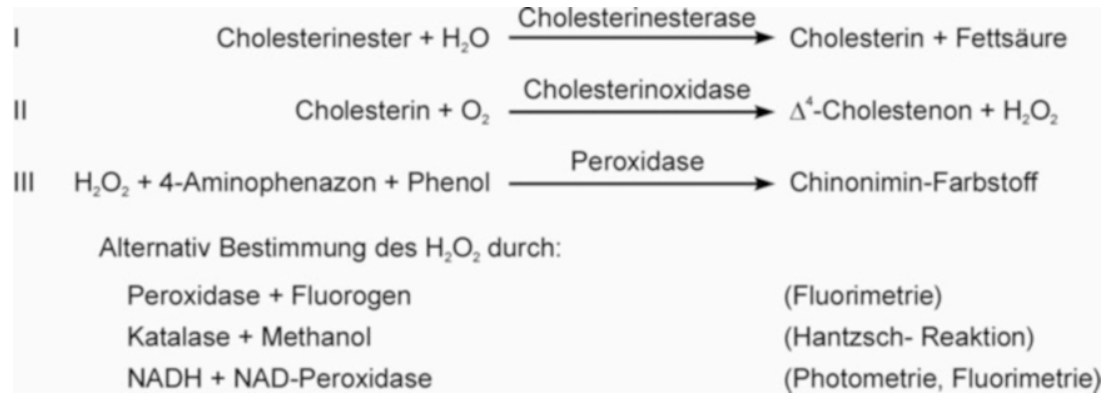

Daneben sind elektrochemische Bestimmung des $\mathrm{O}_{2}$-Verbrauchs und die UV-spektrometrische Bestimmung von Cholestenone beschrieben.

Die enzymatischen Methoden erreichen bei korrekter Handhabung eine Unpräzision $<3 \%$. Störfaktoren: Bilirubin $>20 \mathrm{mg} / \mathrm{dL}$. Hämolyse und Lipämie stören nur minimal.

\section{Konventionelle Einheit $\mathrm{mg} / \mathrm{dL}$.}

Internationale Einheit $\mathrm{mmol} / \mathrm{L}$.

Umrechnungsfaktor zw. konv. u. int. Einheit 0,02586.

Referenzbereich - Frauen Referenzbereiche im eigentlichen Sinn existieren nicht. Stattdessen werden im Hinblick auf das kardiovaskuläre Risiko in Abhängigkeit vom Alter, Risikofaktoren und Vorerkrankungen meist Zielwerte für das LDL-Cholesterin angegeben. Die 95. Perzentile für Gesamtcholesterin liegt in Mitteleuropa in der 3. Lebensdekade bei ca. $220 \mathrm{mg} / \mathrm{dL}$ und steigt bis zur 7. Dekade auf ca. $280 \mathrm{mg} / \mathrm{dL}$ an.

Referenzbereich - Männer S. oben. Das 95. Perzentil liegt bei Männern im höheren Alter mit ca. $270 \mathrm{mg} / \mathrm{dL}$ etwas niedriger als bei Frauen.

Referenzbereich - Kinder 95. Perzentile ca. 200 mg/dL.

Indikation Jeder Erwachsene jenseits des 25. Lebensjahres sollte mindestens einmal eine Bestimmung von Cholesterin, Triglyzeriden und HDL-Cholesterin erhalten, um ein möglicherweise erhöhtes kardiovaskuläres Risiko zu entdecken.

Interpretation Serumcholesterinspiegel werden zusammen mit den Triglyzeridwerten und insbesondere den Cholesterinkonzentrationen in der LDL- ( $>$ Low Density Lipoprotein) und HDL-Fraktion ( $\triangleright$ High Density Lipoprotein) bewertet. Dazu werden die Empfehlungen von Fachgesellschaften (z. B. European Society of Cardiology, European Atherosclerosis Society, American Heart Association) hinzugezogen.

\section{Cholesterinesterase}

K. J. Lackner und D. Peetz

Synonym(e) Carboxylesterhydrolase; Cholesterinesterhydrolase

Englischer Begriff cholesterol esterase; cholesteryl ester hydrolase

Definition Enzyme, die Cholesterinester hydrolytisch in Cholesterin und freie Fettsäuren spalten.

\section{Literatur}

Yeaman SJ (2004) Hormone-sensitive lipase-new roles for an old enzyme. Biochem J 379:11-22

\section{Cholesterinesterhydrolase}

Cholesterinesterase

\section{Cholesterinoxidase}

K. J. Lackner und D. Peetz

Synonym(e) EC 1.1.3.6

Englischer Begriff cholesterol oxidase 
Definition Enzyme, die Cholesterin in Gegenwart von $\mathrm{O}_{2} \mathrm{zu}$ Cholestenon oxidieren.

Beschreibung Cholesterinoxidasen werden aus verschiedenen Bakterien oder Hefen isoliert, z. B. Brevibacterium, Nocardia, Pseudomonas oder Streptomyces sp. Sie werden in der enzymatischen Cholesterinbestimmung eingesetzt.

\section{Literatur}

Warnick GR (1986) Enzymatic methods for quantification of lipoprotein lipids. Methods Enzymol 129:101-123

\section{Cholesterol}

Cholesterin

\section{Cholesterylester-Transferprotein}

K. J. Lackner und D. Peetz

\section{$\operatorname{Synonym(e)~CETP~}$}

Englischer Begriff cholesteryl ester transferprotein

Definition 476 Aminosäuren langes Glykoprotein, das den Austausch von Cholesterinestern und Triglyzeriden zwischen HDL und VLDL katalysiert.

Molmasse $74 \mathrm{kDa}$.

Struktur CETP gehört zu einer Lipidtransferproteinfamilie, der u. a. noch Phospholipidtransferprotein, Lipopolysaccharidbindungsprotein (LBP) und das permeabilitätsinduzierende Protein (BPI) angehören. CETP vermittelt den Transfer von Cholesterinestern von HDL nach VLDL im Austausch gegen Triglyzeride. Diese Funktion ist wichtig für den reversen Cholesterintransport. Die Bedeutung von CETP für die Pathogenese der Atherosklerose wird kontrovers diskutiert. Studien mit verschiedenen CETP-Inhibitoren zeigten zwar eine Erhöhung des HDL-Cholesterins jedoch keine Reduktion der Inzidenz kardiovaskulärer Ereignisse. Die Entwicklung von 3 Substanzen wurde deswegen beendet. Auch wenn ein CETP-Mangel zu erhöhtem HDL-Cholesterin führt, scheint eine verminderte Transferaktivität mit einem erhöhten kardiovaskulären Risiko einherzugehen.
Analytik Analytisch können sowohl die CETP-Masse mit konventionellen Ligandenbindungsassays als auch die Transferaktivität mit artefiziellen, radioaktiv oder fluoreszent markierten Substraten oder einfach durch die Abnahme von HDLCholesterinestern nach Hemmung der Lecithin-Cholesterinacyltransferase erfasst werden. Eine Standardisierung der Methodik existiert nicht. Die Korrelation zwischen Masse und Aktivität liegt bei etwa 0,85. Die Plasmakonzentration beträgt je nach Assay ca. 1-3 mg/dL. Die Transferaktivität hängt stark von den gewählten Assaybedingungen ab.

Diagnostische Wertigkeit Die Bestimmung von CETP kann bei der Abklärung eines erhöhten HDL-Cholesterins nützlich sein.

\section{Literatur}

Rifai N, Warnick GR, Dominiczak MH (2000) Handbook of lipoprotein testing, 2. Aufl. AACC Press, Washington, DC

\section{Cholinesterase II}

- Pseudocholinesterase

\section{Cholsäure}

$>$ Gallensäuren

\section{Chondrex}

> YKL-40

\section{Chondroitinsulfat-Dermatansulfat- Proteoglykane}

H.-D. Haubeck

Englischer Begriff chondroitin sulfate/dermatan sulfate proteoglycans 
Definition Chondroitinsulfat-/Dermatansulfat-Proteoglykane sind wichtige Komponenten der Extrazellulärmatrix in zahlreichen Geweben.

Beschreibung Chondroitinsulfat-/Dermatansulfat-Proteoglykane (CS-PG) bilden eine Gruppe von Proteoglykanen, bei denen das Core-Protein jeweils mit einer oder mehreren Chondroitinsulfat- bzw. Dermatansulfatketten substituiert ist. Die Chondroitinsulfat-Glykosaminoglykanketten, durch die die biochemischen Eigenschaften der Proteoglykane entscheidend geprägt werden, sind lineare Polysaccharide aus repetitiven Disaccharideinheiten von Glucuronsäure (GlcA) und $\mathrm{N}$-Acetyl-Galaktosamin (GalNAc) mit der Struktur [-4 GlcA $\beta 1 \rightarrow 3$ GalNAc $\beta 1 \rightarrow 4]$ n. $N$-Acetyl-Galaktosamin kann in 4- und 6-Stellung durch spezifische Sulfotransferasen sulfatiert werden. Beim Dermatansulfat wird ein Teil der Glucuronsäurereste in der Glykosaminoglykankette durch die C5Epimerase zu Iduronsäure epimerisiert. Diese Modifikationen erlauben die spezifische Interaktion der CS-PG mit verschiedenen Liganden, z. B. den Kollagenen vom Typ I, Typ II und Typ VI. Dementsprechend besitzen CS-PG vielfältige Funktionen in der Extrazellulärmatrix zahlreicher Gewebe.

$\mathrm{Zu}$ den CS-PG gehören neben dem $>$ Aggrecan weitere Mitglieder der Aggrecan-Genfamilie wie Versican, Neurocan, Brevican, das Basalmembran-assoziierte Bamacan, Phosphacan und die beiden Mitglieder der Familie der kleinen Leucin-reichen Proteoglykane (SLRP, ,small leucin-rich proteoglycans") $\triangleright$ Decorin und $>$ Biglykan.

Decorin und Biglykan sind u. a. für die Regulation der Fibrillogenese der Kollagene verantwortlich. Dementsprechend führen Gendefekte bei den Decorin- und Biglykan-defizienten (Knock-out-)Mäusen zur Bildung abnormer Kollagenfibrillen. Der Phänotyp dieser Mäuse umfasst ein breites Spektrum von Krankheiten des Bewegungsapparates, u. a. Osteoporose, Osteoarthritis sowie Bänder-, Sehnen- und Gelenkinstabilitäten.

CS-PG der arteriellen Gefäßwand, d. h. vor allem Versican, Decorin und Biglykan, wird eine Beteiligung an atherosklerotischen Prozessen zugeschrieben. Hierbei spielt die Fähigkeit dieser Proteoglykane, Lipoproteine zu binden und in der Gefäßwand zurückzuhalten, eine wichtige Rolle.

CS-PG, vor allem Neurocan, Brevican, Phosphacan und Versican sind nicht nur während der Entwicklung, sondern auch im reifen Zentralnervensystem (ZNS) weit verbreitet. CS-PG können nicht nur das Auswachsen von Neuriten inhibieren, sondern auch die axonale Regeneration nach ZNS-Schädigung. Sie werden darüber hinaus nach einer Schädigung lokal verstärkt exprimiert.

Störungen des Abbaus der Chondrotinsulfat-/Dermatansulfat-Glykosaminoglykanketten führen zur Speicherung der Glykosaminoglykane in mesenchymalen Geweben, im Nervengewebe und in verschiedenen inneren Organen und dadurch zu Speicherkrankheiten, den sog. Mukopolysaccharidosen ( $\triangleright$ Mukopolysaccharide und Glykosaminoglykane).

\section{Literatur}

Jones LL, Margolis RU, Tustynski MH (2003) The chondroitin sulfate proteoglycans neurocan, brevican, phosphacan, and versican are differenzially regulated following spinal cord injury. Exp Neurol 182:399-411

Williams KJ (2001) Arterial wall chondroitin sulfate proteoglycans: diverse molecules with distinct roles in lipoprotein retention and atherogenesis. Curr Opin Lipidol 12:477-487

\section{Chordozentese}

J. Arnemann

Synonym(e) Nabelschnurpunktion

Englischer Begriff cordocentesis

Definition Chordozentese oder Nabelschnurpunktion bezeichnet einen invasiven Eingriff bei der Schwangeren, um durch Punktion der Nabelschnurvene fetales Blut für gezielte diagnostische Analysen zu gewinnen.

Beschreibung Die fetale Nabelschnur hat im Normalfall 2 Arterien, die das vom Feten verbrauchte, sauerstoffarme Blut in den maternalen Kreislauf zurückführt, sowie eine Vene, die das sauerstoffreiche Blut in den fetalen Kreislauf führt. Die Punktion der Nabelschnurvene ist relativ risikoreich, zumal sie nur schlecht zu arretieren und damit sicher zu punktieren ist. Meist wird versucht, den relativ stabilen Anteil der Nabelschnur beim Übergang in die Plazenta zu treffen. Aufgrund der hohen Risiken für den Feten und die Schwangerschaft, u. a. auch aufgrund von möglichen Infektionen oder Blutungen, sollte eine Nabelschnurpunktion nur bei sehr hohem individuellen genetischen Risiko und/oder Abklärung von Stoffwechselstörungen erfolgen, meist nach der 20. Schwangerschaftswoche. Diagnostisch steht auch hier meist eine Chromosomenanalyse im Vordergrund, die schon innerhalb von 2-3 Tagen zu einem Ergebnis führt, während die Kultur und Chromosomenanalyse der Amnionzellen ungefähr 14 Tage dauert.

\section{Querverweise Amnionflüssigkeit}

\section{Literatur}

Weiner CP et al (1991) Risk factors for cordocentesis and fetal intravascular transfusion. Am J Obstet Gynecol 165:1020-1025 


\section{Choriongonadotropin, humanes}

\section{S. Holdenrieder und P. Stieber}

$\operatorname{Synonym(e)~hCG;~hCG~} \beta$

Englischer Begriff human chorionic gonadotropin; human choriogonadotropin

Definition Das humane Choriongonadotropin ist ein gonadotropes, in der Plazenta produziertes Glykoprotein mit einem Kohlenhydratanteil von ca. $30 \%$ und besitzt Hormoneigenschaften.

Struktur Das humane Choriongonadotropin besteht aus 237 Aminosäuren und ist aus einer $\alpha$ - und einer $\beta$-Kette zusammengesetzt, die nicht kovalent miteinander verbunden sind. Die 92 Aminosäurereste umfassende $\alpha$-Kette ist nahezu identisch ist mit der von Follitropin ( $\triangleright$ Follikelstimulierendes Hormon), Lutropin ( $\triangleright$ Luteinisierendes Hormon) und - Thyreotropin. Die 139 Aminosäure lange $\beta$-Kette, auch als hCG $\beta$ bezeichnete Untereinheit, hingegen ist spezifisch für hCG.

\section{Molmasse $38 \mathrm{kDa}$.}

Synthese - Verteilung - Abbau - Elimination Physiologisch wird das humane Choriongonadotropin in Synzytiotrophoblasten der Plazenta gebildet. Bei Keimzelltumoren geht seine Bildung von trophoblastären Strukturen oder auch von synzytiotrophoblastären Riesenzellen (den Seminomen) aus. Die Ausscheidung erfolgt überwiegend renal; desialinisierte Varianten werden vornehmlich hepatisch über die Bindung an den Asialoglykoproteinhormon-Rezeptor der Leber eliminiert. Beeinträchtigungen der Nierenfunktion können zu erhöhten hCG-Werten führen.

hCG wird schon früh nach Konzeption in der sich entwickelnden Plazenta in den Synzytiotrophoblasten synthetisiert und steigt zu Beginn der Schwangerschaft rasch im Serum und Urin der Mutter an. Die beiden Ketten werden zunächst getrennt voneinander synthetisiert. Während die $\alpha$-Kette von einem einzigen Gen kodiert wird, existieren 6 Gene für die $\beta$-Untereinheit. Die Sekretion erfolgt erst nach Dimerisierung und Glykosilierung. Die Ausscheidung erfolgt renal; desialinisierte Varianten werden überwiegend hepatisch über eine Bindung an den Asialoglykoprotein-Rezeptor der Leber eliminiert.

Halbwertszeit Die Halbwertszeit konnte in Patienten nach vollständiger Entfernung eines hCG-bildenden Tumors ermittelt werden. Danach fällt die Serumkonzentration mit einer angenäherten Halbwertszeit von 1-3 Tagen ab.
Funktion - Pathophysiologie Im Vergleich zum Schwangerschaftshormon hCG treten bei Patienten mit Trophoblastentumoren verschiedene definierte molekulare Varianten von hCG auf: Diese Mikroheterogenität des Hormons betrifft u. a.:

- Variationen in der Peptidstruktur und ihrer Verbindungen (,nicked hCG“)

- Veränderungen im terminalen Sialinsäuregehalt („AsialohCG“)

- Fragmentierung des hCG-Moleküls

Veränderungen im Kohlenhydratanteil des hCG beeinflussen den hepatischen Metabolismus und somit die physiologische Halbwertszeit. Außerdem ist die biologische Wirkung des Hormons vom Glykosilierungsgrad abhängig. Trotz der hCG-Varianten ist die Spezifität ( $\triangleright$ Spezifität, diagnostische) von hCG als $>$ Tumormarker nicht eingeschränkt.

Der Nachweis erheblicher Mengen von hCG im Blut oder Urin einer Frau ist ein sehr starker Indikator für eine Schwangerschaft. Physiologisch verhindert dieses Hormon die Monatsblutung nach Einnistung des Embryos in die Gebärmutterschleimhaut. In vielen malignen Tumoren lassen sich erhöhte Werte von hCG oder hCG $\beta$ nachweisen.

Untersuchungsmaterial - Entnahmebedingungen Serum/ Plasma oder Urin (Schwangerschaft); Serum/Plasma, Aszites, Pleurapunktat (maligne Tumoren).

Präanalytik Keine besonderen Vorkehrungen erforderlich.

Probenstabilität Im Serum bei Raumtemperatur bis 2 Tagen, bei $4{ }^{\circ} \mathrm{C}$ bis 1 Woche.

Analytik $>$ Enzymimmunoassay (EIA), \ Radioimmunoassay (RIA), Immunradiometrischer Assay (IRMA), - Elektrochemilumineszenz-Immunoassay (ECLIA), insbesondere unter Verwendung monoklonaler $>$ Antikörper.

Es existieren 3 verschiedene Immunoassays zur Bestimmung von hCG und/oder seiner $\beta$-Untereinheit. Sie erfassen

- das intakte dimere hCG-Molekül, bestehend aus einer $\alpha$ und $\beta$-Untereinheit (hCG),

- nur die freie $\beta$-Untereinheit (hCG $\beta$ ),

- sowohl intaktes hCG als auch die freie $\beta$-Untereinheit $(\mathrm{hCG}+\mathrm{hCG} \beta)$.

Für den Einsatz als Tumormarker muss das Testsystem hCG und hCG $\beta$ erfassen, da bestimmte Untergruppen von Hodentumoren, v. a. Seminome und selten Chorionkarzinome nur die freie $\beta$-Kette und kein intaktes hCG sezernieren können. 


\section{Konventionelle Einheit U/L.}

Referenzbereich - Frauen Empfohlener Referenzbereich im Serum: bis $5 \mathrm{IU} / \mathrm{L}$ (Serum, hCG und hCG + hCG $\beta$ ) vor der Menopause (jedoch nicht bei Schwangeren); bis $10 \mathrm{U} / \mathrm{L}$ (Serum, hCG und hCG + hCG $\beta$ ) nach der Menopause; bis 0,2 IU/L (Serum, freies hCG $\beta$ ).

In der Schwangerschaft (Wochen nach Empfängnis):

- 3. Woche bis $50 \mathrm{U} / \mathrm{L}$

- 4. Woche bis $400 \mathrm{U} / \mathrm{L}$

- 7. Woche 5000-90.000 IU/L

- 10. Woche 40.000-230.000 IU/L

- 13. Woche 40.000-140.000 IU/L

- 2. Schwangerschaftsdrittel 8000-100.000 IU/L

- 3. Schwangerschaftsdrittel 5000-65.000 IU/L

Mittels käuflicher Schwangerschaftstests wird lediglich ein qualitativer Nachweis von hCG und hCG $\beta$ im Harn geführt.

Referenzbereich - Männer Bis 5 IU/L (Serum, hCG und $\mathrm{hCG}+\mathrm{hCG} \beta$ ); bis $0,2 \mathrm{IU} / \mathrm{L}$ (Serum, freies hCG $\beta$ ).

\section{Referenzbereich - Kinder S. Männer}

Indikation Vorwiegend dient die Bestimmung von hCG und hCG $\beta$ zur frühen Erkennung einer Schwangerschaft. Der Test kann aus dem Serum oder aus dem Urin geführt werden. hCG wird aber auch von einigen seltenen Tumoren der Keimdrüsen produziert und dient daher als Tumormarker, insbesondere bei der Verlaufskontrolle und Therapieüberwachung. Dabei kann zwischen einer absoluten und einer relativen Indikation unterschieden werden.

\section{Absolute Indikation}

- Diagnose, Therapiemonitoring und Nachsorge bei Keimzelltumoren

- Blasenmole und Chorionkarzinom der Frau

- Hodentumor des Mannes

- Extragonadale Keimzelltumoren

\section{Relative Indikation}

- Überwachung von Patienten mit erhöhtem Risiko eines Keimzelltumors

- Maldescensus testis

- Gesunder eineiiger Zwillinge eines Patienten mit Hodentumor

- Patienten in Vollremission nach Therapie eines Hodentumors

- Andere Tumoren, die hCG sezernieren; insbesondere Prognose

\section{Weitere Indikationen}

- Frühdiagnose der Schwangerschaft

- Diagnose des Spontanabortes

- Diagnose chromosomaler Anomalien (Trisomie 21)

Es ist darauf hinzuweisen, dass einige Testhersteller die Diagnose oder Überwachung von Tumorerkrankungen ausdrücklich nicht in die Indikationsliste ihres hCG-Assays aufgenommen haben.

Interpretation Die meisten hCG-Assays sind für die Anwendung im Serum und Plasma ausgetestet und können auch für die hCG-Bestimmung in anderen Körperflüssigkeiten eingesetzt werden.

Die hCG-Bestimmung ist nicht als Screeningmethode maligner Tumoren geeignet, kann jedoch für die Überwachung von Risikogruppen (s. Indikation) eingesetzt werden. Ist eine Schwangerschaft ausgeschlossen, sprechen Konzentrationen über $10 \mathrm{U} / \mathrm{L}$ mit großer Wahrscheinlichkeit für einen malignen Tumor: Für die Diagnostik von Keimzelltumoren ist die Kombination von hCG und AFP ( $\triangleright \alpha_{1}$-Fetoprotein) angezeigt. Erhöhte hCG-Konzentrationen finden sich bei insbesondere beim testikulären oder plazentaren Chorionkarzinom und der Blasenmole (jeweils bis zu einigen Millionen U/L), außerdem beim Seminom (definitionsgemäß AFPnegativ) und bei nichtseminomatösen Keimzelltumoren des Hodens mit Ausnahme des hCG-negativen (und AFPpositiven) Dottersacktumors. Dabei ist zu beachten, dass im Verlauf eine Wandlung des Tumortyps erfolgen kann, wodurch sich auch die Markerkonstellation verändern kann.

Auch nichttrophoblastische Tumoren wie das kolorektale Karzinom, Magenkarzinom, Pankreaskarzinom, hepatozelluläre Karzinom, Bronchialkarzinom, Ovarialkarzinom, Mammakarzinom und das Nierenzellkarzinom können hCG und insbesondere die freie $\beta$-Kette des hCG sezernieren. Aufgrund der geringeren Freisetzung dient hier das hCG weniger der Unterstützung der Diagnose; allerdings hat es bei einigen Tumoren prognostische Bedeutung.

Ebenso finden sich bei Metastasen nichtseminomatöser Keimzelltumoren im Vergleich zum Primärtumor seltener Erhöhungen des hCG. Eine Normalisierung des hCGSpiegels nach Orchiektomie kann in diesen Fällen somit eine Tumorentfernung vortäuschen.

Benigne Erkrankungen führen in der Regel nicht zu erhöhten hCG-Konzentrationen im Serum. Ausnahme sind Niereninsuffizienzen, bei denen die Elimination von hCG beeinträchtigt ist. Außerdem ist bei der Bewertung der hCG-Konzentration eine potenziell vorliegende Schwangerschaft zu berücksichtigen, die insbesondere im ersten Trimenon mit deutlich erhöhten Werten einhergeht. 
Eine Erhöhung des hCG ist ein natürlicher Indikator einer Schwangerschaft (insbesondere Mehrlingsschwangerschaften).

\section{Diagnostische Wertigkeit}

- Keimzelltumoren (Blasenmole und Chorionkarzinom, Hodentumor): Diagnose, Therapiemonitoring und Rezidiverkennung

- Extragonadale Keimzelltumoren: Diagnose, Therapiemonitoring und Rezidiverkennung

- Überwachung von Risikogruppen für die Entwicklung eines Keimzelltumors

- Nichttrophoblastische Tumoren: Prognose

Die Zuverlässigkeit der Urinschwangerschaftstests ist $>95 \%$. Diese Tests liefern i. d. R. bei bestehender Schwangerschaft etwa 14 Tage nach der Befruchtung (ca. 1 Tag nach Ausbleiben der Regelblutung) ein positives Ergebnis. Im Blut gelingt der Nachweis von hCG etwas früher als im Harn (ca. 9 Tage nach der Empfängnis, also noch vor Ausbleiben der Menstruation). Falsch negative Ergebnisse im Harn finden sich in der Frühschwangerschaft bei starker Diurese und bei Spätovulation. Wenn der Test also negativ ausfällt, ist eine Schwangerschaft nicht sicher ausgeschlossen und sollte bei begründetem Verdacht nach einigen Tagen wiederholt werden. Ein falsch positives Testergebnis kann resultieren, wenn es zur Befruchtung und Einnistung der Eizelle kommt, die zu einem frühen Zeitpunkt aufgrund einer Fehlentwicklung abgestoßen wird.

\section{Literatur}

Lamerz R (2012) hCG (humanes Choriongonadotropin. In: Thomas L (Hrsg) Labor und Diagnose, 8. Aufl. TH-Books, Frankfurt am Main, S 1666-1673

Stieber P, Heinemann V (2008) Sinnvoller Einsatz von Tumormarkern. J Lab Med 32:339-360

Sturgeon CM, Duffy MJ, Stenman UH et al (2008) National Academy of Clinical Biochemistry laboratory medicine practice guidelines for use of tumor markers in testicular, prostate, colorectal, breast, and ovarian cancers. Clin Chem 54:e11-e79

Sturgeon CM et al (2009) Differences in recognition of the 1st WHO international reference reagents for hCG-related isoforms by diagnostic immunoassays for human chorionic gonadotropin. Clin Chem $55: 1484-1491$

Trapé $\mathrm{J}$ et al (2011) Increased plasma concentrations of tumour markers in the absence of neoplasia. Clin Chem Lab Med 49:1605-1620

\section{Choriongonadotropintest im Urin}

- Schwangerschaftstest im Urin

\section{Chorionzotten-Biopsie}

\section{J. Arnemann}

\section{Synonym(e) CVS}

Englischer Begriff chorion villus sampling (CVS)

Definition Die Chorionzotten-Biopsie (CVS) ist eine Methode zur pränatalen Diagnostik chromosomaler oder genetischer Störungen aus invasiv gewonnenen Chorionzotten (fetale plazentare Zellen).

Beschreibung Die Chorionzotten-Biopsie wurde eingeführt, um gegenüber der Amniocentese die Pränataldiagnostik zu einem früheren Zeitpunkt durchzuführen, nämlich seinerzeit bereits ab der 9. Schwangerschaftswoche. Dieser Zeitpunkt wurde aus medizinischen Gründen auf heutzutage ab der 11. Schwangerschaftswoche verschoben. Die medizinischen Indikationen sind z. B. mütterliches Altersrisiko, auffällige Ergebnisse beim Erstsemester-Screening, auffällige Nackenfalte, auffällige pränatale Ultraschalluntersuchungen oder familiäre Belastung mit einer Chromosomenstörung oder Anlageträgerschaft für eine genetische Erkrankung.

Zur Durchführung der Chorionzotten-Biopsie wird transzervikal mittels Katheder oder, bevorzugt, transabdominal mittels Punktion unter Ultraschallmonitoring ein Bioptat der möglichst fetalen Chorionzotten entnommen. Die Chorionzotten werden mittels Übersichtsmikroskop bezüglich fetaler und maternaler Zellen auseinanderdividiert und die fetalen Zotten entweder für eine Chromosomenlangzeitkultur angesetzt oder direkt für eine Chromosomenpräparation aufgearbeitet. Weiterhin wird die DNA extrahiert. Durch die Direktpräparation kann man das Ergebnis der Chromosomenanalyse im optimalen Fall bereits nach 24 Stunden erhalten, gegenüber 10-14 Tagen bei einer Chromosomenlangzeitkultur. Auch die meist gezielte Mutationsanalyse aus der DNA ergibt innerhalb kürzester Zeit ein Ergebnis.

Eine Chorionzotten-Biopsie ist aber auch mit Risiken verbunden. Im Vordergrund steht das Risiko einer Fehlgeburt als Folge des invasiven Eingriffs, das kontrovers diskutiert wird und mit $1-5 \%$ angegeben wird. Bei einer zeitlich sehr frühen Chorionzotten-Biopsie gibt es ein leicht erhöhtes Risiko für eine Deformation der Gliedmaßen. Weiterhin wird in 1-2\% aller Fälle ein plazentales Chromosomenmosaik beobachtet, das insbesondere bei auffälligen Chromosomenbefunden oftmals einen unauffälligen Chromosomensatz verbirgt.

Querverweise $>$ Amnionflüssigkeit 


\section{Literatur}

Royal College of Ostetricians and Gynaecologists (2010) Amniocentesis and chorionic villus sampling. Green-top guideline No. 8

\section{$\mathrm{CHr}$}

> Retikulozytenhämoglobin

\section{Christmas-Faktor}

> Gerinnungsfaktor IX

\section{Chrom}

D. Meißner und T. Arndt

\section{Englischer Begriff chromium}

Definition Chrom (chemisches Symbol: $\mathrm{Cr}$ ) ist ein ubiquitär vorkommendes Übergangsmetall ( $\triangleright$ Übergangsmetalle) mit der Ordnungszahl 24. Es gehört zu den essenziellen $>$ Ultraspurenelementen, zeigt jedoch auch zahlreiche toxische Wirkungen.

Struktur Von Bedeutung sind dreiwertiges $\mathrm{Cr}(\mathrm{Cr}(\mathrm{III}))$ als Kation $\left(\mathrm{Cr}^{3+}\right)$ und sechswertiges $\mathrm{Cr}(\mathrm{Cr}(\mathrm{VI}))$ als Anion $\left(\mathrm{CrO}_{4}{ }^{2-}\right)$. Im Blut liegt $\mathrm{Cr}(\mathrm{III})$ an $\beta$-Globulin und $>$ Transferrin gebunden im Plasma und $\mathrm{Cr}(\mathrm{VI})$ an den Globinanteil des $>$ Hämoglobin gebunden in den Erythrozyten vor.

Molmasse Relative Atommasse: 51,996.

Synthese - Verteilung - Abbau - Elimination. Über die Nahrung zugeführtes Chrom wird an > Aminosäuren gebunden und über die Mukosazellen des Dünndarms absorbiert. Mit der Atemluft inhaliertes Chrom wird durch Endozytose in die Lunge aufgenommen. Die Absorption von $\mathrm{Cr}(\mathrm{VI})$ ist deutlich höher als die von Cr(III). Die stabile Form im Organismus ist $\mathrm{Cr}(\mathrm{III})$. $\mathrm{Cr}(\mathrm{VI})$ wird rasch reduziert. Hauptspeicherorte sind Leber, Nieren, Milz, Lunge und Knochen.

Oral aufgenommenes Cr(III) wird zu 99 \% über den Stuhl und nur zu $0,5 \%$ über den Harn ausgeschieden. Inhalativ resorbiertes $\mathrm{Cr}(\mathrm{III})$ unterliegt einer stärkeren renalen Ausscheidung. Die Eliminationshalbwertszeit soll dann nur 4-10 Stunden betragen. Die Ausscheidung oral aufgenom- menen $\mathrm{Cr}(\mathrm{VI})$ erfolgt zu $80 \%$ innerhalb von 4 Tagen über den Urin, wobei $60 \%$ der resorbierten Menge schon innerhalb der ersten 8 Stunden im Urin erscheinen. Die damit einhergehenden hohen Chromkonzentrationen in den Nierentubili sollen auch für die Nephrotoxizität von $\mathrm{Cr}(\mathrm{VI})$ Verbindungen verantwortlich sein.

Es bestehen $>$ Interaktionen mit einigen organischen Verbindungen sowie mit $\triangleright$ Zink, $\triangleright$ Eisen und $\triangleright$ Vanadium. Das radioaktive Isotop ${ }^{51} \mathrm{Cr}$ wird zur Markierung von Erythrozyten bei der Bestimmung der Erythrozytenüberlebenszeit verwendet.

Körperbestand $\left(\mathrm{Cr}_{\text {ges }}\right) 10-20 \mathrm{mg}$, Bedarf $<20 \mu \mathrm{g} / \mathrm{Tag}$, empfohlene Zufuhr 50-200 $\mu \mathrm{g} / \mathrm{Tag}$, tolerierbare Aufnahme pro Tag 3,5 $\mu \mathrm{g} / \mathrm{kg}$ KG. Chromreich sind Fleisch, Vollkorn, Pflanzenöl, Bierhefe.

Halbwertszeit 3 Monate.

Funktion - Pathophysiologie Eine essenzielle Funktion hat $\mathrm{Cr}(\mathrm{III})$, während $\mathrm{Cr}(\mathrm{VI})$ toxisch wirkt. Chrommangel tritt bei normaler Mischkost nicht auf, ist aber bei Patienten mit totaler parenteraler Ernährung und bei Älteren mit einseitigen Essgewohnheiten möglich. Cr(III) ist Bestandteil des sog. Glukosetoleranzfaktors (Komplexverbindung mit Nikotinsäure - Niacin, \Glutaminsäure, > Cystin und > Glyzin), der die Glukosetoleranz verbessert. Bei Chrommangel werden Hyperglykämie und reduzierte Glukosetoleranz beobachtet, die durch Chromsupplementierung beseitigt werden können. Dieses Verhalten ist zum Nachweis eines Chrommangels geeignet. Chrom soll einen positiven Einfluss auf HerzKreislauf-Krankheiten und Arteriosklerose haben.

Belastungsquellen für Chrom: Metallüberzüge, Farbpigmente, Klärschlämme, Zement, in der Galvanik, der Färberei und der Lederbearbeitung. Der Gefahr durch Chrom(VI)Migration aus Kinderspielzeug wird besondere Aufmerksamkeit geschenkt (EU-Richtlinie 2009).

Ein Überschuss an $\mathrm{Cr}$ (III) führt zur Hemmung der Superoxiddismutase und dadurch zur Verminderung des Schutzes gegen Sauerstoffradikale $>$ Reaktive Sauerstoffspecies. $\mathrm{Cr}$ (VI) wirkt toxisch auf Haut (Kontaktallergien, Ekzeme, schwer heilbare Ulzera), Schleimhäute der Atemwege, Lunge (Tumoren) und oral aufgenommen auf Magen-Darm-Trakt, Nieren und Kreislauf. Cr(VI) ist kanzerogen.

Untersuchungsmaterial - Entnahmebedingungen Blut, Serum, Plasma, Urin.

Probenstabilität Blut: $20{ }^{\circ} \mathrm{C} 7$ Tage. Serum und Plasma: $20{ }^{\circ} \mathrm{C} 7$ Tage, $4-8{ }^{\circ} \mathrm{C} 14$ Tage, $-20{ }^{\circ} \mathrm{C} 1 \mathrm{Jahr}$. Urin: $20{ }^{\circ} \mathrm{C}$ 3 Tage, $4-8{ }^{\circ} \mathrm{C} 7$ Tage, $-20^{\circ} \mathrm{C} 1 \mathrm{Jahr}$.

Präanalytik Hohe Kontaminationsgefahr. Blutabnahme in Spurenelementröhrchen mit stahlfreien oder beschichteten 
Kanülen, andernfalls sind möglichst mehrfach gebrauchte Kanülen zu verwenden (Chromabgabe). Zur Chrombestimmung nicht die ersten 1-2 mL Blut einsetzen.

Analytik Elektrothermische $>$ Atomabsorptionsspektrometrie.

Konventionelle Einheit $\mu \mathrm{g} / \mathrm{L}, \mu \mathrm{g} / \mathrm{d}$.

Internationale Einheit $\mathrm{nmol} / \mathrm{L}, \mathrm{nmol} / \mathrm{d}$.

Umrechnungsfaktor zw. konv. u. int. Einheit nmol/L (d) $=19,232 \times \mu \mathrm{g} / \mathrm{L}(\mathrm{d}), \mu \mathrm{g} / \mathrm{L}(\mathrm{d})=0,051996 \times \mathrm{nmol} / \mathrm{L}(\mathrm{d})$

Referenzbereich - Erwachsene Urin: $\mathrm{Cr}_{\text {ges }}<0,6 \mu \mathrm{g} / \mathrm{L}$, $\mathrm{Cr}_{\text {ges }}<0,7 \mu \mathrm{g} / 24 \quad \mathrm{~h}$. Plasma und Serum: $\mathrm{Cr}(\mathrm{III})$ $<0,5 \mathrm{mg} / \mathrm{L}$. Vollblut: $\mathrm{Cr}_{\text {ges }}$ 0,5-4,0 $\mu \mathrm{g} / \mathrm{L}$. Erythrozyten: $\mathrm{Cr}$ (VI) $<0,7 \mathrm{mg} / \mathrm{L}$ (Schroeder 2016).

Referenzbereich - Kinder s. Erwachsene.

Indikation Verdacht auf Chrommangel bei gestörter Glukosetoleranz oder schwer einstellbarem Diabetes mellitus, Verdacht auf übermäßige Aufnahme von Chrom, Chromvergiftung, arbeitsmedizinische Untersuchung.

Interpretation $\mathrm{Da} \mathrm{Cr}(\mathrm{III})$ ein essenzielles Ultraspurenelement ist, durch seine geringe Löslichkeit und Resorption eine geringe Toxizität aufweist und wohl nicht krebserregend ist, $\mathrm{Cr}(\mathrm{VI})$ aber hochtoxisch und krebserregend, wären Analysenverfahren, die eine Differenzierung von $\mathrm{Cr}(\mathrm{III})$ und $\mathrm{Cr}$ (VI) ermöglichen, zu bevorzugen. Sie haben sich allerdings im klinisch-chemischen Routinelabor noch nicht als Standard durchgesetzt. Es wird deshalb zumeist noch mit der Gesamtchromkonzentration $\left(\mathrm{Cr}_{\text {ges }}\right)$ gearbeitet.

Deren Referenzwerte liegen nahe der $\gg$ Nachweisgrenze, weshalb der Nachweis des Chrommangels nur bedingt möglich ist. Zur Beurteilung des Chromstatus ist Chrom im Plasma am besten geeignet. Die Chrombestimmung hat in der Arbeitsmedizin zur Kontrolle einer Expositionsbelastung große Bedeutung. Ein BAT-Wert ist gegenwärtig nicht definiert (ausgesetzt wegen krebserzeugenden Eigenschaften von Cr(VI)-Verbindungen). Die aktuelle BAT-Liste (DFG 2017) definiert einen BAR-Wert für Chrom und seine Verbindungen $\left(\mathrm{Cr}_{\text {ges }}\right)$ im Urin von $0,6 \mu \mathrm{g} / \mathrm{L}$.Zu vom $\mathrm{CrO}_{3}$-Gehalt der Arbeitsraumluft abhängigen zulässigen $\mathrm{Cr}_{\text {ges }}$-Konzentrationen in Erythrozyten (Vollblut) bzw. Urin siehe Kapitel 13 in DFG 2017).

Erhöhte Chromkonzentrationen bedeuten nicht unmittelbar und unbedingt ein gesundheitliches Risiko, sollten aber stets kontrolliert werden, wobei Kenngrößen und Funktionswerte möglicherweise betroffener Organsysteme parallel untersucht werden sollten.
Diagnostische Wertigkeit Diagnose der übermäßigen Aufnahme, Belastung oder Vergiftung durch Chrom.

\section{Literatur}

DFG (2017) Ständige Senatskommission zur Prüfung gesundheitsschädlicher Arbeitsstoffe. Mitteilung 53. MAK- und BAT-Liste 2017. Wiley-VCH, Weinheim

EU-Richtlinie (2009) Richtlinie 2009/48/eg des Europäischen Parlaments und des Rates vom 18. Juni 2009 über die Sicherheit von Spielzeug. http://eur-lex.europa.eu/legal-content/DE/TXT/?uri=CE LEX:32009L0048; letzter Zugriff 29.08.2017

Meißner D (2002) Chrom. In: Biesalski HK, Köhrle J, Schümann K (Hrsg) Vitamine, Spurenelemente und Mineralstoffe. Georg Thieme Verlag, Stuttgart/New York, S 235-236

Schroeder C (2016) Problematik, Klinik und Beispiele der Spurenelementvergiftung - Chrom. Toxichem Krimtech 83:79-91

\section{6-Chromanol}

> Vitamin E

\section{Chromatin}

J. Arnemann

\section{Synonym(e) DNA-Kernprotein-Komplex}

\section{Englischer Begriff chromatin}

Definition Chromatin ist ein Komplex aus Makromolekülen, wie DNA und Proteinen, der u. a. die DNA platzsparend verpackt, die DNA auf die Mitose vorbereitet, DNA-Schäden verhindert, die Genexpression und die Replikation kontrolliert.

Beschreibung Die Hauptbestandteile des Chromatins sind Proteine der Histon-Familie, die die DNA kompakt verpacken. Histone sind positiv geladene Proteine von 102-135 Aminosäuren. Sie bilden einen Proteinkern (,core“), der aus insgesamt 8 Histonmolekülen, nämlich jeweils 2 Molekülen H2A, 2 Molekülen H2B, 2 Molekülen H3 und 2 Molekülen H4 besteht. Um diesen Proteinkern sind Abschnitte von146 bp doppelsträngiger DNA gewickelt und bilden damit ein einzelnes Nukleosom von $10 \mathrm{~nm}$ Durchmesser. Die Nukleosomen sind miteinander über kurze DNA-Abschnitte, sog. Spacer, verbunden, sodass durch die Aneinanderreihung eine perlschnurartige Struktur entsteht. Durch eine starke Spiralisierung der Nukleosomen entsteht eine sog. Chromatinfaser von $30 \mathrm{~nm}$ Durchmesser, die während der Interphase in Schleifen angeordnet im Zellkern liegt. Diese relaxierte Struktur ist Voraussetzung für einen unmittelbaren Zugang von regulatorischen 
Proteinen zur DNA, aber auch für eine Transkription der Gene oder die Duplikation der DNA während der Replikationsphase.

Während des Zellzyklus ist das Chromatin unterschiedlich stark gepackt, was u. a. durch posttranslationale Modifikationen der Histone reguliert wird. So ist das Chromatin in der Interphase locker verpackt und zugänglich zur Transkriptionsmaschinerie und zu DNA-Reparaturfaktoren. In der Metaphase dagegen ist das Chromatin dicht gepackt und stark verkürzt und für die Zellteilung innerhalb des Zellkerns an einem Gerüst (,„scaffold“) aufgehängt.

Die meisten posttranslationalen Modifikationen betreffen die Enden der Histone, wo die Art der Modifikation, wie z. B. Acetylierung oder Methylierung, und die modifizierte Aminosäure den Zugang regulatorischer Faktoren zum Chromatin und die Verpackungsdichte regeln. So bedeutet eine Histon-Acetylierung im Allgemeinen eine Auflockerung des Chromatins und damit verbundene Transkriptionsaktivitäten und auch eine Replikation der DNA. Eine Methylierung der Histone greift ebenfalls in die Transkription der verpackten DNA ein, wobei es abhängig ist, welche Lysin-Position beispielsweise methyliert wird. So bedingt eine Methylierung von Histon H3 Lysin 4 eine Hochregulation der Transkription, während eine Methylierung der Positionen Histon H3 Lysin 9 oder Lysin 27 eine Repression der Transkription und eine Zunahme der Chromatinverdichtung bedingt.

Das Chromatin wird in 2 unterschiedliche Typen eingeteilt, nämlich das transkriptionsaktive Euchromatin, das sich bei den gefärbten Chromosomen i. d. R. als der „hellere“ Anteil darstellt, und in das mehrheitlich transkriptionsinaktive Heterochromatin, das sich als der „dunklere“ Anteil darstellt. Heterochromatin ist dicht gepacktes Chromatin, das sich in der Chromosomenfärbung (GTG-Banden) sehr stark anfärben lässt. In den Zentromerbereichen der Chromosomen, aber auch im langen Arm des männlichen Y-Chromosoms, findet sich vorwiegend das konstitutive Heterochromatin, das vor allem aus repetitiven DNASequenzen besteht. Im Gegensatz hierzu gibt es noch das fakultative Heterochromatin, das in seiner Struktur leicht variiert und manchmal auch transkribiert wird.

\section{Literatur}

Strachan T, Read AP (2005) Molekulare Humangenetik. Elsevier $\mathrm{GmbH}$, München

\section{Chromatogramm}

T. Arndt

Englischer Begriff chromatogram
Definition Im häufigsten Fall eine Zeit-Strom- oder ZeitSpannungs-Kurve.

Beschreibung Die im Chromatogramm enthaltenen Signale (Peaks) sind unter optimierten Bedingungen der Konzentration der Analyte in der mobilen Phase am Säulenausgang proportional. Ein Chromatogramm wird durch den Prozess der Chromatographie auf einer als Chromatograph bezeichneten Apparatur gewonnen. In der D Dünnschichtchromatographie kann auch die Abbildung der auf der DC-Platte detektierten Zonen als Chromatogramm verstanden werden. Die folgende Abbildung zeigt wichtige Kenngrößen innerhalb eines Chromatogramms wie die Totzeit $t_{0}$, die Retentionszeit des Analyten $t_{\mathrm{R} 1}$ (hier z. B. Levetirazetam) und die Retentionszeit des internen Standards $t_{\mathrm{R} 2}$ :

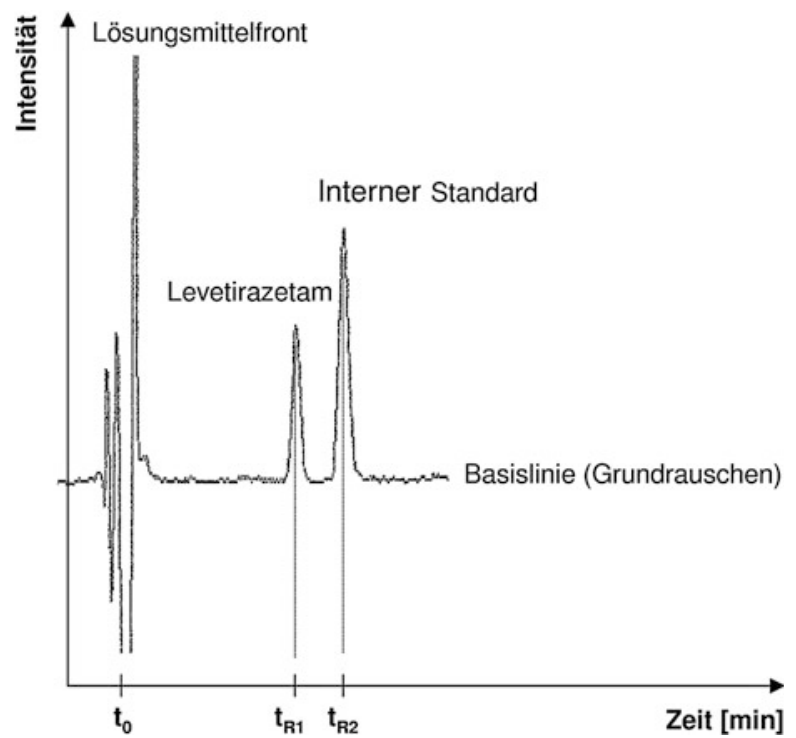

\section{Literatur}

Ettre LS (1993) Nomenclature for chromatography. Pure Appl Chem 65:819-872

\section{Chromatograph}

T. Arndt

Synonym(e) Chromatographiegerät

Englischer Begriff chromatograph; chromatographic system

Definition Zusammenstellung von Geräteteilen, mit denen eine chromatographische Analyse durchgeführt wird. 
Beschreibung In seiner allgemeinsten Form besteht ein Chromatograph aus einem Reservoir für die mobile Phase (Eluent), einer Einrichtung zum Transport des Eluenten durch das chromatographische System (im einfachsten Fall durch Kapillarkräfte), einem Probenaufgabemodul, einem analytischen Trennbett (stationäre Phase) und einem Detektor mit Registriereinheit.

\section{Literatur}

Ettre LS (1993) Nomenclature for chromatography. Pure Appl Chem $65: 819-872$

\section{Chromatographie}

T. Arndt

\section{Englischer Begriff chromatography}

Definition Physikalisch-chemisches Trennverfahren, bei dem die zu trennenden Substanzen zwischen 2 Phasen verteilt werden. Dabei ist eine Phase fixiert ( $\triangleright$ Stationäre Phase), während sich die andere in einer bestimmten Richtung bewegt ( $\triangleright$ Mobile Phase).

Physikalisch-chemisches Prinzip Die chromatographische Trennung der Probenbestandteile beruht auf der in Abhängigkeit von ihrer physikochemischen Natur unterschiedlich stark ausgeprägten, wiederholten Adsorption und Desorption an der stationären Phase. Dabei führen starke Wechselwirkungen zu einer langsamen, schwach ausgeprägte zu einer schnellen Elution der entsprechenden Substanzen.

Einsatzgebiet Die Chromatographie ist nahezu universell zur Analyse einfacher und komplexer Stoffgemische einsetzbar. In Abhängigkeit von ihrer Zusammensetzung kann die Probe direkt, das heißt ohne Probenvorbereitung oder nach entsprechender Probenaufbereitung mit $>$ Flüssig-FlüssigExtraktion oder $>$ Festphasenextraktion (SPE: „solid phase extraction") in den Chromatographen injiziert werden.

Im klinisch-chemischen Labor wird die Chromatographie, stets auf die jeweiligen Anforderungen optimiert, zur qualitativen und quantitativen Analyse von niedrig- und hochmolekularen Substanzen, wie Drogen und Medikamente, Vitamine und Hormone, Nahrungsbestandteile und Stoffwechselprodukte, eingesetzt.

Untersuchungsmaterial Blut und alle aus ihm gewonnenen Materialien wie Serum, Plasma, Zelllysate etc., Urin, Mageninhalt, Extrakte aus Faeces-, Gewebs- und Haarproben, Asservate von Nahrungsmitteln und Pharmaka/Drogen.
Instrumentierung Die Chromatographie wird mit einem - Chromatographen durchgeführt. Dieser besteht in seiner allgemeinsten Form aus einem Reservoir für die mobile Phase (Eluent), einer Einrichtung zum Transport des Eluenten, einem Probenaufgabemodul, einem analytischen Trennbett (stationäre Phase) und einem Detektor mit Registriereinheit.

Die Vielfalt der Einsatzgebiete und Applikationen führte zu zahlreichen Modifikationen der Chromatographie mit einer auf verschiedenen Einteilungskriterien beruhenden, relativ unübersichtlichen Terminologie.

\section{Terminologie und Einteilungskriterien}

1. Nach dem Aggregatzustand der mobilen und stationären Phase:

Dabei werden nacheinander die Aggregatzustände von mobiler und stationärer Phase genannt:

- Gas-Flüssig-Chromatographie (GLC: ,gas liquid chromatography").

- Gas-Fest-Chromatographie (GSC: ,gas solid chromatography").

- Flüssig-Flüssig-Chromatographie (LLC: „liquid liquid chromatography").

- Flüssig-Fest-Chromatographie (LSC: „liquid solid chromatography").

Allerdings werden insbesondere die Abkürzungen nicht konsistent angewandt, sodass z. B. die LSC (als derzeit wohl am häufigsten eingesetzte Technologie) gewöhnlich als LC oder in ihrer wichtigsten Sonderform als HPLC bezeichnet wird.

2. Nach der Art des Trägers der stationären Phase:

- Säulenchromatographie, bei der sich die stationäre Phase in einer Säule befindet.

- Dünnschichtchromatographie (DC), bei der die stationäre Phase auf einem ebenen Träger fixiert ist. Bei der (heute seltener angewandten) Papierchromatographie sind die planare stationäre Phase und der Träger des Trennbettes identisch.

3. Polarität der Oberfläche der stationären Phase:

- Normalphasenchromatographie (NPC), bei der die stationäre Phase (z. B. Kieselgel oder $\mathrm{Al}_{2} \mathrm{O}_{3}$ ) polarer als die mobile Phase ist.

- Umkehrphasenchromatographie (RPC: „reversed-phase chromatography"), bei der die stationäre Phase unpolarer als die mobile Phase ist. Hier werden die polaren Gruppen der stationären Phase durch chemische Modifikation, z. B. mit Alkylgruppen der Kettenlänge C8 oder C18, maskiert. Man spricht dann von einer RP-C8- oder RP-C18-Umkehrphase oder-Umkehrsäule.

4. Nach dem Aggregatzustand der mobilen Phase:

- Flüssigchromatographie (LC: „liquid chromatography“), sprachlich exakter, aber selten verwandt, Flüssigkeits- 
chromatographie. Untergruppen der LC sind die Säulenchromatographie und Dünnschichtchromatographie.

- Gaschromatographie (GC).

Moderne Formen der Flüssigkeitschromatographie nutzen sehr kleine Teilchen (Durchmesser meist 3-10 $\mu \mathrm{m}$ ) als stationäre Phase, die dicht gepackt auf einer Säule (2-20 cm Länge) einen hohen Eingangsdruck erzeugen. Der daraus resultierende hohe Druck im System (nicht selten über 100 at) führte zum Begriff Hochdruck-Flüssigkeitschromatographie (HPLC: ,high pressure liquid chromatography"). Allerdings ist diese Bezeichnung veraltet. Stattdessen wird heute mit dem Begriff $>$ HochleistungsFlüssigkeitschromatographie (HPLC: „high performance liquid chromatography“) das hohe Trennvermögen dieser Systeme angesprochen. Analog spricht man von Hochleistungs-Dünnschichtchromatographie (HPTLC: „high performance thin layer chromatography“).

Befindet sich die mobile Phase in einem überkritischen flüssigen Zustand wird der Terminus überkritische Fluidchromatographie (SFC: ,super critical fluid chromatography") benutzt.

5. Nach der zeitlich konstanten oder veränderlichen Zusammensetzung der mobilen Phase:

- Isokratische Chromatographie.

- Gradientenchromatographie: Dabei kann der Gradient kontinuierlich oder stufenweise variiert werden (Chromatographie mit kontinuierlichem Gradienten oder Stufengradienten).

6. Nach den Retentionsmechanismen

- Adsorptionschromatographie.

- Affinitätschromatographie.

- Ausschlusschromatographie.

- Gelpermeationschromatographie.

- Ionenaustauschchromatographie.

- Verteilungschromatographie, Einzelheiten hierzu unter den einzelnen Stichwörtern.

Instrumentierung in Reihenfolge des Flussschemas eines Chromatographen (Abb.1) Das Reservoir für die mobile Phase besteht bei der Gaschromatographie aus einem Gasdruckbehälter mit entsprechenden Reduzier- und Regelventilen, die einen kontrollierten Volumenstrom von mobiler Phase (Trägergas, meist Stickstoff) in das Gerät einspeisen. In der Flüssigkeitschromatographie bilden ein Behälter mit der bereits vollständig gemischten mobilen Phase oder 2-4 Behälter mit den nach einem Programm vom System zu mischenden Komponenten das Eluentenreservoir.

Der Transport der mobilen Phase wird bei der Gaschromatographie durch den Druck des Trägergases und bei der Flüssigkeitschromatographie durch eine oder mehrere pulsationsfrei arbeitende Pumpen realisiert.

Wird die mobile Phase durch die systeminternen Pumpen gemischt, ist diesen eine Mischkammer vor- oder nachge-

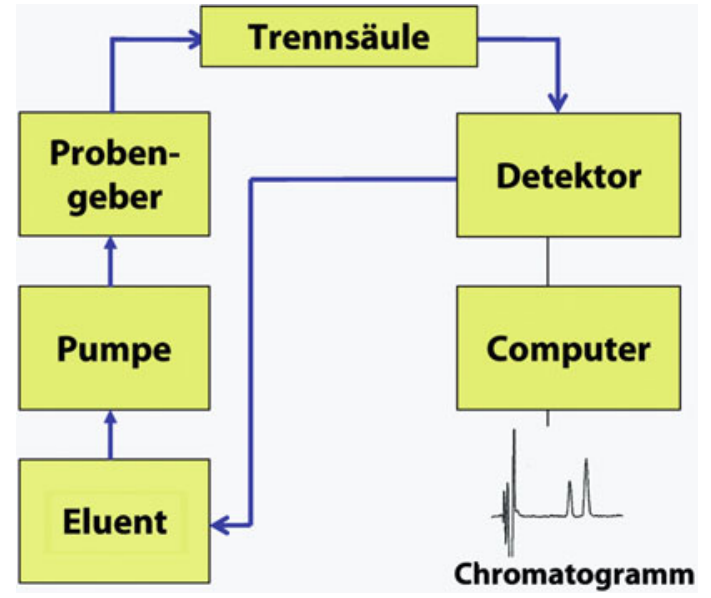

Chromatographie, Fig. 1 Flussschema in der Chromatographie/ eines Chromatographen

schaltet. Man spricht dann von Niederdruck- oder Hochdruckmischung. Auch bei isokratischer Arbeitsweise wird dadurch eine stets frische und in der Zusammensetzung reproduzierbare mobile Phase erhalten.

Mitunter beinhaltet ein Chromatograph auch einen sog. Degasser zur Entgasung der mobilen Phase. Hierdurch wird verhindert, dass Gase aus der mobilen Phase im chromatographischen System austreten, die Kapillaren blockieren und/ oder zu Störungen am Detektor führen.

Im Flussschema ist nach Pumpen und Mischkammer das Probenaufgabemodul positioniert. Dies kann im einfachsten Fall eine Pipette (DC), am häufigsten jedoch ein Sechswegeventil, z. B. für die manuelle, einmalige Probeninjektion, oder eine Pipettierstation für die mechanisierte, sequenzielle und ggf. wiederholte Applikation von bis zu mehreren Hundert Proben sein (GC, LC).

Bei der sog. Direktinjektion erfolgt die Probenaufgabe unmittelbar in den Strom der mobilen Phase. Bei der indirekten Injektion wird mittels Probenschleifen (sog. „bypass injector") die Probe zunächst in eine vom Strom der mobilen Phase durch ein Ventil getrennte Schleife (,loop“) gefüllt. Durch Umschalten des Ventils wird die mobile Phase durch die Schleife umgeleitet. Dadurch wird die Probe aus der Schleife in die Kapillare, die Probenaufgabemodul und Trennsäule miteinander verbindet, geschoben.

Eine Vorsäule schützt die Trennsäule vor Abrieb und starker Verschmutzung. Hierdurch wird die Haltbarkeit der vergleichsweise erheblich teureren Trennsäule verlängert.

Die Trennsäule (,column“) ist ein Rohr mit einem Innendurchmesser von 0,1-1,0 mm (GC) bzw. 2-5 mm (HPLC). Ihre Länge beträgt wenige Zentimeter (LC) bis mehrere Meter (GC). Die Trennsäule fixiert die stationäre Phase. Man unterscheidet gepackte Säulen, die möglichst dicht mit stationärer Phase gefüllt sind, und offene Kapillarsäulen, bei denen die 
innere Wand selbst als stationäre Phase wirkt oder ein dünner Flüssigkeitsfilm bzw. eine dünne Schicht eines Festkörpers als stationäre Phase dient.

Das Packungsmaterial einer Trennsäule (stationäre Phase) ist ein Festkörper, ein mit Trennflüssigkeit imprägniertes Trägermaterial oder ein gequollenes Gel. Der Festkörper kann vollständig porös sein oder aus einem kompakten Kern mit einer dünnen porösen Außenschicht bestehen. Oft wird die Oberfläche der stationären Phase durch geeignete chemische Verfahren modifiziert, weshalb heute eine unüberschaubare Vielfalt an Trennsäulen mit speziellen Oberflächeneigenschaften verfügbar ist.

Man unterscheidet zwischen differenziellen und integralen - Detektoren. Der zumeist eingesetzte differenziell arbeitende Detektor registriert jede Veränderung der Zusammensetzung der mobilen Phase, die hier gewöhnlich als Eluat bezeichnet wird. Man unterscheidet konzentrationsempfindliche Detektoren, deren Signal der Konzentration des Analyten in der Probe proportional ist, und massenstromempfindliche Detektoren, deren Signal der Stoffmenge, die pro Zeiteinheit den Detektor erreicht, proportional ist. Stoppt man bei einem konzentrationsempfindlichen Detektor den Eluentenstrom, bleibt das Signal erhalten, bei einem massenstromempfindlichen Detektor dagegen nicht. Im Allgemeinen werden in der Chromatographie konzentrationsempfindliche Detektoren eingesetzt. Dabei steht das am Detektorausgang anliegende Signal im Zusammenhang mit der in der Messzelle des Detektors gerade vorhandenen Konzentration der zu bestimmenden Substanz. Im Idealfall ist dieser Zusammenhang linear proportional.

Wie die chromatographischen Techniken werden auch die Detektoren nach verschiedenen Kriterien unterteilt. Dies können u. a. die Selektivität ( $>$ Selektivität) oder Spezifität ( $\triangleright$ Spezifität, analytische) sowie das physikalische und/oder chemische Prinzip sein, auf dem der Detektor beruht. Wichtige Detektorentypen (mit zumeist einer Vielzahl von Untertypen) sind:

- Brechungsindexdetektor

- Flammenionisationsdetektor

- Elektrochemischer Detektor

- Fluoreszenzdetektor

- Leitfähigkeitsdetektor

- Massenspektrometrischer Detektor

- UV- und UV/VIS-Detektor

Durch Registrierung der Konzentrationsveränderungen in der Messzelle in Abhängigkeit von der Zeit nach Probenaufgabe und deren graphische Darstellung wird ein $>$ Chromatogramm gewonnen. Heute erfolgen Auswertung und Integration der Messsignale eines Chromatogramms gewöhnlich computerunterstützt.

Der Anschluss der Trennsäulen an das Probendosiersystem und den Detektor erfolgt zumeist mit Edelstahlkapillaren mit Innendurchmessern im Bereich von 0,10-0,25 mm, um Rückvermischungseffekte zu minimieren.

Spezifität In Abhängigkeit von der Qualität der chromatographischen Trennung und der Selektivität und Spezifität des Detektors ist die Spezifität der Analyse ausreichend bis außerordentlich hoch. Dies führt dazu, dass chromatographische Verfahren in Kombination mit geeigneten Detektoren auch als Referenzverfahren eingesetzt werden können. So wird z B. die Kombination aus GC oder LC und $>$ Massenspektrometrie (MS) als GC-MS, LC-MS oder LC-MS/MS als rechtssicheres Mittel zum Nachweis oder Ausschluss eines Drogenkonsums eingesetzt.

Sensitivität Die Sensitivität der Methode ist abhängig von der jeweiligen Applikation, das heißt der Probenverdünnung infolge einer Probenaufbereitung, dem injizierten Probenvolumen und insbesondere vom Detektortyp. Heute sind > Nachweisgrenzeen im ng/L-Bereich erreichbar.

Fehlermöglichkeit Fehler in der Probenvorbereitung, z. B. durch Analytverluste, können durch Einsatz eines internen Standards ( $>$ Standard, interner) oder durch das Prinzip der $>$ Standardaddition kompensiert werden.

Eine unzureichende Spezifität des Detektors bei ungenügender chromatographischer Trennung von mehreren Probenkomponenten kann zu Fehlbestimmungen des Analyten führen. Dies kann durch eine Veränderung der Eigenschaften der mobilen und/oder stationären Phase, durch eine modifizierte Flussrate der mobilen Phase, durch längere oder dichter gepackte Trennsäulen etc. verhindert werden. Die Spezifität einer chromatographischen Analyse hängt in entscheidendem Maße von der Qualität der chromatographischen Trennung der Probenbestandteile ab.

Praktikabilität - Automatisierung - Kosten Heutige LC-Systeme basieren zumeist auf dem Prinzip der HPLC. Hierfür stehen eine Vielzahl von Einzelkomponenten, aber auch Komplettanlagen zur Verfügung. Die Anschaffungspreise betragen mehrere 10.000 Euro. Komplettkits zur Durchführung von HPLC-Analysen sind teurer (oft zwischen 5-10 Euro/Analyse) als Eigenentwicklungen mit oft geringen Materialkosten. Bei letzteren wird die HPLC-Säule mit 250-600 Euro die größten Verbrauchskosten erzeugen. Allerdings sind gewöhnlich mehrere Hundert bis 1000 (bei sog. Mikrobore-HPLC-Systemen mehrere 10.000) Analysen mit einer Trennsäule durchführbar.

Bewertung - Methodenhierarchie (allg.) Die GC und HPLC sind ausgereifte Analysenmethoden mit hoher Robustheit im Routinebetrieb und langer Standzeit. Derzeit hält die Kombination aus LC und Massenspektrometrie als LC-MS oder LC-MS/MS einen breiten Einzug in das klinischchemische und toxikologische Laboratorium. Anschaffungs- 
kosten von mehreren Hunderttausend Euro bremsen diese Entwicklung noch ab. Es scheint jedoch wahrscheinlich, dass massenspektrometrische Detektoren in naher Zukunft einen wesentlichen Anteil der in der Chromatographie eingesetzten Detektoren ausmachen.

In der Methodenhierarchie sind chromatographische Methoden bzgl. Spezifität in oberster Reihe einzuordnen. Siehe auch $>$ Ultra-Performance-Flüssigkeitschromatographie.

\section{Literatur}

Ettre LS (1993) Nomenclature for chromatography. Pure Appl Chem 65:819-872

Unger KK (Hrsg) (1989) Handbuch der HPLC. Teil 1 Leitfaden für Anfänger und Praktiker. GIT Verlag, Darmstadt

\section{Chromatographiegerät}

Chromatograph

\section{Chromogranin A}

S. Holdenrieder und P. Stieber

$\operatorname{Synonym}(e) \operatorname{CgA}$

Englischer Begriff Chromogranin A; CgA

Molmasse $68 \mathrm{kDa}$.

Funktion - Pathophysiologie Die klinische Bedeutung der Chromogranin-A-Bestimmung liegt im Therapiemonitoring und der Rezidiverkennung von neuroendokrinen Tumoren, v. a. des gastroenteropankreatischen (GEP) Systems. CgA wird in den sekretorischen Granula neuroendokriner Zellen gespeichert und nach Stimulation zusammen mit anderen Peptidhormonen und Neuropeptiden freigesetzt. Verschiedene Subtypen von Chromogranin A binden mit unterschiedlicher Spezifität und Affinität an die Antikörper von Immunoassays.

Untersuchungsmaterial-Entnahmebedingungen Serum, Körperflüssigkeiten.

Analytik $>$ Enzymimmunoassay (EIA), $>$ Radioimmunoassay (RIA), > Immunradiometrischer Assay (IRMA).
Konventionelle Einheit $\mu \mathrm{g} / \mathrm{L}=\mathrm{ng} / \mathrm{mL}$.

Referenzbereich - Erwachsene 19-98 ng/mL (methodenund altersabhängig).

\section{Indikation}

- Therapiekontrolle, Nachsorge und Prognose von gastroenteropankreatischen, neuroendokrinen Tumoren

- Therapiekontrolle anderer neuroendokriner Tumoren (kleinzelliges Bronchialkarzinom, APUDom, Neuroblastom, medulläres Schilddrüsenkarzinom)

Interpretation Die meisten Chromogranin-A-Assays sind für die Anwendung im Serum ausgetestet. Darüber hinaus kann Chromogranin A auch in anderen Körperflüssigkeiten bestimmt werden.

Chromogranin A ist weder tumor- noch organspezifisch. Es wird in hohen Wertlagen jedoch vornehmlich bei neuroendokrinen Tumoren des gastroenteropankreatischen (GEP) Systems, beim klein- und großzelligen Bronchialkarzinom sowie bei neuroendokrinen Tumoren anderer Lokalisation ins Serum freigesetzt. Bei GEP-Tumoren ist es anderen neuroendokrinen Markern wie NSE und ProGRP an Sensitivität und Spezifität überlegen. Die Sensitivität von $\mathrm{CgA}$ liegt bei ca. 60-80\%, abhängig von der Lokalisation des Primärtumors, dem Tumorstadium, der Tumorgröße, des Tumordifferenzierungsgrads und der Metastasierung. Zur Therapiekontrolle und Nachsorge der neuroendokrinen klein- und großzelligen Bronchialkarzinome empfiehlt sich die kombinierte Bestimmung von CgA mit NSE und ProGRP.

Unspezifisch erhöhte CgA-Werte finden sich auch in Patienten mit diversen benignen Erkrankungen, v. a. bei Niereninsuffizienz, kardiologischen und inflammatorischen Erkrankungen sowie nach Gabe von Protonenpumpenhemmern. Dies ist bei der differenzialdiagnostischen Einordnung zu berücksichtigen. Neben der Unterstützung der Diagnose ist der Einsatz von CgA zur Prognoseabschätzung, zur Therapiekontrolle und zur frühzeitigen Diagnostik von Rezidivtumoren in der Nachsorgesituation insbesondere bei GEPTumoren, aber auch bei anderen neuroendokrinen Tumoren von Bedeutung.

\section{Diagnostische Wertigkeit}

- Gastroenteropankreatische (GEP), neuroendokrine Tumoren: Diagnose, Therapiekontrolle, Nachsorge und Prognose

- Andere neuroendokrine Tumoren (kleinzelliges Bronchialkarzinom, APUDom, Neuroblastom, medulläres Schilddrüsenkarzinom): Therapiekontrolle 


\section{Literatur}

Korse CM, Taal BG, Vincent A et al (2012) Choice of tumour markers in patients with neuroendocrine tumours is dependent on the histological grade. A marker study of Chromogranin A, Neuron specific enolase, Progastrin-releasing peptide and cytokeratin fragments. Eur J Cancer 48:662-671

Verbeek WH, Korse CM, Tesselaar ME (2016) GEP-NETs UPDATE: secreting gastro-enteropancreatic neuroendocrine tumours and biomarkers. Eur J Endocrinol 174:R1-R7

\section{Chromosom}

\section{J. Arnemann}

Synonym(e) Kondensierte Chromatinfaser

\section{Englischer Begriff chromosome}

Definition Chromosomen sind makromolekulare Verpackungseinheiten definierter DNA-Stränge mit Proteinen zur gezielten Weitergabe der Erbinformation an die nächste Generation (Chromosomentheorie der Vererbung).

Beschreibung Chromosomen kommen im Zellkern von eukaryotischen Zellen vor und dienen der Speicherung und der gezielten Weitergabe der Erbinformation an die nächste Generation (Chromosomentheorie der Vererbung). Dabei kommen beim Menschen die insgesamt 46 Chromosomen in jeweils 2 Kopien, sog. D Diploidie, vor, wobei sich beim Mann die Geschlechtschromosomen X und Y unterscheiden. Chromosomen stellen dabei makromolekulare Verpackungseinheiten um den DNA-Kern dar.

Die DNA, als Erbinformation der Zelle, besteht aus Desoxyribonukleinsäuren, die strangförmig als Doppelhelix angeordnet sind und mit Proteinen nach einem definierten Muster verpackt ist. Die Kombination von DNA und Proteinen wird auch als Chromatin bezeichnet.

Im Detail ist der DNA-Strang perlschnurartig zu $>\mathrm{Nu}$ kleosomen verpackt, in denen ein doppelsträngiger DNAAbschnitt von 146 bp um einen Proteinkern (,,core“) gewickelt ist, der aus insgesamt $8>$ Histon-Molekülen, nämlich jeweils 2 Molekülen H2A, 2 Molekülen H2B, 2 Molekülen H3 und 2 Molekülen H4. Histone sind kleine, positiv geladene Proteine von 102-135 Aminosäuren, die gut mit der DNA binden. Die Nukleosomen sind miteinander über kurze DNA-Abschnitte, sog. Spacer, verbunden, sodass eine perlschnurartige Struktur entsteht. Diese wird weitergehend spiralisiert und bildet ein Chromosom, das als - ChromatinFaser während der Interphase in Schleifen angeordnet im
Zellkern liegt. Diese relaxierte Struktur ist Voraussetzung für eine Expression der Gene ( $\triangleright$ Gen-Expression).

Innerhalb des Zellzyklus liegen die Chromosomen meist in der G0-Phase der Interphase vor. Soll es zu einer Teilung der Zelle mit obligater Replikation der DNA kommen, dann geht die Zelle über eine G1-Phase in die S-Phase über, in der ein zweiter DNA-Strang synthetisiert und eine zweite Chromatinfaser ausgebildet werden. Die 2 DNA-Doppelhelices werden initial über die Zentromerstrukturen zusammengehalten. Beim Übergang von der S- zur G2-Phase beginnen sich diese Chromosomen stark zu kondensieren. In der M- oder - Mitose-Phase ordnen sich die 46 stark verkürzten, aus 2 Chromatiden bestehenden Chromosomen in der Metaphasespindel an und werden von den Mikrotubuli gebunden, die jeweils ein Chromatid zu den gegensätzlich angeordneten Spindelpolen auseinanderziehen. Somit werden bei der darauf folgenden Zellteilung insgesamt 92 Chromosomen geordnet auf 2 Tochterzellen verteilt. In der Metaphase lassen sich die stark kondensierten Metaphasechromosomen durch spezifische Farbstoffe, wie z. B. Giemsa, anfärben und für eine mikroskopische Auswertung hinsichtlich Anzahl und Struktur sichtbar machen.

Abweichend zur mitotischen Teilung gibt es in den Keimzellen auch noch eine meiotische Teilung ( $\triangleright$ Meiose), bei der 2 Zellteilungen bei nur einer DNA-Replikation dafür sorgen, dass haploide Gameten (Eizelle bzw. Spermatozoen) entstehen. Durch die bei der Befruchtung stattfindende Verschmelzung der haploiden Gameten entsteht eine diploide Zygote, die nun wieder den mitotischen Teilungs- und Vermehrungszyklus aufnehmen kann.

Bei der Meiose kann es zu Verteilungsfehlern einzelner Chromosomen kommen, die zu einer $>$ Aneuploidie in der Zygote führen. Diese Fehler werden als Non-Disjunction bezeichnet und sind meist maternalen Ursprungs. Während theoretisch alle Chromosomen fehlverteilt werden können, sind nur Feten mit Trisomien der Chromosomen 13, 18, 21, $\mathrm{X}$ und $\mathrm{Y}$ bedingt lebensfähig. Diese Chromosomenfehlverteilungen sind meist altersbedingt.

\section{Literatur}

Alberts et al (2002) The global structure of chromosomes; in molecular biology of the cell, 4. Aufl. Garland Science, New York

Strachan T, Read AP (2005) Molekulare Humangenetik. Elsevier $\mathrm{GmbH}$, München

\section{Chromosom, geschlechtsunabhängiges}

Autosom 


\section{Chromosomenanalyse}

J. Arnemann

Synonym(e) Chromosomen-Test

Englischer Begriff chromosome analysis

Definition Die Chromosomenanalyse oder konventionelle Karyotypisierung ist eine Methode, die menschlichen Chromosomen quantitativ und qualitativ, d. h. zahlenmäßig und feinstrukturell, auf Auffälligkeiten oder Normabweichungen zu testen.

Beschreibung Bei der Chromosomenanalyse oder konventionellen Karyotypisierung werden i. d. R. Metaphasechromosomen, stark spiralisierte und dicht gepackte Chromatinbündel, analysiert. Hierzu werden Gewebestücke, Wangenabstriche oder vor allem mit dem Antikoagulant Lithium-Heparin versehene Blutproben verwendet. Blutproben werden Jugendlichen und Erwachsenen durch Venenpunktion, Babys als Kapillarblutprobe auch aus Fingerbeere oder Ferse entnommen. Die Proben werden anschließend in einem Kulturmedium unter Zugabe von Kälberserum und einem Mitogen, wie z. B. Phytohämagglutinin (PHA), für insgesamt 72 Stunden bei $37^{\circ} \mathrm{C}$ und einem $\mathrm{pH}$-Wert 7,0-7,4 inkubiert. Hierbei werden die Zellen in ihrem Zellzyklus optimalerweise synchronisiert und während der mitotischen Teilung dann in der Metaphase durch das Spindelgift Colchizin arretiert, was auch den auszuwertenden Mitoseindex erhöht. Anschließend werden die Zellen durch Behandlung mit einer hypotonen Lösung (0,075 M KCl-Lösung) zum Anschwellen gebracht, wobei innerhalb des Zellkerns auch die Chromosomen auseinanderdriften. Die Zellen werden danach mit einem Gemisch aus Alkohol (Ethanol oder Methanol) und Eisessig fixiert und entweder manuell aus einer Höhe von 40-80 cm auf Objektträger aufgetropft oder mittels bestimmter Zytofugen auf die Objektträger zentrifugiert. Bei beiden Methoden platzen die Zellkerne und lassen die Chromosomen frei. Die Objektträger werden luftgetrocknet und die Chromosomen so fixiert. Anschließend werden die Chromosomen je nach Fragestellung mit unterschiedlichen Protokollen gefärbt. Als Beispiele seien folgende Färbemethoden genannt:

- G-Banden: Die Chromosomen werden mit Trypsin vorbehandelt und anschließend mit Giemsa gefärbt, wobei die GTG-Bänderung erzeugt wird. Helle Banden sind G/Creich und angereichert mit Genen.

- R-Banden: Die Chromosomen werden in Salzlösung hitzedenaturiert und anschließend mit Giemsa gefärbt. Durch die Hitzebehandlung gehen die A/T-reichen Abschnitte auseinander, sodass die G/C-reichen Abschnitte bevorzugt gefärbt werden und damit die Umkehrung der G-Banden darstellen. Eine Alternative zur Giemsa-Färbung ist hierbei eine Färbung mit Acridinorange.

- Q-Banden: Die Chromosomen werden mit einem interkalierenden Fluoreszenzfarbstoff wie Quinacrin, DAPI oder Hoechst33258 gefärbt, wobei sich bevorzugt die A/Treichen Regionen anfärben lassen. Eine Auswertung erfolgt mit dem Fluoreszenzmikroskop. Die Banden entsprechen im Wesentlichen den G-Banden.

- C-Banden: Mit dieser Färbung werden die Zentromerregionen und das konstitutive Heterochromatin angefärbt. Hierbei werden die Chromosomen vor der Giemsa-Färbung mit einer gesättigten Bariumhydroxidlösung denaturiert.

Die eigentliche Karyotypanalyse erfolgt mikroskopisch und i. d. R. mithilfe eines digitalen Auswertesystems. Dies ermöglicht eine Sortierung der Chromosomen entsprechend Größe und Referenzbandenmuster und die Erstellung des Karyogramms. Die pro Chromosom darstellbare Anzahl an Banden ist im Wesentlichen von der Länge und der Auflösung der Chromosomen abhängig. Durch Standardisierung (International System of Cytogenetic Nomenclature, ISCN, 1981) werden Bandenauflösungsstufen von 400, 550 und 850 (Prometaphase) Banden pro haploiden Chromosomensatz definiert, wobei eine Hochauflösung der Bänderung für eine Feinstrukturanalyse die besten Ergebnisse ergibt. Ziel der Analyse ist es, neben numerischen Aberrationen insbesondere feinstrukturelle Auffälligkeiten, wie z. B. Inversionen, Deletionen, Insertionen oder Translokationen, aufzufinden. Der unauffällige männliche Karyotyp wird als 46,XY, der weibliche als 46,XX beschrieben. Bei der Beschreibung feinstruktureller Auffälligkeiten wird die ISCN-Richtlinie angewendet. So werden der kurze Chromosomenarm als p-Arm, der lange als q-Arm definiert. Die Banden werden, jeweils vom Zentromer ausgehend, mit dem Präfix des Chromosoms und des Arms gezählt, wie z. B. 2q21.2, was Chromosom 2, langer Arm, Bande 21, Subbande 2 bedeutet. Dies ermöglicht eine exakte und auch in anderen Laboratorien reproduzierbare Beschreibung der Auffälligkeit.

\section{Literatur}

Guttenbach et al (1997) Analysis of structural and numerical chromosome abnormalities in sperm of normal men and carriers of constitutional chromosome aberrations. A review. Hum Genet 100:1-2

Rooney D (Hrsg) (2001) Human cytogenetics: Constitutional analysis, 3. Aufl. Oxford university Press, Oxford

\section{Chromosomenfehlverteilung}

$>$ Aneuploidie 


\section{Chromosomenmutation}

$>$ Chromosom

\section{Chromosomenstörung}

- Chromosom

\section{Chromosomen-Test}

- Chromosomenanalyse

\section{Chromosomentranslokation}

J. Arnemann

Synonym(e) Translokation

Englischer Begriff chromosomal translocation

Definition Unter Chromosomentranslokation versteht man die Verschmelzung von Abschnitten nichthomologer Chromosomen zu einem neu arrangierten Translokationschromosom.

Beschreibung Bei einer Translokation werden i. d. R. 2 Abschnitte von nichthomologen Chromosomen zu einem sog. Translokationschromosom fusioniert. Das Translokationschromosom muss obligat ein Zentromer haben, um sich mitotisch teilen zu können.

Bei Translokationen unterscheidet man zwischen balanzierten und unbalanzierten, wie auch zwischen konstitutiven und somatischen Translokationen. Eine balanzierte Translokation liegt vor, wenn es durch den Austausch von Chromosomenabschnitten in der Summe zu keinem Verlust an genetischem Material kommt, während es bei unbalanzierten Translokationen, oftmals bei den Nachkommen des Trägers einer balanzierten Translokation, zu Verlusten oder Duplikationen von chromosomalen Abschnitten kommen kann. Eine bekannte Form der balanzierten Translokation ist die Robertson-Translokation, bei der 2 akrozentrische Chromosomen im kurzen Arm unter Verlust der SatellitenDNA (Cluster für ribosomale DNA) miteinander verschmelzen.

Während man bei der Entstehung von konstitutiven Translokationen als häufigste Ursache eine Rekombination zwi- schen fehlerhaft gepaarten Chromosomen in der Meiose annimmt, werden für die somatischen Translokation eher Störungen im DNA-Reparatursystem postuliert.

Translokationsereignisse können in nichtkodierenden Abschnitten (intergenisch) stattfinden, dann zeigt sich auf Ebene der Genexpression keine größere Änderung, aber auch intragenisch, d. h. durch Bruch und Verlust in einem Gen kann das Expressionsmuster pathogen verändert werden.

Somatische Translokationen treten meist im Zusammenhang mit Neoplasien oder Tumoren auf und weisen oftmals eine pathogene Funktion auf. Ein Beispiel hierfür ist die $\mathrm{t}$ (9;22)(q34;q11) oder BCR-ABL-Translokation bei der chronisch myeloischen Leukämie (CML). Bei dieser somatischen Translokation erfolgt der Bruch direkt in 2 Genen, nämlich leicht variabel in den Exonen 1, 13, 14 oder $19 \mathrm{im}$ BCR-Gen auf Chromosom 22q11 und konstant im Exon 2 des ABL-Gens auf Chromosom 9q34. Durch Verschmelzung des $5^{6}$-Bereichs von BCR mit dem $3^{6}$-Bereich des ABL-Gens entsteht durch diese Translokation ein Fusionsgen, bei dem unter dem BCR-Promotor die ABL-Kinasedomäne konstitutiv exprimiert wird.

Eine weitere Besonderheit sind Translokationen zwischen einem Autosom und dem X-Chromosom. Hier kann u. U. sich die X-Inaktivierung auf den autosomalen Bereich ausdehnen und auch diesen Inaktivieren, sodass es einer pathogenen Monosomie für den autosomalen Bereich und den dort lokalisierten Genen entspricht.

\section{Literatur}

Rowley JD (2001) Chromosome translocations: dangerous liaisons revisited. Nat Rev Cancer 1:245-250

Zheng J (2013) Oncogenic chromosomal translocations and human cancer (review). Oncol Rep 30:2011-2019

\section{Chronic Kidney Disease Epidemiology Collaboration formula}

- CKD-EPI-Formel

\section{Chylomikronen}

K. J. Lackner und D. Peetz

\section{Englischer Begriff chylomicrons}

Definition Triglyzeridreiche Lipoproteine, die im Darm resorbierte Lipide transportieren. 
Beschreibung Chylomikronen sind große, triglyzeridreiche Lipoproteine, die von den Zellen der Dünndarmmukosa gebildet werden. Sie bestehen zu über $97 \%$ aus Lipiden, vorwiegend Triglyzeriden. Ihr Gehalt an Phospholipiden, Cholesterin und Cholesterinestern ist gering. Ihr Hauptapolipoprotein ist ApoB-48. Daneben enthalten sie noch ApoA-I, ApoA-IV und verschiedene C-Apolipoproteine. Sie werden in die intestinale Lymphe sezerniert und erreichen die venöse Zirkulation über den Ductus thoracicus. Im Blut geben sie unter Einwirkung der Lipoproteinlipase ihre Triglyzeride $a b$ und werden zu Chylomikron-Remnants, die hepatisch aufgenommen werden. Im Nüchternplasma finden sich normalerweise keine Chylomikronen. Defekte der Lipoproteinlipase führen zur familiären Hyperchylomikronämie mit exzessiv erhöhten Serumtriglyzeridwerten.

\section{Chylus}

$>$ Lymphe

\section{Chymosin}

R. Tauber und F. H. Perschel

\section{Englischer Begriff Chymosin}

Definition Chymosin (EC 3.4.23.4) ist eine Aspartatproteinase, die in den Hauptzellen der Magenmukosa als inaktives Prochymosin gebildet und in das Magenlumen sezerniert wird, wo Prochymosin bei saurem $\mathrm{pH}$ durch Abspaltung eines $\mathrm{N}$-terminalen Propeptids in das aktive Enzym umgewandelt wird.

Beschreibung Die Aspartatproteinase Chymosin katalysiert die Verdauung von Nahrungsproteinen im Gastrointestinaltrakt. Chymosin wird als inaktives Zymogen durch die Hauptzellen der Magenmukosa synthetisiert, gespeichert und bei Aufnahme von Nahrung in das Magenlumen sezerniert. Im sauren Magensaft erfolgt durch Abspaltung eines N-terminalen Propeptids eine autokatalytische Aktivierung zum aktiven Enzym. Prochymosin bildet zusammen mit Pepsinogen A, Pepsinogen B und Progastricsin die Zymogene des Magens. - Pepsinogen A, Pepsinogen B und Progastricsin werden im Magen des Erwachsenen, Prochymosin im Magen des Neugeborenen gebildet.

\section{Literatur}

Richter C, Tanaka T, Yada RY (1998) Mechanism of activation of the gastric aspartic proteinases: pepsinogen, progastricsin and prochymosin. Biochem J 335:481-490

\section{Chymotrypsin}

A. M. Gressner und O. A. Gressner

Synonym(e) EC 3.4.21.1

Englischer Begriff chymotrypsin

Definition Pankreatogene Serinproteinase mit Bedeutung für die intestinale Proteinverdauung und diagnostischer Relevanz im Blut für die akute Pankreatitis und in Fäzes für die exokrine Pankreasinsuffizienz.

Molmasse $25 \mathrm{kDa}$.

Synthese - Verteilung - Abbau - Elimination Die in den Azinuszellen synthetisierte Proform ( $\triangleright$ Zymogene) Chymotrypsinogen wird wie Trypsinogen sezerniert und im Intestinaltrakt durch N-terminale limitierte Proteolyse mit $>$ Trypsin und nachfolgender autokatalytischer Prozessierung durch Chymotrypsin zu einem linearen Peptid von etwa $130>$ Aminosäuren aktiviert. Die Aktivierung durch Trypsin erfolgt zwischen Arginin 15 und Isoleucin 16. Es liegen 2 Isoenzyme vor:

- Anionisches Chymotrypsin(ogen)-1

- Kationisches Chymotrypsin(ogen)-2 (dominierende Form, pH-Optimum 8,0)

Die Serinproteinase Chymotrypsin hydrolysiert Peptidbindungen, die Carboxylgruppen von Tryptophan, Leucin, Tyrosin oder Phenylalanin enthalten. Daneben besteht hydrolytische Aktivität für andere Bindungstypen: Ester (N-substituierte Tyrosinester) $>$ Amide $>$ Peptide. Dominantes Isoenzym ist kationisches Chymotrypsin-2, das wie anionisches Chymotrypsin-1 im Blut komplexiert mit $\alpha_{1}$-Proteinaseinhibitor und $\alpha_{2}$-Makroglobulin vorliegt.

Funktion - Pathophysiologie Bei entzündlichen Pankreaserkrankungen (akute Pankreatitis) und Pankreaskarzinom erfolgt die Freisetzung von Chymotrypsin-2 in die Zirkulation. Im aspirierten Duodenalsaft und in Fäzes reduzierte Chymotrypsinkonzentrationen (-aktivitäten) in Abhängigkeit vom Ausmaß der exkretorischen Pankreasinsuffizienz. 
Untersuchungsmaterial-Entnahmebedingungen Serum, EDTA-Plasma, Fäzes, Duodenalsaft.

Probenstabilität Probenstabilität im Serum ca. 8 Tage bei $4{ }^{\circ} \mathrm{C}$ oder langzeitig bei $-20^{\circ} \mathrm{C}$, im Stuhl ist das Enzym für 3 Wochen bei Raumtemperatur stabil.

Präanalytik 4 Tage vor Probennahme (Fäzes) Absetzen von Substitutionspräparaten (Enzyme).

Analytik Sowohl im Serum/Plasma als auch im Duodenalsaft und Fäzes sind folgende Methoden in Anwendung:

1. Immunreaktive Konzentrationsbestimmung im Serum: Immunoassay für Chymotrypsin-2 reagiert auch mit Chymotrypsinogen-2 und Chymotrypsin(ogen)-1, auch im Komplex mit $\alpha_{1}$-Proteinaseinhibitor; Komplex mit $\alpha_{2}$ Makroglobulin wird nicht detektiert.

2. Katalytische Aktivitätsbestimmung im Duodenalsaft und Fäzes:

Prinzip 1: Photometrische Methode ( $\triangleright$ Photometrie)

$$
\begin{aligned}
& \text { N-Succinyl-Ala-Ala-Pro-Phe-p-Nitroanilid }+\mathrm{H}_{2} \mathrm{O} \\
& \underset{\text { Chymotrypsin }}{\stackrel{\mathrm{pH} 9,0}{\longrightarrow}} \text { N-Succinyl-Ala-Ala-Pro-Phe } \\
& + \text { p-Nitroanilin (gelb) }
\end{aligned}
$$

Die Bildungsgeschwindigkeit von $p$-Nitroanilin aus dem substituierten Tetrapeptid wird bei $405 \mathrm{~nm}$ kontinuierlich gemessen und ist der Chymotrypsinaktivität proportional.

Prinzip 2: Titrimetrische Methode

$$
\begin{aligned}
& \text { N-Acetyl-L-Tyrosyl-ethylester (ATEE) } \\
& \stackrel{\text { Chymotrypsin }}{\longrightarrow} \text { Acetyltyrosin + Ethanol }
\end{aligned}
$$

Die pro Zeiteinheit gebildete Menge Acetyltyrosin wird titrimetrisch (pH-Stat) oder das gebildete Ethanol enzymatisch gemessen, beide Produktkonzentrationen sind der Chymotrypsinaktivität im optimierten Testverfahren proportional.

Referenzbereich - Erwachsene Sehr stark methodenabhängig. Serum: 15-78 $\mu \mathrm{g} / \mathrm{L}$, Fäzes: $>3 \mathrm{U} / \mathrm{g}$ Feuchtgewicht (Graubereich 3-6 U/g)

\section{Indikation}

- Adjuvante Diagnostik der akuten Pankreatitis und des Pankreaskarzinoms (Serum)

- Diagnostik der zystischen Pankreasfibrose (Nabelschnurblut)

- Diagnostik und Verlaufskontrolle der exokrinen (digestiven) Pankreasinsuffizienz (Fäzes, Duodenalsaft)
Interpretation Der wesentliche Einsatz der Chymotrypsinbestimmung konzentrierte sich auf Stuhluntersuchungen, um aus der Abnahme der Ausscheidungsmenge des intestinal relativ resistenten Chymotrypsins eine exokrine Pankreasinsuffizienz $\mathrm{zu}$ diagnostizieren und $\mathrm{zu}$ kontrollieren (chronische Pankreatitis, zystische Pankreasfibrose). Heutzutage ist diese Kenngröße durch die immunologische Bestimmung der fäkalen Pankreaselastase ( $\triangleright$ Elastase, pankreasspezifische) verdrängt worden.

Im Serum 2- bis 35-facher Anstieg der immunreaktiven Chymotrypsin-2-Konzentration bei akuter Pankreatitis, etwa 2,5-facher Anstieg bei Pankreaskarzinomen, bis zu 2-facher Anstieg bei hepatobiliären Erkrankungen und signifikanter Anstieg bei Niereninsuffizienz infolge Retention.

Diagnostische Wertigkeit Gegenüber Trypsin im Stuhl überlegene diagnostische Kriterien. Im Vergleich mit Elastase-1 liegen die Sensitivität mit $64 \%$ und die Spezifität ( $\triangleright$ Spezifität, diagnostische) mit 89 \% für exokrine Pankreasinsuffizienz niedriger.

\section{Literatur}

Löser C, Möllgaard A, Fölsch UR (1996) Faecal elastase 1: a novel, highly sensitive, and specific tubeless pancreatic function test. Gut 39:580-586

$\mathrm{Cl}$

- Ionisationsmethoden (Massenspektrometrie)

- Massenspektrometrie

\section{Ciclosporin}

C. Vidal und W.-R. Külpmann

Synonym(e) Cyclosporin A

Englischer Begriff ciclosporine; cyclosporine; cyclosporin A

Definition Immunsuppressivum.

Molmasse $1203 \mathrm{~g}$.

Synthese - Verteilung - Abbau - Elimination Nach Inkorporation wird Ciclosporin hepatisch mittels Zytochrom P450 3A zu mehr als 30 verschiedenen, nicht nur inaktiven Metaboliten abgebaut, die über die Galle ausgeschieden werden. 
Halbwertszeit 15 Stunden (Erwachsene) (Plasma).

Funktion - Pathophysiologie Als unerwünschte Wirkungen treten auf: Nephrotoxizität, Hepatotoxizität, Muskelschwäche, Übelkeit und Hypertonie. Ciclosporin wirkt diabetogen.

Untersuchungsmaterial-Entnahmebedingungen EDTAVollblut.

Analytik Immunoassay (z. T. Erfassung von Metaboliten), HPLC ( $>$ Hochleistungs-Flüssigkeitschromatographie), LC-MS/MS ( $>$ Chromatographie, $\triangleright$ Massenspektrometrie).

Indikation Therapeutisches Drug Monitoring:

*Bis 3 Monate nach Transplantation

Interpretation Immunoassays sind unterschiedlich spezifisch und erfassen mehr oder weniger stark auch die Metabolite. Deren Anteil kann bei Störung der Gallenbildung/ausscheidung ansteigen, wodurch die Beurteilung von Immunoassay-Resultaten zusätzlich erschwert ist.

\section{Literatur}

Armstrong VW, Schütz E, Oellerich M (1999) Drug monitoring nach Organtransplantation. In: Bruhn HD, Fölsch UR (Hrsg) Lehrbuch der Labormedizin. Schattauer Verlag, Stuttgart, S 124-131

CID

- Massenspektrometrie

CIMP

- CpG-Island-Methylator Phenotyp

\begin{tabular}{|l|l|l|}
\hline & \multicolumn{2}{|l}{ Therapeutischer Bereich für Blut (mg/L) } \\
\hline Transplantat & Initialtherapie* & Erhaltungstherapie \\
\hline Niere & $0,150-0,225$ & $0,100-0,150$ \\
\hline Leber & $0,225-0,300$ & $0,100-0,150$ \\
\hline Herz & $0,250-0,350$ & $0,150-0,250$
\end{tabular}

\section{C1-INH}

C1-Esterase-Inhibitor

\section{Circadianer Rhythmus}

Circadiane Rhythmik

\section{Circadiane Rhythmik}

C. Vidal und W.-R. Külpmann

Synonym(e) Circadianer Rhythmus; Zirkadiane Rhythmik; Zirkadianer Rhythmus

Englischer Begriff circadian rhythm

Definition Änderung von Körperfunktionen in Abhängigkeit von der Tageszeit.

\begin{tabular}{l|l|l|} 
& $\begin{array}{l}\text { Plasmakonzentration }_{\text {max }} \\
\text { (Uhrzeit) }\end{array}$ & $\begin{array}{l}\text { Plasmakonzentration }_{\text {min }} \\
\text { (Uhrzeit) }\end{array}$ \\
\hline Kortisol & $6-10$ & $0-4$ \\
Kalium & $14-16$ & $23-1$ \\
Melatonin & $0-6$ & $7-22$ \\
STH & $21-23$ & $1-21$
\end{tabular}

Beschreibung Als Folge circadianer Rhythmik finden sich in Abhängigkeit von der Tageszeit bestimmte Substanzen in unterschiedlicher Konzentration in Blut oder Urin; Beispiele s. folgende Tabelle:

Aus diesem Grunde soll beachtet werden:

- Stets Dokumentation der Uhrzeit bei der Probennahme

- Blutentnahme möglichst immer zur selben Uhrzeit (z. B. 8:00 Uhr)

- Bei Referenzintervallermittlung Einbezug des Zeitpunkts der Probennahme

- Durchführung der quantitativen Bestimmung im Urin möglichst mit 24-Stunden-Sammelurin

\section{Literatur}

\section{C1-Inaktivator}

C1-Esterase-Inhibitor
Wisser H (1995) Einflussgrößen und Störgrößen. In: Greiling H, Gressner AM (Hrsg) Lehrbuch der klinischen Chemie und Pathobiochemie, 3. Aufl. Schattauer Verlag, Stuttgart 


\section{Circulating tumour cells}

\ Tumorzellen, zirkulierende

\section{Cit}

$>$ Citrullin

\section{Citrat als Antikoagulans}

- Antikoagulanzien in vitro

\section{Citrat im Urin}

W. G. Guder

Englischer Begriff citrate in urine; citric acid in urine

Definition Erfassung von Zitronensäure und ihren Salzen im 24-Stunden-Urin.

Struktur $\mathrm{C}_{6} \mathrm{H}_{8} \mathrm{O}_{7}$ (Citronensäure).

Molmasse 192,1 g (als Säure)

Synthese - Verteilung - Abbau - Elimination Citrate und Zitronensäure aus der Nahrung werden im Duodenum resorbiert und in der Niere durch Filtration und Metabolismus im proximalen Tubulus eliminiert. Urin-Citrat kommt im Wesentlichen aus dem sekretorischen und metabolischen Citrat des distalen Tubulus.

Halbwertszeit Im Blut von kurzer Halbwertszeit (wenige Minuten), da glomerulär frei filtrierbar und mit Resorption im proximalen Tubulus eliminiert.

Funktion - Pathophysiologie Distal tubuläre Citratsekretion ist wesentliche Ursache für Citratelimination im Urin. Sie wird gesteigert durch diätetisches Ansäuern des Urins. Da Citrat wesentlicher Faktor für die Löslichkeit von Calcium im Urin ist, wird die Citratausscheidung als Teil des $>$ Steinmetaphylaxe-Programms zur Quantifizierung empfohlen.

Untersuchungsmaterial - Entnahmebedingungen 24Stunden-Sammelurin, instabil im Nativurin, Ansäuern auf $\mathrm{pH}<2$ empfohlen.
Analytik Enzymatisch mit Citratlyase.

Konventionelle Einheit $\mathrm{mg} / 24 \mathrm{~h}$.

Internationale Einheit $\mathrm{mmol} / 24 \mathrm{~h}$.

Umrechnungsfaktor zw. konv. u. int. Einheit Konv. $\times 0,0052=$ intern. bzw. intern. $\times 191,1=$ konvent.

Referenzbereich - $\begin{array}{cccc}\text { Frauen } 2-4 & \mathrm{mmol} / 24 & \mathrm{~h}\end{array}$ (382-764 mg/24 h).

Referenzbereich - Männer $2-4 \quad \mathrm{mmol} / 24 \quad \mathrm{~h}$ (382-764 mg/24 h).

Referenzbereich $\quad-\quad$ Kinder $2-4 \quad \mathrm{mmol} / 24 \quad \mathrm{~h}$ $(382-764 \mathrm{mg} / 24 \mathrm{~h})$.

Indikation Teil des Untersuchungsprogramms von Steinträgern.

Interpretation Ziel der Therapie ist eine Citratausscheidung $>2,5 \mathrm{mmoL} / 24 \mathrm{~h}(>481 \mathrm{mg} / 24 \mathrm{~h})$.

Diagnostische Wertigkeit Da die Citratausscheidung von vielen diätetischen und renalen Faktoren abhängt, ist seine Messung nicht von der gleichen Bedeutung wie die der steinbildenden Substanzen (Oxalat, Calcium, Harnsäure).

\section{Literatur}

Hesse A, Jahnen A, Klocke K et al (1994) Nachsorge bei Harnsteinpatienten. Gustav-Fischer-Verlag, Jena Stuttgart

\section{Citrullin}

A. C. Sewell

$\operatorname{Synonym(e)~Cit~}$

Englischer Begriff citrulline

Definition Citrullin ist eine $\alpha$-Aminosäure. Von lateinisch citrullus $=$ Wassermelone, aus der sie im Jahr 1930 auch zuerst isoliert wurde. Citrullin besitzt eine Schlüsselrolle im Harnstoffzyklus. 


\section{Struktur}

$$
\stackrel{\mathrm{O}}{\mathrm{II}} \underset{\mathrm{NH}}{\mathrm{C}}-\mathrm{NH}-\mathrm{CH}_{2}-\mathrm{CH}_{2}-\mathrm{CH}_{2}-\underset{\substack{\mathrm{C} \\ \mathrm{NH}_{2}}}{\mathrm{CH}}-\mathrm{COOH}
$$

Molmasse $175,2 \mathrm{~g}$.

Synthese - Verteilung - Abbau - Elimination Citrullin wird aus Ornithin und Carbamoylphosphat im Harnstoffzyklus synthetisiert. Es entsteht aber auch aus Arginin als Nebenprodukt der durch Stickstoffmonoxidsynthetase katalysierten Reaktion.

Funktion - Pathophysiologie Normalerweise ist der Citrullinspiegel im Plasma niedrig und die Urinausscheidung minimal. Stark erhöhte Plasmawerte (10-fach über Norm) und eine erhöhte Urinausscheidung sind wegweisend für eine Citrullinämie. Bei Patienten mit rheumatoider Arthritis finden sich erhöhte Antikörpertiter gegen citrullinierte Proteine ( $\triangleright$ Autoantikörper gegen citrullinierte Peptide).

Untersuchungsmaterial - Entnahmebedingungen Serum, Plasma, Urin, Liquor, Trockenblut.

Analytik $>$ Aminosäuren.

Referenzbereiche $>$ Aminosäuren.

Indikation Verdacht auf Hyperammoniämie unterschiedlicher Ursachen. Überwachung von Patienten mit einer angeborenen Harnstoffzyklusstörung.

\section{Literatur}

Duran M (2008) Amino acids. In: Blau N, Duran M, Gibson KM (Hrsg) Laboratory guide to the methods in biochemical genetics. Springer, Berlin, S 53-90

\section{CK}

Kreatinkinase

\section{CK-18}

- M30-Antigen

- M65-Antigen

- Tissue Polypeptide Antigen

$\checkmark$ Tissue Polypeptide Specific Antigen
CK18-Asp396-NE

M30-Antigen

\section{CK18-Fragmente}

- M65-Antigen

\section{CK/AST-Quotient}

- Szasz-Quotient

\section{CK-BB}

Kreatinkinase-Isoformen

\section{CKD-EPI-Formel}

T. Arndt

Synonym(e) Chronic Kidney Disease Epidemiology Collaboration formula

Englischer Begriff CKD-EPI formula

Definition Formeln zur Berechnung der endogenen glomerulären Kreatinin-Clearance, der endogenen Cystatin-C-Clearance oder der endogenen Kreatinin- und Cystatin-C-Clearance entsprechend der Chronic-Kidney-Disease-Epidemiology-Collaboration-Gruppe.

Beschreibung Zur Quantifizierung der glomerulären Filtration (GFR) der Niere ( $\triangleright$ Filtration, glomeruläre) wurde eine Vielzahl von mathematischen Modellen beschrieben, die die individuelle glomeruläre Filtration möglichst exakt beschreiben und damit glomeruläre Nierenschäden möglichst frühzeitig aufdecken sollen. Hierzu werden verschiedene klinisch-chemische Laborparameter wie $>$ Kreatinin in Urin und/oder Serum oder $\triangleright$ Cystatin C im Serum, morphologische Kenngrößen wie Körpergröße, Körpermasse, aber auch Geschlecht und/oder Rasse ausgewertet.

Beispiele sind die $\triangleright$ Cockroft-Gault-Formel, die $\triangleright$ Kreatinin-Clearance, die MDRD-Formel ( $\triangleright$ Kreatinin-Clearance) 
und die $>$ Schwartz-Formel. Weitere Beispiele sind die CKD-EPI-Formel(n), die in ihrer zuletzt publizierten Form der CKD-EPI-Kreatinin-Cystatin-C-Formel Kreatinin und Cystatin C im Serum sowie Alter, Geschlecht und Rasse des Patienten berücksichtigen. Die in den 3 Tabellen gelisteten Modelle gelten nicht für Patienten mit Nierentransplantat.

Die CKD-EPI Kreatinin-Gleichung (CKD-EPI 2009) basiert analytisch auf einer Messung des Kreatinins im Serum (Tab. 1).

Die CKD-EPI-Cystatin C-Gleichung (CKD-EPI 2012) basiert analytisch auf einer auf einen internationalen Standard rückführbaren Messung des Cystatin C im Serum (Tab. 2).

Die CKD-EPI-Kreatinin-Cystatin-C-Gleichung basiert analytisch auf 2 auf internationale Standards rückführbare Messungen des Serum-Kreatinins und des Serum-Cystatin C (Tab. 3).

Formeln zur Abschätzung der glomerulären Filtration von Patienten mit chronischer Nierenerkrankung werden von Inker et al. im Supplementum 3 wiedergegeben. Diese Modelle beziehen sich ebenso auf internationalen Standards rückführbare Kreatinin- und Cystatin-C-Messergebnisse (Tab. 4).

Nach Inker et al. ist eine 3 Monate oder länger währende Reduktion der glomerulären Filtration auf $<60 \mathrm{~mL} / \mathrm{min} /$ $1,73 \mathrm{~m}^{2}$ Körperoberfläche (= Schwellenwert zur chronischen Nierenerkrankung; normal $\geq 90 \mathrm{~mL} / \mathrm{min} / 1,73 \mathrm{~m}^{2}$ ) diagnostisches Kriterium für eine chronische Nierenerkrankung und assoziiert mit einer schlechten Prognose, einschließlich Tod.
Die GFR aus Serum-Kreatinin und Serum-Cystatin C zeigt nach Inker et al. von allen derzeit bekannten mathematischen Modellen die höchste Präzision und Richtigkeit zur labormedizinischen Erkennung einer chronischen Nierenerkrankung. Dies gilt auch für sehr schlanke Patienten mit einem $>$ Body-MassIndex $<20$, bei denen aufgrund der geringen Muskelmasse und der damit verbundenen geringen Kreatininproduktion rein kreatininbasierte Modelle falsch-niedrige GFR ergeben.

Nach Inker et al. soll die Berechnung der glomerulären Filtration nach der CKD-EPI-Kreatinin-Gleichung nicht prinzipiell durch die CKD-EPI-Cystatin-C-Gleichung oder die hier auch vorgestellte Kombination ersetzt werden. Stattdessen soll z. B. bei einer kreatininbasierten GFR von $45-59 \mathrm{~mL} / \mathrm{min} /$ 1,73 $\mathrm{m}^{2}$ Cystatin C im Serum, sozusagen als Bestätigungstest, für die Diagnose einer chronischen Nierenerkrankung bestimmt und anschließend aus den nun verfügbaren SerumKreatinin- und Cystatin-C-Konzentrationen die GFR nach der CKD-EPI-Kreatinin-Cystatin-C-Gleichung berechnet werden.

Mit dieser Strategie kann ein nicht unerheblicher Anteil an Patienten mit einer kreatininbasierten GFR von $45-59 \mathrm{~mL} / \mathrm{min} /$ $1,73 \mathrm{~m}^{2}$ als nicht chronisch nierenkrank reklassifiziert werden. Diese stufenweise Labordiagnostik führt nicht nur zu einem optimalen Einsatz der Laborressourcen, sondern insbesondere auch zur Vermeidung unnötiger Nachfolgeuntersuchungen und ggf. Medikationen infolge von Falschklassifizierungen von (gesunden) Patienten als chronisch Nierenkranke.

CKD-EPI-Formel, Tab. 1 CKD-EPI-Kreatinin-Gleichungen (CKD-EPI 2009; nach: Inker et al. 2012)

\begin{tabular}{|c|c|c|}
\hline Geschlecht & Serum-Kreatinin (Scr) & Formel \\
\hline Weiblich & $\begin{array}{l}\leq 0,7 \mathrm{mg} / \mathrm{dL}(\leq 61,9 \\
\mu \mathrm{mol} / \mathrm{L})\end{array}$ & $\mathrm{GFR}=144 \times(\mathrm{Scr} / 0,7)^{-0,329} \times 0,993^{\text {Alter }}$ \\
\hline Weiblich & $\begin{array}{l}>0,7 \mathrm{mg} / \mathrm{dL}(>61,9 \\
\mu \mathrm{mol} / \mathrm{L})\end{array}$ & GFR $=144 \times(\mathrm{Scr} / 0,7)^{-1,209} \times 0,993^{\text {Alter }}$ \\
\hline Männlich & $\begin{array}{l}\leq 0,9 \mathrm{mg} / \mathrm{dL}(\leq 79,6 \\
\mu \mathrm{mol} / \mathrm{L})\end{array}$ & GFR $=141 \times(\mathrm{Scr} / 0,9)^{-0,411} \times 0,993^{\text {Alter }}$ \\
\hline \multirow[t]{2}{*}{ Männlich } & $\begin{array}{l}>0,9 \mathrm{mg} / \mathrm{dL}(>79,6 \\
\mu \mathrm{mol} / \mathrm{L})\end{array}$ & $\mathrm{GFR}=141 \times(\mathrm{Scr} / 0,9)^{-1,209} \times 0,993^{\text {Alter }}$ \\
\hline & & $\begin{array}{l}\text { Für Patienten mit schwarzer Hautfarbe sind die Ergebnisse aus o. g. Formeln mit } 1,159 \mathrm{zu} \\
\text { multiplizieren. }\end{array}$ \\
\hline $\begin{array}{l}\text { Allgemeine } \\
\text { Formel }\end{array}$ & \multicolumn{2}{|c|}{$\begin{array}{l}\mathrm{GFR}=141 \times \min (\mathrm{Scr} / \kappa, 1)^{\alpha} \times \max (\mathrm{Scr} / \kappa, 1)^{-1,209} \times 0,993^{\text {Alter }} \\
\text { Das Ergebnis ist für Frauen mit } 1,018, \text { für Patienten mit schwarzer Hautfarbe mit } 1,159 \text { zu multiplizieren, für Frauen mit } \\
\text { schwarzer Hautfarbe also mit } 1,018 \text { und } 1,159 . \\
\text { Scr }=\text { Serum-Kreatinin, } \kappa=0,7 \text { für Frauen und } 0,9 \text { für Männer, } \alpha=-0,329 \text { für Frauen und }-0,411 \text { für Männer, } \\
\text { min }=\text { Minimum des Serum-Kreatinins } / \kappa \text { oder } 1, \max =\text { Maximum des Serum-Kreatinins } / \kappa \text { oder } 1\end{array}$} \\
\hline
\end{tabular}

CKD-EPI-Formel, Tab. 2 CKD-EPI-Cystatin-C-Gleichungen (CKD-EPI 2012; nach: Inker et al. 2012)

\begin{tabular}{|c|c|c|}
\hline Geschlecht & Serum-Cystatin C (Scys) & Formel \\
\hline Unisex & $\leq 0,8 \mathrm{mg} / \mathrm{L}$ & $\mathrm{GFR}=133 \times(\mathrm{Scys} / 0,8)^{-0,499} \times 0,996^{\text {Alter }}$ \\
\hline Unisex & $>0,8 \mathrm{mg} / \mathrm{L}$ & $\mathrm{GFR}=133 \times(\mathrm{Scys} / 0,8)^{-1,328} \times 0,996^{\text {Alter }}$ \\
\hline & & Für Frauen sind die Ergebnisse aus o. g. Formeln mit 0,932 zu multiplizieren. \\
\hline Allgemeine Formel & \multicolumn{2}{|c|}{$\begin{array}{l}\mathrm{GFR}=133 \times \min (\mathrm{Scys} / 0,8,1)^{-0,499} \times \max (\mathrm{Scys} / 0,8,1)^{-1,328} \times 0,996^{\text {Alter }} \\
\text { Dass Ergebnis ist für Frauen mit } 0,932 \mathrm{zu} \text { multiplizieren } \\
\text { Scys }=\text { Serum-Cystatin C }\end{array}$} \\
\hline
\end{tabular}


CKD-EPI-Formel, Tab. 3 CKD-EPI-Kreatinin-Cystatin-C-Gleichungen (CKD-EPI 2012: nach: Inker et al. 2012)

\begin{tabular}{|c|c|c|c|}
\hline Geschlecht & $\begin{array}{l}\text { Serum-Kreatinin } \\
\text { (Scr) }\end{array}$ & $\begin{array}{l}\text { Serum-Cystatin } \\
\text { C (Scys) }\end{array}$ & Formel \\
\hline Weiblich & $\begin{array}{l}\leq 0,7 \mathrm{mg} / \mathrm{dL} \\
(\leq 61,9 \mu \mathrm{mol} / \mathrm{L})\end{array}$ & $\leq 0,8 \mathrm{mg} / \mathrm{L}$ & $\mathrm{GFR}=130 \times(\mathrm{Scr} / 0,7)^{-0,248} \times(\mathrm{Scys} / 0,8)^{-0,375} \times 0,995^{\text {Alter }}$ \\
\hline Weiblich & $\begin{array}{l}\leq 0,7 \mathrm{mg} / \mathrm{dL} \\
(\leq 61,9 \mu \mathrm{mol} / \mathrm{L})\end{array}$ & $>0,8 \mathrm{mg} / \mathrm{L}$ & $\mathrm{GFR}=130 \times(\mathrm{Scr} / 0,7)^{-0,248} \times(\mathrm{Scys} / 0,8)^{-0,711} \times 0,995^{\text {Alter }}$ \\
\hline Weiblich & $\begin{array}{l}>0,7 \mathrm{mg} / \mathrm{dL} \\
(>61,9 \mu \mathrm{mol} / \mathrm{L})\end{array}$ & $\leq 0,8 \mathrm{mg} / \mathrm{L}$ & $\mathrm{GFR}=130 \times(\mathrm{Scr} / 0,7)^{-0,601} \times(\mathrm{Scys} / 0,8)^{-0,375} \times 0,995^{\text {Alter }}$ \\
\hline Weiblich & $\begin{array}{l}>0,7 \mathrm{mg} / \mathrm{dL} \\
(>61,9 \mu \mathrm{mol} / \mathrm{L})\end{array}$ & $>0,8 \mathrm{mg} / \mathrm{L}$ & $\mathrm{GFR}=130 \times(\mathrm{Scr} / 0,7)^{-0,601} \times(\mathrm{Scys} / 0,8)^{-0,711} \times 0,995^{\text {Alter }}$ \\
\hline Männlich & $\begin{array}{l}\leq 0,9 \mathrm{mg} / \mathrm{dL} \\
(\leq 79,6 \mu \mathrm{mol} / \mathrm{L})\end{array}$ & $\leq 0,8 \mathrm{mg} / \mathrm{L}$ & $\mathrm{GFR}=135 \times(\mathrm{Scr} / 0,9)^{-0,207} \times(\mathrm{Scys} / 0,8)^{-0,375} \times 0,995^{\text {Alter }}$ \\
\hline Männlich & $\begin{array}{l}\leq 0,9 \mathrm{mg} / \mathrm{dL} \\
(\leq 79,6 \mu \mathrm{mol} / \mathrm{L})\end{array}$ & $>0,8 \mathrm{mg} / \mathrm{L}$ & $\mathrm{GFR}=135 \times(\mathrm{Scr} / 0,9)^{-0,207} \times(\mathrm{Scys} / 0,8)^{-0,711} \times 0,995^{\text {Alter }}$ \\
\hline Männlich & $\begin{array}{l}>0,9 \mathrm{mg} / \mathrm{dL} \\
(>79,6 \mu \mathrm{mol} / \mathrm{L})\end{array}$ & $\leq 0,8 \mathrm{mg} / \mathrm{L}$ & GFR $=135 \times(\mathrm{Scr} / 0,9)^{-0,601} \times(\mathrm{Scys} / 0,8)^{-0,375} \times 0,995^{\text {Alter }}$ \\
\hline \multirow[t]{2}{*}{ Männlich } & $\begin{array}{l}>0,9 \mathrm{mg} / \mathrm{dL} \\
(>79,6 \mu \mathrm{mol} / \mathrm{L})\end{array}$ & $>0,8 \mathrm{mg} / \mathrm{L}$ & $\mathrm{GFR}=135 \times(\mathrm{Scr} / 0,9)^{-0,601} \times(\mathrm{Scys} / 0,8)^{-0,711} \times 0,995^{\text {Alter }}$ \\
\hline & & & $\begin{array}{l}\text { Für Patienten mit schwarzer Hautfarbe sind die Ergebnisse aus o. g. Formeln mit } \\
1,08 \text { zu multiplizieren. }\end{array}$ \\
\hline $\begin{array}{l}\text { Allgemeine } \\
\text { Formel }\end{array}$ & \multicolumn{3}{|c|}{$\begin{array}{l}\mathrm{GFR}=135 \times \min (\mathrm{Scr} / \kappa, 1)^{\alpha} \times \operatorname{ma} \times(\mathrm{Scr} / \kappa, 1)^{-0,601} \times \min (\mathrm{Scys} / 0,8,1)^{-0,375} \times \max (\mathrm{Scys} / 0,8,1)^{-0,711} \times 0,995^{\text {Alter }} \\
\text { Dass Ergebnis ist für Frauen mit } 0,969 \text { und für Patienten mit schwarzer Hautfarbe mit } 1,08 \text { zu multiplizieren, für Frauen mit } \\
\text { schwarzer Hautfarbe also mit } 0,969 \text { und } 1,08 . \\
\text { Scr }=\text { Serum-Kreatinin, } \kappa=0,7 \text { für Frauen und } 0,9 \text { für Männer, } \alpha=-0,248 \text { für Frauen und }-0,207 \text { für Männer, min }=\text { Minimum } \\
\text { des Serum-Kreatinins } / \kappa \text { oder } 1, \max =\text { Maximum des Serum-Kreatinins } / \kappa \text { oder } 1 ; \text { Scys }=\text { Serum-Cystatin C }\end{array}$} \\
\hline
\end{tabular}

CKD-EPI-Formel, Tab. 4 Formeln zur Berechnung der GFR für Patienten mit chronischer Nierenerkrankung (aus: Inker et al. 2012, Supplementum 3)

\begin{tabular}{|c|c|}
\hline Modell & Formel \\
\hline MDRD-Formel & $\begin{array}{l}175 \times \text { standardisiertes } \mathrm{Scr}^{-1,154} \times \\
\text { Alter }{ }^{-0,203} \times 0,75[\text { wenn weiblich] } \times 1,210 \\
{[\text { wenn schwarze Hautfarbe] }}\end{array}$ \\
\hline Cystatin-C-Formel & $\begin{array}{l}127,7 \times(-0,105+1,13 \times \text { standardisiertes } \\
\text { Scys })^{-1,17} \times \text { Alter }^{-0,13} \times 0,91 \text { [wenn weiblich] } \\
\times 1,06 \text { [wenn schwarze Hautfarbe] }\end{array}$ \\
\hline \multirow[t]{3}{*}{$\begin{array}{l}\text { Kreatinin- } \\
\text { Cystatin-C-Formel }\end{array}$} & $\begin{array}{l}177,6 \times \mathrm{Scr}^{-0,65} \times(-0,105+1,13 \times \\
\text { standardisiertes Scys })^{-0,57} \times \text { Alter }^{-0,20} \times 0,82 \\
{[\text { wenn weiblich] } \times 1,11[\text { wenn schwarze }} \\
\text { Hautfarbe] }\end{array}$ \\
\hline & $\begin{array}{l}\text { Scr = Serum-Kreatinin }[\mathrm{mg} / \mathrm{dL}] \\
\text { Scys }=\text { Serum-Cystatin } C[\mathrm{mg} / \mathrm{L}], \text { Alter }[\text { Jahre }]\end{array}$ \\
\hline & $\begin{array}{l}\text { Anmerkung: Der bei Inker et al. in der MDRD- } \\
\text { Formel ausgewiesene Exponent von - } 203 \text { für } \\
\text { das Alter ist falsch, richtig ist ein Exponent } \\
\text { von }-0,203 \text {. }\end{array}$ \\
\hline
\end{tabular}

Die CKD-EPI-Formeln stehen allerdings auch unter Kritik. So soll nach Selistre et al. (2016) die $>$ Schwartz-Formel z. B. für Kinder und Erwachsene im Alter von 18-40 Jahren mit milder oder moderater Nierenfunktionseinschränkung eine richtigere Aussage liefern.

Offenbar scheint das Problem der mathematischen Modellierung der endogenen glomerulären Filtrationsleistung zumindest für einige Subpopulationen von Patienten noch immer nicht abschließend gelöst zu sein, sodass mit weiteren Formeln zu rechnen ist.
Die Messung der glomerulären Filtration anhand der Elimination von exogenen Substanzen wie z. B. bei der Bestimmung der $>$ Inulin-Clearance oder der Iothalamat-Clearance gelten als Goldstandard, haben jedoch das Risiko anaphylaktischer Reaktionen und sind deshalb im klinischen Alltag weniger verbreitet.

\section{Literatur}

Inker LA, Schmid CH, Tighiouart H, Eckfeldt JH, Feldmann HI, Greene T, Kusek JW, Manzi J, van Lente F, Zhang YL, Coresh J, Levey AS for the CKD-EPI Investigators (2012) Estimating glomerular filtration rate from serum creatinine and cystatin c. New Eng $J$ Med 367:20-29. http://www.nejm.org/doi/suppl/10.1056/NEJMoa 1114248/suppl_file/nejmoa1114248_appendix.pdf. Zugegriffen am 07.08.2017

Selistre L, Rabilloud M, Cochat P, de Souza V, Iwaz J, Lemoine S, Beyerle F, Poli-de-Figueiredo CE, Dubourg L (2016) Comparison of the Schwartz and CKD-EPI equations for estimating glomerular filtration rate in children, adolescents, and adults: a retrospective cross-sectional study. PLoS Med 13(3):e1001979. https://doi.org/ 10.1371/journal.pmed.1001979. https://www.ncbi.nlm.nih.gov/pmc /articles/PMC4811544/pdf/pmed.1001979.pdf. Zugegriffen am 07.08 .2017

\section{CK/GOT-Verhältnis}

- Szasz-Quotient 


\section{CK-Isoformen}

Kreatinkinase-Isoformen

CK-MB

- Kreatinkinase-Isoformen

\section{CKmi}

> Kreatinkinase-MB

\section{CK-MM}

- Kreatinkinase-Isoformen

\section{CK-MM(1-3)}

- Kreatinkinase-Isoformen

\section{CK-MT}

Kreatinkinase

\section{C3-Komplement}

G. Töpfer

Synonym(e) $\beta 1 C / \beta 1 A-G l o b u l i n$

Englischer Begriff complement component $\mathrm{C} 3 ; \beta 1 \mathrm{~A} / \beta 1 \mathrm{C}$

Definition Protein des Komplementsystems (s. $>$ Komplementsystem, klassische Aktivierung, - Komplementsystem, alternative Aktivierung), das sowohl durch die klassische Aktivierung als auch durch den alternativen Aktivierungsweg gespalten wird. Die Spaltprodukte sind bedeutungsvoll u. a. für die Opsonierung von Fremdstoffen wie Bakterien und Viren, das Anlocken von Phagozyten (Chemotaxis) und die Einleitung der Bildung des Zellangriffkomplexes, der zur Lyse von Fremdzellen führt. Stellt elektrophoretisch in der Zonenelektrophorese die $\beta 2$-Fraktion des frischen Serums dar.

Struktur Glykoprotein aus 2 Polypeptidketten ( $\alpha$-Kette mit $110 \mathrm{kDa}$ und $\beta$-Kette mit $75 \mathrm{kDa}$ ), die durch 2 Disulfidbrücken zusammengehalten werden. $\mathrm{C} 3$ wird durch einen Genabschnitt von $>40 \mathrm{~Kb}$ im Chromosom 19 des Menschen kodiert.

Molmasse $185 \mathrm{kDa}$.

Synthese - Verteilung - Abbau - Elimination Die Synthese erfolgt in der Leber, in $>$ Monozyten, $>$ Makrophagen, Fibroblasten u. a. Die extrahepatische C3-Synthese scheint die C3-Bereitstellung im Falle des schnellen Bedarfs zu decken, bevor $\mathrm{C} 3$ aus den Kapillaren in ausreichender Konzentration in das Gewebe einströmen kann. Lipid A löst die C3-Synthese in Monozyten und Fibroblasten aus. Z Zytokine lösen die Synthese in Hepatozyten aus ( $\triangleright$ Interleukin-1 und $\triangleright$ Tumornekrosefaktor- $\alpha \quad(\mathrm{TNF}-\alpha)$ zusammen mit Interleukin- 6 oder Interleukin-6 allein). Interleukin-4 verstärkt den Synthesesteigernden Effekt von TNF. Bei Lebersynthesestörungen verläuft die Synthese verzögert. Bei Erkrankungen mit Bildung von Immunkomplexen (s. \ Immunkomplexe) und bei alternativer Komplementaktivierung ( $\triangleright$ Komplementsystem, alternative Aktivierung) ist der Abbau stark beschleunigt. Bei Verbrennungen und bei Proteinverlust (Enteropathie) kann es ebenfalls zum schnellen Abfall kommen.

Halbwertszeit $0,5-1$ Tag.

Funktion - Pathophysiologie C3 ist im Blutplasma gesunder Erwachsener in einer Konzentration von etwa $1 \mathrm{~g} / \mathrm{L}$ $(0,83-1,60 \mathrm{~g} / \mathrm{L})$ vorhanden. $\mathrm{Zu}$ einem kleinen Teil findet ständig spontan eine Spaltung in C3b (176 kDa) und C3a $(9,1 \mathrm{kDa})$ statt. Sowohl im Plasma als auch an körpereigene Zellen gebunden werden die C3-Spaltprodukte so wie sie entstehen auch wieder abgebaut. Auf den Körperzellen gebundenes C3b bindet zwar Faktor B, der durch Faktor D zum $\mathrm{C} 3 \mathrm{bBb}-K o m p l e x$ umgewandelt wird. Körpereigene Zellen binden aber nun Faktor $\mathrm{H}$, der $\mathrm{Bb}$ aus der Bindung mit $\mathrm{C} 3 \mathrm{~b}$ verdrängt und ermöglicht, dass Faktor I C3b inhibiert. Damit ist die Komplementaktivierung im Normalfall blockiert.

Anders, wenn die Bindung des $\mathrm{C} 3 \mathrm{~b}$ (das eine hohe Affinität zu Zellen aufweist) auf Pilzen oder Bakterien erfolgt. In dem Falle ist eine Bindung von Faktor H (aufgrund fehlender Kofaktoren und fehlender Neuraminsäure, die eine Bindung von Faktor $\mathrm{H}$ auf Körperzellen begünstigen) erschwert. Damit wird die Bindung von Faktor P (Properdin) an den $\mathrm{C} 3 \mathrm{bBb}-K o m p l e x$ möglich, der $\mathrm{C} 3 \mathrm{bBb}$ stabilisiert. $\mathrm{C} 3 \mathrm{bBb}$ wirkt als C3-,,Spaltenzym“ (Konvertase). Die Wirkung der Konvertase löst eine Kettenreaktion mit Produktion größerer Mengen an $\mathrm{C} 3 \mathrm{bBb}$ aus. Dieser Aktivierungsweg läuft Anti- 
körper-unabhängig als Sofortreaktion auf das Eindringen eines Pathogens ab (alternative Komplementaktivierung).

Sind spezifische Antikörper der Klasse IgG1, IgG2, IgG3 oder IgM schon an das Antigen (Pathogen) gebunden, so wird die klassische Komplementaktivierung ( $\triangleright$ Komplementsystem, klassische Aktivierung) eingeleitet. C1q bindet zunächst an den (gebundenen) Antikörper. Über mehrere Enzymaktivierungen wird die C3-Konvertase C4b2a gebildet, die eine gleiche Wirksamkeit wie $\mathrm{C} 3 \mathrm{bBb}$ in der alternativen Komplementaktivierung entfaltet, nämlich die Bildung von $\mathrm{C} 3 \mathrm{~b}$ zu katalysieren. Auch dieser Vorgang läuft auf körperfremden Zellen begünstigt ab. Die C3b-Produktion aktiviert nun wegen der Ansammlung von $\mathrm{C} 3 \mathrm{~b}$ auf den Zellen die alternative Komplementaktivierung, sodass die C3bEntstehung aus der klassischen Aktivierung auf dem alternativen Weg eine Verstärkung erfährt (Amplifikation). Die klassische Komplementaktivierung kann auch ohne Antikörper erfolgen:

- Mannose-bindendes Protein (MBP) (1,5 mg/L im Plasma) bindet an Mannose-haltige Strukturen von Mikroorganismen. Da MBP eine chemische Struktur ähnlich dem C1q aufweist, kann MBP die Rolle des Clq bei der unspezifischen Aktivierung übernehmen. MBP-Mangel führt zu einer Infektgefährdung.

- Auch CRP kann die klassische Komplementaktivierung nach Bindung an Bakterienstrukturen einleiten, indem dann eine CRP-C1q-Bindung entsteht (CRP übernimmt den Part des Antikörpers).

Allerdings soll CRP auch die Wirkung von Faktor $\mathrm{H}$ verstärken (Hemmeffekt auf die Aktivierung). Hat sich bei der alternativen Komplementaktivierung genügend $\mathrm{C} 3 \mathrm{~b}$ gebildet, so entsteht aus $\mathrm{C} 3 \mathrm{Bb}$ das $(\mathrm{C} 3 \mathrm{~b})_{2} \mathrm{Bb}$. Durch Bindung eines zweiten C3b-Moleküls bei dem klassischen Aktivierungsweg bildet sich $\mathrm{C} 3 \mathrm{~b} 4 \mathrm{~b} 2 \mathrm{a}$. Sowohl $(\mathrm{C} 3 \mathrm{~b})_{2} \mathrm{Bb}$ als auch $\mathrm{C} 3 \mathrm{~b} 4 \mathrm{~b} 2 \mathrm{a}$ wirken als $\mathrm{C} 5$-Konvertase. Die C5-Spaltung in C5a und $\mathrm{C} 5 \mathrm{~b}$ verlangt eine optimale sterische Anordnung von $\mathrm{C} 3 \mathrm{~b}$ und $\mathrm{C} 5$. Ist diese vorhanden, so wird nunmehr unter Mithilfe von $\mathrm{C} 5 \mathrm{~b}, \mathrm{C} 6, \mathrm{C} 7, \mathrm{C} 8$ und C9 der Membranangriffskomplex gebildet, der zur Zelllyse führt. Ob es zur Bildung dieses Komplexes kommt, hängt von sterischen Voraussetzungen $\mathrm{ab}$ und davon, wie wirksam die Inhibitoren dieses Vorgangs sind. Häufig steht bei der Komplementaktivierung die Aktivierung der Phagozytose durch C3b (Bindung an den Komplementrezeptor CR-1 der Phagozyten u. a.) sowie die Entzündungsreaktion und Anlockung von Phagozyten u. a. durch C3a mehr im Vordergrund des Geschehens als die Lyse der Zellen durch den Membranangriffskomplex.

\section{Funktionen von C3b:}

- Erleichtert die Bindung von Bakterien, Viren und Immunkomplexen an Neutrophile, Monozyten, Makrophagen (wirksamstes Opsonin). Hohe Blutglukose hemmt die Bindung (Opsonierung) von C3b und C3bi an Bakterien.

- Löst die Endozytose und die Phagozytose der Phagozyten aus und aktiviert den „respiratory burst“ durch die CRezeptor-vermittelte Aktivierung.

- Erleichtert die Bindung an Erythrozyten-KomplementRezeptor (CR-1) und damit die Clearance von Immunkomplexen (IK) aus der Zirkulation durch Abbau in der Milz.

\section{Funktionen von C3a:}

- Kontraktion der glatten Muskelzellen.

- Erhöhung der Gefäßpermeabilität.

- Degranulierung von Mastzellen, Freisetzung von Histamin.

- Chemotaktische Anlockung von Granulozyten.

- Interleukin-1-Freisetzung aus Monozyten - Suppression der Antikörperproduktion.

Untersuchungsmaterial - Entnahmebedingungen Serum oder EDTA-Plasma.

Präanalytik Frisch in das Labor! Serum/Plasma sofort bei $<-20{ }^{\circ} \mathrm{C}$ einfrieren. Oder sofort (innerhalb von 1 Stunde) bestimmen, da Anstieg der Werte bei Lagerung um bis zu $15 \%$. Trübungen und Lipämie vor Bestimmung durch 10 Minuten Zentrifugation bei $15.000 \times g$ entfernen (Sedimentation bzw. Flotation).

\section{Analytik}

- Immunturbidimetrie

- Immunnephelometrie

- Immundiffusion, radiale nach Mancini, Carbonara und Heremans

Standard: ERM - DA $470 \mathrm{k} / \mathrm{IFCC}$ basiert auf C3c.

Bestimmung innerhalb von 1 Stunde nach der Blutentnahme erforderlich, da Umwandlung des C3-Moleküls zu Veränderungen der Antigenität führt. VK von Tag zu Tag $=3,8-6,4 \%$ (Immunnephelometrie).

Konventionelle Einheit $\mathrm{mg} / \mathrm{dL}$.

Internationale Einheit $\mathrm{g} / \mathrm{L}$.

Umrechnungsfaktor zw. konv. u. int. Einheit $\mathrm{mg}$ / $\mathrm{dL}: 100=\mathrm{g} / \mathrm{L}$

Referenzbereich - Erwachsene $0,90-1,80 \mathrm{~g} / \mathrm{L}$.

Referenzbereich - Kinder Bis 2 Tage $0,36-1,12 \mathrm{~g} / \mathrm{L}$, bis 4 Tage $0,45-1,27 \mathrm{~g} / \mathrm{L}$, bis 10 Tage $0,45-1,50 \mathrm{~g} / \mathrm{L}$, bis 20 Tage $0,60-1,35 \mathrm{~g} / \mathrm{L}$, bis $1 \mathrm{Jahr} 0,75-1,35 \mathrm{~g} / \mathrm{L}$. 


\section{Indikation}

- Verdacht auf Immunkomplexkrankheiten

- Hereditärer Mangel bei Infektabwehrschwäche

- Verdacht auf hereditäres angioneurotisches Ödem (HANE)

\section{Interpretation}

- Erhöhungen bei Akute-Phase-Reaktion (bei Entzündungen und Tumoren). Bei Sepsis zeigt ein hohes C3-Komplement die Gefahr einer disseminierten intravasalen Gerinnung (DIG) an. Als Risikofaktor für eine koronare Herzkrankheit und/oder Arteriosklerose der Aorta bei Frauen nach der Menopause besonders bei Fettgewebeablagerungen um Herz und Aorta. Risikofaktor für Prädiabetes.

- Erniedrigungen bei Komplementdefekt (selten) oder Verbrauch durch Ausbildung von Immunkomplexen (mit Ag-IgM oder Ag-IgG) bei LE, Glomerulonephritis, Polyarthritis, Hämolyse durch antierythrozytäre Antikörper (Autoimmunhämolyse).

Diagnostische Wertigkeit Verdacht auf folgende Immunkomplexerkrankungen und Verlaufsbeurteilung (Korrelation mit Krankheitsaktivität):

- Lupus erythematodes (dabei häufig auch angeborener C4-, C3-Mangel und $>$ C1-Esterase-Inhibitor-Mangel)

- Vaskulitis

- Glomerulonephritis auch kombiniert mit Autoimmunerkrankungen

- Kryoglobulinämie

- Autoimmunhämolytische Anämie (dabei sollte die folgende Parameterkombination gewählt werden: C3, C4, $\mathrm{CH}-50$, zirkulierende Immunkomplexe und CRP)

- Alternative Komplementaktivierung bei Churg-StraussVaskulitis (C3 erniedrigt und C4 normal)

- Verdacht auf hereditären Komplementdefekt (z. B. bei hämolytisch urämischen Syndrom [HUS] bei Makuladegeneration)

- Rezidivierende Infektionen (dabei CH-50 bestimmen sowie C3/C4-Komplement; falls nicht vermindert, dann C6, C9 und C5 eventuell im Speziallabor bestimmen lassen)

- C1-Inaktivator-Mangel (dabei auch Bestimmung von C4 sowie CRP; C4 ist vermindert, C3 liegt im Referenzbereich; mit CRP wird der Einfluss einer Akute-PhaseReaktion erkannt)

- Verminderung oder Fehlen der $\beta 2$-Fraktion in der Elektrophorese (Elektrophoreseverfahren mit $\beta 2-G l o b u l i n-A b-$ trennung durchführen, um damit ein Screening auf C3-Mangel zu ermöglichen).

\section{Literatur}

Töpfer G, Hornig F, Sauer K, Zawta B (2000) Untersuchungen zur Stabilität von 11 Serumproteinen bei Bestimmung mittels Immunturbidimetrie. J Lab Med 24(3):118-125

Whicher JT, Chir B (1996) Komplement component C3 in serum proteins in clinical medicine. In: Ritchie RF, Navolotskaia O (Hrsg) Serum proteins in clinical medicine. Laboratory section, Bd I, 1. Aufl, Kap. 10.01. Foundation for Blood Research, Scarborough, S 1-7

Zegers I, Keller T, Schreiber W et al (2010) Characterization of the new serum protein reference material ERM-DA $470 \mathrm{k} / \mathrm{IFCC}$ : value assignment by immunoassay. Clin Chem 56(12):1880-1888

\section{C4-Komplement}

\section{G. Töpfer}

Synonym(e) $\beta 1 E-G l o b u l i n$

Englischer Begriff complement component C4

Definition C4 ist die zweite Komponente des Komplementsystems (s. Komplementsystem, klassische Aktivierung, - Komplementsystem, alternative Aktivierung), die bei der klassischen Komplementaktivierung durch $\mathrm{C} 1 \mathrm{~s}$ nach dessen Aktivierung in $\mathrm{C} 4 \mathrm{a}$ und $\mathrm{C} 4 \mathrm{~b}$ gespalten wird. $\mathrm{C} 4 \mathrm{~b}$ bildet mit $\mathrm{C} 2 \mathrm{~b}$ das $\mathrm{C} 3 / \mathrm{C} 5$-aktivierende Enzym. C4-Komplementmangel ist entweder genetisch bedingt (selten) oder ein Verbrauchsphänomen. Bei Autoimmunerkrankungen tritt der C4-Mangel häufig auf.

Struktur C4-Komplement enthält 3 Peptidketten ( $\alpha=93 \mathrm{kDa}$, $\beta=78 \mathrm{kDa}, \gamma=33 \mathrm{kDa})$, die über Disulfidbrücken verbunden sind. Wie bei $>\mathrm{C} 3$-Komplement und $>\alpha_{2}$-Makroglobulin verbindet in der $\alpha$-Kette eine intramolekulare Thioesterbindung Glutamin und Cystein unter Abspaltung von Ammoniak. Die $\alpha$-Kette enthält außerdem eine Membranbindungsstelle und die Bindungsstelle für C4-Bindungsprotein (ein C4-Inhibitor). Auch die $\beta$-Kette ist für die Aktivierung der Bindungsstellen von Bedeutung. Der Sedimentationskoeffizient von C4-Komplement beträgt $\mathrm{S} 20 \mathrm{~W}=10$. Isoelektrischer Punkt $6,0(6,4)$ (elektrophoretische Mobilität als $\beta_{1}$-Globulin, ähnlich wie Transferrin), Kohlenhydratgehalt $4 \%$. Es ist wasserlöslich (Pseudoglobulin) und relativ hitzestabil (im Gegensatz zu anderen Komplementkomponenten). Es gibt 2 Isotypen (C4A und C4B) des C4-Moleküls, die sich in 4 Aminosäuren der $\alpha$-Kette unterscheiden.

Molmasse $206 \mathrm{kDa}$.

Synthese - Verteilung - Abbau - Elimination Hauptsyntheseort sind die Hepatozyten, geringe Mengen werden in 
- Makrophagen und Nierenepithelien synthetisiert. Zunächst wird eine Polypeptidkette synthetisiert (Pro-C4). Durch Spaltung an 2 Stellen entstehen die $\alpha$-, $\beta$ - und $\gamma$-Ketten, die durch Disulfidbrücken zusammengehalten werden. Vor Abgabe in die Blutbahn erfolgen noch die Glykosylierung und Thioesterbindung. C4-Komplement ist ein Akute-Phase-Protein (s. Akute-Phase-Proteine), das in der akuten Phase nur leicht ansteigt. Die auslösenden Zytokine sind nicht genau bekannt. Bei zum Teil genetischem Mangel (es fehlt der C4Aoder C4B-Isotyp) können Plasmakonzentrationen von C4-Komplement im Referenzbereich erreicht werden. Ständig findet im Normalfall eine geringe Aktivierung des klassischen Wegs der Komplementkaskade statt. Über die Bindung an die Rezeptoren von Phagozyten kommt es zur Phagozytose. Ein weiterer Weg des Abbaus ist die Proteolyse durch Enzyme der Gerinnung, der Fibrinolyse und aus Granulozyten. Der Abbau ist stark beschleunigt bei Aktivierung der klassischen Komplementkaskade, beispielsweise bei Fehlen des Hauptinhibitors $>\mathrm{C} 1$-Esterase-Inhibitor oder bei überschießender Bildung von Immunkomplexen (s. - Immunkomplexe) durch Infektionen oder Autoantikörper.

Halbwertszeit $0,5-1$ Tag.

\section{Funktion - Pathophysiologie Bildung der C3/C5-Kon- vertase:}

$\mathrm{C} 4$ wird von $\mathrm{C} 1 \mathrm{~s}$ aktiviert durch Abspalten eines 77 Aminosäuren langen Fragmentes vom N-terminalen Teil der $\alpha$-Kette (C4a). Der größere Teil ist das $\mathrm{C} 4 \mathrm{~b}(\alpha-, \beta$ - und $\gamma$-Kette). Die Aktivierung öffnet die Thioesterbindung und aktiviert die Glutaminsäure. Es entsteht eine aktive Membranbindungsstelle. Ein C1s-Molekül kann bis 30 C4-Moleküle enzymatisch aktivieren, ohne dass sich $\mathrm{C} 4 \mathrm{~b}$ von der Membran ablöst. In Anwesenheit von $\mathrm{Mg}^{2+}$-Ionen wird außerdem C2-Komplement gebunden und von $\mathrm{C} 1 \mathrm{~s}$ zu $\mathrm{C} 2 \mathrm{~b}$ gespalten unter Ablösung von C2a. Der C4bC2b-Komplex spaltet nun $\mathrm{C} 3$, was die Aktivierung von C5-C9 auslöst bzw. zur Opsonisierung des Immunkomplexes führt. Die Konvertaseaktivität wird von $\mathrm{C} 2 \mathrm{~b}$ ausgeübt (Umwandlung von $\mathrm{C} 3 \rightarrow$ $\mathrm{C} 3 \mathrm{a}$ und $\mathrm{C} 3 \mathrm{~b}$ sowie von $\mathrm{C} 5 \rightarrow \mathrm{C} 5 \mathrm{a}$ und $\mathrm{C} 5 \mathrm{~b}$ ). Im entstehenden $\mathrm{C} 4 \mathrm{bC} 2 \mathrm{bC} 3 \mathrm{~b}-K o m p l e x$ (in dem $\mathrm{C} 2 \mathrm{~b}$ als $\mathrm{C} 5$-Konvertase wirkt) kann $\mathrm{C} 3 \mathrm{~b}$ durch $\mathrm{C} 4 \mathrm{~b}$ ersetzt sein $\left((\mathrm{C} 4 \mathrm{~b})_{2} \mathrm{C} 2 \mathrm{~b}\right)$, da die $\beta$-Region von $\mathrm{C} 3$ und $\mathrm{C} 4$ starke Homologien aufweisen. Da $\mathrm{C} 2 \mathrm{~b}$ sehr schnell aus den Komplexen dissoziiert, limitiert sich die C3- und C5-Umwandlung selbst.

\section{Abräumung von Immunkomplexen:}

Die Bindung des C4b2b-Komplexes verhindert eine Polymerisation der Immunkomplexe und hält sie dadurch in Lösung. Erythrozytenmembranrezeptoren binden den ImmunkomplexC4b-Komplex, transportieren ihn in Leber und Milz - Übergabe an den fester bindenden Rezeptor CR3 der Makrophagen und Abbau („Immunkomplex-Shuttle“). Besonders der Isotyp C4A zeigt eine starke Bindung an Immunkomplexe, ein C4A-Mangel könnte somit das Syndrom des klassischen systemischen Lupus erythematodes (SLE) erklären.

\section{Abwehr von Infektionen:}

In einigen Studien wurde eine Verbindung von C4B-Isotypmangel und Infektionen mit verkapselten Mikroorganismen hergestellt. Größere Arbeiten konnten dies nicht bestätigen. Allerdings scheint die Bedeutung zur Abwehr von Virusinfektionen größer zu sein.

\section{Hämolytische Aktivität:}

Die meisten Allotypen von C4A zeigen in vitro nur ein Viertel der hämolytischen Aktivität im Vergleich zu C4B. C4A6 zeigt überhaupt keine hämolytische Aktivität. Die Ursache hierfür ist die stärkere Bildung von Esterbindungen mit Hydroxylgruppen, beispielsweise von Erythrozytenmembranen (Blutgruppensubstanz) oder Polysacchariden von Bakterien durch den Isotyp C4B.

\section{Kontrollmechanismen:}

- C1-Esterase-Inhibitor inhibiert die C4-Umwandlung und die Aktivierung von $\mathrm{C} 3$ durch $\mathrm{C} 1 \mathrm{~s}$.

- In Lösung verliert $\mathrm{C} 4 \mathrm{~b}$ seine Bindungskapazität.

- $\mathrm{C} 2 \mathrm{~b}$ dissoziiert vom $\mathrm{C} 4 \mathrm{bC} 2 \mathrm{~b}-K o m p l e x$.

- C4b-Bindeprotein bindet kompetitiv an C4b und dient als Kofaktor bei der Spaltung von C4b durch Faktor I. Serum Amyloid $\mathrm{P}$ wiederum bindet alternativ 4b-Bindeprotein.

- C4 und C4b werden durch Gewebeleukozyten- und Bakterienproteasen gespalten, auch durch Plasmin und Kallikrein.

- Thiole wie Captopril verursachen Arzneimittel-induziertes Lupus-Like-Syndrom. Diese Wirkstoffe zeigen in vitro eine Inhibition der C4b-Bindung.

Untersuchungsmaterial - Entnahmebedingungen Serum, EDTA-Plasma.

Probenstabilität Frisch in das Labor! Innerhalb 1 Stunde zentrifugieren und bestimmen oder innerhalb 1 Stunde bei $<-20^{\circ} \mathrm{C}$ einfrieren.

Präanalytik Bei Lagerung $>1$ Stunde bei Raumtemperatur Anstieg der Werte um bis zu $20 \%$. Probe bei Trübung oder Lipämie durch Zentrifugation $(10$ Minuten bei $15.000 \times g$ ) klären vor Analytik.

\section{Analytik}

- $>$ Immunturbidimetrie

- $\triangleright$ Immunnephelometrie

- Immundiffusion, radiale nach Mancini, Carbonara und Heremans

Standard: ERM - DA 470 k/IFCC.

Konventionelle Einheit $\mathrm{mg} / \mathrm{dL}$. 


\section{Internationale Einheit g/L.}

Umrechnungsfaktor zw. konv. u. int. Einheit mg/dL: $100=\mathrm{g} / \mathrm{L}$.

Referenzbereich - Erwachsene $0,1-0,4 \mathrm{~g} / \mathrm{L}$.

Anstieg in der Schwangerschaft, dabei vermindertes intaktes $\mathrm{C} 4$, aber erhöhtes $\mathrm{C} 4 \mathrm{~d}$. Nach der Geburt Abfall innerhalb von 6 Monaten. Neugeborene haben 50-75\% der Werte von Erwachsenen.

Referenzbereich - Kinder 3 Monate: 0,09-0,305 g/L, 6 Monate: 0,1-0,355 g/L, 9 Monate: 0,115-0,395 g/L, 12 Monate: 0,12-0,45 g/L, 2-10 Jahre: 0,125-0,4255 g/L, 12-18 Jahre: 0,14-0,435 g/L.

\section{Indikation}

- SLE oder SLE-ähnliche Autoimmunerkrankungen und Immunkomplexerkrankungen (Vaskulitis)

- Membranoproliferative Glomerulonephritis

- Verdacht auf hereditäres angioneurotisches Ödem

Interpretation Immer C-reaktives Protein (schneller Anstieg) mitbestimmen und evtl. $\alpha_{1}$-saures Glykoprotein ( $>$ Glykoprotein, $\alpha_{1}$-saures) (langsamer Anstieg), da Anstieg durch $>$ Akute-Phase-Reaktion die Interpretation erschweren kann. Bei klassischer Aktivierung der Komplementkaskade häufig deutlicherer Abfall als bei $>\mathrm{C} 3$-Komplement. Bei hereditärem angioneurotischen Ödem sind $>\mathrm{C} 1$-EsteraseInhibitor (bei $15 \%$ nur die Funktion) und C4-Komplement vermindert, C3-Komplement aber im Referenzbereich. Beim SLE ist ein C4-Mangel häufig (>50\%).

Diagnostische Wertigkeit Empfindliche Kenngröße der Aktivierung des klassischen Weges der Komplementkaskade (meist empfindlicher als CH50 bzw. CH100). Keine Unterscheidung zum angeborenen Mangel möglich. Dazu sind die schwer verfügbaren Spaltprodukte zu bestimmen. $20 \%$ von Personen mit IgA-Mangel haben auch einen homozygoten C4A-Mangel. Bei Lebererkrankungen ist C4 häufig erniedrigt bei erhöhtem $\mathrm{C} 4 \mathrm{~d}$, ohne dass man beim Gesamt-C4Abweichungen feststellen kann.

\section{Literatur}

Töpfer G, Hornig F, Sauer K, Zawta B (2000) Untersuchungen zur Stabilität von 11 Serumproteinen bei Bestimmung mittels Immunturbidimetrie. J Lab Med 24(3):118-125

Whicher JT, Chir B (1996) Komplement component C3 in serum proteins in clinical medicine. In: Ritchie RF, Navolotskaia O (Hrsg) Serum proteins in clinical medicine. Laboratory section, Bd I, 1. Aufl., Kap. 10.02. Foundation for Blood Research, Scarborough, S 1-9
Zegers I, Keller T, Schreiber W et al (2010) Characterization of the new serum protein reference material ERM-DA $470 \mathrm{k} / \mathrm{IFCC}$ : value assignment by immunoassay. Clin Chem 56(12):1880-1888

\section{C3-Konvertase-Antikörper}

- Autoantikörper gegen C3-Konvertase

\section{C2-Konzentrationen}

C2-Monitoring

\section{Clark-Elektrode}

- Sauerstoffpartialdruck

Clearance, glomeruläre

W. G. Guder

Synonym(e) GFR; Glomeruläre Filtrationsrate

Englischer Begriff glomerular clearance; glomerular filtration rate (GFR)

Definition Die glomeruläre Clearance bezeichnet die Menge Plasma, die pro Minute von einer Substanz durch glomeruläre Filtration befreit wird. In Abhängigkeit von der angewandten Methode spricht man von endogener (z. B. Kreatinin, $\checkmark$ Cystatin C) oder exogener ( $>$ Inulin, Iohexol, ${ }^{99}$ Tc-DTPA) Clearance.

Pathophysiologie Die glomeruläre Clearance einer Substanz hängt ab von ihrer Molmasse, ihrer Ladung und der Bindung an andere größere Blutbestandteile. Eine Reduktion der glomerulären Clearance kann pathophysiologisch prärenale, renale und postrenale Ursachen haben.

Prärenale Ursachen der reduzierten glomerulären Clearance liegen vor, wenn es zum Absinken des kapillären Drucks durch Reduktion der renalen Durchblutung bei Abfall des Blutdrucks, durch lokale Verengung der Nierenarterien oder Erhöhung des venösen Drucks kommt.

Renale Ursachen stellen alle Formen der glomerulären Erkrankungen dar (Glomerulonephritis, diabetische Nephropathie, Nephrosklerose) die eine Reduktion der glomerulären Filtrationsfläche bewirken. Tubuläre Funktionsstörungen 
können durch Erhöhung des intratubulären Drucks (z. B. durch Verschluss des Tubulus bei Bildung von Zylindern oder Kristallen, die den Abfluss behindern), durch Rückkopplung bei Verminderung der Salzreabsorption (tubuloglomerulärer Feedback) die Clearance vermindern.

Bei postrenalen Ursachen der Druckerhöhung durch Tumoren, Steine oder Entzündungen der ableitenden Harnwege kommt es über eine Verminderung der tubulären Funktion zur Reduktion der glomerulären Filtration.

Untersuchungsmaterial In Abhängigkeit von der angewandten Methode wird Plasma/Serum und über definierte Zeiten gesammelter Urin zur Ermittlung der glomerulären Clearance benötigt.

Analytik Bezüglich der Analytik endogener Clearancesubstanzen wird auf die Analyte $>$ Kreatinin und $>$ Cystatin C verwiesen. Die Analytik von Inulin und/oder Iohexol erfolgt spektrophotometrisch.

Referenzbereich Die glomeruläre Clearance wird in $\mathrm{mL} / \mathrm{min}$ angegeben. Es besteht eine deutliche Altersabhängigkeit. Bei Kindern und bei großen Unterschieden in der Muskulatur wird eine zusätzliche Korrektur auf die Körperoberfläche empfohlen, vgl. dazu folgende Tabelle:

\begin{tabular}{|l|l|}
\hline Alter & Glomeruläre Clearance $(\mathrm{mL} / \mathrm{min})$ \\
\hline 5-7 Tage & $38-62$ \\
\hline 1-2 Monate & $54-76$ \\
\hline 3-12 Monate & $64-108$ \\
\hline 3-13 Jahre & $100-145$ \\
14-39 Jahre & $95-160$ \\
40-49 Jahre & $>68$ \\
50-59 Jahre & $>58$ \\
60-69 Jahre & $>50$ \\
\hline 70 Jahre & $>48$ \\
\hline
\end{tabular}

Bewertung Die glomeruläre Clearance stellt eine wesentliche Messgröße zur Erfassung der renalen Funktion dar. Sie wird bei Erprobungen von Medikamenten, Abschätzung des renalen Risikos und Dosierung nierengängiger Medikamente immer noch als das Maß für Nierenfunktion verwendet. Bezüglich der angewendeten Methodik haben sich zunehmend Erkenntnisse über die Grenzen der angewandten Methoden verbreitet. Nach Messung des Kreatinins mit einer enzymatischen Methode wurde deutlich, dass die endogene $>$ Kreatinin-Clearance ca. $20 \%$ höher als die wahre glomeruläre Clearance ist. Da die früher als Goldstandard empfohlene - Inulin-Clearance wegen der Anwendung von zu injizierenden Fremdstoffen und der fehleranfälligen aufwendigen Methodik nicht mehr angewandt wird und Isotopen ebenfalls nur bei strenger Indikation angewandt werden, wurde als alternativer Marker $>$ Cystatin $\mathrm{C}$ vorgeschlagen, das zunehmend als endogene Kenngröße verwendet wird und von Experten für unverzichtbar für die Berechnung der wahren Clearance gesehen wird.

\section{Literatur}

Coresh J, Auguste P (2008) Reliability of GFR formulas based on serum creatinine, with special reference to MDRD Study equations. Scand J Clin Lab Invest 68(Suppl 241):30-38

Delanghe JR (2008) How to establish glomerular filtration rate in children. Scand J Clin Lab Invest 68(Suppl 241):46-51

Grubb A (2017) Cystatin C is indispensable for evaluation of kidney disease. J int Fed Clin Chem 28:268-76

Hofmann W, Ehrich JHH, Guder WG, Keller F, Scherberich J (2011) Diagnostische Pfade bei Nierenerkrankungen. J Lab Med 35:127-146

\section{Clearance, glomeruläre mit Cystatin C}

- CKD-EPI-Formel

Cystatin $\mathrm{C}$

\section{Clearance, glomeruläre mit Kreatinin}

- CKD-EPI-Formel
$>$ Kreatinin-Clearance

\section{Clearance, totale}

\section{Vidal und W.-R. Külpmann}

\section{Englischer Begriff systemic clearance}

Definition Die totale Clearance gibt an, wieviel mL Plasma/ min von einem Stoff befreit wird.

Beschreibung Die totale Clearance unterscheidet nicht, auf welche Weise der Stoff aus dem Plasma entfernt wird, d. h. ob es sich um eine renale und/oder hepatische Clearance handelt. Die totale Clearance $\mathrm{CL}_{\text {tot }}$ kann wie folgt berechnet werden:

$$
\mathrm{CL}_{\mathrm{tot}}=\ln 2 \times \frac{\mathrm{V}}{\mathrm{t}_{1 / 2}}
$$

$\mathrm{t}_{1 / 2}$ : Halbwertszeit im Plasma (min)

$\mathrm{V}$ : Verteilungsvolumen $(\mathrm{mL})$ 


\section{Literatur}

Gladtke E, von Hattingberg HM (1973) Pharmakokinetik. Springer, Berlin/Heidelberg/New York

\section{Cleaved cells}

H. Baum

\section{Englischer Begriff cleaved cells}

Definition Kleine bis mittelgroße Lymphomzelle mit grobscholligem, plumpem Kernchromatin und mehr oder weniger deutlicher, scharfkantiger Einkerbung des Zellkerns. In der Abbildung sind mit Pfeilen markiert die typischen scharfrandigen Einschnitte in die Zellkerne $(1000 \times$, May-GrünwaldGiemsa-Färbung):

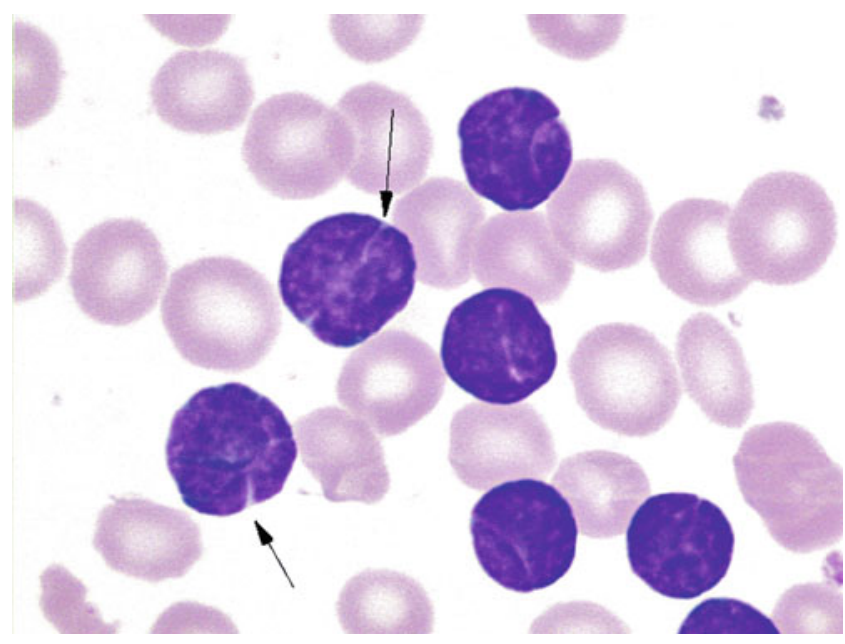

Beschreibung Cleaved cells sind meist kleine bis mittelgroße Zellen mit wenig basophilem Zytoplasmasaum, dichtem, grobscholligem Kernchromatin und einer oder mehrerer scharfkantigen Einkerbung des Zellkernes. Oft sind ein, manchmal auch zwei oder mehrere Nukleolen nachweisbar. Cleaved cells können bei verschiedenen Non-HodgkinLymphomen im peripheren Blut nachgewiesen werden, wobei differenzialdiagnostisch in erster Linie ein Mantelzelllymphom, ein follikuläres Lymphom oder ein Marginalzonenlymphom infrage kommen.

\section{Literatur}

Harris NL, Jaffe ES, Stein H et al (1994) A revised european-american classification of lymphoid neoplasms: a proposal from the international lymphomy study group. Blood 84:1361-1392

\section{Client}

O. Colhoun

Synonym(e) Client computer

\section{Englischer Begriff client}

Definition Computer, der Dienste von einem anderen Computer anfordert.

Beschreibung Ein Programm, das auf eine Dienstleitung eines Servers zugreifen kann, bezeichnet man als ClientProgramm. Die einen Dienst anbietende Einheit heißt Server, eine entsprechende Organisationsstruktur $>$ Client-ServerArchitektur. In der $>$ Labor-EDV sind die Clients alle PC oder Terminals an den Arbeitsplätzen, auf denen die entsprechende Software für den Zugriff auf den Labor-Server ausgeführt wird.

\section{Client computer}

$>$ Client

\section{Client-Server-Architektur}

O. Colhoun

Englischer Begriff client-server concept

Definition Architekturprinzip u. a. von $>$ Labor-EDV-Systemen. Dabei stehen einem oder mehreren zentralen Rechnern, den Servern, mehrere Arbeitsstationen, die Clients, gegenüber, die von den Servern angebotene Dienste in Anspruch nehmen können.

Beschreibung Ein Labor-EDV-Server speichert seine Datenbestände in einer Datenbank, auf die je nach Zugangsberechtigung verschiedene Clients zugreifen können, und stellt Programme, Speicher, Rechenleistung und Kommunikationsdienste zur Verfügung. Ein Client-Rechner ist auch ohne den Server ein arbeitsfähiges System (z. B. Arbeitsplatz-PC im Labor). Seine Aufgabe besteht darin, dem Benutzer eine Benutzeroberfläche zur Verfügung zu stellen. Der entscheidende Vorteil der Client-Server-Architektur besteht darin, dass sie eine effiziente Verteilung von Ressourcen ermöglicht. 


\section{CLIF-C-ACLF-Score}

A. M. Gressner und O. A. Gressner

Synonym(e) ACLF-Score

Englischer Begriff acute-on-chronic-liver failure-score; ACLF grade

Definition Der CLIF consortium organ failure score (CLIF-C-OFs) ACLF dient der prognostischen Beurteilung einer akuten Dekompensation der Leberzirrhose auf Basis labormedizinischer und klinisch-funktioneller Untersuchungsergebnisse.

Beschreibung ACLF (Arroyo et al. 2015) ist ein mit etwa 30 \%iger Prävalenz relativ häufig vorkommendes Syndrom, charakterisiert durch die akute Dekompensation einer Leberzirrhose mit Beteiligung anderer Organe, systemischer Entzündung und hoher kurzfristiger Mortalität. Zur Beurteilung der Prognose dient der CLIF-C-ACLF-Score (Jalan et al. 2014) der anhand von 6 Messgrößen den Schweregrad in 3 Scores einteilt: $>$ Bilirubin $(\mathrm{mg} / \mathrm{dL})$, $>$ Kreatinin $(\mathrm{mg} / \mathrm{dL})$, Gehirn (West-Haven), Gerinnung ( International Normalized Ratio, INR), arterieller Blutdruck und Sauerstoffpartialdruck (mmHg). C-Index ist ein Konkordanzindex, der die Diskriminationsfähigkeit zu MELD- ( $\triangleright$ MELD-Score) und Child-Pugh-Scores angibt. Der prädiktive Wert von ACLF in Bezug auf das Mortalitätsrisiko ist höher als der des MELD-Scores. Mit sequenzieller Anwendung lässt sich das Mortalitätsrisiko von ACLF-Patienten stratifizieren.

Der CLIF-C-AD-Score (acute-decompensation-chronicliver-failure-score) ist ein spezifischer Prognosescore für hospitalisierte Leberzirrhose-Patienten mit akuter Dekompensation (AD: Aszites, Enzephalopathie, gastrointestinale Blutungen und/oder bakterielle Infektionen), aber ohne ACLF. Bei diesem Patientenkollektiv haben sich Alter, Serum-Natriumkonzentration, Leukozytenzahl, Kreatininkonzentration und INR als die besten Prädiktoren der Mortalität erwiesen. Auch soll dieser Score dem Child-Pugh- und MELD-Score als Prognoseprädiktion bei Zirrhotikern ohne ACLF überlegen sein (Jalan et al. 2015).

\section{Literatur}

Arroyo V, Moreau R, Jalan R et al (2015) Acute-on-chronic liver failure: a new syndrome that will reclassify cirrhosis. J Hepatol 62(1): S131-S143

Jalan R, Saliba F, Pavesi M et al (2014) Development and validation of a prognostic score to predict mortality in patients with acute-onchronic-liver-failure. J Hepatol 61(5):1038-1047
Jalan R, Pavesi M, Saliba F et al (2015) the CLIF consortium acute decompensation score (CLIF-C Ads) for prognosis of hospitalized cirrhotic patients without acute-on chronic liver-failure. J Hepatol 62(4):831-840

\section{Clinical and Laboratory Standards Institute}

- National Committee for Clinical Laboratory Standards

clogP

$>\log \mathrm{P}$

\section{Cloned Enzyme Donor Immunoassay}

T. Arndt

\section{$\operatorname{Synonym}(e)$ CEDIA}

Englischer Begriff cloned enzyme donor immunoassay

Definition Sonderform des homogenen Immunoassays ( $\triangleright$ Immunoassay, homogener).

Physikalisch-chemisches Prinzip Der Assay beruht auf dem bakteriellen Enzym $\beta$-Galaktosidase, das gentechnisch in 2 inaktive Fragmente zerlegt wurde. Diese Bruchstücke können sich unter Bildung des aktiven Enzyms spontan wiedervereinigen, das dann durch Substratspaltung eine spektrometrisch messbare Farbänderung hervorrufen kann (Abb. 1).

Prinzip des Assays am Beispiel des Opiatnachweises Opiate der Patientenprobe und opiatmarkierte inaktive Enzymfragmente konkurrieren um eine begrenzte Zahl von Opiat-Antikörper-Bindungsstellen. In einer opiathaltigen Urin- oder Serumprobe werden (in Abhängigkeit von der Opiatkonzentration) wenige oder viele Opiat-AntikörperKomplexe gebildet. Es stehen entsprechend viele oder wenige Opiatantikörper zur Bindung mit den opiatmarkierten Enzymfragmenten zur Verfügung. Die durch Opiatantikörper gebundenen opiatmarkierten Enzymfragmente können aufgrund einer sterischen Behinderung nicht zu kompletten Enzymen reassoziieren. Freie, nicht antikörpergebundene 
Cloned Enzyme Donor Immunoassay, Abb. 1

Konkurrenz von Analyt- und Enzymdonor-Analyt-

Konjugatmolekülen um eine begrenzte Anzahl von Antikörpermolekülen im Cloned Enzyme Donor Immunoassay. (Mit freundlicher Genehmigung von Microgenics, Passau)

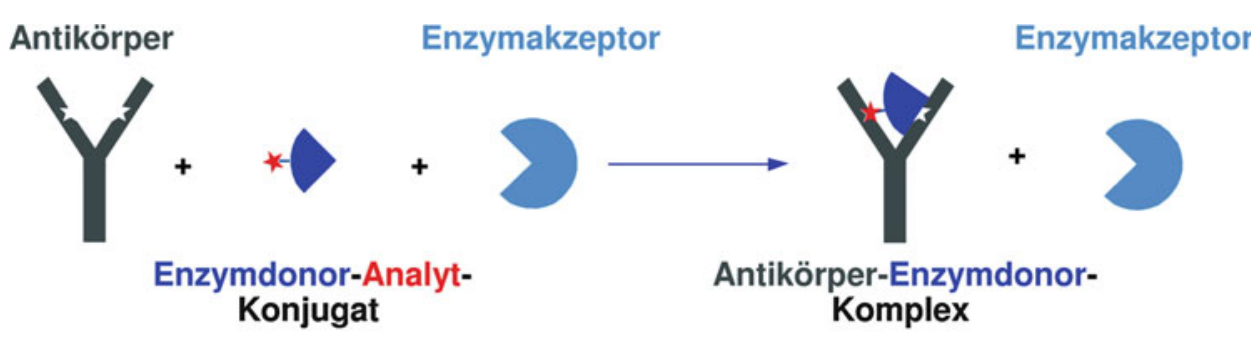

Enzym bleibt inaktiv $\rightarrow$ kein Substratumsatz, keine Farbkomplexbildung

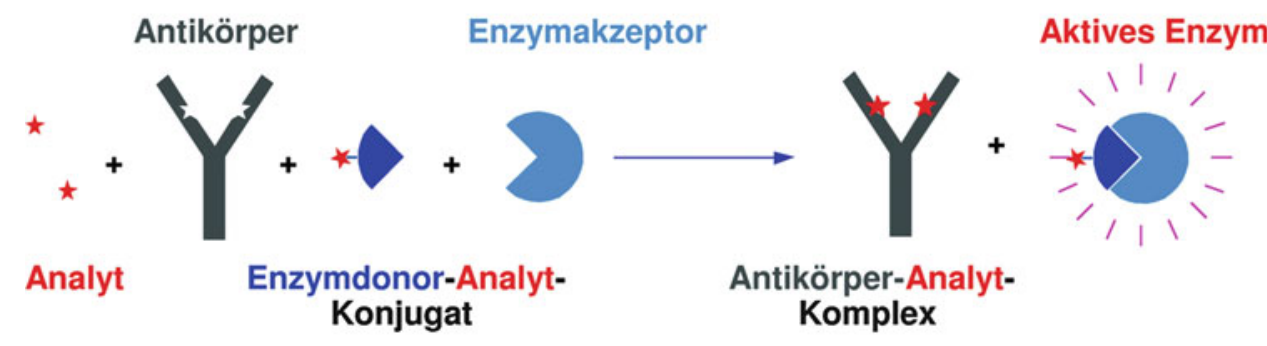

Enzym wird aktiv $\rightarrow$ Substratumsatz mit Farbkomplexbildung opiatmarkierte Enzymfragmente können sich dagegen zu aktiver $\beta$-Galaktosidase vereinigen. Diese spaltet ein chromophores Substrat (o-Nitrophenyl- $\beta$-D-Galaktopyranosid oder Chlorphenolrot- $\beta$-D-Galaktopyranosid) und führt damit $\mathrm{zu}$ einer Farbänderung des Reaktionsansatzes. Die Menge des gebildeten Enzyms und die daraus resultierende Änderung der Extinktion der Reaktionslösung sind der Opiatkonzentration in der Probe proportional. Die Quantifizierung erfolgt spektrometrisch unter Berücksichtigung einer entsprechenden Kalibrationsfunktion.

Einsatzgebiet Drogen- und Medikamentenanalytik.

Untersuchungsmaterial Urin, Serum, Speichel.

Instrumentierung Der CEDIA wird gewöhnlich mechanisiert durchgeführt.

Spezifität Die Spezifität der Methode ist hoch, sodass auch Institute der Rechtsmedizin die CEDIA-Technologie in breitem Maße zum Drogenscreening einsetzen.

Sensitivität Die Sensitivität ist abhängig vom Analyt bzw. der Analytgruppe. Konzentrationen im $\mu \mathrm{g} / \mathrm{L}-$ Bereich können präzise gemessen werden.

Fehlermöglichkeit Die einzelnen Assays wurden umfangreich auf mögliche Quellen für Kreuzreaktionen, die zu falsch positiven Drogennachweisen führen können, untersucht. Solche sind für die am häufigsten eingesetzten Medikamente und deren Metabolite unwahrscheinlich, insgesamt jedoch nicht völlig auszuschließen.

Praktikabilität - Automatisierung - Kosten Die Analyse erfolgt gewöhnlich mechanisiert und aus der Originalprobe (Barcodeleser). Praktikabilität, Probendurchsatz und Reproduzierbarkeit sind entsprechend hoch.

Bewertung - Methodenhierarchie (allg.) Der CEDIA stellt ein qualitativ hochwertiges und (kosten)effizientes Verfahren zum Drogennachweis ( $\triangleright$ Drogenscreening) und zur Medikamentenbestimmung (z. B. Immunsuppressiva) dar. Er hat den FPIA ( $>$ Fluoreszenzpolarisations-Immunoassay) aus der Drogenanalytik verdrängt.

Ein mit dem CEDIA erhobener positiver Drogennachweis bedarf unter forensischen Bedingungen einer Bestätigungsanalyse durch eine physikochemische Analysenmethode ( $\triangleright$ Chromatographie und/oder $\triangleright$ Massenspektrometrie). In letzter Zeit erwächst dem immunologischen Drogenscreening durch die Verfügbarkeit massenspektrometrie-basierter Drogenscreenings Konkurrenz. Eine wesentliche Ursache hierfür liegt in der ausgeprägten Dynamik des Drogenmarktes hinsichtlich aktuell konsumierter Drogen (siehe ((Verweis)) Neue Psychoaktive Substanzen). Entwicklung und Validierung neuer immunologischer Drogentests können mit diesem Tempo gewöhnlich nicht mehr mithalten.

\section{Literatur}

Henderson DR, Friedman SB, Harris JD et al (1986) CEDIA $^{\mathrm{TM}}$, a new homogeneous immunoassay system. Clin Chem 32:1637-1641 


\section{Clonidin-Stimulationstest}

- Clonidin-Wachstumshormon-Stimulationstest

\section{Clonidin-Suppressionstest}

- Clonidin-Test (Suppressionstest)

\section{Clonidin-Test}

- Clonidin-Wachstumshormon-Stimulationstest

\section{Clonidin-Test (Suppressionstest)}

W. Hubl

Synonym(e) Clonidin-Suppressionstest

Englischer Begriff clonidine test; clonidine suppression test

Definition Clonidin hemmt als $\alpha$-adrenerger Agonist die Katecholamin-Sekretion bei gesunden Personen. Bei Vorliegen eines Phäochromozytoms mit autonomer Katecholaminsekretion wird kein Abfall der Plasmakatecholamine oder Plasmametanephrine erzielt.

\section{Durchführung}

- Möglichst mindestens 24 Stunden vor Beginn sollte eine antihypertensive Therapie, außer Calciumantagonisten, abgesetzt werden

- Legen einer Venenkanüle, Patient 30 Minuten in liegender Körperhaltung

- Blutentnahme zur Bestimmung von Adrenalin und Noradrenalin (Basiswerte)

- Gabe von $300 \mu \mathrm{g}$ Clonidin (Catapresan) oral

- Nach 180 Minuten zweite Blutentnahme für die Bestimmung von Adrenalin und Noradrenalin bzw. der Metanephrine im Serum

- Der Test ist unter ständiger Blutdruckkontrolle (in 30Minuten-Abständen) durchzuführen.

Untersuchungsmaterial - Entnahmebedingungen $>\mathrm{Ka}-$ techolamine.

Probenstabilität $>$ Katecholamine.
Präanalytik $\vee$ Katecholamine.

Analytik $>$ Katecholamine.

Referenzbereich - Erwachsene Abfall von Adrenalin und/ oder Noradrenalin bzw. der Metanephrine auf mindestens $50 \%$ des Ausgangswerts.

Indikation Verdacht auf eine autonome Adrenalin- oder Noradrenalinproduktion (Phäochromozytom). Kein Suchtest, sondern ein Bestätigungstest für ein Phäochromozytom nach pathologischen oder grenzwertigen Katecholamin- bzw. Metanephrinwerten.

Kontraindikation(en) Bradykarde Herzrhythmusstörungen.

Nebenwirkung(en) Bei Phäochromozytom-Patienten hypertensive Krisen, bei Gesunden Hypotonie.

Interpretation Ein ausbleibender oder geringerer Abfall von Noradrenalin (bzw. Adrenalin) auf weniger als $50 \%$ des erhöhten Ausgangswerts deutet auf ein Phäochromozytom hin.

Diagnostische Wertigkeit Diagnostische Sensitivität $87 \%$, diagnostische Spezifität $93 \%$.

\section{Literatur}

Schäffler A (Hrsg) (2015) Funktionsdiagnostik in Endokrinologie, Diabetologie und Stoffwechsel. Indikation, Testvorbereitung und -durchführung, Interpretation. Springer/GmbH \& Co. K, Berlin/Heidelberg

Thomas L (Hrsg) (2012) Labor und Diagnose : Indikation und Bewertung von Laborbefunden für die medizinische Diagnostik, 8. Aufl. Th-Books, Frankfurt am Main

\section{Clonidin-Wachstumshormon- Stimulationstest}

W. Hubl

Synonym(e) Clonidin-Test; Clonidin-Stimulationstest

Englischer Begriff clonidine growth hormone stimulation test

Definition Mit einer Clonidinapplikation wird die Stimulierbarkeit der Wachstumshormonsekretion getestet. Der Test dient zur Untersuchung auf einen hypophysären Wachstumshormonmangel im Kindes- und Jugendalter. 


\section{Durchführung}

- Antihypertensive Therapie möglichst 3 Tage vor dem Test absetzen!

- Nahrungskarenz für 8-12 Stunden

- Blutdruckmessungen (Clonidin bewirkt einen Blutdruckabfall) vor und während des Tests

- Blutentnahme am ruhenden, nüchternen Patienten zur Wachstumshormonbestimmung

- Applikation von $150 \mu \mathrm{g} / \mathrm{kg} \mathrm{KG}$ Clonidin oral

- Weitere Blutentnahmen nach 30, 60, 90 und 120 Minuten zur Wachstumshormonbestimmung (STH, HGH)

- Testende mit einer kohlenhydratreichen Mahlzeit

\section{Untersuchungsmaterial-Entnahmebedingungen Serum}

Referenzbereich - Erwachsene Anstieg des Wachstumshormons ( $\triangleright$ Wachstumshormon) auf über $15 \mu \mathrm{g} / \mathrm{L}$.

Indikation Minderwuchs, Zwergwuchs, Verdacht auf Wachstumshormonmangel, Wachstumsretardierung bei Kindern.

Kontraindikation(en) AV-Block 2. Grades und eine schwere arterielle Verschlusskrankheit, Raynaud-Syndrom, schwere Depressionen.

Nebenwirkung(en) Orthostatische Hypotonie.

Interpretation Anstieg der Wachstumshormonkonzentration auf über $15 \mu \mathrm{g} / \mathrm{L}$ : Ausschluss des absoluten Wachstumshormonmangels.

Subnormaler STH-Anstieg: 5-15 $\mu \mathrm{g} / \mathrm{L}$.

Pathologisches Ergebnis: kein STH-Anstieg erniedrigter Ausgangswerte.

Diagnostische Wertigkeit Diagnostische Sensitivität ( $\triangleright$ Sensitivität, diagnostische): $80 \%$; diagnostische Spezifität ( $\triangleright$ Spezifität, diagnostische): $80 \%$. Gilt als Test der 3. Wahl bei Verdacht auf somatotrope Insuffizienz nach dem Insulinhypoglykämietest und dem GH-RH-Test.

\section{Literatur}

Cianfarani S, Tondinelli T, Spadoni GL et al (2002) Height velocity and IGF-I assessment in the diagnosis of childhood onset GH insufficiency: do we still need a second GH stimulation test? Clin Endocrinol (Oxf) 57:161-167

Obara-Moszyńska M, Kedzia A, Korman E, Niedziela M (2008) Usefulness of growth hormone $(\mathrm{GH})$ stimulation tests and IGF-I concentration measurement in GH deficiency diagnosis. J Pediatr Endocrinol Metab 21:569-579

Schäffler A (Hrsg) (2015) Funktionsdiagnostik in Endokrinologie, Diabetologie und Stoffwechsel. Indikation, Testvorbereitung und durchführung, Interpretation. Springer-Verlag/GmbH \& Co. K, Berlin/ Heidelberg

\section{Clopidogrelresistenz}

T. Stief

Englischer Begriff clopidogrel resistance

Definition Die individuelle Variabilität der Hemmung des Rezeptors P2Y12 durch den Antagonisten Clopidogrel kann mit verschiedenen Methoden in vitro getestet werden. Die Invitro-Tests korrelieren mit dem klinischen Ansprechen von Clopidogrel.

Beschreibung Clopidogrel ist ein klinisch bedeutendes orales Thienopyridin, das den ADP-Rezeptor P2Y12 inaktiviert. Das chemisch verwandte Ticlopidin wird wegen des höheren Nebenwirkungsrisikos, wie Neutropenie oder thrombotischthrombozytopenische Purpura (TTP), nicht mehr eingesetzt. Clopidogrel ist ein Prodrug, das in der Leber durch $>$ Cytochrom P450 in aktive Metaboliten umgewandelt wird, die den P2Y12-Rezeptor inaktivieren. Die aktiven Metabolite binden kovalent an Cysteine des Rezeptors, wodurch ADP nicht mehr an den Rezeptor bindet. Zusätzlich scheint Clopidogrel auch die Oligomerstruktur des Rezeptors zu verändern und zur Verteilung des Rezeptors außerhalb von „lipid rafts“ zu führen. „Lipid rafts“ sind Mikrodomänen der Zellmembran, in denen Proteine in Lipiden verankert werden.

Bis zu $30 \%$ der mit Clopidogrel behandelten Patienten zeigen ähnliche Werte wie unbehandelte Patienten. Diese Patienten tragen ein höheres Risiko für rezidivierende ischämische Ereignisse. 5-10 \% der Patienten erleiden unter Clopidogrel eine Thrombose nach dem Einlegen eines Koronarstents, sind folglich klinisch Clopidogrel-resistent.

Als Ursachen werden diskutiert die variable Metabolisierung in der Leber, reduzierte enterale Absorption, Interaktion mit anderen Medikamenten (Benzodiazepine, selektive Serotonin-Wiederaufnahme-Inhibitoren), genetische Polymorphismen für Rezeptor und Cytochrom P450, Unterdosierung von übergewichtigen Patienten (BMI-adaptiert) oder erhöhte Sensibilität der Plättchen ( $\triangleright$ Thrombozytenaggregation und -aktivierung) für ADP und Kollagen (evtl. über Generierung von Faktor 12a, Kallikrein, Thrombin).

Die Clopidogreltherapie kann durch Messung der ADP-induzierten Plättchenaggregation per Turbidometrie (Born-Test) oder Impedanz überwacht werden. Ein neueres Thienopyridin ist Prasugrel, das die ADP-induzierte Plättchenaggregation schneller, verlässlicher (geringere individuelle Variation) und stärker hemmt als Clopidogrel. Seine Aktivierung ist weniger abhängig von spezifischen Cytochrom-P450-Enzymen. Bei manchen Patienten ist die Anwendung von Prasugrel allerdings mit einer höheren Blutungsneigung verbunden. 


\section{Literatur}

Michelson AD (2008) P2Y12 Antagonism, Promises and Challenges. Arterioscler Thromb Vasc Biol 28:33-38

\section{Clot observation time}

> Patientennahe Sofortdiagnostik

\section{Clozapin}

C. Vidal und W.-R. Külpmann

\section{Englischer Begriff clozapine}

Definition Neuroleptikum.

Strukturformel:<smiles>CN1CCN(C2=Nc3cc(Cl)ccc3Nc3ccccc32)CC1</smiles>

Molmasse $326,83 \mathrm{~g}$.

Synthese - Verteilung - Abbau - Elimination Die Bioverfügbarkeit beträgt ca. $50 \%$. Wegen eines ausgeprägten „First-Pass-Metabolismus“ wird Clozapin nur in geringem Maße unverändert renal ausgeschieden.

Halbwertszeit 12 Stunden (Plasma).

Funktion - Pathophysiologie Bei akuten Vergiftungen wurden beobachtet: Tachykardie, Ataxie, Bewusstseinsstörung, Krampfanfälle und Atemdepression.

Untersuchungsmaterial - Entnahmebedingungen Serum, Plasma, Urin. Keine Gelröhrchen wegen Adsorption am Gel.

Analytik HPLC, GC, GC-MS, LC-MS/MS ( $>$ Chromatographie, $\triangleright$ Massenspektrometrie).

Indikation Clozapinintoxikation, therapeutisches Drug Monitoring.

Interpretation Therapeutischer Bereich: 0,35-0,6 mg/L; toxisch ab $1 \mathrm{mg} / \mathrm{L}$ (Hiemke et al. 2012), komatös-letal ab 1,2 mg/L (Schulz et al. 2012).

\section{Literatur}

Degel F, Demme U, Birkhahn HJ et al (2009) Neuroleptic drugs and antidepressants. In: Külpmann WR (Hrsg) Clinical toxicological analysis. Wiley-VCH, Weinheim, S 393-453

Hiemke C et al (2012) AGNP-Konsensus-Leitlinien für therapeutisches Drug-Monitoring in der Psychiatrie: Update 2011. Psychopharmakotherapie 19:91-122

Schulz M, Iwersen-Bergmann S, Andresen H, Schmoldt A (2012) Therapeutic and toxic blood concnetrations of nearly 1,000 drugs and other xenobiotics. Crit Care 16:R136

\section{CLSI}

- National Committee for Clinical Laboratory Standards

\section{Clubdrogen}

T. Arndt

Synonym(e) Klubdrogen; Rave-Drogen

Englischer Begriff club drugs; rave drugs

Definition Oberbegriff für eine nicht näher definierte Gruppe von Drogen, die in Nachtclubs oder bei Langzeittanzveranstaltungen, sog. Rave-Parties, besonders häufig konsumiert werden.

Beschreibung Hierzu gehören zum Beispiel Alkohol ( $\triangleright$ Ethanol), Amphetamine (Methamphetamin, MDMA, Ecstasy), Flunitrazepam ( $\triangleright$ Benzodiazepine), $\downarrow \gamma$-Hydroxybuttersäure, $>$ Ketamin und $>$ LSD. Seit ca. 10 Jahren kommt eine immer noch zunehmende Anzahl von sog. Neuen Psychoaktiven Substanzen (NPS), die zumeist Derivate von seit Langem bekannten Wirkstoffen sind, als „Kräutermischungen“, „Badesalze“ und „Research Chemicals“" auf den Drogenmarkt. Zu Darreichungsformen, Wirkweisen und Analytik s. unter der jeweiligen Wirkstoffgruppe oder unter $>$ Neue Psychoaktive Substanzen (NPS).

\section{Literatur}

Arndt T (Hrsg) (2015) New psychoactive substances - a challenge for modern toxicology. Proceedings of the XIX. GTFCh-Symposium. GTFCh-Eigenverlag, Ingelheim-Jena

Valentine JL, Kerrigan S (2001) „Club“ or „rave“ drugs offer challenges to laboratories. AACC/CAP Educational Newsletter for Toxicology, September issue 


\section{Clusteranalyse}

R.-D. Hilgers, N. Heussen und S. Stanzel

Englischer Begriff cluster analysis

Definition Die Clusteranalyse ist eine multivariate, statistische Methode zur Klassifizierung von Individuen in unbekannte Gruppen.

Beschreibung Im Rahmen der Clusteranalyse werden Beobachtungen zu Gruppen bzw. Clustern zusammengefasst, deren Ausprägungen ,nahe“ beieinander liegen. Die Clusteranalyse ist eine Form der computergestützten Diagnose, die auch als ,unsupervised pattern recognition“ bezeichnet wird, da die Gruppenzuteilung a priori unbekannt ist.

\section{Literatur}

Fisher LD, van Belle G (1993) Biostatistics a methodology for the health sciences. Wiley, New York

Pereira-Maxwell F (1998) A-Z of medical statistics. Arnold, London

\section{Clusterin}

- Apolipoprotein J

Clusterin complement-associated protein SP-40,40

$\checkmark$ Apolipoprotein $\mathrm{J}$

\section{Cluster of differentiation}

> Cluster-of-differentiation-Nomenklatur

\section{Cluster-of-differentiation- Nomenklatur}

H. Renz und B. Gierten

Synonym(e) CD-Nomenklatur
Definition Oberflächenmoleküle auf Leukozyten.

Beschreibung Viele Oberflächenmoleküle auf Leukozyten wurden bereits beschrieben, bevor deren Molekülstruktur und exakte Funktion bekannt waren. In der Nomenklatur entstand eine gewisse Verwirrung, da unterschiedliche Systeme bezugnehmend auf verschiedene, bereits untersuchte Funktionen bestanden. Um Doppelbezeichnungen zu vermeiden wurde die Cluster-of-differentiation-Nomenklatur eingeführt. Sie erfasst die Oberflächenmoleküle systematisch, berücksichtigt werden funktionelle, biochemische und genetische Aspekte.

Die CD-Nomenklatur wird auf regelmäßig stattfindenden Workshops aktualisiert.

\section{Literatur}

Peter H-H, Pichler WJ (1996) Klinische Immunologie, 2. Aufl. Urban \& Schwarzenberg, München, S 16 ff www.ncbi.nlm.nih.gov

\section{Protein I}

> Histidinreiches Glykoprotein

\section{C2-Monitoring}

T. Arndt

Synonym(e) C2-Proben; C2-Werte; C2-Konzentrationen

Englischer Begriff $\mathrm{C} 2$ monitoring; $\mathrm{C} 2$ samples; $\mathrm{C} 2$ concentrations

Beschreibung Im Unterschied zum konventionellen therapeutischen Drug Monitoring ( $\triangleright$ Therapeutisches Drug Monitoring) wird die Pharmakonkonzentration des Bluts nicht unmittelbar vor der nächsten Gabe, das heißt im sog. SteadyState (Talkonzentration, > Fließgleichgewicht), sondern 2 Stunden nach der letzten Gabe des Medikaments und damit in der Spitzenkonzentration zur Therapiekontrolle bestimmt. Letztere steht möglicherweise mit den (toxischen) Nebenwirkungen eines Pharmakons in engerem Zusammenhang als die Talkonzentration. Unplausible Analysenergebnisse für Talkonzentration können zudem über ein C2-Monitoring abgeklärt und ggf. atypischen Metabolisierungsformen (,poor metabolizer“ oder „ultra fast metabolizer“) zugeschrieben werden. 


\section{Literatur}

Juenke JM et al (2004) Specimen dilution for C2 Monitoring with the Abbott TDxFLx cyclosporine monoclonal whole blood assay. Clin Chem 50:1430-1432

\section{C-NPU}

C. Vidal und W.-R. Külpmann

Synonym(e) Committee on Nomenclature, Properties and Units; Properties and Units

Definition Das Komitee ist eine ständige Einrichtung von IFCC ( $\triangleright$ International Federation of Clinical Chemistry and Laboratory Medicine) und IUPAC ( $>$ International Union of Pure and Applied Chemistry). Es legt für die gesamte Laboratoriumsmedizin (z. B. Klinische Chemie, Mikrobiologie, Molekularbiologie, Toxikologie) die Bezeichnung der Messgrößen fest und weist ihnen eindeutige Codes (NPU-Codes) für den sicheren elektronischen Datentransfer zu. NPU ist somit die Alternative $\mathrm{zu}>\mathrm{LOINC}$.

Messgrößenart gemäß C-NPU: Eigenschaft eines Phänomens, eines Körpers oder Substanz, die qualitativ beschrieben und quantitativ ermittelt werden kann.

Beschreibung Eine Messgröße setzt sich zusammen aus:

- System

- Analyt

- Messgrößenart mit Einheit

Im C-NPU-System wird für diesen Datensatz ein eindeutiger Code vergeben, die NPU-Nummer.

Beispiel: Plasma-Urat; Stoffmengenkonzentration $(\mu \mathrm{mol} / \mathrm{L})$; NPU 09356.

Das Messverfahren wird nur angegeben soweit erforderlich. Wenn möglich werden SI-Einheiten verwendet.

\section{Literatur}

Külpmann WR (2005) Das NPU-System (IFCC, IUPAC) der MeßgröBen und Einheiten in der Laboratoriumsmedizin. J Lab Med 29:2-5

\section{COA-SH}

> Pantothensäure

\section{${ }^{13} \mathrm{CO}_{2}$-Atemtest nach Laktose}

\author{
R. Tauber und F. H. Perschel
}

\section{Englischer Begriff ${ }^{13} \mathrm{C}$-lactose breath test}

Definition ${ }^{13} \mathrm{C}$-Atemtest für die Diagnostik der Laktosemalabsorption.

Durchführung Nach oraler Applikation von ${ }^{13} \mathrm{C}$-Laktose wird die ${ }^{13} \mathrm{CO}_{2}$-Exhalation über 4 Stunden in der Ausatemluft kumulativ gemessen.

Funktion - Pathophysiologie Bei gestörter Spaltung von ${ }^{13} \mathrm{C}$-Laktose $\mathrm{zu}{ }^{13} \mathrm{C}$-Glukose und ${ }^{13} \mathrm{C}$-Galaktose infolge primären oder sekundären Laktasemangels sowie bei Malabsorption anderer Genese werden ${ }^{13} \mathrm{C}$-Glukose und ${ }^{13} \mathrm{C}$ Galaktose vermindert im Dünndarm resorbiert und $\mathrm{zu}^{13} \mathrm{CO}_{2}$ verstoffwechselt. Im Vergleich zum Gesunden ist die ${ }^{13} \mathrm{CO}_{2}$ Exhalation vermindert.

Untersuchungsmaterial - Entnahmebedingungen Ausatmungsluft.

Analytik Isotopenverhältnis-Massenspektrometrie (IR-MS; s. Massenspektrometrie) oder nicht dispersive isotopenselektive $>$ Infrarot-Spektrometrie.

Indikation Verdacht auf primären oder sekundären Laktasemangel. Störung der intestinalen Kohlenhydratresorption anderer Genese.

Interpretation Eine gegenüber Gesunden verminderte ${ }^{13} \mathrm{CO}_{2}$-Exhalation zeigt einen Laktasemangel oder eine Störung der intestinalen Kohlenhydratresorption anderer Genese an.

Diagnostische Wertigkeit Wegen der hohen Substratkosten ist der ${ }^{13} \mathrm{C}$-Laktose-Atemtest dem $\mathrm{H}_{2}$-Atemtest nach Laktose unterlegen.

\section{Literatur}

\section{Coagulationsvitamin}

- Vitamin K
Braden B, Lembcke B, Caspary WF (2003) Nichtinvasive Funktionsdiagnostik aus der Atemluft mit ${ }^{13} \mathrm{C}$-Atemtests. Dtsch Ärztebl 100: A3376-A3381 


\section{${ }^{14} \mathrm{CO}_{2}$-Atemtest nach Laktose}

R. Tauber und F. H. Perschel

Englischer Begriff ${ }^{14} \mathrm{C}$-Lactose breath test

Definition Obsoleter ${ }^{14} \mathrm{C}$-Atemtest für die Diagnostik der Laktosemalabsorption.

Durchführung Wegen des Verbots des Einsatzes des radioaktiven Kohlenstoffisotops ${ }^{14} \mathrm{C}$ für klinische Zwecke ist die Durchführung des ${ }^{14} \mathrm{CO}_{2}$-Atemtests mit ${ }^{14} \mathrm{C}$ Laktose obsolet.

\section{Literatur}

Braden B, Lembke B, Caspary WF (2003) Nichtinvasive Funktionsdiagnostik aus der Atemluft mit 13C-Atemtests. Dtsch Ärztebl 100: A3376-A3381

\section{Coating}

T. Arndt

Synonym(e) Antikörperbeschichtung von Reaktionsgefäßen

Englischer Begriff coating

Definition In den Natur- und technischen Wissenschaften vielfältig genutzter Begriff. In seiner allgemeinsten Form handelt es sich um die Beschichtung einer Unterlage mit einem dünnen Film eines speziellen Materials.

Beschreibung Im klinisch-chemischen Labor bezeichnet Coating gewöhnlich die Beschichtung von Reaktionsgefäßen (z. B. \ Mikrotiterplatte) mit Agenzien (z. B. \ Antikörpern). Ziel des Coatings sind Oberflächeneigenschaften, die eine spezifische Bindung der Analyte an der modifizierten Oberfläche ermöglichen, sodass beim anschließenden Waschen der Reaktionsgefäße (ungebundene) Matrixbestandteile effizient entfernt werden können. Die möglichst vollständige Beschichtung verhindert einerseits eine unspezifische Bindung von Analyten und Matrixkomponenten an unbeschichtete Oberflächensegmente und erhöht andererseits die analytische Sensitivität angesichts der direkten Proportionalität zwischen Oberflächenkonzentration der Beschichtungsmoleküle (z. B. Antikörper) und Anzahl der gebundenen Analytmoleküle (z. B. \ Antigene). Ein häufiges Einsatzgebiet „gecoateter“ Mikrotiterplatten sind sog. > Sandwich-Assays oder $>$ Radioimmunoassays.

\section{Cobalamin}

- Vitamin $\mathrm{B}_{12}$

\section{Cobalt}

$>$ Kobalt

\section{$\mathrm{CO}_{2}$-Bindungskapazität}

- Alkalireserve

\section{Cocain}

$>$ Kokain

\section{Cochaperone}

Chaperone

\section{Cockroft-Gault-Formel}

W. G. Guder

Synonym(e) Kreatinin-Clearance aus Serumkreatinin

Englischer Begriff Cockroft and Gault formula

Definition Formel zur Berechnung der endogenen $>$ Kreatinin-Clearance auf der Basis einer einzelnen Bestimmung der Kreatininkonzentration im Plasma/Serum. 
Beschreibung Cockroft und Gault beschrieben im Jahr 1976 eine Formel, die es erlaubt, aus der > Kreatinin-Konzentration im Plasma die endogene Kreatinin-Clearance zu berechnen. Diese berücksichtigte neben der Muskelmasse (angegeben als Körpermasse) das Alter und den Geschlechtsunterschied von Männern und Frauen hinsichtlich Körpermasse und Muskelmasse:

Clearance $(\mathrm{mL} / \mathrm{min})=(140-$ Alter [Jahre] $) \times$ Körpergewicht $(\mathrm{kg}) / 72 \times$ Kreatinin im Plasma/Serum $(\mathrm{mg} / \mathrm{dL})$.

Bei Frauen wird das Ergebnis mit 0,85 multipliziert.

Diese Formel wurde in jüngerer Zeit weitgehend durch die MDRD-Formel und andere Formeln abgelöst ( $\triangleright$ KreatininClearance). Bei weiterer Benutzung bedarf sie der Anpassung an die standardisierte Messung von Kreatinin. Da durch die Bestimmng des wahren Creatinins erst bekannt wurde, daß Creatinin auch sezerniert wird und Creatinin durch die JaffeMethode im Plasma zu hoch gemessen wurde, ist die Creatininclearance nicht mehr die wahre glomeruläre Filtrationsrate und sollte mit neuen Markern kombiniert oder von diesen abgelöst werden ( $\triangleright$ Clearance, glomeruläre).

\section{Literatur}

Cockroft DW, Gault MH (1976) Prediction of creatinine clearance from serum creatinine. Nephron 16:31-41

Grubb A (2010) Non - invasive estimation of glomerular filtration rate (GFR). The Lund model: simultaneous use of cystatin C- and creatinine-based GFR-prediction equations, clinical data and internal qualitycheck. Scand J Clin Lab Invest 70:65-70

\section{Codein}

- Morphin(derivate)

\section{Codein, in Opium}

> Mohn

\section{${ }^{14} \mathrm{C}$ - oder ${ }^{3} \mathrm{H}$-Taurocholat- Absorptionstest}

- Taurocholat-Absorptionstest, ${ }^{14} \mathrm{C}$ - oder ${ }^{3} \mathrm{H}$-markiert

\section{Codogener Strang}

- Sense-Strang

\section{Codon}

J. Arnemann

Synonym(e) Basentriplett

Englischer Begriff codon

Definition Unter Codon versteht man eine festgelegte Abfolge von 3 Nukleotiden (daher auch der Begriff Basentriplett) in der kodierenden genomischen DNA bzw. in der mRNA, die bei der Translation dieser Sequenz eine analoge Aminosäure in den Peptidstrang einbaut oder ein Stoppsignal für diesen Prozess gibt.

Beschreibung Ein Triplett aus 3 benachbarten und nicht überlappenden Nukleotiden einer $\mathrm{zu}$ translatierenden mRNASequenz verschlüsselt (= kodiert) die im Translationsprozess (s. a. > Translation) einzusetzende analoge Aminosäure bzw. das für diesen Prozess relevante Stoppsignal. Diese Information ist als Codon definiert. Da bei einem Codon aus 3 Nukleotiden mehr Kombinationen möglich sind, nämlich 64, als es Aminosäuren gibt, nämlich 20, ist der genetische Code degeneriert, was bedeutet, dass mit Ausnahme der RNA-Codes für die Aminosäuren Methionin (M; AUG) und Tryptophan (W; UGG) mehrere Codes existieren. Hierbei variiert i. d. R. die Position 3 des Tripletts. Ausnahmen hierbei sind die Codes für die Aminosäuren Leucin (L) und Serin (S), bei denen insgesamt 6 verschiedene Codes existieren, die sich an der ersten Position (U oder C) oder an der dritten Position (U, C, A, G) unterscheiden, sowie der Code für das Stoppsignal, bei dem die zweiten und dritten Position eingeschränkt variieren können (UAG, UAA, UGA). Die Translation beginnt obligat mit der Aminosäure Methionin, die immer von einem Triplett kodiert wird und mit einer freien Aminogruppe den N-Terminus des Peptids bildet. Am anderen Ende des Peptids bildet die freie Carboxylgruppe der Aminosäure den C-Terminus.

Bei der Translation binden tRNAs mit komplementärer Erkennungssequenz gegenläufig als Anticodon an das jeweilige Codon. Nach der Wobble-Hypothese muss bei den ersten beiden Basenpositionen die Paarungsregel (U-A und G-C) eingehalten werden, während in der dritten Position eine gewisse Ungenauigkeit und Abweichung toleriert wird. Die tRNAs haben die jeweils Codon-spezifischen Aminosäuren gebunden und sorgen durch die Codon-Anticodon-Bindung 
von mRNA und tRNA dafür, dass die Nukleotidabfolge des Tripletts in die kodierte Aminosäure umgesetzt wird.

\section{Literatur}

Knippers R (2001) Molekulare Genetik, 8. Aufl. Thieme, Stuttgart

Strachan T, Read AP (2005) Molekulare Humangenetik. Elsevier $\mathrm{GmbH}$, München

\section{Coenzym}

T. Arndt

Synonym(e) Coferment

\section{Englischer Begriff coenzyme}

Definition Ein Coenzym ist ein organisches, verhältnismäBig niedermolekulares Molekül (kein Protein), das als Zusatzfaktor zum viel größeren Proteinanteil eines Enzymmoleküls funktioneller Bestandteil des Enzyms ist.

Beschreibung Das Coenzym bindet normalerweise reversibel und nicht kovalent an das Apoenzym und bildet zusammen mit ihm das Holoenzym. Das Coenzym geht - im Gegensatz zu einem Cosubstrat - unverändert aus der katalysierten Reaktion hervor. Viele Coenzyme sind phosphorylierte, wasserlösliche - Vitamine. Bekannte Coenzyme sind z. B. das Coenzym A oder das Coenzym B12. Während der enzymatischen Reaktion spielen sie eine Übertragungsrolle. Dabei werden sie chemisch verändert, weshalb sie nicht als Cokatalysatoren zu betrachten sind.

\section{Literatur}

Falbe J, Regitz M (1999) Römpp Chemie Lexikon, 10. Aufl. Georg Thieme Verlag, Stuttgart/New York

\section{Coenzym A}

> Pantothensäure

\section{Coenzym Q}

$>$ Vitaminoide

\section{Coenzym R}

Biotin

\section{Coeruloplasmin}

A. M. Gressner und O. A. Gressner

Synonym(e) Ferroxidase; Cp; EC 1.16.3.1

Englischer Begriff ceruloplasmin; ferrooxidase

Definition Kupferhaltiges Serumprotein mit enzymatischer Aktivität als Oxidase und diagnostischer Bedeutung für hereditäre Kupferstoffwechselstörungen (z. B. Morbus Wilson).

Molmasse $150 \mathrm{kDa}$.

Synthese - Verteilung - Abbau - Elimination $\mathrm{Cp}$ ist das entscheidende kupferhaltige, aus einer Polypeptidkette (1050 - Aminosäuren) bestehende, 8 Atome $\mathrm{Cu}^{2+}$ pro Molekül enthaltende, deshalb blaugefärbte, in der $\alpha_{2}$-Globulinfraktion wandernde Glykoprotein ( $\triangleright$ Glykoproteine; Kohlenhydratgehalt: $8 \%$, Molmasse: $150 \mathrm{kDa}, \mathrm{pI} 4,4)$ des menschlichen Serums. Der während der Peptidsynthese erfolgende Einbau von $\triangleright \operatorname{Kupfer}\left(\mathrm{Cu}^{2+}\right)$ ist von einer ATPase $7 \mathrm{~b}$ abhängig, die bei Morbus Wilson durch Mutation inaktiviert ist. Dadurch wird ein kupferfreies Apo-Cp gebildet, das bereits intrazellulär degradiert wird. Aufgrund des hohen $\mathrm{Cu}^{2+}$-Gehalts $(0,34 \%$ der Molmasse) sind ca. $95 \%$ des Serumkupfers in der nicht dialysierbaren, kovalent mit $\mathrm{Cp}$ verbundenen Fraktion und $5 \%$ in der dialysierbaren Kupferfraktion, die locker an Albumin und Histidine gebunden ist, vertreten. Die Synthese erfolgt in den Hepatozyten, die Halbwertszeit in der Zirkulation beträgt ca. 96 Stunden. $\mathrm{Cp}$ ist ein relativ schwach reagierendes positives Protein der $\downarrow$ Akute-PhaseReaktion, dessen Zunahme bei akuten Entzündungen zur Grün-Blau-Verfärbung betroffener Seren führen kann.

\section{Funktionelle Eigenschaften}

- Inkorporation von Kupfer während der $\mathrm{Cp}$-Synthese in den Hepatozyten, Sekretion und Transport des $\mathrm{Cu}^{2+}-\mathrm{Cp}$ zu Geweben des $\mathrm{Cu}^{2+}$-Verbrauchs. Cp ist im Gegensatz zu - Albumin kein reversibles Kupfertransportprotein, da die $\mathrm{Cu}^{2+}$-Freisetzung an die Degradation des Cp gebunden ist. Kupfer kann nicht mit dem Cp-Apoprotein in der Zirkulation eine Verbindung eingehen. Dem Kupfertransport dient die dialysierbare Fraktion (s. o.). 
- Katalytische Aktivität als Oxidase (Kupferoxidase, Ferrooxidase), die die Oxidation von $\mathrm{Fe}^{2+} \mathrm{zu} \mathrm{Fe}^{3+}$ vor Bindung an Transferrin, von Polyaminen, Katecholaminen, Polyphenolen und Askorbat katalysiert. $\mathrm{Cp}$ ist für den Eisentransport vom intra- zum extrazellulären Kompartiment und somit in Verbindung mit Ferroportin für den zellulären Eisenefflux verantwortlich.

- Antioxidanzfunktionen.

- Akute-Phase-Protein, jedoch schwächer als > Haptoglobin, $\alpha_{1}$-saures Glykoprotein (Orosomukoid; $\triangleright$ Glykoprotein, $\alpha_{1}$-saures) und $\triangleright$ C-reaktives Protein (CRP).

Funktion - Pathophysiologie Cp-Erniedrigung bei autosomal rezessiv vererbter hepatolentikulärer Degeneration (Morbus Wilson) mit $\mathrm{Cu}^{2+}$-Ablagerungen in Leber, Hirn, Kornea und Niere (Prävalenz 1:50.000-1:100.000).

Untersuchungsmaterial - Entnahmebedingungen Serum, Plasma.

Probenstabilität Analytstabilität bei $4{ }^{\circ} \mathrm{C} 3$ Tage, bei $-20{ }^{\circ} \mathrm{C} 4$ Wochen, bei $-70{ }^{\circ} \mathrm{C}$ unbeschränkt.

Präanalytik Vermeidung von Lipämie und Hämolyse.

\section{Analytik}

- Immunologische Methoden: $>$ Immunnephelometrie und > Immunturbidimetrie, radiale Immundiffusion (RID; - Immundiffusion, radiale nach Mancini, Carbonara und Heremans), Elektroimmunoassay ( $\triangleright$ Elektroimmundiffusion)

- Funktionelle Methode mit Bestimmung der Cp-katalysierten Oxidation von p-Phenylendiamin bei $530 \mathrm{~nm}$ (Rotfärbung)

- Bei Acoeruloplasminämie (erstmals 1987 in Japan beschrieben, Prävalenz 1 auf 2 Mio.) ist eine Mutationsanalyse des $\mathrm{Cp}$-Gens auf dem langen Arm des Chromosoms 3 notwendig. Gegenwärtig sind 45 verschiedene Mutationen bei über 60 Patienten beschrieben, was auf eine ausgeprägte molekulare Heterogenität dieser Erkrankung hinweist.

Referenzbereich - Erwachsene $0,18-0,45 \mathrm{~g} / \mathrm{L}$.

\section{Referenzbereich - Kinder}

\begin{tabular}{|l|l|}
\hline Alter & Coeruloplasmin-Konzentration $(\mathrm{g} / \mathrm{L})$ \\
\hline Neugeborene (bis 3. Monat) & $0,05-0,18$ \\
\hline Kleinkinder & $0,16-0,55$ \\
\hline 4-7 Jahre & $0,24-0,56$
\end{tabular}

\section{Indikation}

- Verdacht auf hereditäre Kupferstoffwechselstörung (Morbus Wilson, Menke-Syndrom)

- Aktivitätsbeurteilung akuter und chronischer entzündlicher Prozesse (Akute-Phase-Reaktion)

Interpretation Serumkonzentrationsveränderungen von $\mathrm{Cp}$ finden sich bei den in der folgenden Tabelle zur Bewertung der Serum-Coerulosplasmin-Konzentration genannten Erkrankungen:

\begin{tabular}{l|l} 
Abnahme & Zunahme \\
\hline Hepatolentikuläre Degeneration & Akute und chronische \\
(Morbus Wilson) & Entzündungen \\
Menke's-kinky-hair-Syndrom & Gewebsnekrosen \\
Proteinverlustsyndrome & - Infektionen \\
- Renal (Nephrose) & - Rheumatoide Arthritis \\
- Enteral (exsudative Enteropathie) & - Myokardinfarkt \\
Schwere & Tumoren in Verbindung \\
Leberparenchymerkrankungen & mit Zellnekrosen \\
(terminale Zirrhose) & - Akute Leukämien \\
Malnutrition & - Hodgkin-Lymphom \\
Malabsorption & Lebererkrankungen \\
& - Akute Hepatitis \\
& - Floride Zirrhose \\
& - Cholestase \\
& - Primäre biliäre Zirrhose \\
& Östrogene \\
& Kontrazeptiva \\
& Schwangerschaft
\end{tabular}

Erhöhungen gehen teilweise auf die Funktion von $\mathrm{Cp}$ als Akute-Phase-Protein ( $\triangleright$ Akute-Phase-Proteine) zurück. Diagnostisch dominierend ist der Einsatz bei Morbus Wilson und Menke's-kinky-hair-Syndrom. Bei Morbus Wilson (Kupferspeicherkrankheit durch über 250 Mutationsstellen des ATP-7b-Gens) ist in $80 \%$ eine Konzentration $<0,2 \mathrm{~g} / \mathrm{L}$ und in $60 \%<0,05 \mathrm{~g} / \mathrm{L}$ festzustellen, doch sind Erniedrigungen weder $100 \%$ sensitiv noch spezifisch für diese Erkrankung, die durch zusätzliche Untersuchungen der mit und ohne D-Penicillamin gesteigerten renalen $\mathrm{Cu}^{2+}$-Ausscheidung ( $>100 \mu \mathrm{g} / 24$ Stunden), der erhöhten $\mathrm{Cu}^{2+}$-Ablagerung in Geweben, z. B. in Leber $(>250 \mu \mathrm{g} / \mathrm{g}$ Trockengewicht $)$ und in der Korneaperipherie in Form des bräunlichen KayserFleischer'schen Kornealrings und durch molekulargenetische Untersuchungen des ATP-7b-Gens nachzuweisen ist. Weitere Ursachen der Erniedrigung sind:

- Renale, enterale und dermale Proteinverlustsyndrome

- Schwere Leberzellinsuffizienz

- Malnutrition

- Malabsorption 
Diagnostische Wertigkeit Sensitivität ( $\triangleright$ Sensitivität, diagnostische) und Spezifität ( $\triangleright$ Spezifität, diagnostische) der $\mathrm{Cp}$-Erniedrigung für Morbus Wilson sind aus Gründen erworbener Ursachen weder absolut spezifisch noch sensitiv. Andererseits kann eine erworbene oder genetisch bedingte Erniedrigung teilweise überlagert sein durch eine Konzentrationserhöhung im Rahmen einer Akute-Phase-Reaktion und/ oder Östrogenzufuhr.

\section{Literatur}

Gitlin JD (2003) Wilson disease. Gastroenterology 125:1868-1877

Roberts EA, Schilsky ML (2003) A practice guideline on Wilson disease. Hepatology 37:1475-1492

\section{Coferment}

Coenzym

\section{Coffein}

C. Vidal und W.-R. Külpmann

\section{Synonym(e) Koffein}

\section{Englischer Begriff caffeine}

Definition Analeptikum.

Strukturformel:<smiles>Cn1c(=O)c2c(ncn2C)n(C)c1=O</smiles>

Molmasse $194,19 \mathrm{~g}$

Synthese - Verteilung - Abbau - Elimination Aufgenommenes Coffein wird in der Leber demethyliert zu Dimethylxanthinen (u. a. Theophyllin) und Monomethylxanthinen, die weiter zu 1,3-Dimethyl- bzw. 1-Methylharnsäure oxidiert werden. Bei Erwachsenen finden sich überwiegend diese Metabolite im Urin, während Neugeborene 85 \% der Coffeindosis unverändert ausscheiden. Theophyllin wird von Neugeborenen teilweise zu Coffein methyliert.
Halbwertszeit Erwachsene: 2-10 Stunden (Plasma); Neugeborene: 30-200 Stunden.

Funktion - Pathophysiologie Die akute Coffeinvergiftung ist gekennzeichnet durch rauschartige Zustände und Schreckhaftigkeit und tritt häufiger bei Kindern auf nach Zufuhr großer Mengen coffeinhaltiger Getränke. Selten finden sich supraventrikuläre Tachyarrhythmien, die zum Tode führen können.

Untersuchungsmaterial - Entnahmebedingungen Serum, Plasma, Urin.

Analytik Immunoassay. HPLC, GC-MS, LC-MS/MS ( $\triangleright$ Chromatographie, $\triangleright$ Massenspektrometrie).

Diagnostische Wertigkeit Therapeutisches Drug Monitoring bei Neugeborenen unter Apnoebehandlung mit Coffein. Angesichts des Metabolismus ist neben Coffein- auch die Theophyllinkonzentration zu überwachen.

Interpretation Therapeutischer Bereich Erwachsene/Neugeborene: 2-15/5-20 mg/L; toxisch: $>15 \mathrm{mg} / \mathrm{L}$; komatös/ letal: $>80 \mathrm{mg} / \mathrm{L}$.

\section{Literatur}

Külpmann WR (Hrsg) (2009) Bronchodilators. In: Clinical toxicological analysis. Wiley-VCH, Weinheim, S 313-316

\section{Coffeinbelastungstest}

Caffein-Eliminationstest

\section{$\mathrm{COHb}$}

- Kohlenmonoxidhämoglobin

\section{Cohn-Fraktionierungsschema}

T. Arndt

Englischer Begriff Cohn process 
Definition Von Edwin J. Cohn (1892-1953) ursprünglich zur Gewinnung von Albumin aus Blut entwickeltes Verfahren zur Trennung der Plasmaproteine in 5 Fraktionen durch Variation von Ethanolanteil, $\mathrm{pH}$, Temperatur und Ionenstärke während der Extraktion.

Beschreibung Ziel war die industrielle Gewinnung von Blutersatzstoffen, u. a. Albumin als Plasmaexpander für im Zweiten Weltkrieg Verletzte. Hiervon unabhängig sind Plasmaprotein-Fraktionierungen im medizinischen Labor mit elektrophoretischen ( $\triangleright$ Serumprotein-Elektrophorese) oder chromatographischen Verfahren, wobei die o. g. Faktoren auch hier von erheblicher Bedeutung für die Trennung sein können.

\section{Literatur}

Edsall JT (1961) Edwin Joseph Cohn 1892-1953. A biographical memoir. National Academy of Sciences. Washington, DC. http:// www.nasonline.org/publications/biographical-memoirs/memoir-pdfs/ cohn-edwin-j.pdf. Zugegriffen am 05.04.2017

https://en.wikipedia.org/wiki/Cohn_process. Zugegriffen am 05.04.2017

\section{${ }^{13}$ C-Oktanoat-Atemtest}

R. Tauber und F. H. Perschel

Englischer Begriff ${ }^{13} \mathrm{C}$-octanoic acid breath test

Definition ${ }^{13} \mathrm{C}$-Atemtest für die Diagnostik von Störungen der Magenentleerung.

Durchführung Applikation einer festen Testmahlzeit, bei der ${ }^{13} \mathrm{C}$-Oktanoat in das Eigelb eines Rühreis eingebacken wird. Nach Entleerung von ${ }^{13} \mathrm{C}$-Oktanoat mit der Nahrung durch den Pylorus in den Dünndarm wird die mittelkettige Fettsäure resorbiert und $\mathrm{zu}^{13} \mathrm{CO}_{2}$ verstoffwechselt. $\mathrm{Zu}$ unterschiedlichen Zeiten nach Applikation der Testnahrung werden Atemluftproben gewonnen und analysiert. Bei einem Untersuchungszeitraum von mehr als 4 Stunden spiegelt die Ausscheidungskinetik von ${ }^{13} \mathrm{CO}_{2}$ in der Atemluft die Kinetik der Magenentleerung wider.

Untersuchungsmaterial - Entnahmebedingungen Ausatmungsluft.

Analytik Isotopenverhältnis-Massenspektrometrie (IR-MS; s. D Massenspektrometrie) oder nicht dispersive isotopenselektive $>$ Infrarot-Spektrometrie (NDIRS).
Indikation Verdacht auf Störung der Magenentleerung z. B. bei diabetischer Neuropathie oder funktioneller Dyspepsie.

Diagnostische Wertigkeit Praktikable, technisch weniger aufwendige Alternative zu nuklearmedizinischen Verfahren zur Untersuchung der Magenentleerung.

\section{Literatur}

Braden B, Lembcke B, Caspary WF (2003) Nichtinvasive Funktionsdiagnostik aus der Atemluft mit 13C-Atemtests. Dtsch Ärztebl 100: A3376-A3381

\section{Colchicin}

- Alkaloide

\section{Cold insoluble globulin}

Fibronectin

\section{Colecalciferol (Vitamin $\mathbf{D}_{3}$ )}

- Vitamin D

\section{College of American Pathologists}

\section{A. M. Gressner und O. A. Gressner}

\section{$\operatorname{Synonym}(e)$ CAP}

Definition CAP ist die weltweit größte medizinische Fachgesellschaft von Pathologen einschließlich Labormedizinern/analytikern in den USA.

Beschreibung Die private (nicht staatliche) Fachgesellschaft von Pathologen und Labormedizinern/-analytikern umfasst mehr als 18.000 Mitglieder weltweit. Die Aktivitäten von CAP konzentrieren sich auf folgende Schwerpunkte: Akkreditierung der in der Krankenversorgung tätigen Labore der Pathologie/Labormedizin, die Labororganisation, die internationale Zusammenarbeit mit Laboratorien gleicher fachlicher Ausrichtung, die Weiterbildung von Fachpersonal durch Lernprogramme, die Publikation von CAP-Guidelines zu diagnostischen und methodischen Anwendungen. Die von CAP seit 1964 durchgeführte Akkreditierung medizinischer 
Laboratorien auf Basis eines eigenen Regelwerkes setzt $u$. a. die obligatorische Teilnahme an den CAP-Ringversuchen voraus, andererseits ist die Akkreditierung Voraussetzung der US-behördlichen Anerkennung diagnostischer Labore. Mehr als 6000 Laboratorien sind aktuell bei CAP akkreditiert.

\section{Adresse des Headquarters:}

College of American Pathologists

325 Waukegan Road

Northfield

IL 60093-2750

USA

\section{Literatur}

http://www.cap.org

\section{Colombi-Index}

A. M. Gressner und O. A. Gressner

Englischer Begriff Colombi's index

Definition Die Summe der kurzlebigen hepatogenen Gerinnungsfaktoren II, V und VII im Plasma, in Prozent der Normalaktivität angegeben, dient als Kenngröße der Leberzellsyntheseleistung (anabole Leberfunktion).

Synthese - Verteilung - Abbau - Elimination Die in Hepatozyten synthetisierten $>$ Gerinnungsfaktoren II (Prothrombin, Halbwertszeit 2-4 Tage), V (Proaccellerin, Halbwertszeit 12-15 Stunden) und VII (Proconvertin, Halbwertszeit 2-5 Stunden) sind aufgrund ihrer kurzen Halbwertszeiten im Blut sensitive Indikatoren der aktuellen hepatozellulären Proteinsyntheseleistung.

Funktion - Pathophysiologie Das Ausmaß ihrer Erniedrigung im Plasma zeigt den Schweregrad der Leberinsuffizienz an, wenn extrahepatische Ursachen wie > Vitamin K-Mangel bzw. -Antagonisierung und Verbrauch auszuschließen sind.

\section{Untersuchungsmaterial - Entnahmebedingungen Citrat- plasma.}

Probenstabilität Stabilität der Faktoren maximal 4 Stunden bei Raumtemperatur.

Analytik Funktionelle Bestimmung der Einzelfaktoren II, V, VII.
Referenzbereich - Erwachsene Einzelfaktoren:

\begin{tabular}{|l|l|}
\hline Gerinnungsfaktor & Anteil der Normalaktivität (\%) \\
\hline II & $70-130$ \\
V & $70-130$ \\
\hline VII & $70-150$ \\
\hline
\end{tabular}

Indikation Diagnose und Abschätzung des Schweregrades einer Leberzellinsuffizienz, insbesondere der aktuellen Proteinsyntheseleistung.

Interpretation Je niedriger der 1967 von A. Colombi eingeführte Index ist, desto schwerwiegender ist die Lebererkrankung: Colombi-Index $<150$ zeigt eine schwere, ein Index $<80$ eine hoch gradige Leberinsuffizienz an. Der Index wird aufgrund seiner relativ aufwendigen Analytik nur selten eingesetzt und ist durch die Bestimmung der $\triangleright$ Thromboplastinzeit (TPZ, Quicktest) ersetzbar, die ein integrales Maß der Gerinnungsfaktoraktivitäten I, II, V, VII und X darstellt. Sowohl bei der Erniedrigung des Colombi-Index als auch bei der Verlängerung des Quick-Wertes sind ursächlich VitaminK-Mangelzustände und/oder Verbrauch von $>$ Gerinnungsfaktoren (z. B. bei disseminierter intravaskulärer Gerinnung) zu berücksichtigen. Zur differenzialdiagnostischen Abgrenzung eines ursächlichen Vitamin-K-Mangels bei Erniedrigung der Vitamin-K-abhängigen Faktoren II und VII ist der $>$ KollerTest bzw. die Bestimmung von Vitamin K geeignet.

\section{Literatur}

Colombi A, Thölen H, Engelhart G et al (1967) Blutgerinnungsfaktoren als Index für den Schweregrad der akuten Hepatitis. Schweit Med Wochenschr 97(51):1716-1721

\section{Colony forming unit lymphoid- myeloid}

CFU-LM

\section{Colton-Blutgruppensystem}

K. Kleesiek, C. Götting, J. Diekmann, J. Dreier und M. Schmidt

Synonym(e) AQP1; Aquaporin 1; Channel forming integral protein (CHIP-1); CHIP-1; Colton (Co)

Englischer Begriff Colton blood group system 
Colton-Blutgruppensystem, Tab. 1 Eigenschaften der Hauptantigene des Colton-Blutgruppensystems

\begin{tabular}{|c|c|c|c|c|c|c|c|}
\hline \multirow[b]{2}{*}{$\begin{array}{l}\text { Colton- } \\
\text { Antigen }\end{array}$} & \multirow{2}{*}{$\begin{array}{l}\text { ISBT- } \\
\text { Symbol } \\
\text { (Zahl) }\end{array}$} & \multirow[b]{2}{*}{$\begin{array}{l}\text { Antigenfrequenz } \\
(\%)^{*}\end{array}$} & \multicolumn{3}{|c|}{ In-vitro-Charakteristika von Alloantikörpern } & \multicolumn{2}{|l|}{$\begin{array}{l}\text { Klinische Signifikanz } \\
\text { von Alloantikörpern }\end{array}$} \\
\hline & & & Immunglobulinklasse & $\begin{array}{l}\text { Optimale } \\
\text { Nachweistechnik }\end{array}$ & Komplementbindung & Transfusionsreaktion & MHN \\
\hline $\mathrm{Co}(\mathrm{a})$ & $\begin{array}{l}\text { CO1 } \\
(015.001)\end{array}$ & 99,9 & IgG & IAT & Nein & $\begin{array}{l}\text { Keine bis moderat/ } \\
\text { verzögert/ } \\
\text { hämolytisch }\end{array}$ & $\begin{array}{l}\text { Mild bis } \\
\text { schwer } \\
\text { (selten) }\end{array}$ \\
\hline $\mathrm{Co}(\mathrm{b})$ & $\begin{array}{l}\mathrm{CO} 2 \\
(015.002)\end{array}$ & 10 & $\operatorname{IgG}$ & IAT & Selten & $\begin{array}{l}\text { Keine bis moderat/ } \\
\text { verzögert } \\
\text { hämolytisch }\end{array}$ & Mild \\
\hline $\begin{array}{l}\mathrm{Co} 3 \\
\left(\mathrm{Co}^{\mathrm{ab}}\right)\end{array}$ & $\begin{array}{l}\mathrm{CO} 3 \\
(015.003)\end{array}$ & 100 & $\operatorname{IgG}$ & IAT & $\mathrm{Ja}$ & Nicht bekannt & Schwer \\
\hline
\end{tabular}

*in allen Populationen; ISBT, International Society Blood Transfusion; IAT, indirekter Agglutinationstest

Definition Membranprotein u. a. von $>$ Erythrozyten, das als Wasserpore fungiert. Es kommt auf der Zelloberfläche von Erythrozyten vor und ist ein erythrozytäres Blutgruppenantigen ( $\triangleright$ Blutgruppensysteme). Colton-Antigene gehören zu der Aquaporin-Proteinfamilie und werden von einem Allel des Gens AQP1 kodiert (Chromosomenlokalisation: 7p14).

Beschreibung Aquaporine haben 6 Transmembrandomänen, die eine Wasserpore bilden. Das AQP1-Protein lagert sich zu einem Homotetramer in der Membran zusammen, wobei 1-2 der 4 Untereinheiten N-glykosyliert sind (Molmasse $28 \mathrm{kDa}$ unglykosilierte, 40-60 kDa glykosilierte Form).

AQP1 und AQP3 (GIL-Blutgruppensystem) sind die einzigen Aquaporine, die in der Erythrozytenmembran vorkommen. Das AQP1-Protein macht 2,4 \% der gesamten Membranproteine des Erythrozyten aus. Aquaporine kommen daneben in verschiedenen anderen Geweben vor (u. a. Tubulusmembran der Niere). Das AQP1-Protein wird zur Bestimmung der Blutgruppenmerkmale ( $\triangleright$ Blutgruppenbestimmung) genutzt.

APQ1 fungiert als Kanal der Zellmembran, um den Durchtritt von Wasser und einigen weiteren Molekülen zu erleichtern (Membrantransport), es dient also zur Regulation von Wasserhomeostase und Urinkonzentrierung. Das APQ1Protein vermittelt $80 \%$ der Wasserreabsorption in der Niere. Colton-Antigen-negative Personen ( $\triangleright$ Null-Phänotyp im Blutgruppensystem) zeigen keine offensichtlichen klinischen Symptome, jedoch weisen ihre Erythrozyten eine kürzere Halbwertszeit auf.

Das Colton-Antigen ist wichtig in der Transfusionsmedizin. 99,9 \% der Individuen tragen das Co(a)-Allel. Die phänotypische Verteilung in der Population ist $\mathrm{Co}(\mathrm{a}+\mathrm{b}-)$ $90 \%, \operatorname{Co}(a-b+) \quad 0,5 \%, \operatorname{Co}(a+b+) \quad 9,5 \%$ und $\operatorname{Co}(a-b-)$ $<0,01 \%$. Individuen mit $\mathrm{Co}(\mathrm{b})$-Allelen oder fehlendem Colton-Antigen tragen ein Risiko für Transfusionsreaktionen wie hämolytische Anämie oder Alloimmunisierung nach Kontakt mit Co(a)-Antigen. Antikörper, die gegen ColtonAntigene gerichtet sind, können auch zu einem Morbus haemolyticus neonatorum (Mhn; s. > Morbus haemolyticus fetalis/neonatorum) führen.
Die Eigenschaften der Hauptantigene des Colton-Blutgruppensystems sind in Tab. 1 zusammengefasst.

\section{Literatur}

Mathai JC, Mori S, Smith BL, Preston GM, Mohandas N, Collins M, van Zijl PC, Zeidel ML, Agre P (1996) Functional analysis of aquaporin-1 deficient red cells. The Colton-null phenotype. J Biol Chem 271:1309-1313

Preston GM, Agre P (1991) Isolation of the cDNA for erythrocyte integral membrane protein of $28 \mathrm{kDa}$ : member of an ancient channel family. Proc Natl Acad Sci U S A 88:11110-11114

Reid ME, Lomas-Francis C (2004) The blood group antigen facts book, 2. Aufl. Elsevier, New York

Sui H, Han BG, Lee JK, Walian P, Jap BK (2001) Structural basis of water-specific transport through the AQP1 water channel. Nature 414:872-878

Verkman AS (2002) Aquaporin water channels and endothelial cell function. J Anat 200:617-627

\section{Colton (Co)}

- Colton-Blutgruppensystem

\section{Committee on Nomenclature, Properties and Units}

C-NPU

\section{COMP}

H.-D. Haubeck

Synonym(e) Thrombospondin-5 
Englischer Begriff COMP; cartilage oligomeric matrix protein

Definition Das oligomere Matrixprotein des Knorpels (COMP) ist ein pentameres Glykoprotein ( $\triangleright$ Glykoproteine), das im Knorpel, in Sehnen und Bändern exprimiert wird.

Beschreibung Das Knorpel-spezifische oligomere Matrixprotein (COMP) wurde ursprünglich aus dem Knorpel isoliert und besteht aus 5 über Disulfidbrücken verknüpften Untereinheiten von ca. $100 \mathrm{kDa}$. Die Molmasse von COMP beträgt $524 \mathrm{kDa}$. Im normalen Knorpel wird COMP überwiegend in den Knorpelhöfen um die Chondrozyten (Territorialmatrix) exprimiert und ist für die Fibrillogenese von Kollagen Typ II notwendig. Es bindet dabei hochaffin an 4 spezifische Bindungstellen des Prokollagens und wirkt als Katalysator der Fibrillenbildung.

Mutationen im COMP-Gen führen zur Pseudoachondroplasie und zur multiplen ephiphysealen Dysplasie, 2 Unterformen der Osteochondrodysplasie.

Fragmente von COMP entstehen im Rahmen von Gelenkerkrankungen durch die Wirkung von > Matrix-Metalloproteinasen (MMP) und $\triangleright$ Disintegrin-Metalloproteinasen (ADAM, ADAM-TS). Sie werden aus dem Knorpel freigesetzt und lassen sich bei Patienten mit Gelenktraumata, Osteoarthritis und rheumatoider Arthritis in der Synovialflüssigkeit und im Serum nachweisen. Da COMP außer im Knorpel nur noch in geringer Menge in Sehnen und Bändern exprimiert wird, kann es im Serum als weitgehend knorpelspezifischer Marker angesehen werden, der aber nur die Knorpelschädigung zeigt und keine Krankheitsspezifität besitzt. Allerdings wird COMP bei einer Knorpelschädigung nicht nur durch die Wirkung der MMP und ADAM/ADAM-TS vermehrt aus dem Knorpel freigesetzt, sondern COMP wird, zumindest während früher Stadien der Osteoarthritis im Sinne eines Reparaturversuchs, auch verstärkt synthetisiert. Dies kann sogar zu einer weiteren Schädigung der Extrazellulärmatrix beitragen, weil durch zu hohe COMP-Konzentrationen das COMP/Prokollagen-Verhältnis gestört wird und damit zu einer ungeordneten, mangelhaften Fibrillogenese des Kollagens Typ II führt. Damit ist COMP nicht respektive nicht nur als Parameter der Knorpeldegradation zu bewerten, sondern eher des Knorpelumsatzes. Vor allem entstammt das im Serum gemessene COMP nicht nur dem betroffenen Gelenk, sondern reflektiert den normalen Turnover aller Knorpelgewebe des Körpers. Trotz dieser Einschränkungen korreliert die COMP-Konzentration im Serum bei rheumatoider Arthritis und Osteoarthritis mit der Krankheitsprogression und eignet sich damit für die Therapiekontrolle und als prognostischer Marker.

Für die Messung der COMP-Konzentration im Serum und in der Synovialflüssigkeit steht ein $\triangleright$ Enzymimmunoassay zur Verfügung.

\section{Literatur}

Dickinson SC, Vankemmelbeke MN, Buttle DJ et al (2003) Cleavage of cartilage oligomeric matrix protein (thrombospondin-5) by matrix metalloproteinases and metalloproteinase with thrombospondin motifs. Matrix Biol 22:267-278

Hedbom E, Antonsson P, Hjerpe A et al (1992) Cartilage matrix proteins. J Biol Chem 267:6132-6136

\section{Complement-associated protein SP-40,40}

$\checkmark$ Apolipoprotein $\mathrm{J}$

\section{Complement receptor type 1 (CR1)}

- Knops-Blutgruppensystem

\section{Complement S-Protein}

Vitronectin

\section{Complexed PSA}

> Prostataspezifisches Antigen, komplexiertes

\section{Compliance}

\section{A. M. Gressner und O. A. Gressner}

\section{Englischer Begriff compliance}

Definition Bereitschaft des Patienten (Probanden) zur Mitarbeit bei medizinischen Maßnahmen durch Einhaltung von Richtlinien und Verfahrensmaßregeln (Regeltreue).

Beschreibung Die Mitarbeit des Patienten (Probanden) bei Laboratoriumsuntersuchungen ist auf die $>$ präanalytische Phase beschränkt und bezieht sich beispielsweise

- auf das Absetzen interferierender Medikamente oder Diäten,

- auf die korrekte und regelmäßige Einnahme verschiedener Medikamente,

- die korrekte Sammlung und Verwahrung des 24-StundenSammelurins und des Fäzes, 
- auf die Einnahme von Testsubstanzen bei Funktionstesten,

- auf die Einhaltung des Nüchternzustandes und körperlicher Ruhe vor Gewinnung des Untersuchungsmaterials,

- auf die korrekte Identifizierung häuslich gewonnenen Untersuchungsmaterials u. v. a.

Fehlende Compliance kann eine wesentliche, zu Missinterpretation führende Fehlerquelle bei Laboruntersuchungen, besonders im ambulanten Bereich, sein. Die Compliance kann erhöht werden, wenn die Patienten über Art und Ursache der Erkrankung sowie Notwendigkeit, Nutzen, Nebenwirkungen und Kosten von diagnostischen Maßnahmen in geeigneter Weise aufgeklärt werden.

\section{Literatur}

Scherenberg V (2003) Patientenorientierung-Compliance und disease management Programme. Verlag für Wissenschaft und Kultur, Bonn

\section{Compliance, Labor-EDV}

\section{O. Colhoun}

\section{Synonym(e) Richtlinientreue}

Definition Im Rahmen der Labor-EDV die Erfüllung von Vorgaben, Gesetzen, Normen und Richtlinien für das medizinische Labor, z. B. Rilibäk, DIN EN ISO 15189:2007, Richtlinien des Paul-Ehrlich-Instituts für Blutprodukte oder Eurocode.

\section{Compound antigens}

K. Kleesiek, C. Götting, J. Diekmann, J. Dreier und M. Schmidt

Definition Zusammengesetzte Antigene, wobei $>$ Antikörper gegen beide Antigene gerichtet sind. Es handelt sich nicht um ein Antikörpergemisch, d. h., es ist keine Reaktion mit den einzelnen Antigenkomponenten nachweisbar (z. B. RH6 = ce, $\mathrm{RH} 7=\mathrm{Ce})$.

\section{Connecting Peptide}

C-Peptid

\section{Conn, Jerome W.}

M. Bidlingmaier

Lebensdaten Geboren 24. September 1907 in New York City; gestorben 11. Juni 1994 in Naples, Florida. Amerikanischer Internist, Endokrinologe. Medizinstudium ab 1925 zunächst an der Rutgers University, seit 1928 an der University of Michigan Medical School in Ann Arbor. Abschluss (MD) 1932. 1935 Assistent Professor, seit 1943 Leiter der Abteilung für Endokrinologie und Stoffwechsel. 1944 Professor für Innere Medizin, seit 1968 LH Newburgh Distinguished University Professor. Conn verbachte seine gesamte akademische Karriere bis zu seiner Emeritierung 1974 an der University of Michigan. Er erhielt für seine Arbeiten eine Vielzahl wissenschaftlicher Auszeichnungen, unter anderem 1958 die Banting-Medaille der American Diabetes Association.

Verdienste Obwohl Conn auch wichtige Studien zur Erforschung des Kohlehydratstoffwechsels beigetragen hat, sind seine wichtigsten wissenschaftlichen Arbeiten die zur Rolle der Steroide in der Regulation von Blutdruck und Salz-WasserHaushalt. 1954 beschrieb er den Fall einer 34 Jahre alten Patientin mit Hypertonie, Hypokaliämie und metabolischer Alkalose. Conn konnte eine erhöhte Konzentration des salzretinierenden Steroids Aldosteron im Urin der Patientin nachweisen und vermutete als Ursache des Mineralokortikoidexzesses einen adrenalen Tumor. In der Tat konnte ein solcher Tumor bei einem operativen Eingriff gefunden und entfernt werden, die Symptome verschwanden. In den folgenden Jahren klärte Conn weitere Teilaspekte des Renin-Angiotensin-Aldosteron-Systems auf und führte unter anderem die bis heute in Form des Aldosteronzu-Renin-Quotienten verwendete Berücksichtigung der Suppression von Renin in die Diagnostik ein. Der inzwischen als häufigste Ursache der sekundären Hypertonie erkannte primäre Hyperaldosteronismus wird nach seinem Erstbeschreiber auch Conn-Syndrom genannt.

\section{Literatur}

Conn JW, Part I (1955) Painting background. Part II. Primary aldosteronism, a new clinical syndrome. J Lab Clin Med 45:3-17

Conn JW, Cohen EL, Rovner DR (1964) Suppression of plasma renin activity in primary aldosteronism. JAMA 190:213-221

National Academy of Sciences (1997) Biographical memoirs, Bd 71. The National Academies Press, Washington, DC. https://doi.org/ $10.17226 / 5737$ 


\section{Consensus Value}

C. Vidal und W.-R. Külpmann

Synonym(e) Konsensuswert

Englischer Begriff consensus value

Definition Teilnehmermittelwert.

Beschreibung Der Konsensuswert wird in manchen Ländern zur Bewertung von Ringversuchen verwendet. Er wird ermittelt, indem zunächst alle für die Bestimmung einer Messgröße mit einem bestimmten Verfahren eingegangenen Messwerte gemittelt werden $(\bar{x})$ und die Standardabweichung (s) errechnet wird. Werte außerhalb $\bar{x} \pm 3$ s werden anschließend als Ausreißer eliminiert. Der Konsensuswert ergibt sich als arithmetisches Mittel der verbliebenen Messwerte. Nachteile des Vorgehens:

- Grundsätzliche Mängel eines bestimmten Verfahrens werden nicht erkannt.

- Allgemeine Nachlässigkeiten bei der Handhabung der Proben werden toleriert (z. B. kein Lichtschutz bei $\triangleright$ Bilirubin-Bestimmung).

\section{Literatur}

Stamm D, Büttner J (1995) Klinisch-chemische Analytik. In: Greiling H, Gressner AM (Hrsg) Lehrbuch der klinischen Chemie und Pathobiochemie. Schattauer Verlag, Stuttgart, S 6-36

\section{Coomassie-Blau-Färbung}

\Coomassie-Färbung

\section{Coomassie-Färbung}

R. Westermeier

Synonym(e) Coomassie-Blau-Färbung

Englischer Begriff coomassie staining
Definition Die Coomassie-Färbung dient dem Nachweis von elektrophoretisch getrennten Proteinzonen und Immunpräzipitaten in Agarose- oder Polyacrylamidgelen. Diese Färbung ist empfindlicher als Amidoschwarz.

Beschreibung Zwei verschiedene Coomassie-Farbstoffe stehen zur Verfügung: Coomassie Brillant Blau R-250 (R für rötlichen Ton) und Coomassie Brillant Blau G-250 (G für grünlichen Ton).

Es gibt verschiedene Varianten der Coomassie-Färbung, die je nach Geltyp und $>$ Elektrophorese-Methode angewendet werden:

- Nach der Agarosegelelektrophorese werden die Proteine im Gel mit einer Säure oder mit Antikörpern (Immunfixation) fixiert. Nach dem mehrmaligen Waschen des Gels wird es vollständig auf seinem Glas- oder Folienträger getrocknet Anschließend erfolgt eine - wegen der dünnen Schicht - schnelle Färbung der Proteinzonen: 5 Minuten in $1,5 \%(\mathrm{~g} / \mathrm{v})$ Coomassie Brillant Blau R-250 in $45 \%$ Methanol $/ 10 \%$ Essigsäure $/ 45 \%$ Wasser. Entfärbt wird mit $25 \%$ Methanol/10 \% Essigsäure/65 \% Wasser.

- Bei Polyacrylamidgelen dauert die Färbung wegen der dicken Gelschicht und der kleinen Poren deutlich länger. Um zu vermeiden, dass bei der Entfärbung des Gelhintergrundes auch die Proteinbanden teilweise entfärbt werden, werden alkoholfreie Methoden oder kolloidale Coomassie-Färbung empfohlen.

- Bei Gelen der isoelektrischen Fokussierung ist insbesondere darauf zu achten, dass vor der Färbung die Trägerampholyten ausgewaschen werden, während die Proteine durch Fixierung im Gel gehalten werden.

\section{Literatur}

Fazekas de St Groth S, Webster RG, Datyner A (1963) Two new staining procedures for quantitative estimation of proteins in electrophoresis strips. Biochim Biophys Acta 71:377-391

Neuhoff V, Arold N, Taube D et al (1988) Improved staining of proteins in polyacrylamide gels including isoelectric focusing gels with clear backgroud at nanogram sensitivity using Coomassie Brilliant Blue G-250 and R-250. Electrophoresis 9:255-262

Coombs-Serum

- Antiglobulinserum 


\section{Copeptin}

W. Hubl

Synonym(e) Carboxy-terminales-pro Arginin Vasopressin (C-terminales proAVP); C-terminaler Teil als Element des Arginin-Vasopressin-Prä-Prohormons (CT-proAVP)

\section{Englischer Begriff copeptin}

Definition Copeptin ist ein Glykopeptid mit 39 Aminosäuren (Molmasse $5 \mathrm{kDa}$ ). Die physiologische Funktion ist noch weitgehend unbekannt. Erhöhte Copeptinwerte wurden bei Patienten mit Sepsis, Herzinsuffifizienz, akutem Myokardinfarkt, chronischer Bronchitis und Pneumonie beobachtet.

Beschreibung Copeptin wird gemeinsam mit dem Vasopressin (Arginin-Vasopressin, Antidiuretisches Hormon, ADH) und dem Neurophysin II aus dem Prohormon PreProvasopressin gebildet. Das Glykopeptid Copeptin stammt dabei vom C-terminalen Teil des Prohormons.

Im Gegensatz zum Vasopressin, das sehr instabil ist, wodurch die diagnostische Relevanz in der klinischen Routinepraxis eingeschränkt ist, ist Copeptin im Blut über mehrere Tage stabil. Aus diesem Grund wird Copeptin als mögliche Alternative zum Vasopressin (Surrogatmarker) bei zahlreichen Erkrankungen, wie Polyurie, Diabetes insipidus, septischer Schock etc., untersucht.

Bei Patienten mit akutem Myokardinfarkt deuten die Resultate auf einen unabhängigen prognostischen Marker des Copeptins neben dem BNP ( $\triangleright$ brain natriuretic peptide) bzw. NTproBNP hin, insbesondere zur Risikostratifizierung der Patienten. Bei Herzinsuffizienz wurden erhöhte Copeptinwerte beobachtet. Bei Patienten mit einer akuten Exazerbation der chronisch obstruktiven Lungenerkrankung lieferte Copeptin ebenfalls prognostische Hinweise insbesondere hinsichtlich einer Hospitalisation. Differenzierung zwischen einem zentralem Diabetes insipidus totalis (Copeptin $<4,9$ $\mathrm{pmol} / \mathrm{l}$ ) und einem renalen Diabetes insipidus (Copeptin $>21,4$ pmol/1). Deutlich ansteigende Copeptinkonzentrationen zeigten den zunehmenden Schweregrad einer Sepsis ( $\triangleright$ Sepsiskenngrößen) bei Patienten mit Pneumonie an. Insgesamt deuten die Ergebnisse der Copeptin-Studien darauf hin, dass dieser Parameter auf Intensivstationen eine diagnostische Relevanz erlangt.

\section{Literatur}

Khan SQ, Dhillon OS, O'Brien RJ et al (2007) C-terminal provasopressin (Copeptin) as a novel and prognostic marker in acute myocardial infarction. Leicester Acute Myocardial Infarction Peptide (LAMP) Study. Circulation 115:2103-2110

Morgenthaler N, Struck J, Alonso C, Bergmann A (2006) Assay for the measurement of copeptin, a stable peptide derived from the precursor of Vasopressin. Clin Chem 52:112-119

Timper K, Fenske W, Kühn F et al (2015) Diagnostic accuracy of copeptin in the differential diagnosis of the polyuria-polydipsia syndrome: a prospective multicenter study. J Clin Endocrinol Metab 100:2268-2274

\section{Coproporphyrin}

- Porphyrine

\section{Coproporphyrinogen:oxygen oxidoreduktase}

- Koproporphyrinogenoxidase

\section{Coqueo}

- Kokakauen vs. Kokainkonsum

\section{Cori, Gerty Theresa und Carl Ferdinand}

\section{H. Fiedler}

Lebensdaten Gerty Theresa Cori (geb. Radnitz), böhmischamerikanische Biochemikerin, geboren 1896 in Prag, gestorben 1957 in St. Louis/Missouri; Carl Ferdinand Cori, böhmisch-amerikanischer Arzt und Physiologe, geboren 1896 in Prag, gestorben 1984 in Cambridge/Massachusetts.

Verdienste Beide Coris begannen im Jahr 1914 das Medizinstudium an der deutschen Carl-Ferdinand-Universität in Prag und heirateten 1920. Gemeinsame Promotion über Komplementfaktoren. Nach 2 Jahren in Wien und Graz gingen beide an das New York State Institute for the Study of Malignant Diseases. Gemeinsame Forschung wurde dort abgelehnt. Ab 1931 leitete Carl die Pharmakologische Abteilung an der Washington University School of Medicine in St. Louis. Gerty durfte nur als unterbezahlte Assistentin in der Biochemie arbeiten, wo sie erst nach dem Wechsel von Carl in die Biochemie eine Professur bekam. Dazu beigetragen hat zweifellos auch die Verleihung des Nobelpreises (1947), den beide Coris zusammen mit Bernardo Alberto 
Houssay (1887-1971, argentinischer Physiologe, Wachstumshormon im Glukosestoffwechsel) erhielten. Gerty Cori ist die erste weibliche Trägerin des Nobelpreises für Medizin. Im selben Jahr erkrankte Gerty Cori an Myelofibrose, setzte aber ihre Arbeit unvermindert bis zu ihrem Tod fort. Nach seiner Emeritierung 1966 wurde Carl Cori Honorarprofessor an der Harvard Medical School und forschte über Mutationen der Glukose-6-Phosphatase (Von-Gierke-Glykogenose).

Forschungsschwerpunkte waren Untersuchungen $\mathrm{zu}$ Struktur, Synthese und Abbau von $>$ Glykogen und Isolierung, Kristallisation und kinetische Charakterisierung der beteiligten Enzyme. Erstbeschreibung des Glukose-1Phosphats (sog. Cori-Ester) als Schlüsselmetabolit im Glykogenstoffwechsel. Entdeckung des Cori-Zyklus als Verbindung zwischen Skelettmuskel und Leber. Weitere gemeinsame Forschungen haben die Pathogenese von Glykogenosen aufgeklärt: Die Glykogenspeicherkrankheit Typ III (Cori- bzw. Forbes-Krankheit) beruht auf der insuffizienten > Amylo-1,6-Glukosidase (,debrancher enzyme“, von den Coris entdeckt). J.C. Pompe beschrieb 1932 eine infantile tödliche Krankheit, die 1954 von G. Cori als Glykogenspeicherkrankheit Typ II erkannt und 1965 von H.G. Hers als Glykogenose mit Insuffizienz der lysosomalen $\alpha-1,4-G l u k o s i d a s e ~ e r k a n n t$ wurde.

\section{Literatur}

Cori CF (1969) The call of science. Annu Rev Biochem 38:1-21

Sentner CP, Hoogeveen IJ, Weinstein DA et al (2016) Glycogen storage disease type III; diagnosis, genotype, management, clinical course and outcome. J Inherit Metab Dis 39:697-704

\section{Corpus-Iuteum-Hormon}

$>$ Progesteron

\section{Corrinoide}

- Vitamin $\mathrm{B}_{12}$

\section{Corticosteroide}

Kortikosteroide

\section{Corticotropin-freisetzendes Hormon}

Kortikotropin-Releasing-Hormon

Corticotropin-Releasing Factor (CRF)

Kortikotropin-Releasing-Hormon

\section{Corticotropin-Releasing-Factor-Test}

CRH-Test

\section{Corticotropin-Releasing-Hormon-Test}

- CRH-Test

\section{Cortine}

Kortikosteroide

\section{Cortisol-Tagesprofil}

Kortisol-Tagesprofil

\section{Corynebacterium diphtheriae}

W. Stöcker

\section{Englischer Begriff Diphtheria}

Beschreibung des Erregers Corynebacterium diphtheriae ist ein grampositives, fakultativ anaerobes, keulenförmiges Stäbchenbakterium aus der Ordnung der Actinomycetales. Es ist unbeweglich und bildet weder Kapsel noch Sporen. Gegenüber Umwelteinflüssen ist $C$. diphtheriae relativ resistent, kann aber durch Erhitzen und Desinfektionsmittel rasch abgetötet werden.

Die Virulenz von $C$. diphtheriae wird durch das sehr potente, aus 2 Polypeptidketten A und B bestehende Diph- 
therietoxin $\left(\mathrm{LD}_{50} 0,3 \mu \mathrm{g} / \mathrm{kg}\right)$ verursacht. Da die genetische Information zur Synthese dieses Exotoxins von dem Prophagen $\beta$ kodiert wird, sind nur solche $C$.-diphtheriae-Stämme toxigen, die mit diesem infiziert sind. Das Diphtherietoxin bewirkt die Inaktivierung des eukaryontischen Elongationsfaktors EF2. Dies hat die Hemmung der Proteinbiosynthese und den Tod der infizierten Zellen zur Folge.

Erkrankungen Diphtherie ist eine weltweit vorkommende Infektionskrankheit, die in vielen Entwicklungsländern und Russland noch immer endemisch ist und daher nicht aus dem Blick geraten darf, in Mitteleuropa aber nur noch vereinzelt auftritt. Ein Erkrankungsrisiko besteht für Personen mit fehlendem oder ungenügendem Impfschutz (in Deutschland ca. $50 \%$ der Erwachsenen). Der Erreger befällt ausschließlich den Menschen und wird bei pharyngealem Befall durch Tröpfcheninfektion und bei Hautdiphtherie überwiegend durch Schmierinfektion übertragen.

Meist beginnt die Erkrankung nach einer Inkubationszeit von 2-5 Tagen mit allgemeinem Krankheitsgefühl, Fieber, Hals-, Leib- und Gliederschmerzen, es folgen Pharyngitis, Laryngitis und Tonsillitis mit Pseudomembranen aus Fibrin, Leukozyten, Zellresten und Keimen. Charakteristisch sind

- süßlicher Mundgeruch,

- bellender Husten mit Stridor,

- Heiserkeit,

- Atemnot,

- Gaumensegelparese und

- Lymphknotenschwellungen.

Weitere lokale Manifestationsarten sind die Nasen-, Wund-, Haut- und Bindehautdiphtherie. Bei allen Formen kann es im weiteren Verlauf zu einer systemischen Intoxikation und damit zu lebensgefährlichen Organschädigungen kommen. Mögliche Spätfolgen sind

- Myokarditis,

- Leber- und Nierenfunktionsstörungen und

- Lähmungen im Bereich der motorischen Hirnnerven.

Im Fall einer klinischen Verdachtsdiagnose wird Personen mit fehlendem oder ungewissem Impfschutz sofort Diphtherieantitoxin verabreicht. Unterstützend wirkt eine antibiotische Therapie mit Penicillin oder einem Makrolid. Verläufe mit Komplikationen können weitere Interventionen erfordern, z. B. Intubation oder Entfernung der die Atemwege verlegenden Pseudomembranen. Die Prophylaxe besteht in einer aktiven Immunisierung mit einem Toxoidimpfstoff. Gemäß Infektionsschutzgesetz sind der Krankheitsverdacht, die Erkrankung und der Tod an Diphtherie sowie der direkte oder indirekte Nachweis toxinbildender Diphtheriebakterien meldepflichtig.
Analytik Mikroskopische Präparate von C. diphtheriae zeigen grampositive, keulenförmige Stäbchen mit charakteristischer V- oder Y-förmiger Lagerung. Die endständigen Polkörperchen werden in der Neisser-Färbung als schwarzblaue Granula sichtbar.

Die Anzucht von C. diphtheriae erfolgt auf eiweißhaltigen Nährböden (Blutagar, Löffler-Serum-Agar) und tellurithaltigen Selektivmedien (Tindsdale-Agar, Clauberg-III-Agar) unter aeroben Bedingungen mit 5-10\%iger $\mathrm{CO}_{2}$-Begasung bei $37{ }^{\circ} \mathrm{C}$. Verdächtig sind gräuliche Kolonien mit evtl. schwachem Hämolysehof auf Blutagar sowie schwarze Kolonien mit blauem Hof auf Telluritböden. Zeigen diese das typische Bild im mikroskopischen Präparat, werden Subkulturen angelegt (Blutagar, Löffler-Medium). Die endgültige Identifizierung beruht auf biochemischen Merkmalen (Katalase positiv, Urease negativ, Glukosefermentation positiv, Saccharosefermentation negativ, Nitratreduktion positiv). Die Fähigkeit isolierter Stämme zur Toxinbildung wird mit dem Elek-Ouchterlony-Immundiffusionstest oder durch den Nachweis des Toxingens mittels $>$ PCR (Polymerase-Kettenreaktion) geprüft.

Zur Bestimmung spezifischer Antikörper gegen das Diphtherietoxin setzt man die indirekte Immunfluoreszenz ( $\vee \mathrm{Im}$ munfluoreszenz, indirekte), \ Enzymimmunoassay, \ Neutralisationstest oder Hämagglutinationstests ein.

Untersuchungsmaterial - Probenstabilität Direktnachweis und Kultur: Untersucht werden Abstriche (von unterhalb der Pseudomembranen) von Rachen, Tonsillen, Nasenschleimhaut. Das Material sollte bis zur Weiterverarbeitung bei $+4{ }^{\circ} \mathrm{C}$ bis $+8^{\circ} \mathrm{C}$ aufbewahrt werden. Direktnachweise sind innerhalb von 24 Stunden durchzuführen, Kulturen innerhalb von 6 Stunden anzulegen. Bei längerer Transportzeit ist das Material einzufrieren.

Serologie: Serum oder Plasma für den Nachweis der Antikörper sind bei $+4{ }^{\circ} \mathrm{C}$ bis zu 2 Wochen lang beständig, bei $-20^{\circ} \mathrm{C}$ über Monate und Jahre hinweg. Zur Tiefkühlkonservierung des IgM kann man den Proben 80 \% gepuffertes Glyzerin beifügen.

Diagnostische Wertigkeit $C$. diphtheriae kann mikroskopisch nicht eindeutig von anderen, apathogenen Corynebakterien unterschieden werden. Vielmehr müssen verdächtige Kolonien in Reinkultur isoliert, identifiziert und auf Toxinproduktion geprüft werden. Für den Beweis einer akuten Diphtherie ist allein der positive Toxinnachweis ausschlaggebend. Die quantitative Bestimmung von Antikörpern gegen das Diphtherietoxin hat seine Priorität bei epidemiologischen Fragestellungen sowie bei der Überprüfung der Immunitätslage bzw. des Impfstatus.

In der Differenzialdiagnostik sind unter anderem abzugrenzen: 
- Infektiöse Mononukleose

- Angina Plaut-Vincenti

- Streptokokken-Angina

- Virusinduzierte Pharyngitis

- Mumps

\section{Literatur}

Darai G, Handermann M, Sonntag HG, Tidona CA, Zöller L (Hrsg) (2009) Lexikon der Infektionskrankheiten des Menschen, 3. Aufl Springer, Berlin, S 189-192

Köhler W, Eggers HJ, Fleischer B, Marre R, Pfister H, Pulverer G (Hrsg) (2001) Medizinische Mikrobiologie, 8. Aufl. Urban \& Fischer Verlag, München, S 383-387

\section{COSMIC-Datenbank}

\section{J. Arnemann}

Synonym(e) Tumor-Mutationsdatenbank

\section{Englischer Begriff COSMIC database}

Definition Die COSMIC-Datenbank (Catalogue Of Somatic Mutations In Cancer; http://cancer.sanger.ac.uk/cosmic) ist weltweit eine der größten Datenbanken, um den Zusammmenhang von somatischen Mutationen und Tumorerkrankungen abzubilden.

Beschreibung Die COSMIC-Datenbank ist eine zentrale Referenzstelle, um spezifische somatische Mutationen mit dem klinischen Bild der Tumorerkrankungen in Verbindung zu bringen.

Die Suchalgorithmen können Gen, spezifische Mutation, Typ des Tumors, chromosomale Region bzw. Abschnitt in der Sequenz des humanen Genoms umfassen. Für die Praxis ist es von großer Bedeutung, die für verschiedene Tumorentitäten bekannten Hot-Spot-Mutationen gezielt zu testen und mögliche therapeutische Ansätze zu finden.

\section{Literatur}

http://cancer.sanger.ac.uk/cosmic

\section{COST3}

> York-Antigen

\section{Cotinin}

- Tabak-Alkaloide

\section{Coulomb-Potenzial}

Zetapotenzial

Coulometrie

T. Arndt

Englischer Begriff coulometry

Definition Elektrochemische Analysenmethode auf der Basis der Messung von für die Elektrolyse einer Substanz benötigten Ladungsmengen.

Beschreibung Die theoretische Grundlage der Coulometrie sind die Faradayschen Gesetze. So besteht bei Elektrolysen, die quantitativ (vollständig) und eindeutig ablaufen, ein einfacher Zusammenhang zwischen der Menge der freigesetzten oder abgeschiedenen Substanz $(\mathrm{m})$ und der dazu benötigten Elektrizitätsmenge $(\mathrm{Q}=$ Stromfluss $\mathrm{I} \times$ Zeit $\mathrm{t})$, den das 1 . Faradaysche Gesetz beschreibt:

$$
\mathrm{m}=\mathrm{k} \times \mathrm{I} \times \mathrm{t}=\mathrm{k} \times \mathrm{Q}
$$

Unter Hinzunahme des 2. Faradayschen Gesetzes, nach dem gleiche Elektrizitätsmengen verschiedene Stoffe mit der molaren Masse (M) im Verhältnis ihrer Äquivalente (der elektrochemischen Wertigkeit z) abscheiden, ergibt sich mit

$$
\mathrm{m}=\frac{\mathrm{M} \times \mathrm{Q}}{\mathrm{z} \times \mathrm{F}}
$$

$(\mathrm{F}=$ Faraday-Konstante $)$ ein Zusammenhang, der zur quantitativen Bestimmung von reduzier- oder oxidierbaren anorganischen sowie von polarographisch aktiven organischen Substanzen genutzt werden kann.

Der Aufbau der Elektrolysezellen muss dem jeweiligen analytischen Problem angepasst werden. Man unterscheidet Drei- und Vierelektrodenzellen für die coulometrische Analyse (potentiostatische Coulometrie) und die coulometrische Titration (galvanostatische Coulometrie), wobei Anoden- und Kathodenraum, das heißt Gegen- und Arbeitselektroden, durch ein $\triangleright$ Diaphragma getrennt werden. Dieses verhindert, dass die Elektrolyseprodukte an die Gegenelektrode diffundieren. 
Eine klassische Anwendung der coulometrischen $>$ Titration ist die Bestimmung von Chloridionen $\left(\mathrm{Cl}^{-}\right)$einer Lösung. Dabei werden durch Elektrolyse, das heißt unter Stromverbrauch, Silberionen $\left(\mathrm{Ag}^{+}\right)$aus einer Silberelektrode (Arbeitselektrode, auch als Opferelektrode bezeichnet, da sie ,aufgebraucht“ oder ,geopfert“ wird) herausgelöst. Diese verbinden sich unmittelbar mit den Chloridionen und fallen als $\mathrm{AgCl}$ aus. Sobald überflüssige Silberionen in der Lösung vorliegen, steigt deren Leitfähigkeit an, was über die Gegenelektrode registriert wird und zum Abbruch der Elektrolyse führt. Die bis zu diesem Zeitpunkt verbrauchte Strommenge ist nach o. g. Gesetzen der Silberionenmenge und über den stöchiometrischen Zusammenhang der AgCl-Fällungsreaktion der Chloridionenkonzentration proportional. Neben dieser Fällungstitration kommen auch Komplexbildungs-, Säure-Basen- und Redoxtitrationen zum Einsatz. Die Coulometrie hat im klinisch-chemischen Labor nur für Spezialanalysen Bedeutung.

\section{Literatur}

Latscha HP, Linti GW, Klein HA (2004) Analytische chemie chemiebasiswissen III. Springer, Berlin/Heidelberg/New York

\section{Coulter-Prinzip der Zellzählung}

H. Baum

Synonym(e) Impedanzmessverfahren; Widerstandsmessprinzip

Englischer Begriff Coulter principle

Definition Automatisierte Zellzählung durch Messung einer Widerstandsänderung beim Durchtritt der Zelle durch eine Kapillare in einer elektrisch leitenden Flüssigkeit.

Beschreibung Methode zur Zellzählung in einer Suspension, die in den 1940er-Jahren von Wallace H. Coulter ( $\triangleright$ Coulter, Wallace H.) entwickelt wurde. Die zellulären Bestandteile des Bluts sind elektrische Nichtleiter. Werden sie in einer elektrisch leitenden Flüssigkeit verdünnt und diese Suspension durch eine Kapillare geleitet, durch die ein konstanter elektrischer Strom fließt, ändert sich beim Durchtritt einer Zelle der elektrische Widerstand. Die Widerstandsänderung ist dabei gleichzeitig proportional zur Größe der durchtretenden Zelle. Somit können simultan die Konzentration (Zahl) der Zellen in der Lösung und das Volumen der Einzelzellen bestimmt werden.

\section{Literatur}

Seeger HT, Poppy U (1991) Zellzähl- und Differenziergeräte. In: Boll I, Heller S (Hrsg) Praktische Blutzelldiagnostik. Springer, Berlin/Heidelberg/New York, S 115-161

\section{Coulter, Wallace $\mathrm{H}$.}

H. Baum

Lebensdaten Amerikanischer Elektroingenieur, Erfinder und Geschäftsmann, geboren 17. Februar 1913 in Little Rock, Arkansas, gestorben am 07. August 1998 in Fullerton, Kalifornien.

Verdienste Wallace H. Coulter entwickelte eine automatische, elektronische Zählmethode für suspendierte mikroskopische Partikel, die auch zur Blutzellzählung verwendet werden kann. Dieses nach ihm benannte Coulter-Prinzip ( $>$ Coulter-Prinzip der Zellzählung) basiert auf der Messung der Widerstandsänderung zwischen 2 Elektroden beim Durchtritt eines Partikels oder Blutzelle durch eine Kapillare im elektrischen Feld.

Zusammen mit seinem Bruder Joseph Gründer der Coulter Corporation. Wallace H. Coulter erhielt für seine Entwicklungen auf dem Gebiet der Zellzählung zahlreiche Preise.

\section{Literatur}

www.whcf.org/

\section{Coxsackie-Viren}

W. Stöcker

Englischer Begriff human coxsackie virus A/B

Beschreibung des Erregers Unbehüllte Einzelstrang-RNAViren, ikosaedrale Form, Durchmesser ca. 30 nm, hitzelabil, Inaktivierung mit $0,1 \mathrm{~N} \mathrm{HCl}$ oder $0,3 \%$ Formaldehyd. Hohe Umweltresistenz.

Coxsackie-Viren repräsentieren eine Vielzahl verschiedener, keine Kreuzimmunität aufweisender Serotypen des Genus humane Enteroviren. Sie gehören zur Familie der Picornaviridae. 
Erkrankungen Die Infektionen verlaufen überwiegend (90-95 \%) asymptomatisch. Manifestation als Sommergrippe, Pneumonie, Diarrhoe, Enzephalitis, aseptische Meningitis, Hepatitis, Myokarditis, Perikarditis, Pleurodynie (Morbus Bornholm), Gingivo-Stomatitis, Exanthem (HandFuß-Mund-Krankheit), Konjunktivitis, fetale Schädigung.

Übertragung Fäkal-oral, aerogen (Tröpfchen, Mund-zuMund-Kontakt, kontaminiertes Trinkwasser, kontaminierte Meeresfrüchte) und diaplazentar. Männer sind doppelt so häufig betroffen wie Frauen, Kleinkinder häufiger als Erwachsene. Erhebliche Weiterverbreitung durch Ausscheidungen asymptomatisch Infizierter.

Inkubationszeit Im Mittel 7-14 Tage, weltweites Vorkommen.

Therapie und Prophylaxe Symptomatisch; antivirale Medikamente und Impfstoffe sind noch nicht verfügbar.

Analytik Kultur: Einige Coxsackie-A-Viren sind nur in neugeborenen Mäusen kultivierbar, andere in primären Affennierenzellen bzw. in RD- oder SKCO-1-Zellen. Die Kultivierung von Coxsackie-B-Viren ist in HEp-2- bzw. HeLa-Zellen sowie in primären Affennierenzellen problemlos möglich.

Direktnachweis: In erster Linie mittels PCR $(\triangleright$ PCR, quantitative in Echtzeit), im Forschungsbereich auch mittels cDNA-Sonden. Antigen-ELISA-Tests sind zu insensitiv und erfordern eine vorausgehende Virusanreicherung. Erregertypisierung über definierte $>$ Antikörper.

Serologie: Indirekte Immunfluoreszenz $(\triangleright$ Immunfluoreszenz, indirekte), $\triangleright$ Neutralisationstest, ELISA ( Enzymelinked Immunosorbent Assay) und Komplementbindungsreaktion. Letztere sollte wegen massiver $\triangleright$ Kreuzreaktivität mit anderen Enteroviren und eingeschränkter Sensitivität nicht mehr zur Serodiagnostik von Enteroviren eingesetzt werden. Bei Verwendung von Antigenlysaten sind auch bei ELISA immunologische Kreuzreaktionen zu beobachten, weshalb hier die Bestimmung gruppenspezifischer Antikörper im Mittelpunkt steht. Kreuzreaktionen werden z. T. auch im Neutralisationstest beobachtet (A3 mit A8, A11 mit A15, A13 mit A18). Zum serologischen Beweis einer frischen Infektion ist ein signifikanter Anstieg der Konzentration erregerspezifischer IgG-Antikörper innerhalb von 7-14 Tagen oder der Nachweis spezifischer IgM-Antikörper erforderlich.

Untersuchungsmaterial - Entnahmebedingungen - Probenstabilität Direktnachweis und Kultur: Untersucht werden Stuhl, Rachen-, Rektal- und Konjunktivalabstriche, Blut, Liquor und Bläschensekret oder Biopsien. Das Material sollte bis zur Weiterverarbeitung bei +4 bis $+8^{\circ} \mathrm{C}$ aufbewahrt werden. Direktnachweise sind innerhalb von 24 Stunden durchzuführen, Kulturen innerhalb von 6 Stunden anzulegen. Bei längerer Transportzeit ist das Material einzufrieren.
Serologie: Serum oder Plasma für den Nachweis der Antikörper sind bei $+4{ }^{\circ} \mathrm{C}$ bis zu 2 Wochen lang beständig, bei $-20^{\circ} \mathrm{C}$ über Monate und Jahre hinweg. Zur Tiefkühlkonservierung des IgM kann man den Proben 80 \% gepuffertes Glycerin beifügen.

Diagnostische Wertigkeit Wesentliche Bedeutung hat der Erregernachweis mittels PCR oder Kultur. In der Serologie wird dem Nachweis neutralisierender Antikörper ebenfalls Bedeutung beigemessen. Der Nutzen der Serologie ist aufgrund hoher Durchseuchungsraten und massiver Kreuzreaktivitäten zwischen den verschiedenen Serotypen eingeschränkt. Der signifikante Anstieg spezifischer Antikörpertiter innerhalb 2 Wochen beweist eine frische Infektion.

\section{Literatur}

Pallansch M, Roo R (2007) Enteroviruses: polioviruses, coxsackieviruses, echoviruses and newer enteroviruses. In: Knipe DM et al (Hrsg) Fields virology, Bd 1, 5. Aufl. Wolters Kluwer Lippincott Williams \& Wilkins, Philadelphia, S 2839-2893

Zeichhardt H, Grunert HP (2003) Enteroviruses: polioviruses, coxsackieviruses, echoviruses and enteroviruses. In: Cohen I, Powderly WG, Opal SM (Hrsg) Infectious diseases, Bd 213, 2. Aufl. Elsevier Health Sciences, London, S 1993-2006

\section{$\mathrm{Cp}$}

$\checkmark$ Coeruloplasmin

\section{C-Peptid}

M. Bidlingmaier

Englischer Begriff C-peptide; connecting peptide

Definition Während der Synthese des Insulins in der $\beta$-Zelle abgespaltenes Peptid, das äquimolar mit Insulin sezerniert wird. Indikator der endogenen Insulinsekretion.

Struktur Peptid mit 31 Aminosäureresten.

Molmasse 3020 Da.

Synthese - Verteilung - Abbau - Elimination C-Peptid entsteht als Nebenprodukt der in mehreren Schritten ablaufenden Synthese und Sekretion von Insulin. In der $\beta$-Zelle wird zunächst das aus der A-Kette, der B-Kette, dem C-Peptid und einer Signalsequenz bestehende Präproinsulin syntheti- 
siert. Nach Translokation in das endoplasmatische Retikulum wird die 24 Aminosäuren lange Signalsequenz abgespalten. Vom Proinsulin (81 Aminosäuren) wird in den Vesikeln des Golgi-Apparats schließlich das C-Peptid abgespalten. Das Insulin (51 Aminosäuren) - bestehend aus den über Disulfidbrücken verbundenen A- und B-Ketten - und das kürzere C-Peptid (31 Aminosäuren) werden äquimolar in die Blutbahn sezerniert. Im Vergleich zum Insulin hat C-Peptid eine längere Halbwertszeit, unterliegt kaum einem hepatischen First-Pass-Effekt und wird bei normaler Nierenfunktion mit konstanter Rate renal eliminiert. Eine eingeschränkte Nierenfunktion kann daher die Konzentrationen des C-Peptids beeinflussen.

\section{Halbwertszeit 20-30 Minuten.}

Pathophysiologie Aufgrund der äquimolaren Sekretion mit Insulin eignet sich C-Peptid als Indikator der endogenen Insulinsekretion. Unter physiologischen Bedingungen bewegen sich die Konzentrationen von Insulin und C-Peptid gleichsinnig. Bei Zufuhr exogenen Insulins hingegen wird die endogenen Insulinsynthese supprimiert, was an der Suppression des C-Peptids erfassbar ist. Ferner wird die Bestimmung eingesetzt, um die Sekretionsreserve der $\beta$-Zelle abzuschätzen. Hierbei werden neben basalen Messungen (nüchtern oder postprandial) vor allem verschiedene physiologische und pharmakologische Stimuli der Insulinsekretion eingesetzt.

Untersuchungsmaterial Plasma (bevorzugt), Serum,(Urin).

Probenstabilität Proben sollten rasch ins Labor gebracht und zentrifugiert werden. Kann die Analyse nicht am selben Tage erfolgen, müssen die Proben eingefroren werden $\left(-20^{\circ} \mathrm{C}\right)$. Eingefroren $\left(-20^{\circ} \mathrm{C}\right)$ mindestens 2 Monate.

Präanalytik Nüchternstatus notieren. EDTA-Plasma wegen besserer Stabilität für die meisten Assays empfohlen. Hämolyse vermeiden. Rasches Zentrifugieren nach Abnahme.

Analytik Immunoassay. Auf die Kreuzreaktion mit Proinsulin ist $\mathrm{zu}$ achten, sie sollte $<10 \%$ sein.

Konventionelle Einheit ng/mL.

Internationale Einheit $\mathrm{nmol} / \mathrm{L}$.

Umrechnungsfaktor zw. konv. u. int. Einheit $1 \mathrm{ng} / \mathrm{mL}=$ $0,333 \mathrm{nmol} / \mathrm{L}$.

Referenzbereich - Erwachsene Die Messergebnisse verschiedener C-Peptidassays unterscheiden sich - trotz internationaler Standardisierungsbemühungen - weiterhin deutlich.
Außerdem unterscheiden sich die Entscheidungsgrenzen bei unterschiedlichen Stimulationstests.

Orientierend gelten:

- Nüchtern (8-12 Stunden Fasten): 0,8-4,2 ng/mL

- Im Hungerversuch (längeres Fasten) $<0,8 \mathrm{ng} / \mathrm{mL}$

\section{Indikation}

- Diagnose des Typ-I-Diabetes

- Abschätzung der Sekretionsreserve der $\beta$-Zelle bei Typ-Iund Typ-II-Diabetes

- Abklärung der nicht diabetesassoziierten Hypoglykämie (Insulinom, exogene Insulinadministration (hypoglycaemia factitia))

Interpretation S. Pathophysiologie und Referenzbereich. Die Interpretation muss unter Berücksichtigung des Nüchternstatus sowie eventueller Stimulations- oder Suppressionsteste erfolgen.

Diagnostische Wertigkeit In vielen Situationen reicht die Bestimmung von Insulin alleine. C-Peptid ist jedoch der zentrale Parameter zum Nachweis eines endogenen Ursprungs der Insulinsekretion. Bei Funktionstests zur Abschätzung der Sekretionsreserve der $\beta$-Zelle empfiehlt die American Diabetes Association (ADA) aufgrund überlegener Spezifität und Sensitivität die Bestimmung von C-Peptid nach Glukagonstimulation und im ,mixed meal tolerance test“ (MMTT).

\section{Literatur}

Leighton E, Sainsbury CA, Jones GC (2017) A practical review of C-peptide testing in diabetes. Diabetes Ther 8(3):475-487

Little RR, Wielgosz RI, Josephs R, Kinumi T, Takatsu A, Li H, Stein D, Burns C (2017) Implementing a reference measurement system for C-peptide: successes and lessons learned. Clin Chem 63(9):1447-1456 Sacks DB, Arnold M, Bakris GL, Bruns DE, Horvath AR, Kirkman MS, Lernmark A, Metzger BE, Nathan DM (2011) Guidelines and recommendations for laboratory analysis in the diagnosis and management of diabetes mellitus. Clin Chem 57(6):e1-e47

CpG-Island

J. Arnemann

Synonym(e) Methylierungs-Hotspot

Englischer Begriff $\mathrm{CpG}$ island 
Definition CpG-Insel steht für die Reihenfolge der Basen $5^{\prime}-$ Cytosin $(\mathrm{C})$ - Phosphatrest (p) - Guanin $(\mathrm{G})-3^{\prime}$ in einem DNA-Strang, wobei das Cytosin in der CpG-Insel bevorzugt durch eine DNA-Methyltransferase in ein 5-Methylcytosin überführt werden kann, während die Kombination GpCNukleotide davon nicht betroffen ist.

Beschreibung Wenn CpG-Dinukleotide statistisch gehäuft vorliegen, so spricht man von CpG-Inseln im engeren Sinn. CpGs finden sich bevorzugt in den an Guanin und CytosinNukleotiden (G/C-reich) reichen Promotorbereichen von Genen. An diese $\mathrm{G} / \mathrm{C}$-reichen, meist weniger als $1 \mathrm{~kb}$ langen Abschnitte binden Transkriptionsfaktoren, wie z. B. der Sp1-Transkriptionsfaktor, direkt in einer Protein-DNAInteraktion und starten die Transkription bzw. Expression des nachfolgenden Genes. Die Methylierung eines CpGDinukleotids innerhalb dieses Abschnittes inhibiert diese Bindung und damit die Transkription bzw. Expression des nachgelagerten Gens.

Das menschliche Genom hat einen Anteil von $42 \% \mathrm{G} / \mathrm{C}$ Nukleotiden, wobei die Reihenfolge $\mathrm{CpG}$ entgegen der statistischen Erwartung nur mit $1 \%$ statt $4 \%$ vertreten ist. Ein Grund hierfür ist, dass ein Methylcytosin in einer CpG-Insel durch Deaminierung leicht in Thymin mutieren kann. $\mathrm{C}>\mathrm{T}$ Transitionen gehören zu den häufigsten Mutationen im humanen Genom.

Die Methylierung von CpG-Inseln und die Auswirkung auf Expressionsmuster ist auch ein wichtiger Aspekt der Epigenetik (s. a. $>$ Epigenetik).

\section{Literatur}

Deaton AM, Bird A (2011) CpG islands and the regulation of transcription. Genes Dev 25:1010-1022

\section{CpG-Island-Methylator Phenotyp}

J. Arnemann

\section{$\operatorname{Synonym(e)~CIMP~}$}

Englischer Begriff $\mathrm{CpG}$ island methylator phenotype (CIMP)

Definition Der Begriff CpG-Island-Methylator Phenotype (CIMP) wird in Verbindung mit einer Untergruppe von Tumoren benutzt, bei denen eine tumorspezifische Methylierung von Promotorbereichen auftritt.
Beschreibung Die aberrante Methylierung von Promotorbereichen definierter Gene werden oftmals als tumorspezifische Biomarker gelistet. Die pathogene Hypermethylierung ist oftmals die Folge einer aberrant erhöhten und gestörten Expression von DNA-Methyltransferasen (DNMTs) und/oder einer Anreicherung von DNA-Schäden. Als Folge der Hypermethylierung werden die betroffenen Gene inaktiviert. Dieses Muster eines pathogenen Genfunktionsausfall aufgrund einer Promotorhypermethylierung wird als CpG-Island-Methylator Phenotyp (CIMP) definiert. Der Nachweis von CIMPMarkern in klinisch diagnostischen Tests ist mit einer eher ungünstigen Prognose für den Patienten korreliert.

\section{Literatur}

Hughes et al (2013) The CpG Island methylator phenotype: What's in a Name? Cancer Res 73:5858-5868

\section{CPOX}

Koproporphyrinogenoxidase

\section{CPPD-Kristalle}

- Calciumpyrophosphatdihydrat-Kristalle

\section{C2-Proben}

C2-Monitoring

\section{CPSA}

- Potenziometrische Strippinganalyse

- Prostataspezifisches Antigen, komplexiertes

\section{CP-Substanzen}

$\checkmark$ Spice

\section{CPT}

- Carnitin-Palmitoyl-Transferase 


\section{CPX}

Koproporphyrinogenoxidase

\section{C1q-Antikörper}

- Autoantikörper gegen $\mathrm{C} 1 \mathrm{q}$

\section{C1q-Bindungstest}

> Immunkomplexe

\section{CRAB-Kriterien}

A. M. Gressner und O. A. Gressner

Synonym(e) Labordiagnostische Kriterien des Multiplen Myeloms

Englischer Begriff labordiagnostic criteria for multiple myeloma

Definition Von der International Myeloma Working Group (IMWG) 2014 publizierte labormedizinische Diagnosekriterien für das (a)symptomatische Multiple Myelom.

Beschreibung Die von der IMWG 2014 erweiterten Diagnosekriterien schließen neu definierte Biomarker ein, die es möglich machen sollen, bisher nicht erfasste, asymptomatische Myelom-Patienten mit hohem Progressionsrisiko bereits in einem Frühstadium zu erfassen und damit einer aktuellen Therapie zuzuführen (Rajkumar et al. 2014). Hierzu wurden CRAB-Kriterien $(\mathrm{C}$, erhöhtes Calcium im Blut; $\mathrm{R}$, renale Funktionsstörungen; A, Anämie; B, Knochen(bone)-Beteiligung) und einige neue Biomarker definiert (s. unten).

Definition des (a)symptomatischen Multiplen Myeloms nach den aktuellen IMWG-Kriterien (Gerecke et al. 2016):

1. Klonale Plasmazellen im Knochenmark $>10 \%$ oder ein durch Biopsie bestätigtes Plasmozytom des Knochens oder einer extramedullären Manifestation und eines der folgenden CRAB-Kriterien

2. CRAB-Kriterien
- Hypercalcämie: Serum-Calcium $>0,25 \mathrm{mmol} / \mathrm{L}$ oberhalb des oberen Referenzbereiches oder $>2,75 \mathrm{mmol} / \mathrm{L}$ $(>11 \mathrm{mg} / \mathrm{dL})$

- Niereninsuffizienz: glomeruläre Filtrationsrate (GFR) $<40 \mathrm{~mL} /$ min oder Serum-Kreatinin $>177 \mu \mathrm{mol} / \mathrm{L}$

- Anämie: $>2,0 \mathrm{~g} / \mathrm{dL}$ unterhalb des unteren Referenzbereiches oder $<10 \mathrm{~g} / \mathrm{dL}$

- Knochenläsionen: $>1$ Läsion mittels Röntgenaufnahme, Computer- oder Positronenemmissionstomographie

3. Biomarker

- Klonale Plasmazellen im Knochenmark >60 \%

- Verhältnis involvierter/nicht involvierter freier Leichtketten $>100$

- >1 fokale Läsion in der Bildgebung der Magnetresonanztomographie (MRT) $>5 \mathrm{~mm}$

\section{Literatur}

Gerecke C, Fuhrmann S, Strifler S et al (2016) Diagnostik und Therapie des multiplen Myeloms. Dtsch Ärztebl 113(27-28):470-476

Rajkumar SV, Dimopoulos MA, Palumbo A et al (2014) International myeloma working group updated criteria for the diagnosis of multiple myeloma. Lancet Oncol 15:538-548

\section{Crack}

T. Arndt

Definition Straßenname/Deckname für ein Kokainprodukt ( $\vee$ Straßennamen von Drogen: Kokain).

\section{${ }^{51} \mathrm{Cr}$-Albumin-Test}

R. Tauber und F. H. Perschel

\section{Englischer Begriff ${ }^{51} \mathrm{Cr}$ albumin-test}

Definition Funktionstest zum Nachweis eines enteralen Albuminverluste in den Darm, der wegen der mit seiner Durchführung verbundenen radioaktiven Belastung nur selten durchgeführt wird.

Durchführung Zahlreiche Dünndarmerkrankungen führen zu einem Verlust von $>$ Albumin durch die Darmmukosa in das Darmlumen. Der quantitative Nachweis eines enteralen Albuminverlustes mittels des ${ }^{51} \mathrm{Cr}$-Albumin-Tests beruht auf 
der Unfähigkeit der Enterozyten, Chromsalze zu resorbieren. Nach parenteraler Applikation von ${ }^{51} \mathrm{Cr}$-Albumin verbleibt ${ }^{51} \mathrm{Cr}$, das infolge des enteralen Verlusts von ${ }^{51} \mathrm{Cr}$-Albumin in das Darmlumen gelangt, im Darminhalt und kann durch Aktivitätsmessung im Stuhl quantifiziert werden. Hierzu wird der Stuhl nach parenteraler Applikation einer Dosis von $25 \mu \mathrm{Ci}$

${ }^{51}$ Cr-Albumin über 96 Stunden gesammelt und die Aktivität in Prozent der applizierten Dosis gemessen.

Referenzbereich - Erwachsene Normal ist eine Ausscheidung von weniger als $0,1-0,7 \%$ der applizierten Dosis.

Indikation Verdacht auf exsudative Enteropathie.

Interpretation Heute weitgehend ersetzt durch die $>\alpha_{1}$ Proteinaseinhibitor-Clearance, fäkale.

\section{Literatur}

Krejs GJ, Horica C, Benes I, Blum AL (1975) Modified 51CrChromium-Albumin test for the differential diagnosis of exudative gastropathies and enteropathies. Schweiz Med Wochenschr 105:1135-1137

\section{C-reaktives Protein}

A. M. Gressner und O. A. Gressner

\section{$\operatorname{Synonym(e)~CRP~}$}

\section{Englischer Begriff C-reactive protein}

Definition In den Hepatozyten synthetisiertes Akute-PhaseProtein ( $\triangleright$ Akute-Phase-Proteine), dessen Konzentration im Plasma bei bakteriellen und abakteriellen akuten Entzündungen bis zu 2000-fach ansteigt und deshalb für die Entzündungsdiagnostik und Verlaufskontrolle große Bedeutung hat.

\section{Molmasse $118 \mathrm{kDa}$.}

Synthese - Verteilung - Abbau - Elimination C-reaktives Protein (CRP) wurde im Jahr 1930 von Tillet und Francis im Serum von Patienten im akuten Stadium der Lobärpneumonie aufgrund seiner Eigenschaft entdeckt, C-Polysaccharide der Kapsel von Streptococcus pneumoniae $\mathrm{zu}$ binden und $\mathrm{zu}$ präzipitieren, 1941 wurde CRP identifiziert. Strukturell handelt es sich um ein aus fünf identischen Untereinheiten in Form eines fünfgliedrigen Ringes (zyklische pentamere Symmetrie) zusammengesetztes, unglykosyliertes, nahezu aus- schließlich in den Hepatozyten synthetisiertes Protein der Molmasse $118 \mathrm{kDa}$ mit phylogenetisch weitgehend konservierter Struktur. Chromosomenlokalisation: 1q 21-23. Starke Homologien zur Serum-Amyloid-P-Komponente (SAP), mit dem es in die Gruppe der Pentraxine gehört. Jede der durch Disulfidbrücken verbundenen Untereinheiten (Molmasse $24 \mathrm{kDa}$ ) besitzt 2 funktionelle Regionen:

- zwischen Aminosäuren 51 und 66 ein Bindungsbereich für Phosphorylcholin und

- zwischen Aminosäuren 133 und 147 ein Bindungsbereich für $\mathrm{Ca}^{2+}$.

CRP besitzt elektrophoretische $\gamma$-Globulinmobilität.

Etwa $4 \%$ der normalen peripheren Blutlymphozyten haben CRP an ihrer Oberfläche gebunden ohne es zu synthetisieren.

Die Funktionen resultieren aus seinen Bindungseigenschaften (Abb. 1):

- Calciumabhängig werden negativ geladene Moleküle wie Phosphorylcholin und zahlreiche Polyanionen (z. B. Nukleinsäuren) gebunden

- Calciumabhängige Bindung galaktosereicher Glykoproteine (Galaktane)

- Calciumunabhängige Bindung von Polykationen, z. B. Histone, Chromatin, basische Proteinkomplexe

Aufgrund dieser multiplen Bindungseigenschaften führt CRP nicht nur zur Präzipitation löslicher Liganden, sondern agglutiniert auch partikuläre Liganden, z. B. Bakterien, Viren, Detritus nekrotischer körpereigener Zellen, die somit für die Erkennung und Elimination mittels Phagozytose durch - Makrophagen des retikuloendothelialen Systems (Leber, Milz, Knochenmark) vorbereitet werden (Opsoninfunktion). Ergänzt wird die Opsoninwirkung durch die Eigenschaft des CRP, den klassischen Komplementweg am Clq zu aktivieren.

Halbwertszeit 13-16 Stunden.

Funktion - Pathophysiologie CRP gehört zu den am stärksten reagierenden positiven Akute-Phase-Proteinen, dessen Konzentration im Plasma bis zu 2000-fach durch $>$ Interleukin-6-vermittelte Expressions- und Sekretionssteigerung in den Hepatozyten ansteigen kann. Anstieg erfolgt innerhalb von 4-6 Stunden nach Eintreten bakterieller oder abakterieller Entzündungen.

Untersuchungsmaterial - Entnahmebedingungen Serum, Synovialflüssigkeit, Liquor, Nabelschnurblut.

Probenstabilität Bei $4{ }^{\circ} \mathrm{C}$ bis zu 72 Stunden, bei $-20{ }^{\circ} \mathrm{C}$ 6 Monate, bei $-70{ }^{\circ} \mathrm{C}$ unbeschränkt. 


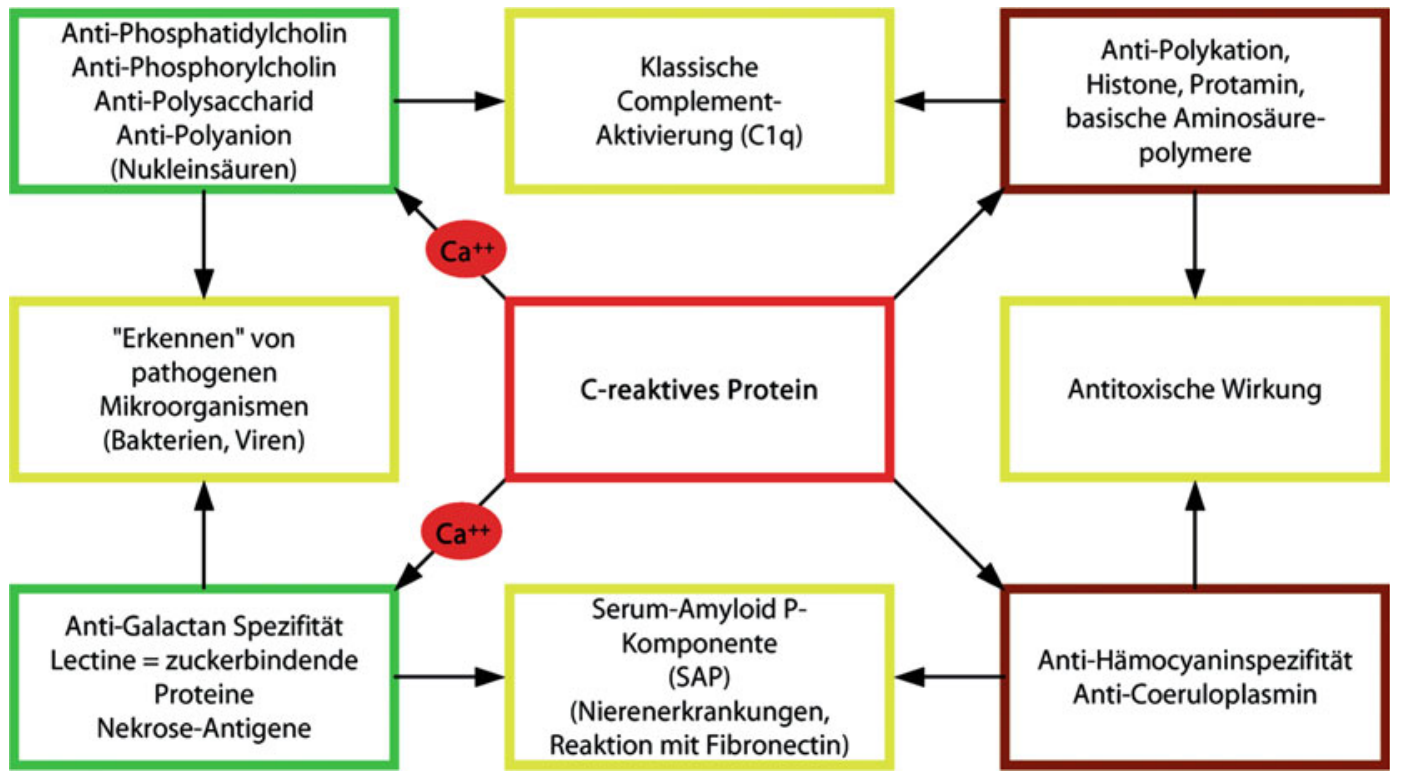

C-reaktives Protein, Abb. 1 Funktionen des C-reaktiven Proteins. (Modifiziert nach: Sölter u. Uhlenbruck 1982)

Lipämie und Hämolyse sind zu vermeiden.

Analytik Immunologische Methoden:

- $>$ Immunnephelometrie

- Immunturbidimetrie

- Radiale Immundiffusion ( $>$ Immundiffusion, radiale nach Mancini, Carbonara und Heremans)

Schnellteste zum Nachweis erhöhter CRP-Konzentrationen:

- Latexagglutinationsteste ( $\triangleright$ Agglutinationstest)

Bestimmung des ultrasensitiven CRP:

- Latexverstärkte Immunnephelometrie

Referenzbereich - Erwachsene $<10 \mathrm{mg} / \mathrm{L}$.

Referenzbereich - Kinder Nabelschnurblut: $<0,35 \mathrm{mg} / \mathrm{L}$.

\section{Indikation}

- Screeningdiagnose und Differenzialdiagnose von organischen im Gegensatz zu funktionellen Erkrankungen

- Bestimmung der Aktivität entzündlicher Erkrankungen

- Diagnose interkurrenter Infektionen bei systemischem Lupus erythematodes, Leukämien und im postoperativem Verlauf

- Diagnose der neonatalen Sepsis und Meningitis

- Bestimmung des Koronarskleroserisikos (ultrasensitives CRP, $>$ C-reaktives Protein, ultrasensitiv)

- Diagnose intrauteriner Infektionen (unter Verwendung von Nabelschnurblut)
Interpretation CRP ist der am häufigsten verwendete Parameter der $>$ Akute-Phase-Reaktion bei allen Formen der septischen und aseptischen, bakteriellen und abakteriellen Entzündung, Gewebenekrosen, Neoplasien und Traumatisierungen. Die folgende Tabelle gibt eine Auswahl von Ursachen für CRP-Erhöhungen im Serum wieder:

\begin{tabular}{|c|c|c|}
\hline \multicolumn{3}{|c|}{ CRP-Erhöhungen im Serum (mg/L) } \\
\hline $\begin{array}{l}\text { Normal/gering } \\
(<10)\end{array}$ & Mäßig (10-100) & Stark $(>100)$ \\
\hline $\begin{array}{l}\text { - Starke } \\
\text { körperliche } \\
\text { Belastung } \\
\text { - Erkältung } \\
\text { - Schwangerschaft } \\
\text { - Angina } \\
\text { - Asthma } \\
\text { - Apoplexie } \\
\text { - Zerebrale } \\
\text { Krampfanfälle }\end{array}$ & $\begin{array}{l}\text { - Myokardinfarkt } \\
\text { - Malignome } \\
\text { - Pankreatitis } \\
\text { - Bronchitis } \\
\text { - Cystitis } \\
\text { - Lupus } \\
\text { erythematodes } \\
\text { (SLE) } \\
\text { - Colitis ulcerosa } \\
\text { - Gicht } \\
\text { - M. Crohn }\end{array}$ & $\begin{array}{l}\text { - Akute bakterielle } \\
\text { Infekte } \\
\text { - Größere Traumata } \\
\text { - Postoperativ } \\
\text { systemische Vaskulitis } \\
\text { - Floride rheumatoide } \\
\text { Arthritis } \\
\text { - Sepsis } \\
\text { (hyperinflammatorische } \\
\text { Phase) }\end{array}$ \\
\hline
\end{tabular}

Aus dem Konzentrationsanstieg lässt sich die Aktivität des entzündlichen Prozesses, aus der Relation zu anderen AkutePhase-Reaktanten, z. B. Haptoglobin, saures $\alpha_{1}$-Glykoprotein, das Entzündungsstadium festlegen. Die kurze Reaktionszeit von 4-6 Stunden wird lediglich durch den Anstieg des Interleukin-6 (Mediator der Akute-Phase-Reaktion) unterboten. Wichtiger Einsatz des CRP in der Differenzialdiagnose funktioneller versus organischer Erkrankungen.

Mit dem „ultrasensitiven CRP“ ( $>$ C-reaktives Protein, ultrasensitiv) werden Konzentrationserhöhungen im Referenzbereich $(<10 \mathrm{mg} / \mathrm{L})$ gemessen, die einen unabhängigen Risikoindikator für die entzündliche Pathogenese der Koronarsklerose darstellen. 
Diagnostische Wertigkeit Bedeutende Kenngröße zur Diagnose und Verlaufskontrolle (Aktivität) aller, vor allem bakteriell bedingter Akute-Phase-Reaktionen (z. B. Entzündungen) und zur Differenzierung funktioneller und organischer Erkrankungen.

\section{Literatur}

Sölter J, Uhlenbruck G (1982) Neue Aspekte des C-reaktiven Proteins. Dtsch Med Wochenschr 107:391-394

Special edition (2009) Clin Chem 55:201-385 (www.clinchem.org)

\section{C-reaktives Protein, ultrasensitiv}

\section{A. M. Gressner und O. A. Gressner}

Synonym(e) CRP, hochsensitiv

Englischer Begriff C-reactive protein, ultrasensitive, high sensitive

Definition Additiver und unabhängiger Risikoindikator der (entzündlichen) Atherogenese (Koronarsklerose), der auf der Konzentrationsmessung des C-reaktiven Proteins ( $\triangleright \mathrm{C}$ reaktives Protein) innerhalb des Referenzbereichs mittels einer hoch (ultra-)sensitiven Methode beruht.

Beschreibung Unter einem ultrasensitiven CRP wird ein Test verstanden, der in der Lage ist, sehr niedrige CRPKonzentrationen (innerhalb des Referenzbereiches) zuverlässig zu messen. Die Empfehlung besteht, dass der hochsensitive CRP-Test bei einer Konzentration von $0,2 \mathrm{mg} / \mathrm{L}$ eine Unpräzision $<10 \%$ aufweisen darf. Messverfahren sind latexverstärkte $>$ Immunturbidimetrie, $>$ Immunnephelometrie und $>$ Chemolumineszenz. Die klinische Bedeutung des ultrasensitiven CRP besteht in der prognostischen Beurteilung von Patienten mit instabiler Angina pectoris als additiver Risikofaktor zu den Hauptrisikoindikatoren Cholesterin, LDL-Cholesterin $(\triangleright$ Low density lipoprotein), Hypertonie und Nikotinabusus. Patienten mit CRP-Konzentrationen im obersten Quintil $(>3,6 \mathrm{mg} / \mathrm{L})$ haben im Vergleich zu solchen im untersten Quintil $(<0,71 \mathrm{mg} / \mathrm{L})$ ein doppelt so hohes Risiko für ein koronares Ereignis, jedoch ist der prädiktive Wert bei Angina pectoris in neueren Untersuchungen wieder relativiert worden. Pathophysiologisch ist die moderate Konzentrationserhöhung als systemischer Ausdruck der inflammatorischen Komponente der Atherogenese (Koronarsklerose) zu interpretieren, wo CRP möglicherweise direkt am atherothrombotischen Prozess beteiligt ist und in atherosklerotischen Gefäßwänden und an Plasmamembranen geschädigter Zellen lokalisiert ist. Es trägt zur Komplementaktivierung über den klassischen Weg bei.

\section{Literatur}

Danseh J et al (2004) C-reactive protein and other circulation markers of inflammation in the prediction of coronary heart disease. N Engl J Med 350:1387-1397

\section{Creatin}

$>$ Kreatin

\section{Creatinin}

- Kreatinin

\section{Creatinkinase}

- Kreatinkinase

\section{Creatinkinase-MB}

- Kreatinkinase-MB

\section{Creatinphosphokinase}

- Kreatinkinase

\section{Creatinphosphokinase Isoenzym MB}

- Kreatinkinase-MB

\section{Cresol(isomere)}

- Kresol(isomere) 


\section{CRF}

- Kortikotropin-Releasing-Hormon

\section{CRF(corticotropin-releasing-factor)-}

Test

$>$ CRH-Test

\section{CRH}

- Kortikotropin-Releasing-Hormon

\section{CRH-Test}

W. Hubl

Synonym(e) Corticotropin-Releasing-Factor-Test; Corticotropin-Releasing-Hormon-Test; CRF(corticotropin-releasingfactor)-Test

Englischer Begriff corticotropin-releasing hormone test

Definition Der CRH-Test dient zur spezifischen Überprüfung der ACTH-Stimulation ( $\triangleright$ ACTH-Test) in der Adenohypophyse.

\section{Durchführung}

- 18-20 Uhr: Legen eines peripheren venösen Zugangs bei Bettruhe des Patienten

- Eine Stunde später erste Blutentnahme (EDTA-Blutröhrchen) zur Bestimmung von ACTH und $>$ Kortisol

- Danach langsame i.v. Injektion von $100 \mu \mathrm{g}$ CRH (bzw. $1 \mu \mathrm{g} / \mathrm{kg} \mathrm{KG})$

- Weitere Blutentnahmen für ACTH und Kortisol nach 15, 30, 45, 60 und 90 Minuten

Fehlerquellen: Eine Glukokortikoidbehandlung des Patienten muss mindestens 24 Stunden zuvor abgesetzt werden. Bei Nichtbeachtung einer ausreichend langen Pause kann eine sekundäre Nebennierenrindeninsuffizienz vorgetäuscht werden.
Untersuchungsmaterial-Entnahmebedingungen EDTAPlasma.

Probenstabilität $\triangleright$ Kortisol und $>$ adrenokortikotropes Hormon.

Präanalytik $>$ Kortisol und $>$ adrenokortikotropes Hormon.

Analytik > Immunoassay, \adrenokortikotropes Hormon und $\triangleright$ Kortisol.

Referenzbereich - Erwachsene Anstieg des ACTH nach CRH-Stimulation auf mindestens $150 \%$.

Anstieg des Kortisols nach CRH-Stimulation um mindestens $200 \mathrm{nmol} / \mathrm{L}$.

Referenzbereich - Kinder Anstieg des ACTH nach CRHStimulation auf mindestens $150 \%$.

Anstieg des Kortisols nach CRH-Stimulation um mindestens $200 \mathrm{nmol} / \mathrm{L}$.

\section{Indikation}

1. Prüfung der Adenohypophyse auf eine ausreichende ACTH-Sekretion. Bei einer Hypophysenvorderlappeninsuffizienz bleibt dieser Anstieg aus

2. Differenzialdiagnose des Cushing-Syndroms:

- Anstieg eines basal bereits erhöhten ACTH bzw. Kortisols: hypophysäres Cushing-Syndrom

- Kein Anstieg des ACTH bzw. Kortisols bei basal erhöhten Werten: ektopes ACTH-Syndrom, zentrales Cushing-Syndrom (Makroadenom)

- Kein Anstieg des basal erniedrigten ACTH bzw. Kortisols: adrenales Cushing-Syndrom (Tumor oder bilaterale mikronoduläre oder makronoduläre Nebennierenrindenhyperplasie)

3. Differenzierung einer sekundären und tertiären Nebennierenrinden-(NNR-)Insuffizienz:

- Ausreichende ACTH-Stimulation: tertiäre (hypothalamische) NNR-Insuffizienz

- Kein ACTH-Anstieg: Hypophysenstörung (kortikotrope Zellen der Hypophyse defekt)

4. Beurteilung des Therapieerfolgs nach einer Operation von Hypophysen- bzw. Nebennierenrindentumoren

5. Einschätzung einer wieder einsetzenden ACTH- und Kortisolsekretion nach iatrogenen Cushing-Syndrom (Glukokortikoidtherapie)

Kontraindikation(en) Überempfindlichkeit gegenüber CRH.

Nebenwirkung(en) Wärmegefühl (Flush-Symptomatik) mit einem leichten Blutdruckabfall. 


\section{Interpretation}

\begin{tabular}{|c|c|c|}
\hline $\begin{array}{l}\text { Basales } \\
\text { ACTH bzw. } \\
\text { Kortisol }\end{array}$ & $\begin{array}{l}\text { ACTH- } \\
\text { Anstieg } \\
\text { nach CRF } \\
(\%)\end{array}$ & Diagnose \\
\hline Niedrig & $<150$ & Hypophysenvorderlappeninsuffizienz \\
\hline Erhöht & $>150$ & Hypophysäres Cushing-Syndrom \\
\hline Erhöht & $<150$ & $\begin{array}{l}\text { Ektopes ACTH-Syndrom, zentrales } \\
\text { Cushing-Syndrom }\end{array}$ \\
\hline Niedrig & $<150$ & Adrenales Cushing-Syndrom \\
\hline Niedrig & $>150$ & $\begin{array}{l}\text { Tertiäre, hypothalamische } \\
\text { NNR-Insuffizienz }\end{array}$ \\
\hline Niedrig & $<150$ & $\begin{array}{l}\text { Sekundäre, hypophysäre } \\
\text { NNR-Insuffizienz }\end{array}$ \\
\hline
\end{tabular}

\section{Literatur}

Mönig H, Harbeck B, Domm C et al (2014) Dynamische Funktionstests in der Endokrinolgie und Diabetologie. In: Lehnert H (Hrsg) Rationelle Diagnostik und Therapie in Endokrinologie, Diabetologie und Stoffwechsel. Thieme-Verlag, Stuttgart, S 642-690

Schäffler A (Hrsg) (2015) Funktionsdiagnostik in Endokrinologie, Diabetologie und Stoffwechsel. Indikation, Testvorbereitung und -durchführung, Interpretation. Springer/GmbH \& Co. K, Berlin/Heidelberg

\section{CRM}

- Referenzmaterial, zertifiziertes

\section{CROM}

Cromer-Blutgruppensystem

\section{Cromer-Blutgruppensystem}

\section{K. Kleesiek, C. Götting, J. Diekmann, J. Dreier und} M. Schmidt

Synonym(e) CROM; DAF; Decay accelerating factor; CD55

Englischer Begriff Cromer blood group system

Definition Der ,decay accelerating factor“ (DAF) ist ein Membranprotein, der das Komplementsystem ( Komplementsystem, alternative Aktivierung; $>$ Komplementsystem, klassische Aktivierung) auf der Zelloberfläche reguliert. Das Protein verhindert die Anlagerung der C3- und C5-Konvertase oder beschleunigt die Auflösung der präformierten Konvertasekomplexe, womit die Bildung des terminalen lytischen Komplexes (,membrane attack complex") verhindert wird. DAF ist die antigene Determinante des Cromer-Blutgruppensystems ( $\downarrow$ Blutgruppensysteme; Tab. 1).

Beschreibung Das 70-kDa-Glykoprotein kommt auf verschiedenen hämatopoietischen und nicht hämatopoietischen Zellen vor ( $\triangleright$ Erythrozyten, \ Leukozyt, \ Thrombozyten, Trophoblasten der Plazenta, endotheliale und epitheliale Gewebe). Die lösliche Form des DAF-Proteins ist in Plasma und Urin nachweisbar. Das Cromer-Antigen besteht aus 319 Aminosäuren und ist über einen Glykosylphosphatidylinositol-(GPI-)Anker an die Zellmembran gebunden. Das Protein trägt aminoterminal 4 Domänen (,,short consensus repeat domains“, SCR 1-4).

Das Cromer-Antigen wird auf Erythrozyten von Patienten mit paroxysmaler nächtlicher Hämoglobinurie Typ III (PNH

Cromer-Blutgruppensystem, Tab. 1 Eigenschaften der Hauptantigene des Cromer-Blutgruppensystems

\begin{tabular}{|c|c|c|c|c|c|c|c|}
\hline \multirow[b]{2}{*}{$\begin{array}{l}\text { CROM- } \\
\text { Antigen }\end{array}$} & \multirow{2}{*}{$\begin{array}{l}\text { ISBT- } \\
\text { Symbol } \\
\text { (Zahl) }\end{array}$} & \multirow[b]{2}{*}{$\begin{array}{l}\text { Antigenfrequenz } \\
(\%)\end{array}$} & \multicolumn{3}{|c|}{ In-vitro-Charakteristika von Alloantikörpern } & \multicolumn{2}{|l|}{$\begin{array}{l}\text { Klinische Signifikanz } \\
\text { von Alloantikörpern }\end{array}$} \\
\hline & & & Immunglobulinklasse & $\begin{array}{l}\text { Optimale } \\
\text { Nachweistechnik }\end{array}$ & Komplementbindung & Transfusionsreaktion & MHN \\
\hline $\mathrm{Cr}^{\mathrm{a}}$ & $\begin{array}{l}\text { CROM1 } \\
(021.001)\end{array}$ & 100 & $\operatorname{IgG}$ & IAT & Nein & Keine bis milde & Keine \\
\hline $\mathrm{Tc}^{\mathrm{a}}$ & $\begin{array}{l}\text { CROM2 } \\
(021.002)\end{array}$ & 100 & $\operatorname{IgG}$ & IAT & Nein & Keine bis milde & Keine \\
\hline $\mathrm{Tc}^{\mathrm{b}}$ & $\begin{array}{l}\text { CROM3 } \\
(021.003)\end{array}$ & $\begin{array}{l}<0,01 \text { (weiße) } \\
6 \text { (schwarze) }\end{array}$ & $\operatorname{IgG}$ & IAT & Nein & Nicht bekannt & $\begin{array}{l}\text { Nicht } \\
\text { bekannt }\end{array}$ \\
\hline $\mathrm{Tc}^{\mathrm{c}}$ & $\begin{array}{l}\text { CROM4 } \\
(021.004)\end{array}$ & $<0,01$ & $\operatorname{IgG}$ & IAT & Nein & Keine bis milde & Keine \\
\hline
\end{tabular}

$I A T$, indirekter Agglutinationstest 
III) nicht exprimiert. Dies ist jedoch nicht die Ursache für die PNH-Erkrankung.

Die häufigsten DAF-Allele kommen in allen Populationen mit einer Frequenz nahe 100 \% vor, wobei einige antithetische Epitope von Antigenen von $\mathrm{Cr}(\mathrm{a}), \mathrm{Tc}^{\mathrm{a}}, \mathrm{Dr}^{\mathrm{a}}, \mathrm{Es}^{\mathrm{a}}, \mathrm{IFC}+$, $\mathrm{WES}^{\mathrm{b}}, \mathrm{UMC}+$, GUTI+ vorkommen. Davon weisen einige Allele eine sehr niedrige Inzidenz auf und kommen z. T. nur in einer Familie vor oder sind regional begrenzt.

Die Eigenschaften der Hauptantigene des CromerBlutgruppensystems sind in Tab. 1 zusammengefasst.

\section{Literatur}

Blood Group Antigen Gene Mutation Database, NCBI National Center of Biotechnilogy Information, Bethesda, Maryland

Reid ME, Lomas-Francis C (2004) The blood group antigen facts book, 2. Aufl. Elsevier, New York

\section{Crossing over}

\section{J. Arnemann}

Synonym(e) Kreuzweise Überlagerung

Englischer Begriff crossing over

Definition Crossing over ist ein Ereignis der Meiose und beschreibt die kreuzweise Überlagerung von paternalen und maternalen Chromatiden mit nachfolgender Rekombination.

Beschreibung Im Zygotänstadium der Prophase I der Meiose bildet sich der synaptonemale Komplex aus. Diese komplexe Proteinstruktur ist daran beteiligt, dass sich die väterlichen und mütterlichen Chromosomen aneinanderlegen, miteinander paaren und dabei Bivalente ausbilden. In der Folge kommt es zu kreuzweisen Überlagerungen der Nicht-Schwesterchromatiden. Hierbei kommt es zu Brüchen in der Doppelhelix und die mütterlichen und väterlichen Enden werden wechselweise physisch verknüpft, was als Chiasmata bezeichnet wird. Es kommt somit zu zahlreichen Neukombinationen von mütterlicher und väterlicher DNA (intrachromosomale Rekombination). Als Folge sind die Gameten genetisch heterogen und vereinen Eigenschaften des väterlichen und mütterlichen Genoms.

\section{Literatur}

Alberts et al (2002) Molecular biology of the cell, 4. Aufl. Garland Science, New York

\section{$\beta$-Crosslaps}

Carboxyterminales Typ-I-Kollagen-Telopeptid, quervernetztes

Crowfoot-Hodgkin, Dorothy Mary

\section{H. Fiedler}

Lebensdaten Englische Chemikerin, geboren am 12. Mai 1910 in Kairo, gestorben am 30. Juli 1994 in Shipston-onStour, England. In der Literatur wird sie oft als Dorothy Hodgkin geführt.

Verdienste Crowfoot-Hodgkin studierte am Somerville College Oxford und an der Universität Cambridge unter Leitung des hervorragenden Kristallographen John Desmond Bernal (1901-1971). Im Jahr 1934 kehrte sie als Research Fellow an das Somerville College zurück und wurde 1960 zur Wolfson Research Professorin der Royal Society ernannt. 1964 erhielt sie als dritte Frau den Nobelpreis für Chemie für die Entschlüsselung des Aufbaus von Vitaminen (besonders Vitamin $B_{12}$ ), Steroiden und Proteinen mittels der Röntgenstrukturanalyse der jeweiligen Kristalle. Sie engagierte sich außerdem für soziale Fragen und in der Friedensbewegung und war von 1976-1988 Präsidentin der Pugwash Conference on Science and World Affairs. 1976 erhielt sie als erste Frau die seit 1731 jährlich an Männer vergebene Copley-Medaille der Royal Society.

Nach ersten Studien mit kristallisiertem Pepsin klärte sie zusammen mit Bernal die Raumstruktur von über 100 Steroiden auf und korrigierte die bis dahin akzeptierten WindausWieland-Formeln ( $>$ Windaus, Adolf Otto Reinhold, $>$ Wieland, Heinrich Otto). Sie nutzte (wie Max Ferdinand Perutz, 1914-2002) den isomorphen Ersatz von Anionen oder Kationen zuerst bei der Strukturaufklärung von Cholesteryliodid und Benzylpenicillin (1945, erstmalig die Laktamstruktur festgestellt). Weitere Höhepunkte waren die Strukturbestimmungen von $>$ Vitamin $\mathrm{B}_{12}$ (1948, nach 8 Jahren) und - Insulin (1969, nach 34 Jahren Arbeit). Bis zu ihrem Tod war sie trotz jahrzehntelanger chronischer Krankheit stets wissenschaftlich tätig und bildete viele Schüler in Röntgenstrukturanalyse aus.

\section{Literatur}

Glusker JP (1994) Dorothy Crowfoot Hodgkin (1910-1994). Protein Sci 3:2465-2469 


\section{CRP}

C-reaktives Protein

CRP, hochsensitiv

DC-reaktives Protein, ultrasensitiv

\section{Crystal}

T. Arndt

Synonym(e) Crystal Speed (Drogen); Meth (Drogen); N-Methylamphetamin

Definition Auch Crystal Speed, Meth, N-Methylamphetamin. Straßenname/Deckname für Methamphetamin ( $\triangleright$ Straßennamen von Drogen: Amphetamine). Siehe auch $\checkmark$ Amphetamine.

Querverweise $>$ Methamphetamin

\section{Crystal Meth}

> Methamphetamin

\section{Crystal Speed (Drogen)}

$\triangleright$ Crystal

\section{CS-846-Epitop}

- Aggrecan

CSF

- Liquor cerebrospinalis

\section{CSF-Monozytoidzellen}

- Liquor-Monozyten

\section{CSF/Serum-Quotientendiagramme für $\lg G, \lg A, \lg M$}

- Immunglobulinbestimmung, intrathekal empirisch

\section{CTAD-Röhrchen}

W. G. Guder

Synonym(e) Röhrchen zur Thrombozytenstabilisierung

Englischer Begriff CTAD (citrate, theophylline, adenosine, dipyramidol) tube

Definition Citratplasmaröhrchen (109 mmol/L Citrat) mit zusätzlichen Hemmstoffen der Thrombozytenaktivierung (Theophyllin, Adenosin, Dipyramidol), um diese zu stabilisieren und Störungen bei der Bestimmung von Heparin und Inhibitoren zu vermeiden.

\section{CTC}

- Tumorzellen, zirkulierende

C-terminaler Teil als Element des Arginin-Vasopressin-Prä-Prohormons (CT-proAVP)

$\checkmark$ Copeptin 


\section{C-terminales proAVP}

Copeptin

\section{CTL}

CD16/56

\section{CT-proAVP}

Copeptin

\section{CTX}

- Carboxyterminales Typ-I-Kollagen-Telopeptid

- Carboxyterminales Typ-I-Kollagen-Telopeptid, quervernetztes

\section{$\beta-C T x$}

- Carboxyterminales Typ-I-Kollagen-Telopeptid, quervernetztes

\section{Cumarine}

C. Vidal und W.-R. Külpmann

\section{Englischer Begriff coumarins}

Definition Antikoagulanzien.

Molmasse Cumarin 146,2 g; Phenprocoumon 280,3 g; Warfarin $308,3 \mathrm{~g}$.

Strukturformel Cumarin:<smiles>O=c1ccc2ccccc2o1</smiles>

Strukturformel Phenprocoumon:<smiles>CCC(c1ccccc1)c1c(O)c2ccccc2oc1=O</smiles>

Strukturformel Warfarin:<smiles>CC(=O)CC(c1ccccc1)c1c(O)c2ccccc2oc1=O</smiles>

Synthese - Verteilung - Abbau - Elimination Bei den zur Antikoagulation verwendeten Cumarinen handelt es sich um oral wirksame Pharmaka.

Halbwertszeit Phenprocoumon: 100-160 Stunden (Plasma); Warfarin: 37-50 Stunden (Plasma).

Pathophysiologie Die genannten Cumarine sind VitaminK-Antagonisten. - Vitamin K ist bedeutsam für die Synthese der $\triangleright$ Gerinnungsfaktoren II, VII, IX und X. Die Wirkung der Cumarine tritt deshalb zeitlich verzögert ein.

\section{Untersuchungsmaterial Plasma, Urin.}

Analytik HPLC, GC-MS, LC-MS/MS ( $\triangleright$ Chromatographie, - Massenspektrometrie).

Indikation Therapeutisches Drug Monitoring, Vergiftung:

\begin{tabular}{|l|l|l|l|}
\hline & \multicolumn{3}{|l|}{ Plasmakonzentration $(\mathrm{mg} / \mathrm{L})$} \\
& Therapeutisch & Toxisch & Komatös-letal \\
\hline Phenprocoumon & $0,15-3,5$ & $>5$ & $>?$ \\
\hline Warfarin & $1-7$ & $>10$ & $>100$ \\
\hline
\end{tabular}

Interpretation Der therapeutische Einsatz von Antikoagulanzien wird grundsätzlich mit entsprechenden hämostaseologischen Verfahren überwacht. Bei Verdacht auf mangelnde Compliance oder Münchhausen-Syndrom ist die quantitative Bestimmung der Cumarine selbst indiziert. Dasselbe gilt bei Verdacht auf Intoxikation mit rodentiziden Cumarinderivaten. 
Dazu zählen neben Warfarin die sog. Superwarfarine (z. B. Brodifacoum, Difenacoum) mit einer 100- bis 200-fach längeren Wirksamkeit im Vergleich zu Phenprocoumon.

\section{Literatur}

Von Meyer L, Geldmacher-von Mallinckrodt M (2009) Anticoagulants. In: Külpmann WR (Hrsg) Clinical toxicological analysis. WileyVCH, Weinheim, S 301-312

\section{Cumarinsensitivität}

T. Stief

Englischer Begriff coumarin sensitivity

Definition Cytochrom-P450-2C9- (CYP2C9-) sowie > Vitamin K-Epoxidreduktase-(VKORC1-)Varianten.

Beschreibung Cumarinderivate ( $\triangleright$ Cumarine) haben ein enges therapeutisches Fenster: Hämorrhagien oder Thrombosen sind ernste Komplikationen einer ungenügenden Cumarineinstellung. Cumarintherapien werden üblicherweise überwacht mit der INR ( $\triangleright$ International Normalized Ratio $=$ standardisierte Prothrombinzeit), die meistens zwischen 2,0 und 3,0 liegen soll. Varianten von Cytochrom P450 2C9 oder Vitamin-K-Epoxidreduktase 1 verändern die Wirksamkeit von Cumarinen. Cytochrom-P450-Enzyme sind Hydoxylasen für endogene (z. B. Steroide) oder exogene (z. B. Medikamente) Substrate in den Mikrosomen der Hepatozyten. Cytochrom P450 2C9 (CYP2C9; >100 Varianten) ist assoziiert mit einem reduzierten Metabolismus von Cumarin.

\section{C- und c-Antigen}

Rhesus-Blutgruppensystem

\section{Curie, Marie}

\section{O. A. Gressner und A. M. Gressner}

Lebensdaten Chemikerin polnischer Herkunft in Frankreich lebend, geboren am 7. November 1867 in Warschau, gestorben an Leukämie am 4. Juli 1934 in Sancellemoz (Savoyen).
Verdienste Gattin von Pierre Curie (1859-1906), mit dem sie einen Teil ihrer Untersuchungen gemeinsam durchführte. Sie entdeckte als radioaktives Element das nach ihrer polnischen Heimat benannte Polonium und isolierte aus Pechblende 1898 das Radium. Im Jahr 1903 erhielt Marie Curie anteilig den Nobelpreis für Physik für die Reindarstellung des Radiums und die Bestimmung seiner Eigenschaften. Im Jahre 1911 erhielt M. Curie zusätzlich den obelpreis für Chemie und gehört damit zu den wenigen Wissenschaftlern, deren Forschung mit zwei Nobelpreisen gewürdigt wurde (s.a. Sanger, Frederick). zusätzlich Nobelpreis für Chemie.

\section{Literatur}

Eve Curie

Madame Curie: Eine Biographie. fisherverlag ISBN:978-3-596 22243-8

\section{Curschmann, Heinrich}

A. M. Gressner und O. A. Gressner

Lebensdaten Deutscher Mediziner, geboren am 28. Juni 1846 in Gießen, gestorben am 6. Mai 1910 in Leipzig.

Verdienste Professor für Innere Medizin in Hamburg und Leipzig, hat zahlreiche und neue Beobachtungen über Infektionskrankheiten (Pocken, Fleckfieber, Typhus) und über Bronchialasthma, Abdominaltyphus, Blattern etc. beschrieben. Wurde besonders bekannt durch seine Entdeckung der - Curschmann-Spiralen im Sputum bei Bronchialasthma.

\section{Curschmann-Spiralen}

A. M. Gressner und O. A. Gressner

Englischer Begriff Curschmann's spirals

Definition Im schleimigen Sputum der Bronchialasthmatiker vorkommende, seilartig gedrehte, durchscheinende Strukturen.

Beschreibung Von dem Internisten Heinrich Curschmann ( $\vee$ Curschmann, Heinrich) beschriebene, im glasig-schleimigen, zähen Sputum von Patienten mit Asthma bronchiale und spastischer Bronchitis nachweisbare Einschlüsse. Es handelt sich bei mikroskopischer Betrachtung des ausgebreiteten Sputums um 
oft fest gedrehte, elastische und in ihrem ganzen Verlauf ohne Unterbrechung gewundene Spiralen, die einen Zentralfaden aufweisen, der als Achse durch die ganze Spirale zieht. Durch Zusatz 30 \%iger Essigsäure deutliches Hervortreten des Zentralfadens. Häufig gemeinsames Auftreten mit $>$ Charcot-LeydenKristallen.

\section{Literatur}

Hallmann L (1980) Klinische Chemie und Mikroskopie, 11. Aufl. Georg Thieme Verlag, Stuttgart/New York

\section{Cuscohygrin}

$>$ Kokakauen vs. Kokainkonsum

\section{Cushing, Harvey Williams}

M. Bidlingmaier

Lebensdaten Geboren am 8. April 1869 in Cleveland, Ohio; gestorben am 7. Oktober 1939 in New Haven, Connecticut. Amerikanischer Neurochirurg. Harvey Cushing entstammte einer puritanischen Arztfamilie. College in Yale, seit 1891 Medizinstudium an der Harvard Medical School in Boston, unter anderem bei William Osler. Nach Abschluss des Studiums und einem Jahr als Assistenzarzt am Massachusetts General Hospital Wechsel an das Johns Hopkins Hospital in Baltimore. Von 1912 bis zur Emeritierung 1932 Professor für Chirurgie am neu gegründeten Peter Bent Brigham Hospital in Boston (Harvard Medical School).

Verdienste Cushing ist hauptsächlich bekannt als einer der bedeutendsten Vertreter der Neurochirurgen des 20. Jahrhunderts. Neben den dokumentierten 2023 Operationen von Hirntumoren trug er durch bahnbrechende Entwicklungen zur Verbesserungen chirurgischer und neurochirurgischer Operationstechniken bei. U. a. gehen die Einführung von Silber-Clips zur Blutungskontrolle sowie die Elektrokauterisation auf Cushing zurück. Er war auch einer der ersten, die eine durchgängige Messung und Dokumentation von Vitalparametern zur Überwachung der Narkose einführten (Narkoseprotokoll). Durch Cushings Wirken konnte die Mortalität vieler chirurgischer Eingriffe drastisch reduziert werden. Auf ihn geht auch die Erstbeschreibung des durch einen ACTH-produzierenden Tumors des Hypophysenvorderlappens verursachten
Hyperkortisolismus zurück. Der mit dem Kortisolexzess assoziierte Symptomenkomplex wurde 1943 auf Anregung des Endokrinologen Albright „Morbus Cushing“ genannt. Von Cushing stammen auch wichtige Arbeiten zur histologischen Klassifikation von Hypophysentumoren und zur Akromegalie.

\section{Literatur}

Bliss M (2005) Harvey Cushing: a life in surgery. University of Toronto Press, Toronto, Canada

Cushing H (1912) The pituitary body and its disorders: clinical states produced by disorders of the hypophysis cerebri. J. B. Lippincott Company, Philadelphia/London

\section{Cut-off-Wert}

C. Vidal und W.-R. Külpmann

Englischer Begriff cut-off value

Definition Entscheidungsgrenze, die festlegt, bis zu welchem Messergebnis ein negativer Befund und $\mathrm{ab}$ welchem ein positiver Befund vorliegt.

Beschreibung Der Cut-off-Wert stellt für eine bestimmte Fragestellung das optimale Verhältnis von richtig negativen und richtig positiven Befunden dar. Für eine andere Fragestellung ist u. U. der Cut-off-Wert anhand der ROC-Kurve zu ändern.

\section{Literatur}

DIN 58985 (2003) Entscheidungsgrenzen. Beuth-Verlag, Berlin

\section{Cut-off-Wert der ROC}

$>$ Schwellenwert der ROC

\section{CV2-Antikörper}

- Autoantikörper gegen neuronale Antigene

\section{CVS}

Chorionzotten-Biopsie 


\section{C2-Werte}

C2-Monitoring

\section{Cyanid}

C. Vidal und W.-R. Külpmann

Englischer Begriff cyanide

Definition Cyanid geht hervor aus Kaliumcyanid (KCN „Cyankali“) bzw. Blausäure (HCN).

\section{Struktur $\mathrm{CN}^{-}$}

Molmasse 26,02 g.

Synthese - Verteilung - Abbau - Elimination Die Zufuhr erfolgt durch Inhalation von Blausäure oder orale Aufnahme von Alkalicyaniden. Geringe Mengen Cyanid können in Form von Thiozyanat entgiftet werden.

Funktion - Pathophysiologie Cyanid ist ein sehr stark wirksames Gift. Es blockiert bereits in ganz geringer Konzentration die intrazelluläre Atmung durch Bindung an $\mathrm{Fe}^{3+}$ der Zytochromoxidasen und führt so rasch zum Tod.

Untersuchungsmaterial - Entnahmebedingungen Serum, Plasma.

Analytik CN-selektive Elektrode. Nicht mehr durchgeführt: Mikrodiffusion nach Conway.

Indikation Cyanidvergiftung.

Interpretation Mögliche Ursachen: Blausäure-, Alkalicyanid- oder Rauchgasvergiftung. $\mathrm{CN}^{-}$-Plasmakonzentration physiologisch: $<0,001 \mathrm{mg} / \mathrm{L}$; toxisch: $>0,1 \mathrm{mg} / \mathrm{L}$; komatösletal: $>1 \mathrm{mg} / \mathrm{L}$.

\section{Literatur}

Geldmacher-von Mallinckrodt M (2009) Cyanide. In: Külpmann WR (Hrsg) Clinical toxicological analysis. Wiley-VCH, Weinheim, S 646-661

\section{Cyanocobalamin}

- Vitamin $\mathrm{B}_{12}$

\section{Cycle-Sequencing}

\section{J. Arnemann}

Synonym(e) Sequenzier-PCR

Englischer Begriff cycle-sequencing

Definition Cycle-Sequencing ist eine spezifische PCRbasierte Methode zur DNA-Sequenzierung nach Sanger.

Beschreibung Physikalisch-chemisches Prinzip: Die Grundlage des Cycle-Sequencings ist eine unidirektionale PCR unter Einsatz eines Primers und einer Mischung aus 4 normalen dNTPs (Desoxyribonucleosidtriphosphate) und 4 unterschiedlich fluoreszenzmarkierten ddNTPs (Didesoxyribonukleosidtriphosphate). Die Methode folgt dabei dem Prinzip der Sequenzierung nach Sanger. Die Dideoxynukleotide (ddNTPs) bewirken bei Einbau in den neu zu synthetisierenden DNAStrang einen Kettenabbruch. Mittels dieser Methode werden auch aus kleinen Mengen DNA hinreichend markierte Sequenzprodukte hergestellt. Die Produkte werden aufgereinigt, denaturiert und mittels Kapillarelektrophorese aufgetrennt. Die fluoreszenzmarkierten Sequenzfragmente werden vom Laserdetektor automatisch dokumentiert und nachfolgend mittels spezifischer Computerprogramme benutzergerecht aufbereitet (s. a. - Sanger-Sequenzierung).

\section{Literatur}

Hughes S, Moody A (Hrsg) (2007) PCR. Scion Publishing Ltd., Bloxham

\section{Cyclisches Adenosinmonophosphat}

T. Arndt

$\operatorname{Synonym(e)}$ cAMP

Englischer Begriff cyclic adenosin monophosphate

Definition Niedermolekularer Botenstoff (,second messenger") der zellulären Signaltransduktion, der u. a. zur Aktivierung von Proteinkinasen führt.

Molmasse 329,2 g. 
Synthese - Verteilung - Abbau - Elimination Aktivierung eines G-Protein-gekoppelten Rezeptors (z. B. durch $>$ Parathormon) führt zur Aktivierung der zellmembranständigen Adenylatcyclase und Bildung von cAMP aus ATP. Abbau unter Wirkung der Phosphodiesterase zu AMP (Details s. Lehrbücher der Biochemie).

Funktion - Pathophysiologie Durch cAMP stimulierte Aktivierung von Proteinkinasen werden z. B. $\mathrm{Ca}^{2+}-$ Kanäle geöffnet, die glatte Muskulatur relaxiert sowie zahlreiche Stoffwechselfunktionen wie Glykogenolyse und Lipolyse reguliert.

Untersuchungsmaterial - Entnahmebedingungen Spontanurin, 24-Stunden-Sammelurin (unter Kühlung sammeln, ggf. Zusatz von Borsäure oder Thymol, Aliquot bis zur Analyse einfrieren). EDTA-Plasma (kein Heparin- und Citratplasma, Blutabnahmegefäß in Eiswasser, sofort gekühlt zentrifugieren, Plasma einfrieren).

Probenstabilität Untersuchungsmaterialien sofort einfrieren.

Präanalytik Geringfügige zirkadiane Rhythmik mit Maximum um 12:00 Uhr und niedrigsten Plasmakonzentrationen am späten Abend.

Analytik Kompetitiver Immunoassay (z. B. mit ${ }^{3} \mathrm{H}$-markiertem cAMP).

Konventionelle Einheit $\mathrm{ng} / \mathrm{mL}$ (Plasma), $\mathrm{mg} / \mathrm{g}$ Kreatinin, $\mathrm{mg} /$ Tag (Urin).

Internationale Einheit $\mathrm{nmol} / \mathrm{L}$ (Plasma), $\mu \mathrm{mol} / \mathrm{mol}, \mu \mathrm{mol} /$ Tag (Urin).

Umrechnungsfaktor zw. konv. u. int. Einheit $\mathrm{ng} / \mathrm{mL}$ $\times 3,04=\mathrm{nmol} / \mathrm{L}, \mathrm{mg} / \mathrm{g} \times 344=\mu \mathrm{mol} / \mathrm{mol}, \mathrm{mg} / \mathrm{Tag} \times 3,04=$ $\mu \mathrm{mol} /$ Tag.

Referenzbereich - Erwachsene EDTA-Plasma-cAMP: Frauen: 4,3-7,6 ng/mL, Männer: 4,6-8,6 ng/mL.

Urin-cAMP Frauen und Männer: 0,29-2,10 mg/g, 0,33$3,58 \mathrm{mg} /$ Tag.

Glomerulär filtriertes cAMP (s. u.): 18,3-45,5 nmol/L.

Referenzbereich - Kinder Keine Daten.

\section{Indikation}

- Verdacht auf Pseudohyperparathyreoidismus Typ I und II
- Differenzialdiagnose Hypoparathyreoidismus vs. Pseudohypoparathyreoidismus

- Verdacht auf Hyperparathyreoidismus mit grenzwertigen P Parathormon-Befunden

Interpretation EDTA-Plasma-cAMP nur für Berechnung der glomerulären cAMP-Filtration wichtig.

Urin-cAMP erhöht bei

- primärem Hyperparathyreoidismus (85\% der Patienten),

- Pseudohypoparathyreoidismus Typ II und

- humoraler Hyperkalziämie des Tumorpatienten (50 \%), Calcium-Malabsorption, Manie, Familiärem Mittelmeerfieber.

Urin-cAMP erniedrigt bei

- Hypoparathyreoidismus,

- Pseudohypoparathyreoidismus Typ I und

- Depression.

\section{Diagnostische Wertigkeit}

- Etwa $50 \%$ des Urin-cAMP resultiert aus der glomerulären Filtration des Plasma-cAMP, die anderen $50 \%$ aus der Synthese in der Niere und tubularer Sezernierung (= nephrogenes cAMP). Letzteres steht unter direkter Kontrolle des Parathormons.

- Da Parathormon in der Nierenrinde die Adenylatcyclase stimuliert, resultiert bei Hyperparathyreoidismus eine erhöhte, bei Hypoparathyreoidismus eine verminderte cAMP-Ausscheidung.

- Pseudohypoparathyreoidismus Typ I entspricht einer Endorganresistenz gegen Parathormon durch einen Defekt des Parathormonrezeptors. Parathormon kann deshalb die Adenylatcyclase nicht aktivieren, woraus eine verminderte cAMP-Ausscheidung resultiert.

- Bei Pseudohypoparathyreoidismus Typ II ist dagegen der Parathormonrezeptor intakt (nur die Weiterverarbeitung des chemischen Signals gestört), sodass hohe Parathormonkonzentrationen auch zu einer erhöhten Ausscheidung von cAMP führen.

Wegen schwankender cAMP-Konzentrationen und cAMP/ Kreatinin-Quotienten im Urin in Abhängigkeit z. B. vom Wasserhaushalt und dem Geschlecht hat es sich bewährt, die cAMP-Ausscheidung in Bezug zur glomerulären Filtration anzugeben:

$$
\mathrm{cAMP}-\text { filtriert }(\mathrm{nmol} / \mathrm{dL})=\frac{\operatorname{Urin}-\mathrm{cAMP}(\mathrm{nmol} / \mathrm{L}) \times \operatorname{Serum}-\operatorname{Kreatinin}(\mathrm{mg} / \mathrm{dL})}{\operatorname{Urin}-\operatorname{Kreatinin}(\mathrm{mg} / \mathrm{L})}
$$


Urin-cAMP ist wertvoll für die Erkennung von ParathormonResistenzzuständen (Pseudohypoparathyreoidismus) und deren Differenzierung.

\section{Literatur}

Wu AHB (Hrsg) (2006) Tietz clinical guide to laboratory tests. Saunders Elesevier, St. Louis

\section{Cyclosporin A}

Ciclosporin

CYFRA 21-1

- Zytokeratin-19-Fragment

CYP

- Cytochrom P450

\section{CYP19A1}

Aromatase

\section{CYP450 21A2-Mutation}

M. Bidlingmaier

Synonym(e) Adrenogenitales Syndrom; 21-Hydroxylasemangel; Steroid-21-Hydroxylase-Genmutation

Englischer Begriff P450 21A2 mutation; steroid 21-hydroxylase mutation; steroid 21-monooxygenase mutation; 21$\alpha$-hydroxylase mutation; 21 hydroxylase deficiency; congenital hyperplasia $(\mathrm{CAH})$

Definition Das Enzym Cytochrom P450 21A2 ist die wichtigste Steroid-21-Hydroxylase. Der durch Mutationen im entsprechenden Gen hervorgerufene Enzymmangel ist verantwortlich für ungefähr $95 \%$ aller Fälle des adrenogenitalen Syndroms (AGS) beim Menschen, einer mit Störungen der adrenalen Steroidbiosynthese einhergehenden Erkrankung.
Beschreibung Cytochrom P450 21A2 ist eine aus 494 Aminosäuren bestehende Oxidoreduktase (Molekulargewicht 55,9 kDa). Das Enzym katalysiert die 21-Hydroxylierung von Progesteron und 17 $\alpha$-Hydroxyprogesteron zu 11-Deoxykortikosteron und 11-Deoxykortisol und stellt damit ein Schlüsselenzym auf dem Weg zur Synthese der adrenalen Steroide Kortisol und Aldosteron dar.

Das Gen ist auf Chromosom 6 innerhalb der HLA-KlasseIII-Region. Mutationen entstehen oft durch Rekombination mit einem ca. $30 \mathrm{~kb}$ entfernt gelegenen Pseudogen CYP21A1P. Die Inzidenz des klassischen AGS mit 21-Hydroxylasemangel variiert stark zwischen ethnischen Gruppen, mit durchschnittlich ca. 1 Fall auf 10000 Geburten gehört es jedoch zu den häufigsten monogenetisch vererbten Erkrankungen. Bei autosomal-rezessivem Erbgang beträgt die Heterozygotenfrequenz 1:55.

Aus der reduzierten oder fehlenden Enzymaktivität resultiert ein Mangel an Gluko- und Mineralokortikoiden, welcher auf hypophysärer Ebene wegen des ausbleibenden negativen Feedbacks zu einer vermehrten ACTH-Freisetzung führt. Dies bewirkt die adrenale Hyperplasie sowie eine permanente Stimulation der adrenalen Steroidbiosyntheseschritte vor dem Enzymdefekt. Nachdem einzig die Synthese der Androgene nicht durch den Enzymmangel betroffen ist, werden die angestauten Präkursoren - insbesondere $17 \alpha$-Hydroxyprogesteron - über alternative Stoffwechselwege hin zu den Androgenen metabolisiert.

Klinisch unterscheidet man beim 21-Hydroxylasedefekt eine schwere, klassische und eine mildere, nicht klassische, früher auch als "late-onset" bezeichnete Form, bei der ca. 20-30\% der Enzymaktivität erhalten ist. Bei der klassischen Form sind wiederum eine mit schweren adrenalen Krisen des Neugeborenen verbundene Salzverlustform und eine einfach virilisierende Form abzugrenzen. Bei letzterer sind ca. 1-2 \% der Enzymaktivität erhalten, was zusammen mit einer minimalen Aldosteronproduktion die Krisen verhindert. Neben der unterschiedlich stark ausgeprägten Nebennierenrindeninsuffizienz steht die Hyperandrogenämie klinisch im Vordergrund, diese führt je nach Geschlecht und Schwere des Enzymdefekts zu unterschiedlich starker Virilisierung. Bei Mädchen kommt es durch die massive pränatale Androgenexposition bei chromosomal weiblichem Geschlecht $(46, \mathrm{XX})$ zum Pseudohermaphroditismus femininus mit männlichem äußeren Genitale. Unbehandelt kommt es bei beiden Geschlechtern zu einer Pseudopubertas praecox mit beschleunigtem Knochenwachstum, aber vorzeitigem Schluss der Epiphysenfugen. Die hohen Androgenspiegel führen zu einer Hemmung der Entwicklung der Gonaden mit Amenorrhoe bzw. Hodenatrophie und Azoospermie. Bei der milden, zunächst oft unbemerkt gebliebenen nicht klassischen Form des AGS können Mädchen in der Pubertät durch unterschiedlich stark ausgeprägte Symptome wie Hirsutismus, Akne, Klitorishypertrophie und prämature Pubarche auffallen, Knaben und Männer sind meist symptomlos. 
Im Zentrum der derzeit verfügbaren therapeutischen Strategien steht eine adäquate Substitution von Gluko- und ggf. auch Mineralokortikoiden. Die Patienten brauchen eine angemessene Schulung für die unerlässliche Anpassung der Glukokortikoiddosis in Krisensituationen und einen Notfallausweis. Die Substitutionstherapie hat neben der Verhinderung von potenziell tödlichen Nebennierenkrisen auch zum Ziel, über die Hemmung der ACTH-Sekretion den Androgenexzess zu kontrollieren. Theoretisch möglich ist eine pränatale Therapie der Mutter mit Dexamethason. Die Therapie ist umstritten, da bei heterozygoten Eltern ja nur einer von 8 Feten homozygot weiblich wäre und somit potenziell profitieren würde. Die potenziell nicht unerheblichen Risiken der pränatalen Dexamethasonexposition auch für nicht betroffene Feten müssen hier genauso mit bedacht werden wie die Möglichkeiten und Risiken einer pränatalen Diagnostik (Chorionzottenbiopsie, Amniozentese, zellfreie DNA). Andere Therapieoptionen (Enzyminhibition, ACTH-Antagonisierung, Gentherapie) werden erst untersucht.

Labordiagnostisch steht meist die Messung des charakteristischen Präkursors 17 $\alpha$-Hydroxyprogesteron im Vordergrund. Dieses ist bei schweren Formen bereits basal erhöht. Unter Stimulation mit ACTH fallen jedoch Heterozygote durch einen überschießenden Anstieg auf. Ergänzend wird das adrenale Androgen Androstendion gemessen. Die Bestimmung von 17$\alpha$-Hydroxyprogesteron ist heutzutage in über 40 Ländern routinemäßiger Bestandteil des Neugeborenenscreenings. Die frühzeitige Diagnose erlaubt eine adäquate Therapie und somit die Verhinderung der gefürchteten neonatalen Nebennierenkrisen, auch wenn das Screening wegen der mäßigen Spezifität nicht unumstritten ist. Bei der molekularbiologischen Analyse des zugrunde liegenden Gendefekts muss die Anwesenheit des Pseudogens berücksichtigt werden.

\section{Literatur}

El-Maouche D, Arlt W, Merke DP (2017) Congenital adrenal hyperplasia. Lancet 11;390(10108):2194-2210

Pallan PS, Wang C, Lei L, Yoshimoto FK, Auchus RJ, Waterman MR, Guengerich FP, Egli M (2015) Human Cytochrome P450 21A2, the Major Steroid 21-Hydroxylase: structure of the enzyme progesterone substrate complex and rate-limiting $\mathrm{C}-\mathrm{H}$ bond cleavage. J Biol Chem 290(21):13128-13143

\section{CYP450 11B1-Mutation}

M. Bidlingmaier

Synonym(e) Steroid-11 $\beta$-Hydroxylase-Mutation; Steroid$11 \beta$-Hydroxylase-Defizienz; 11 $\beta$-Monooxygenase-Mutation
Englischer Begriff steroid 11 $\beta$-hydroxylase mutation; steroid 11 $\beta$-hydroxylase deficiency; CPN1 mutation, cytochrome P450 family 11 subfamily B member 1 mutation

Definition Das Enzym Cytochrom P450 11B1 katalysiert die Hydroxylierung von Steroiden an Position 11. Ein durch Mutationen im entsprechenden Gen hervorgerufener Enzymmangel führt $\mathrm{zu}$ einer selteneren Form des adrenogenitalen Syndroms (AGS) beim Menschen.

Beschreibung Das Enzym Cytochrom P450 11B1 ist in der inneren mitochondrialen Membran lokalisiert. Die Hydroxylierung an Position 11 betrifft in der adrenalen Steroidbiosynthese in der Zona fasciculata die Umwandlung von 11-Desoxykortisol zu Kortisol und von 11-Desoxykortikosteron zu Kortikosteron. In der Zona glomerulosa kann hingegen durch das Isoenzym CYP11B2 11-Desoxykortikosteron weiter zu Kortikosteron metabolisiert werden. Die Angaben zur Prävalenz schwanken stark ( 1 in 100.000 bis 1 in 9.000.000). Ähnlich der Situation beim wesentlich häufigeren 21-Hydroxylasemangel kommt es beim ebenfalls autosomal rezessiv vererbten Steroid-11 $\beta$-Hydroxylasemangel zu einer Erhöhung der Präkursoren, die dann in Richtung der adrenalen Androgene weitermetabolisiert werden. Weibliche Neugeborene weisen je nach Ausmaß des Enzymdefekts unterschiedliche Grade der Virilisierung bis hin zum Vollbild des Pseudohermaphroditismus femininus auf. Außerdem treten eine beschleunigte Skelettreifung mit reduzierter Endgröße und eine Pubertas praecox auf. Anders als beim 21-Hydroxylasemangel, bei dem es aufgrund des Fehlens der Mineralokortikoide zum Salzverlust mit Hypotension kommen kann, tritt bei dem - auf dem Weg zum Aldosteron weiter distal gelegenen - 11$\beta$-Hydroxylasemangel gehäuft eine Salzretention mit konsekutiver Entwicklung eines hyporeninämischen Hypertonus auf. Als Ursache wurde diskutiert, dass das exzessiv ansteigende 11-Desoxykortikosteron bereits eine mineralokortikoide Wirkung hat. Allerdings ist die Mehrzahl der Betroffenen bei Diagnosestellung normotensiv, eine Korrelation zwischen den Konzentrationen von 11-Desoxykortikosteron und dem Ausmaß der Hypertonie besteht nicht, der genaue Pathomechanismus der Hypertonie offen. Neugeborene können neben einer Hypertonie eine Hypokaliämie aufweisen, mildere Formen werden bei Geburt oft nicht erkannt. Im Erwachsenenalter verschwinden die Elektrolytstörungen oft spontan. Der Androgen- und ggf. Mineralokortikoidexzess und der Glukokortikoidmangel werden durch die Gabe von Glukokortikoiden therapiert.

Die biochemische Diagnose wird durch die erhöhten Konzentrationen von ACTH, 11-Desoxykortikosteron und 11-Desoxykortisol gestellt, molekularbiologisch ist ein Mutationsnachweis möglich. Es wurden bislang über 100 verschiedene Mutationen beschrieben. 


\section{Literatur}

Bulsari K, Falhammar H (2017) Clinical perspectives in congenital adrenal hyperplasia due to $11 \beta$-hydroxylase deficiency. Endocrine 55(1):19-36

\section{Cys}

$>$ Cystin

Cys-Gly-Dipeptidase

- Cysteinyl-Glycin-Dipeptidase

\section{Cystathionin}

A. C. Sewell

Englischer Begriff cystathionine

Definition Eine schwefelhaltige Aminosäure.

Beschreibung Zwischenprodukt der Cysteinsynthese, ausgehend von $\triangleright$ Homocystein und $\triangleright$ Serin. Cystathionin wird zu $\triangleright$ Cystein und 2-Oxobutyrat abgebaut. Erhöhte Konzentrationen werden bei Patienten mit einem Cystathionasemangel gefunden.

\section{Literatur}

Bremer HJ, Duran M, Kamerling JP et al (1981) Disturbances of aminoacid metabolism: clinical chemistry and diagnosis. Urban \& Schwarzenberg, Munich/Baltimore

Duran M (2008) Amino acids. In: Blau N, Duran M, Gibson KM (Hrsg) Laboratory guide to the methods in biochemical genetics, Springer Berlin, S 53-90

\section{Cystatin C}

W. G. Guder

Synonym(e) Gamma-trace
Definition Cystatin C ist ein basisches, nicht glykiertes Mikroprotein aus der Cystatinfamilie, das als Cysteinproteinaseninhibitor im Extrazellulärraum fungiert.

Struktur Ubiquitär exprimiertes, nicht glykiertes Peptid.

Molmasse $13,36 \mathrm{kDa}$.

Synthese - Verteilung - Abbau - Elimination Das Gen wird in allen kernhaltigen Zellen exprimiert und das Protein so als Cysteinproteinaseinhibitor in konstanter Rate an die verschiedenen Extrazellulärräume abgegeben (housekeeping gene). Aufgrund seiner niedrigen Molmasse und seiner geringen Bindung an andere Proteine wird es glomerulär frei filtriert. Die Halbwertszeit im Blut beträgt so nur etwa 2-3 Minuten. Nach glomerulärer Filtration werden über $99 \%$ proximal tubulär rückresorbiert und hier lysosomal zu Aminosäuren abgebaut.

Funktion - Pathophysiologie Cystatin C findet sich in allen extrazellulären Körperflüssigkeiten. Ein angeborener Mangel im Zerebrospinalraum (wenige Fälle in Island beschrieben) führt zu einer schlaganfallartigen Blutung im Gehirn durch blutdruckunabhängige Ruptur arterieller Gefäße im ZNS ( $\triangleright$ Liquor-Cystatin C).

Aufgrund der ubiquitären Synthese von Cystatin C ist die Konzentration im Plasma konstant ab dem 4. Monat nach der Geburt und wird weder durch entzündliche Erkrankungen noch durch Tumor- oder degenerative Erkrankungen verändert. Nach der Geburt liegen höhere Konzentrationen vor, die mit wachsender renaler Funktion bis zum 6. Monat abnehmen. So schien das Protein in idealer Weise als Marker für die glomeruläre Clearance geeignet. Wegen der geringeren extrarenalen Faktoren, die zu einer Veränderung führen, konnte früher und präziser die glomeruläre Clearance aus einer einfachen Serum-/Plasmabestimmung vorausgesagt werden. Lediglich bei hoher Glukokortikoidbehandlung wurde ein Anstieg des Cystatins gefunden. Leichte Anstiege bei malignen Tumoren wurden bei fortgeschrittenen Stadien von Kolonkarzinom ohne Anstieg des Kreatinins beschrieben.

Untersuchungsmaterial - Entnahmebedingungen Plasma (Heparin-, EDTA-) oder Serum sind in gleicher Weise geeignet. Die Messung im Urin wird derzeit nicht benötigt (• Liquor-Cystatin C).

Probenstabilität Plasma/Serum über 2 Tage bei Raumtemperatur, 1 Woche im Kühlschrank und über 3 Monate gefrorenen. EDTA-Plasma führt zu längerer Stabilität.

Präanalytik Wegen der geringen intraindividuellen und interindividuellen Variabilität sind weder Zeitpunkt noch Ernährungszustand für die Ergebnisse des Cystatins $\mathrm{C}$ von 
Bedeutung. Lediglich lipämische (nüchtern) oder hämolytische Seren/Plasmen sollten vermieden werden.

Analytik Particle-enhanced turbidimetric Immunoassay (PETIA; - Immunturbidimetrie) oder Particle-enhanced nephelometric Immunoassay (PENIA; > Immunnephelometrie), Kalibration mit internationalem Referenzmaterial (Grubb et al. 2010).

\section{Internationale Einheit $\mathrm{mg} / \mathrm{L}$.}

Referenzbereich Unterschiede zwischen den Methodenergebnissen sind nach Einführung eines einheitlichen Referenzstandards weggefallen.

Referenzbereich - Frauen $<50$ Jahre $0,4-0,99 \mathrm{mg} / \mathrm{L},>50$ Jahre $0,4-0,99 \mathrm{mg} / \mathrm{L}$.

Referenzbereich - Männer $<50$ Jahre $0,37-0,74 \mathrm{mg} / \mathrm{L}$, $>50$ Jahre $0,4-0,99 \mathrm{mg} / \mathrm{L}$.

Referenzbereich - Kinder $<1$ Jahr: nach Geburt 2- bis 3-mal so hoch wie bei Erwachsenen $(1,1-2,2 \mathrm{mg} / \mathrm{L}) \mathrm{mit}$ raschem Abfall auf $<2 \mathrm{mg} / \mathrm{L}$ in den ersten 3 Wochen; $a b$ 1. Lebensjahr: $0,5-1,0 \mathrm{mg} / \mathrm{L}$.

Ermittlung der glomerulären Clearance:

In folgender Weise kann die Clearance ( $\triangleright$ Clearance, glomeruläre) bei Erwachsenen aus dem Plasma-/Serum-Cystatin $\mathrm{C}$ abgeleitet werden:

Clearance $(\mathrm{mL} / \mathrm{min})=84,7 /$ Cystatin $\mathrm{C}^{1,68}(\mathrm{mg} / \mathrm{L})$.

Bei Frauen ist das Ergebnis mit dem Faktor 0,85 zu multiplizieren, bei Kindern unter 14 Jahren mit dem Faktor 1,384.

Dabei ist die lineare Beziehung zwischen der reziproken Cystatinkonzentration und der Clearance ab dem 1. Jahr weder vom Alter noch von der Muskelmasse oder anderen extrarenalen Faktoren abhängig.

Indikation Abschätzung der glomerulären Clearance ( $\triangleright$ Clearance, glomeruläre) ab dem 3. Monat bis Lebensende. Cystatin $\mathrm{C}$ wird gegenüber $\triangleright$ Kreatinin als ,idealer“ Marker der glomulären Clearance angesehen. Er bietet folgende Vorteile:

- Nahezu keine Alters- und Geschlechtsabhängigkeit

- Keine Abhängigkeit von der Muskelmasse oder anderen extrarenalen Faktoren

- Plasmaanstiege aufgrund der geringen interindividuellen Streuung bereits im sog. kreatininblinden Bereich, d. h. bei gering gradiger Nierenschädigung

- Durch die weitgehende Unabhängigkeit der Plasmakonzentration von extrarenalen Faktoren ist die Abschätzung der Clearance direkt aus dem Plasma-Cystatin möglich
Interpretation Eine erhöhte Konzentration von Cystatin $\mathrm{C}$ spricht für eine reduzierte glomeruläre Clearance, wenn seltenere Ursachen für eine Erhöhung ausgeschlossen sind (Glukokortikoidtherapie, Hyperthyreose, fortgeschrittene Kolonkarzinomerkrankung, Melanom im metastasierenden Stadium). Dies gilt auch, wenn Kreatinin noch im Referenzbereich ist.

Diagnostische Wertigkeit Die diagnostische Wertigkeit und Überlegenheit gegenüber Kreatinin wurde in vielen Krankheitsgruppen belegt: Screening im pädiatrischen und Erwachsenenalter besonders bei Patienten über 60 Jahren, wo häufig nur Cystatin die reduzierte Clearance anzeigt. Bei Tumorpatienten, Patienten mit entzündlichen und fieberhaften Erkrankungen, Diabetikern und unter potenziell nephrotoxischen Medikamenten wurde Cystatin C als empfindlicherer Marker erkannt. Auch bei rasch sich verändernder glomerulärer Clearance stieg Cystatin $\mathrm{C}$ einen Tag eher an als Kreatinin.

\section{Literatur}

Grubb A (2017) Cystatin C is indispensable for evaluation of kidney disease. J Int Fed Clin Chem 28:268-76

Grubb A, Nymann U, Björk J, Lindström V, Rippe B, Sterner G, Christensson A (2005) Simple cystatin C-based prediction equations for glomerular filtration rate compared with the modification of diet in renal disease prediction equation for adults and the Schwartz and the Counahan-Barratt prediction equations for children. Clin Chem 51(8):1420-1431

Grubb A, Blirup-Jensen S, Lindström V, Schmidt C, Althaus H, Zegers I, On behalf of the IFCC working group on standardisation of cystatin C (WG-SCC) (2010) First certified reference material for cystatin $\mathrm{C}$ in human serum ERM-DA471/IFCC. Clin Chem Lab Med 48:1619-1621

Harmoinen A, Lethimäki T, Korpela M, Turjanmaa V, Saha H (2003) Diagnostic accuracies of plasma creatinine, Cystatin C, and glomerular filtration rate calculated by the Cockroft-Gault and Levey (MDRD) formulas. Clin Chem 49:1223-1225

Hofmann W, Ehrich JHH, Guder WG, Keller F, Scherberich J (2011) Diagnostische Pfade bei Nierenerkrankungen. Nieren und Hochdruckkrankheiten 40:47-70

\section{Cystein}

A. C. Sewell

\section{Englischer Begriff cysteine}

Definition Eine nicht essenzielle, schwefelhaltige Aminosäure. 
Beschreibung Cystein ist sehr instabil und wird rasch zu Cystin oxidiert. Im Rahmen der $\triangleright$ Aminosäurenanalytik wird im Allgemeinen Cystein als Cystin bestimmt. Die Cysteinthiolgruppe ist sehr reaktiv und besitzt zahlreiche biologische Funktionen, darunter die Glutathionsynthese, Quervernetzung von Proteinen und Bindung von Metallionen. Cystein wird außerdem in der Produktion verschiedener Aromastoffe und von Kosmetika, z. B. Produkte für Dauerwelle, eingesetzt. Bei Schafen ist Cystein für die Wollproduktion von essenzieller Bedeutung.

Durch die Fähigkeit, Acetaldehyd (Alkoholkonsum) zu neutralisieren, könnte Cystein als „Hangover-Medikament“ Einsatz finden. N-Acetylcystein wird in der Medizin als Hustenmittel und Mukosolvans eingesetzt.

\section{Literatur}

Bremer HJ, Duran M, Kamerling JP et al (1981) Disturbances of aminoacid metabolism: clinical chemistry and diagnosis. Urban \& Schwarzenberg, Munich/Baltimore

\section{Cysteinyl-Glycin-Dipeptidase}

R. Tauber und F. H. Perschel

Synonym(e) Aminopeptidase N; Cys-Gly-Dipeptidase

Englischer Begriff Cysteinyl-glycine dipeptidase

Definition Dipeptidase (EC 3.4.11.2), die mit breiter Spezifität N-terminale Aminosäuren von nicht substituierten Oligopeptiden hydrolysiert.

Beschreibung Cysteinyl-Glycin-Dipeptidase ist identisch mit Aminopeptidase N, die mit breiter Spezifität und einem pH-Optimum von etwa $7.0 \mathrm{~N}$-terminale Aminosäuren von nicht substituierten Oligopeptiden hydrolysiert. CysteinylGlycin-Dipeptidase ist ein Typ-2-Membranprotein und ein Ektoenzym vorwiegend der Bürstensaummembran von Leber, Dünndarm und Niere. Im Dünndarm katalysiert das Enzym Schritte der Protein- und Peptidverdauung. Eine klinische Bedeutung besteht nicht.

\section{Literatur}

Barrett AJ, Rawlings ND, Woessner JF (Hrsg) (1998) Handbook of proteolytic enzymes. Academic, London, S 1001-1002

\section{Cystin}

A. C. Sewell

$\operatorname{Synonym(e)}$ Cys

Englischer Begriff cystine

Definition Cystin ist eine nicht essenzielle Aminosäure ( $\triangleright$ Aminosäuren). Sie wurde im menschlichen Urin im Jahr 1810 durch Wollaston entdeckt. Erst 1899 wurde sie nach Isolierung aus Rinderhorn als Baustein von Proteinen erkannt.

\section{Struktur}

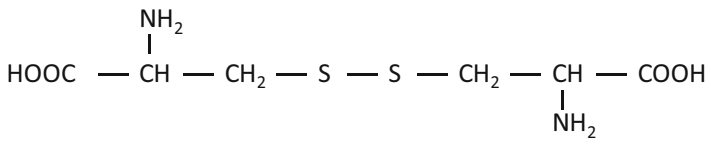

Molmasse 240,3 g.

Synthese - Verteilung - Abbau - Elimination Cys entsteht aus Methionin und anschließender Verbindung zweier $\triangleright$ Cysteinmoleküle über eine Disulfidbrücke. Besondere Bedeutung hat sie für die räumliche Darstellung zahlreicher Proteine.

Funktion - Pathophysiologie Cys ist stets in Plasma nachweisbar. Erhöhte Werte sind jedoch nicht beschrieben. Erhöhte Werte im Urin zusammen mit Arg, Lys und Orn sind charakteristisch für hereditäre Cystinurie. Da Cys bei normalen Urin-pH-Werten kaum wasserlöslich ist, führt dieser Zustand unbehandelt zur Bildung von Harnsteinen und späterer Niereninsuffizienz. Die intralysosomale Cystinspeicherung ist Marker der Cystinose.

Untersuchungsmaterial - Entnahmebedingungen Serum, Plasma, Urin, Leukozyten. Cave: Cys bindet sich bei Lagerung rasch an Proteine. Daher müssen Plasmaproben innerhalb 20 min nach Blutentnahme enteiweißt werden.

Analytik $>$ Aminosäuren.

Referenzbereiche $>$ Aminosäuren.

Indikation Diagnostik der Cystinurie und Cystinose. 


\section{Literatur}

Duran M (2008) Amino acids. In: Blau N, Duran M, Gibson KM (Hrsg) Laboratory guide to the methods in biochemical genetics, Springer 53-90

Mattoso A, Goldfarb DS (2008) Cystinuria. Semin Neprol 28:181-191

\section{Cystin im Urin}

W. G. Guder

Synonym(e) Aminosäure (Cystin (Cys-Cys), Arginin, Lysin, Ornithin)-Transportstörung; Cystinkristalle im Sediment

Englischer Begriff cystinuria; cystin stones; cystin cristals in urinary sediment

Definition Kristallbildung von Cystin bei vermehrter Ausscheidung dieser Aminosäure im Urin auf der Basis der autosomal rezessiv vererbbaren Cystinurie, die durch einen Defekt des Aminosäurecarriers für Cystin, > Ornithin und - Lysin im proximalen Tubulus beruht.

Struktur Dimer von $\alpha$-Amino- $\beta$-Mercaptopropionsäure (Cystein); $>$ Aminosäuren.

Molmasse $242 \mathrm{~g}$.

Pathophysiologie Aufgrund einer Mutation des Gens für den Transporter von dibasischen Aminosäuren (Arginin, Lysin und Ornithin) kommt es zu einer Hemmung der Resorption des im Tubuluslumen durch Oxidation aus Cystein entstehenden Cystins. Dies wird nach Harnkonzentrierung im Sammelrohr bei physiologischem Harn-pH (sauer) unlöslich, bildet Cystinkristalle im Harnsediment und in der Folge größere Harnkonkremente. Wenn die Größe der Kristalle die Weite des ableitenden Harnwegs überschreitet, kommt es zur klinischen Symptomatik der Urolithiasis.

Untersuchungsmaterial Zur Untersuchung auf Kristalle im Harnsediment genügt eine Portion $>$ Spontanurin. Wegen der geringen Löslichkeit des Cystins ist eine Quantifizierung der Cystinausscheidung nur nach Auflösung aller Kristalle aus 24-Stunden-Sammelurin möglich. Jedes Konkrement sollte auf Cystin als Bestandteil untersucht werden.

Probenstabilität 24 Stunden gekühlt, wenn Cystein und Cystin gemeinsam bestimmt werden; $\mathrm{pH}>7,5$ verhindert Kristallisation.
Analytik Qualitativer Nachweis der Kristalle im Harnsediment, Steinanalyse mit $>$ Infrarot-Spektrometrie oder Röntgendiffraktion. Quantitative Bestimmung mit HPLC ( $>$ Chromatographie) oder am Aminosäureanalysator.

Internationale Einheit $\mathrm{mmol} / 24 \mathrm{~h}$ oder $\mathrm{mg} / 24 \mathrm{~h}$.

Umrechnungsfaktor $\mathrm{mmol} \times 235=\mathrm{mg}$; $\mathrm{mg} \times 0,00425=$ mmol.

Referenzbereich Frauen, Männer, Kinder ab dem 12 Lebensjahr: $0,17-0,33 \mathrm{mmol} / 24 \mathrm{~h}(40-80 \mathrm{mg} / 24 \mathrm{~h})$.

Indikation Jeder abgehende Harnstein sollte untersucht werden. Bei Steinsymptomatik Sedimentuntersuchung auf Cystinkristalle. Darüber hinaus achtet man auf Cystinkristalle bei jeder Harnsedimentuntersuchung. Bei familiärer Belastung und vor Therapie eines nachgewiesenen Cystinsteins quantitative Cystinbestimmung.

Diagnostische Wertigkeit Der Nachweis eines Cystinsteins oder wiederholter Cystinkristallbildung im Harn ist für das Vorliegen einer Cystinurie beweisend.

\section{Literatur}

Hesse A, Jahnen A, Klocke K, Nolde A, Scharrel O (1994) Nachsorge bei Harnsteinpatienten. Gustav Fischer Verlag, Jena

\section{Cystinkristalle im Sediment}

Cystin im Urin

\section{Cystinsteine}

Cystin im Urin

\section{Cystinurie}

Cystin im Urin

\section{Cytochrom P450}

O. A. Gressner und A. M. Gressner

Synonym(e) CYP 
Englischer Begriff cytochrome p450

Definition Familie von Hämproteinen mit mischfunktioneller Monooxygenase-Aktivität.

Beschreibung Der erstmalige Nachweis eines CO-bindenden Pigments in Lebermikrosomen erfolgte durch $\mathrm{M}$. Klingenberg 1958, welcher diesem aufgrund seines photometrischen Absorptionsmaximums bei $450 \mathrm{~nm}$ den Namen Cytochrom P450 (CYP) gab. Bei CYP handelt sich um eine Familie von Hämproteinen (MW 44-55 kDa) mit Oxidoreduktase-Aktivität, welche Eisen-Protoporphyrin IX als prosthetische Gruppe enthalten. Die häufigste durch CYP katalysierte Reaktion ist eine Monooxygenase-Reaktion, d. h. Insertion eines Sauerstoffatoms in ein organisches Substrat $(\mathrm{RH})$, während das andere Sauerstoffatom zu Wasser reduziert wird: $\mathrm{RH}+\mathrm{O}_{2}+2 \mathrm{H}^{+}+2 \mathrm{e}^{-} \rightarrow \mathrm{ROH}+\mathrm{H}_{2} \mathrm{O}$. Hierdurch wird die Löslichkeit des Substrats verbessert und somit seine Elimination gewährleistet (Biotransformation). Als solche sind CYP die wichtigsten Enzyme des Phase-I-Metabolismus zur hepatischen Detoxifikation.

CYP kommen ubiquitär in Bakterien, Pflanzen und Tieren vor und sind in der Phospholipidmatrix des endoplasmatischen Retikulums eukaryonter Zellen, mit höchster Dichte in den Hepatozyten der Leber, lokalisiert. Bisher sind mehr als 50 verschiedene CYP-Isoenzyme beim Menschen identifiziert worden, hierunter als wichtigste Vertreter CYP1A2, CYP2C9, CYP2D6 und vor allem CYP3A4 mit dem breitesten Substratspektrum. Das Isoenzymmuster zeigt eine zellspezifische Variabilität. Durch die Aufnahme spezifischer Fremdstoffe kann die Expression verschiedener Cytochrom-P450-Gene selektiv erhöht werden (Enzyminduktion). Die Folge ist eine verstärkte Biotransformation des (induzierenden) Fremdstoffs.

\section{Literatur}

Sigel R, Sigel A, Sigel H (2007) The ubiquitous roles of cytochrome P450 proteins: metal ions in life sciences. Wiley, New York

\section{Cytochrom-P450-II-E1-System}

- Mikrosomales Ethanol-oxidierendes System

\section{Cytocuprein}

$\checkmark$ Cerebrocuprein

\section{Cytokeratin 18}

$$
\begin{aligned}
& \text { M30-Antigen } \\
& \text { M65-Antigen } \\
& \text { - Tissue Polypeptide Antigen } \\
& \text { - Tissue Polypeptide Specific Antigen }
\end{aligned}
$$

\section{Cytokine}

- Zytokine

\section{Cytomegalie-Viren}

W. Stöcker

Englischer Begriff Cytomegalovirus

Beschreibung des Erregers Familie: Herpesviridae; humanes Herpes-Virus 5.

Erkrankung Cytomegalie (Manifestation einer CMVInfektion) wird horizontal über infektiöse Körperflüssigkeiten (Muttermilch, Speichel, Urin, Genitalsekret), Blut- und Blutprodukte sowie transplantierte Organe übertragen oder vertikal, von der Schwangeren auf das Kind. Die Inkubationszeit beträgt je nach Übertragungsweg 3-12 Wochen. Die Infektion verläuft in der Regel asymptomatisch, gelegentlich ähnlich wie eine infektiöse Mononukleose mit Fieber, Pharyngitis und Lymphadenopathie. Bei immunsupprimierten Patienten (Transplantatempfänger, AIDS) manifestiert sich eine Cytomegalie dagegen häufig als Retinitis, interstitielle Pneumonie und Enteropathie. Reaktivierungen einer latenten Infektion verlaufen bei immunkompetenten Personen asymptomatisch, bei Personen mit geschwächter Immunität dagegen oft unter dem Krankheitsbild der akuten Infektion. In Deutschland liegt die Seroprävalenz in Abhängigkeit von Lebensstandard und Lebensalter im Erwachsenenalter bei $30-40 \%$.

Cytomegalie-Viren sind die häufigste Ursache konnataler Infektionen mit einer Rate von etwa $1 \%$ aller Neugeborenen. Bei Primärinfektionen in der Schwangerschaft beträgt die Transmissionsrate 30-40\%, bei Reaktivierungen lediglich $1,4 \%$. Schädigungen des Fetus sind vor allem bei Infektionen in den ersten 20 Wochen der Schwangerschaft zu beobachten: Von den Infizierten kommen 5 \% mit Hautblutungen, Hepatosplenomegalie, Ikterus, Mikrozephalus, Chorioretinitis und anderen Schädigungen zur Welt (Letalität $10 \%$ ). Die übrigen 
$95 \%$ der CMV-infizierten Neugeborenen erscheinen klinisch zunächst unauffällig, bei jedem Zehnten von ihnen muss allerdings mit Hörschäden und einer mentalen Retardierung gerechnet werden. Eine Infektion über die Muttermilch ist möglich, bleibt aber für reife Neugeborene in der Regel folgenlos - Frühgeborene können allerdings an einer akuten CMV-Primärinfektion erkranken.

Es ist wichtig, die seronegativen Schwangeren frühzeitig zu identifizieren, um ihnen Expositionsprophylaxe und Hygienemaßnahmen nahezulegen. Die Ermittlung des CMV-Antikörperstatus ist derzeit noch nicht in der infektionsserologischen Vorsorgediagnostik für Schwangere vorgesehen, was von einigen Experten kritisiert wird. Transfusionen für Transplantatempfänger oder andere immunkompromittierte Patienten sollten ausschließlich mit dem Blut CMV-seronegativer Spender durchgeführt werden, wenn solche nicht zur Verfügung stehen, ist es anzuraten, die Leukozyten z. B. vor der Transfusion abzufiltrieren.

Ein geeigneter Impfstoff ist derzeit noch nicht verfügbar. Sowohl im Falle der konnatalen Cytomegalie als auch bei CMV-Erkrankungen immunsupprimierter Patienten werden Virostatika eingesetzt. Innerhalb der Schwangerschaft sind diese Medikamente nicht zugelassen. Hier liegen Studien zur Gabe CMV-spezifischen Hyperimmunglobulins nach Kontakt zu Virusausscheidern vor. In einigen Bundesländern wird CMV-seronegativen schwangeren Kindergärtnerinnen ein Arbeitsverbot erteilt.

Analytik Erregernachweis: gelegentlich noch Virusanzucht in humanen Fibroblasten. In Gebrauch ist der spezifische immunzytologische Nachweis des CMV-Antigens pp65 in Leukozyten (gute Korrelation mit der Krankheitsaktivität). Die PCR-Diagnostik (s. > PCR (Polymerase-Kettenreaktion)) erlaubt den Nachweis des viralen Genoms. Sie wird zur Bestimmung der CMV-Viruslast eingesetzt (Therapiemonitoring).

Serologie: Anti-CMV-Antikörper der Klassen IgG und IgM gegen das Vollvirus werden durch indirekte Immunfluoreszenz ( $\triangleright$ Immunfluoreszenz, indirekte) oder mittels $\triangleright$ Enzymimmunoassay (u. a. \ Enzyme-linked Immunosorbent Assay, Chemilumineszenz Immunoassays) nachgewiesen. Die Bestimmung von IgM- bzw. IgG-Antikörpern gegen die rekombinant hergestellten CMV-Proteine p52 und Glykoprotein $\mathrm{B}(\mathrm{gB})$ sowie Aviditätstests ergänzen die klassische Serologie zur Unterscheidung akuter und konvaleszenter Infektionsphasen oder bei unklaren Befunden. Der Nachweis intrathekal synthetisierter Antikörper im Liquor dient zusammen mit dem Direktnachweis per PCR der Identifikation einer ZNS-Beteiligung.

Untersuchungsmaterial - Probenstabilität Direktnachweis und Kultur: Untersucht werden Urin, Speichel, bron- choalveoläre Lavageflüssigkeit, Blut, Serum, Liquor, Fruchtwasser und Muttermilch. Das Material sollte bis zur Weiterverarbeitung bei +4 bis $+8{ }^{\circ} \mathrm{C}$ aufbewahrt werden. Bei längerer Transportzeit ist das Material einzufrieren.

Serologie: Serum oder Plasma für den Nachweis der Antikörper sind bei $+4{ }^{\circ} \mathrm{C}$ bis zu 2 Wochen lang beständig, bei $-20{ }^{\circ} \mathrm{C}$ über Monate und Jahre hinweg. Zur Tiefkühlkonservierung des IgM kann man den Proben 80 \% gepuffertes Glyzerin beifügen.

Diagnostische Wertigkeit Klinisch ist eine CMV-Infektion nicht eindeutig zu diagnostizieren. Symptomatische akute Infektionen werden durch eine Kombination von Direktnachweis und Serologie erfasst. Bei IgM-reaktiven Proben, die gleichzeitig niedrig avides IgG evtl. in Kombination mit einem fehlenden Nachweis von IgG-Antikörpern gegen gB aufweisen, ist von einer akuten Infektion auszugehen. Ist die Avidität der IgG hoch bzw. sind IgG gegen gB nachweisbar, liegt wahrscheinlich eine Reaktivierung vor. Ein signifikanter Anstieg des spezifischen Anti-CMV-IgG innerhalb von 1-2 Wochen beweist eine akute Infektion. Findet man Antikörper der Klasse IgG mit hoher Avidität, so besteht bei immunkompetenten Personen Schutz vor einer Sekundärinfektion.

In der Transfusions- und Transplantationsmedizin ist der CMV-Status des Spenders und des Empfängers zu beachten, um primäre Infektionen und Reinfektionen zu vermeiden. Auch bei seropositiven Empfängern kann eine Reinfektion ausgelöst werden, insbesondere wenn die Immunitätslage geschwächt ist.

Bei Verdacht auf eine akute Infektion in der Schwangerschaft kann im fetalen Blut spezifisches IgM oder in der Amnionflüssigkeit ( $\triangleright$ Amniocentese) durch PCR virales Genom bestimmt werden. Parallel dazu wird die Schwangerschaft engmaschig mittels Ultraschalldiagnostik überwacht.

Im Rahmen der Schwangerschaftsvorsorge ist die frühe Untersuchung des mütterlichen Serostatus sinnvoll. Im Falle einer negativen Serologie muss eine umfangreiche Beratung betreffs Expositionsprophylaxe erfolgen. Darüber hinaus stehen initiale Ausgangsbefunde zur Verfügung, die später bei Verdacht auf eine Infektion im Verlaufe der Schwangerschaft zusammen mit einer Folgeprobe eine sichere Diagnostik ermöglichen, weil man einen Anstieg des Antikörperspiegels nachweisen oder ausschließen kann.

\section{Literatur}

Enders G (2006) Mütterliche Infektionen mit dem Risiko der kongenitalen Übertragung. Labormedizinische Aspekte bei Cytomegalie und Toxoplasmose. Gynäkol Geburtshilfe 1:24-28

Lazzarotto T, Guerra B, Gabrielli L, Lanari M, Landini MP (2011) Update on the prevention, diagnosis and management of cytomegalovirus infection during pregnancy. Clin Microbiol Infect 17:1285-1293 
Revello MG, Gerna G (2002) Diagnosis and management of human cytomegalovirus infection in the mother, fetus, and newborn infant. Clin Microbiol Rev 15(4):680-715

Revello MG, Zavattoni M, Furione M, Lilleri D, Gorini G, Gerna G (2006) Diagnosis and outcome of preconceptional and periconceptional primary human cytomegalovirus infections. J Infect Dis 186:553-557

Ross SA, Novak Z, Pati S, Boppana SB (2011) Diagnosis of cytomegalovirus infections. Infect Disord Drug Targets 11(5):466-474
Scholz H, Belohradsky BH, Bialek R, Heininger U, Kreth HW, Roos R (2009) Zytomegalovirus-Infektionen. In: DGPI-Handbuch, 5. Aufl. Thieme, Stuttgart, S 565-568

\section{Cytotactin}

Tenascin 